\title{
Between Creed, Rhetoric Façade, and Disregard
}

Dissemination and Theorization of Corporate Social Responsibility in Austria

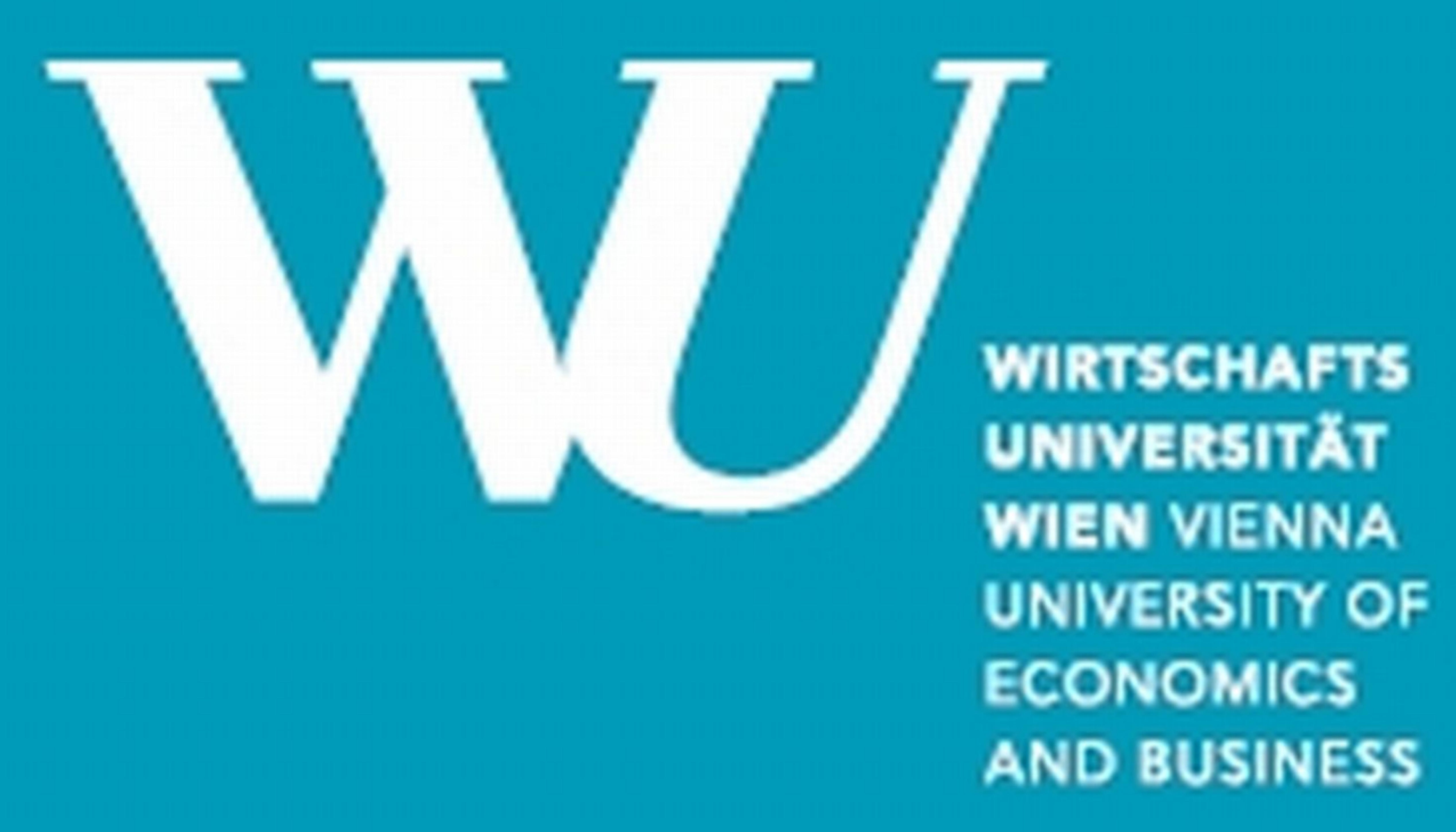


Between Creed, Rhetoric Façade, and Disregard 


\section{Forschungsergebnisse der Wirtschaftsuniversität Wien}

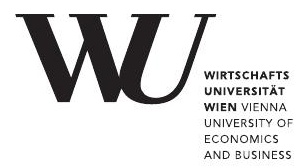

Band 52

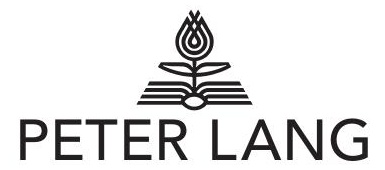

Frankfurt am Main · Berlin · Bern · Bruxelles · New York · Oxford · Wien 


\section{Between Creed, Rhetoric Façade, and Disregard Dissemination and Theorization of Corporate Social Responsibility in Austria}

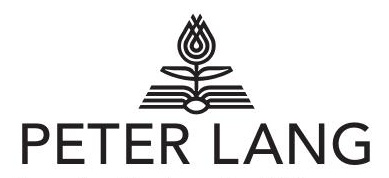

Internationaler Verlag der Wissenschaften 


\section{Bibliographic Information published by the Deutsche Nationalbibliothek}

The Deutsche Nationalbibliothek lists this publication in the Deutsche Nationalbibliografie; detailed bibliographic data is available in the internet at http://dnb.d-nb.de.

Open Access: The online version of this publication is published on www.peterlang.com and www.econstor.eu under the international Creative Commons License CC-BY 4.0. Learn more on how you can use and share this work: http://creativecommons.org/licenses/by/4.0.

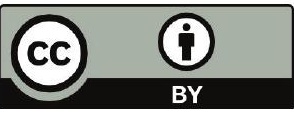

All versions of this work may contain content reproduced under license from third parties.

Permission to reproduce this third-party content must be obtained from these third-parties directly.

This book is available Open Access thanks to the kind support of ZBW - Leibniz-Informationszentrum Wirtschaft.

Sponsored by the Vienna University of Economics and Business.

Cover design:

Atelier Platen according to a design of Werner Weißhappl.

University logo of the Vienna University of Economics and Business:

Printed with kind permission of the University.

ISSN 1613-3056

ISBN 978-3-653-01464-8 (eBook)

10.3726/978-3-653-01464-8

ISBN 978-3-631-61968-1 (Print)

(c) Peter Lang GmbH

Internationaler Verlag der Wissenschaften

Frankfurt am Main 2012

www.peterlang.de 
To my parents \& family

Markus A. Höllerer - 978-3-653-01464-8

Downloaded from PubFactory at 01/11/2019 11:31:02AM

via free access 
Markus A. Höllerer - 978-3-653-01464-8

Downloaded from PubFactory at 01/11/2019 11:31:02AM

via free access 


\section{Foreword and acknowledgements}

The time spent on my doctoral studies and on this dissertation project has been both stressful and enjoyable - and incredibly enriching. I wish to express my genuine gratitude to everyone who has accompanied me on this exciting journey. Numerous people have positively influenced my academic work. While I cannot acknowledge all of them individually here, I nonetheless wish to give credit to those around me with whom I have been able to share my thoughts and discuss my ideas in greater detail: colleagues and friends who, at various stages of the project, provided helpful comments and suggestions that clearly strengthened the overall clarity and potential contribution. This holds especially true for those who acted as my academic mentors and/or companions - their great guidance has not only influenced this project, but also my life.

I am particularly indebted to my primary advisor - Renate Meyer from WU Vienna University of Economics and Business - for introducing me to the academic community and for pointing out signposts that were essential for my research. Thank you for your ideas and comments, your never-ending patience (or tenacity), and your ability to discuss issues in an ever-constructive dialogue. I am honestly appreciative, not just for you being a superb colleague and fair superior, but also for your friendship, which I value deeply. I also gratefully acknowledge the support of my secondary advisor - Mike Lounsbury from the University of Alberta - who accepted me as his student, trusted my capabilities from the very beginning, and has always treated me as a colleague. Thank you for your valuable feedback on various draft versions of my dissertation, the generous guidance, your (renownedly tricky) questions, and, in particular, for making my defensio dissertationis a memorable event.

I wish to show my appreciation to my home institution in Vienna for providing a conducive scholarly environment for the development of my academic work. During data collection, I was also able to count on the support of the Austria Press Agency, the Vienna Stock Exchange, and the Austrian National Library. In addition, several undergraduate students assisted in the gathering of empirical material, ranging from copying a considerable number of documents only available in archives outside the university to extracting data from various texts and databases. Moreover, I thank Susan Dortants and Thomas Crowe for proofreading and language editing. They helped me in splitting up sentences that originally extended over half a page, as well as in getting rid of the most awkward phrases that seem so characteristic for a native German speaker.

Away from home, I have enormously benefitted from several doctoral seminars at Copenhagen Business School, as well as from various conferences and workshops (organized by EGOS, SCANCOR, or the OMT division of the Academy of Management, among others). I also had the opportunity to discuss my ideas and working papers as a visiting scholar at the University of Technology, Sydney, at the 
University of Alberta, and at Stanford University. I wish to thank explicitly Stewart Clegg, Royston Greenwood, and John W. Meyer for acting as sponsors at their academic institutions.

Finally, writing a doctoral dissertation is always also a personal endeavor. Its successful completion would not have been possible without the support of my family, nor the critical remarks, and solace, from those that I am related to in friendship or love - you kept reminding me of what life is really about. So "berzliches Dankeschön!" to all of you who have provided generous assistance, support, and encouragement over the years.

Markus A. Höllerer

Vienna/Müblhofen, September 2010*

* Prior to this publication, the original text of the doctoral dissertation was slightly revised in summer 2011 in order to correct typos and unclear wording. 


\section{Contents}

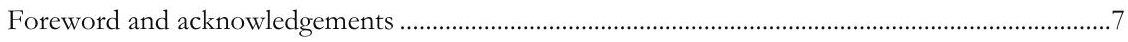

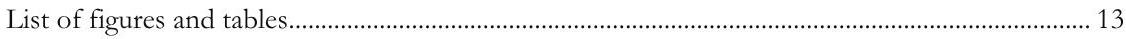

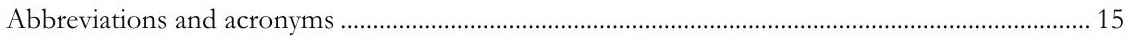

1 Addressing business' responsibilities toward society................................................................. 17

1.1 The global rise of CSR as a management concept.............................................................. 19

1.1.1 CSR as a global trend in corporate governance.......................................................... 19

1.1.2 Continental Europe: From implicit to explicit CSR? ................................................... 21

1.1.3 Assigning meaning to the "new" notion of social responsibility of business ........... 23

1.2 Focus and research questions: Dissemination and meaning ................................................ 24

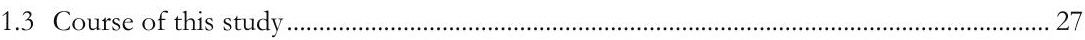

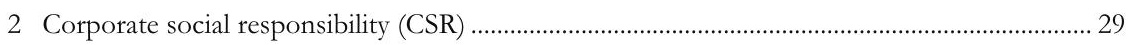

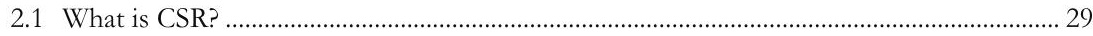

2.2 CSR in the academic debate: A brief historical overview ..................................................... 34

2.3 Defining the range of responsibilities for business organizations ......................................... 37

2.4 Institutional context matters: Explicit versus implicit CSR ………........................................ 40

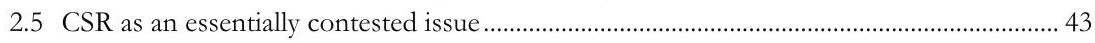

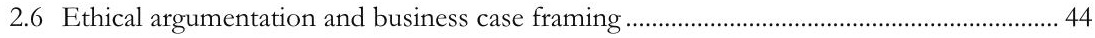

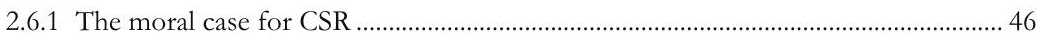

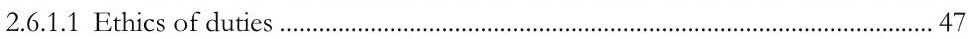

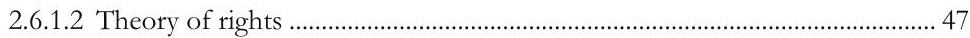

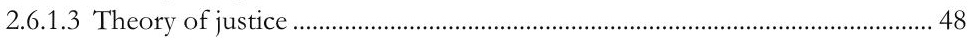

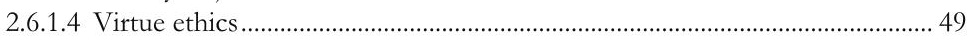

2.6.2 The business case argument for CSR .......................................................................... 49

2.6.2.1 Cost and risk reduction.................................................................................. 50

2.6.2.2 Competitive advantage ................................................................................. 52

2.6.2.3 Developing reputation and legitimacy ……................................................... 53

2.6.2.4 Synergistic value creation................................................................................. 55

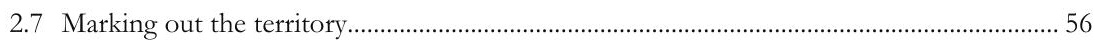

2.7.1 Synonyms, interchangeable concepts, and/or distant relatives? ................................... 57

2.7.1.1 Business ethics.......................................................................................... 57

2.7.1.2 Corporate sustainability …………………….............................................. 57

2.7.1.3 Stakeholder approach..................................................................................... 58

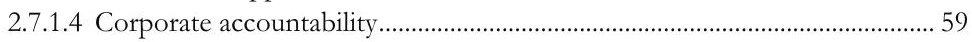

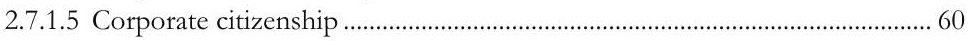

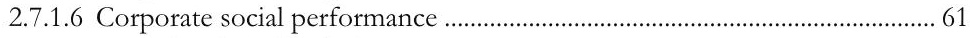

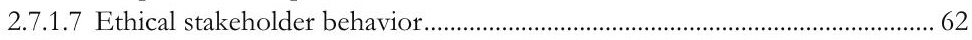

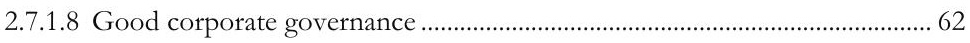

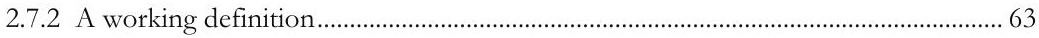

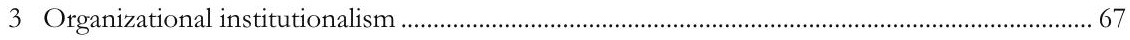

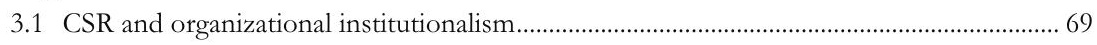


3.2 Research on the diffusion of organizational and managerial practices................................ 71

3.3 A conceptual tool kit for organizational institutional analysis ............................................. 73

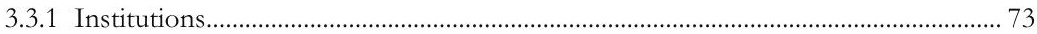

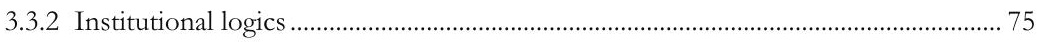

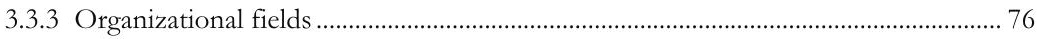

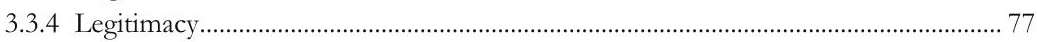

3.3.5 Processes of institutionalization and deinstitutionalization .......................................... 79

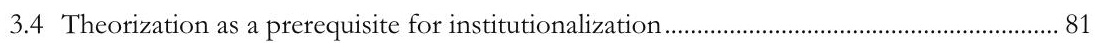

3.5 Adaptation, translation, and bricolage in local contexts ....................................................... 83

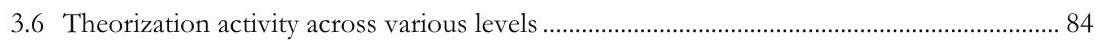

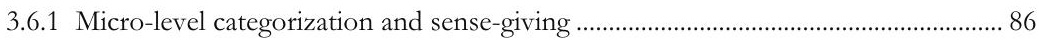

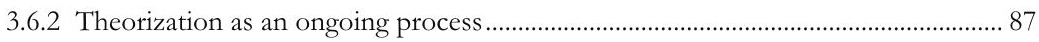

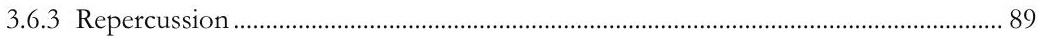

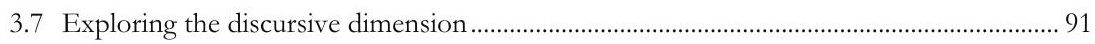

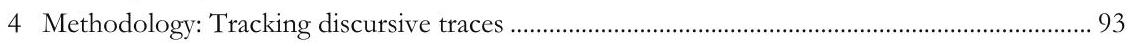

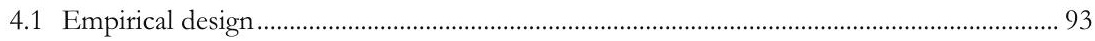

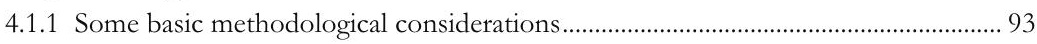

4.1.2 Empirical access: Social disclosure in corporations' annual reports .......................... 95

4.1.3 Implications for data collection and analysis ............................................................. 97

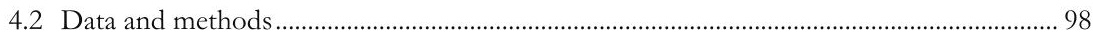

4.2.1 Sample and collection of empirical material ................................................................. 98

4.2.2 Generating data: Archival research and content analysis .......................................... 100

4.2.2.1 Dependent variable(s): Commitment to CSR ............................................... 101

4.2.2.2 Independent and control variables used in regression models ..................... 103

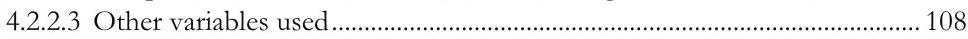

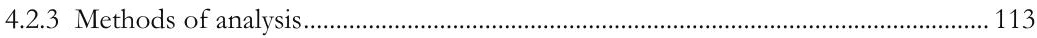

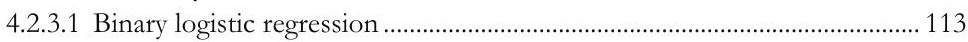

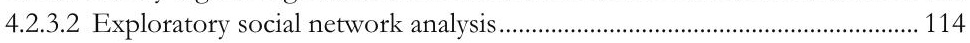

4.2.3.3 Multiple correspondence analysis............................................................... 115

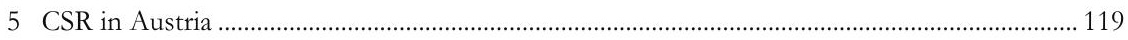

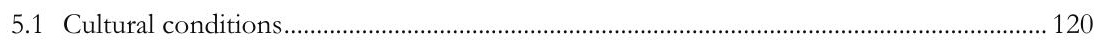

5.1.1 A continental European model of corporate governance ......................................... 120

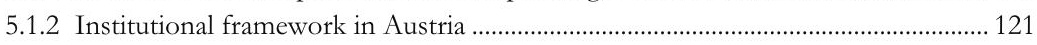

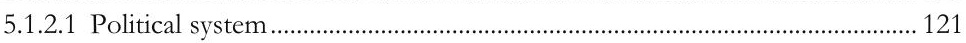

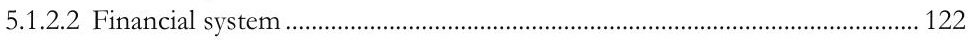

5.1.2.3 Education and labor system ....................................................................... 124

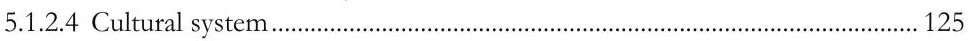

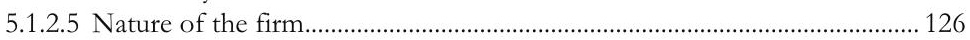

5.1.2.6 Organization of market processes..................................................................... 127

5.1.2.7 Coordination and control system .................................................................. 128

5.1.3 The Austrian CSR arena: Activities and key actors involved .................................. 129

5.1.3.1 The world of business .............................................................................. 129 
5.1.3.2 Labor associations and civil society ………….......................................... 131

5.1.3.3 Governmental organizations.......................................................................... 132

5.2 Social disclosure in Austrian corporations' annual reports ................................................ 133

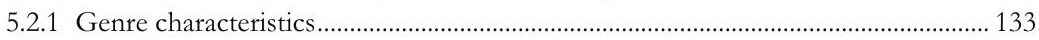

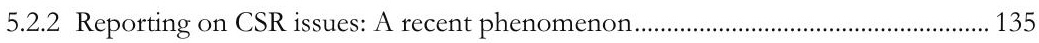

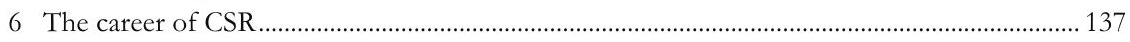

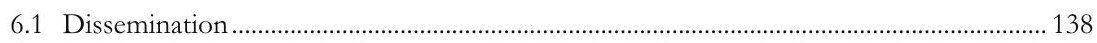

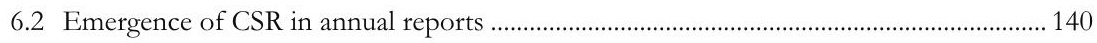

6.2.1 Significance: Anchorage at different levels and extent of reference ......................... 140

6.2.2 Placement on the agenda: Anchorage in annual report sections ............................... 141

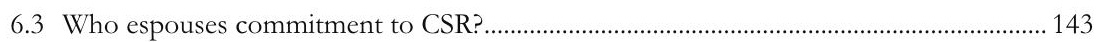

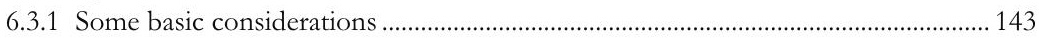

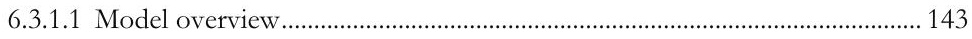

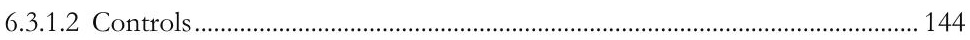

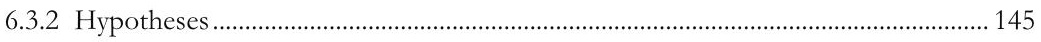

6.3.2.1 Organizational characteristics ..................................................................... 145

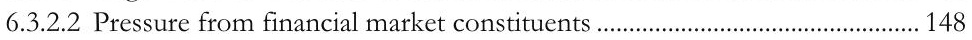

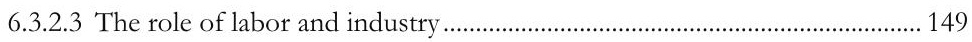

6.3.2.4 Institutional pressures: Public scrutiny and prevalence of the concept ..... 150

6.3.2.5 Normative orientation and/or copy-paste effect.......................................... 152

6.3.2.6 Part of a discursive bundle? CSR and corporate governance ...................... 153

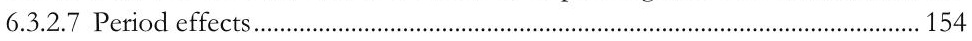

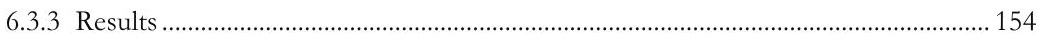

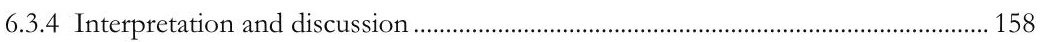

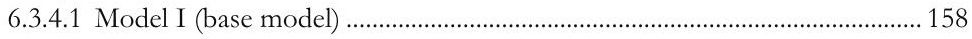

6.3.4.2 Model II (hypotheses 1-5) ............................................................................ 158

6.3.4.3 Model III (hypotheses 6-7) ............................................................................. 159

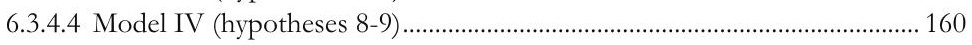

6.3.4.5 Model V (hypotheses 10-12) ..................................................................... 161

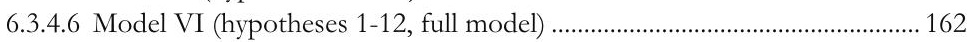

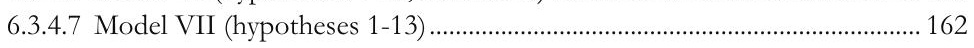

6.3.4.8 Model VIII (hypotheses 1-14, comprehensive model) ................................. 163

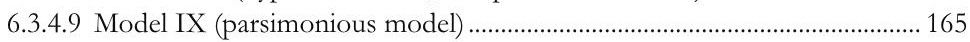

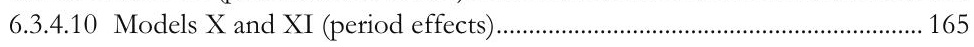

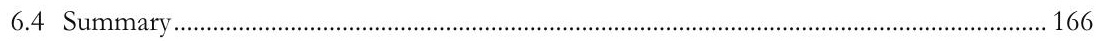

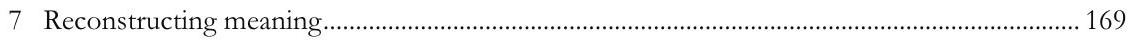

7.1 CSR: An umbrella term for a bundle of conceptual sub-discourses? ................................. 170

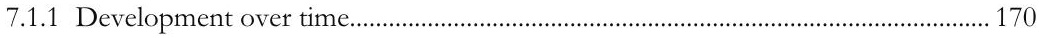

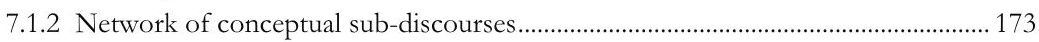

7.2 Responsible for and accountable to whom? Social categorization of actors involved .... 176

7.2.1 The construction of social categories as bottom-up theorization .............................. 176

7.2.2 Responsible conduct of business and relevant actor categories ............................... 179

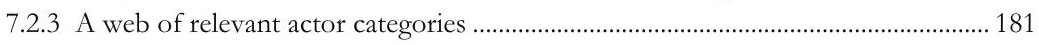


7.2.4 Specifying subjects and objects: Dynamics over time .............................................. 183

7.2.5 Sub-discourses and actor categories: A first correspondence analysis...................... 187

7.2.5.1 Sustainability versus stakeholder-oriented corporate governance................ 190

7.2.5.2 Spheres of responsibility: From bondage to advocacy ................................ 190

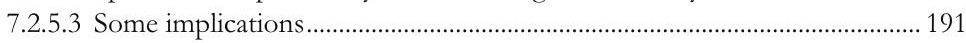

7.3 What are we/they talking about? Thematic embeddings of CSR ....................................... 192

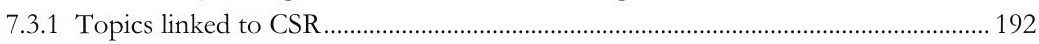

7.3.2 Thematic embeddings and the stabilization of discourse over time ......................... 194

7.3.3 Sub-discourses and thematic embeddings: A second correspondence analysis ..... 196

7.3.3.1 Variations of good corporations .................................................................... 198

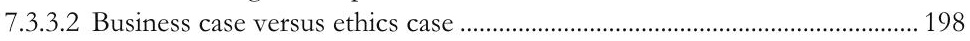

7.3.3.3 Some implications......................................................................................... 199

7.4 Variation and patterns within discourse: Translation into Austrian? .................................. 200

7.4.1 The comprehensive model: A third correspondence analysis ................................... 200

7.4.1.1 Sustainable development versus good corporate governance ..................... 202

7.4.1.2 Economic rationale versus sociopolitical view.............................................. 202

7.4.1.3 Some implications ....................................................................................... 203

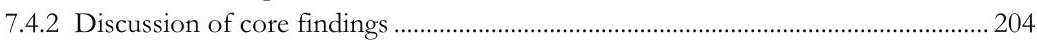

7.4.2.1 Structuring principles of the CSR discourse in Austria ................................. 204

7.4.2.2 Accountability: Adding a political dimension................................................. 207

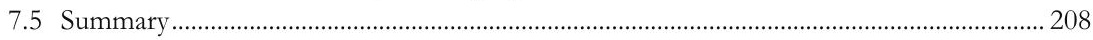

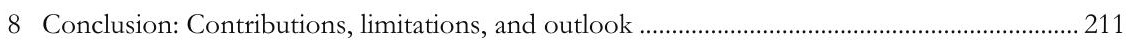

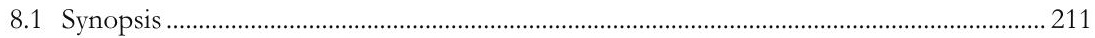

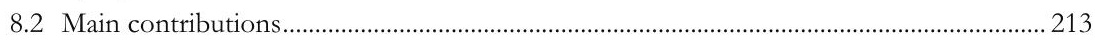

8.2.1 Contributions related to the empirical context and the phenomenon of CSR ....... 213

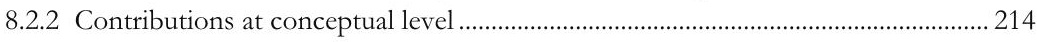

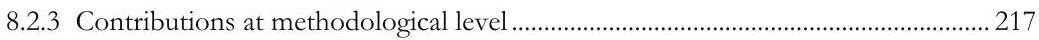

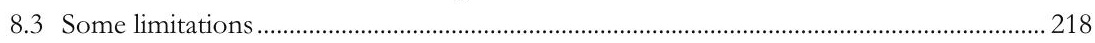

8.3.1 Reflections on methodology: Sampling, genre specifics, and empirical setting .... 219

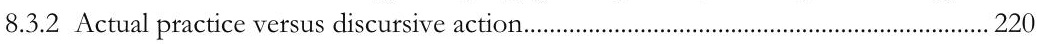

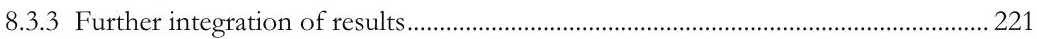

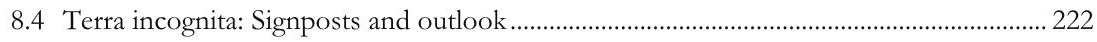

8.4.1 Stand-alone annual CSR reports: A novel sub-genre of annual reports ................... 222

8.4.2 Visual elements: The visual construction of meaning ............................................... 223

8.4.3 Interrelated bundles: Value management versus values management ..................... 225

8.4.4 Meaning construction at micro level: Close-ups ………………................................ 227

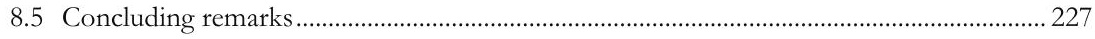

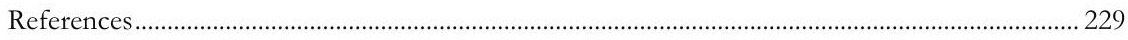




\section{List of figures and tables}

\section{Figures}

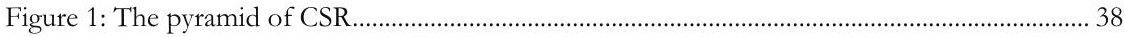

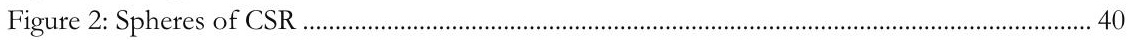

Figure 3: Explicit and implicit CSR compared................................................................................ 41

Figure 4: A continuum between explicit and implicit CSR ….......................................................... 41

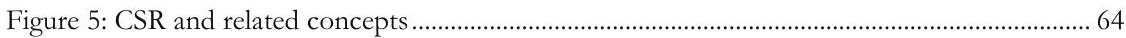

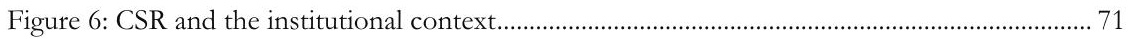

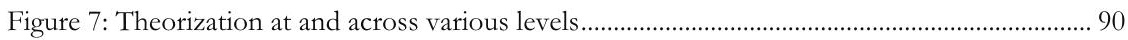

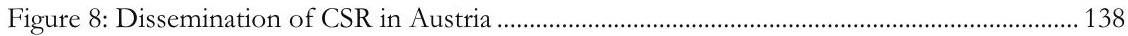

Figure 9: Significance and extent of CSR in annual reports ......................................................... 140

Figure 10: Anchorage of CSR in annual report sections .............................................................. 142

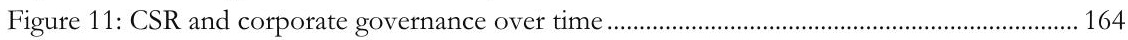

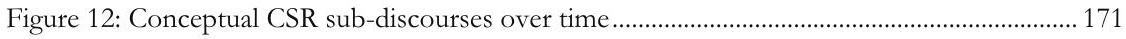

Figure 13: Relative importance of conceptual CSR sub-discourses ............................................... 172

Figure 14: Network of conceptual CSR sub-discourses plus corporate governance ...................... 174

Figure 15: Reference to specific actor categories in the context of CSR ....................................... 179

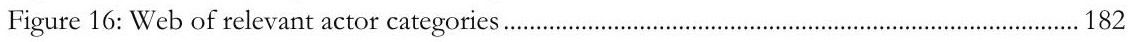

Figure 17: Reference to actor categories over time ....................................................................... 184

Figure 18: Relative importance of actor categories over time ........................................................... 186

Figure 19: Correspondence map: Issue markers and actors ............................................................ 189

Figure 20: Thematic embeddings of CSR issue markers ................................................................. 193

Figure 21: Thematic embeddings of CSR issue markers over time ................................................. 194

Figure 22: Stabilization of thematic embeddings over time......................................................... 195

Figure 23: Correspondence map: Issue markers and thematic embeddings ................................. 197

Figure 24: Correspondence map: Issue markers, actors, and thematic embeddings ..................... 201

Figure 25: Cover pages of selected stand-alone annual CSR reports ............................................. 225

Figure 26: Network of conceptual sub-discourses of several management concepts .................... 226

\section{Tables}

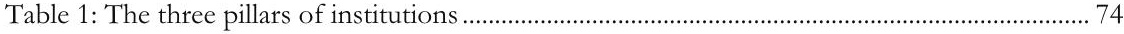

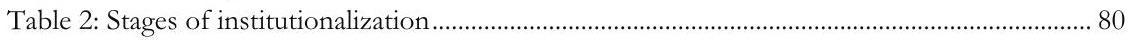

Table 3: Dependent variable(s): Operationalization, measurement, and data sources ................... 102

Table 4: Conceptual CSR sub-discourses: A structured dictionary of phrases and codes ............ 103

Table 5: Control variables: Operationalization, measurement, and data sources ............................ 104

Table 6: Independent variables: Operationalization, measurement, and data sources .................. 107

Table 7: Other variables used: Operationalization, measurement, and data sources ...................... 109

Table 8: Report sections: Construction of variable ......................................................................... 110 
Table 9: Categories of actors: Construction of variable ................................................................ 112

Table 10: Categories of thematic embeddings: Construction of variable ...................................... 113

Table 11: Selected formal-descriptive variables for annual reports ................................................ 135

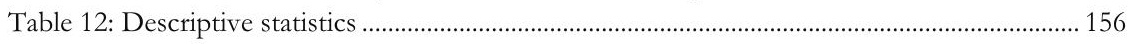

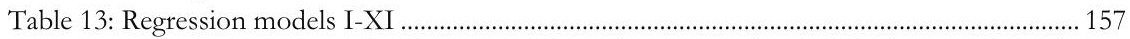

Table 14: Relative probability of co-occurrence of conceptual CSR sub-discourses..................... 175 


\section{Abbreviations and acronyms}

\begin{tabular}{|c|c|}
\hline$A k t G$ & Aktiengesetz (Austrian Stock Corporations Act) \\
\hline APA & Austria Press Agency \\
\hline ATX & Austrian Traded Index \\
\hline BörseG & Börsegesetz (Austrian Stock Exchange Act) \\
\hline $\mathrm{CC}$ & Corporate citizenship \\
\hline $\mathrm{CEO}$ & Chief executive officer \\
\hline $\mathrm{CFO}$ & Chief financial officer \\
\hline CG & Corporate governance \\
\hline CSR & Corporate social responsibility \\
\hline $\mathrm{EU}$ & European Union \\
\hline GDP & Gross domestic product \\
\hline GRI & Global reporting initiative \\
\hline HR & Human resources \\
\hline HSE & Health, safety, and environment \\
\hline IAS & International Accounting Standards \\
\hline IGO & Inter-governmental organization \\
\hline IPO & Initial public offering \\
\hline IR & Investor relations \\
\hline IT & Information technology \\
\hline $\mathrm{MNC}$ & Multinational corporation \\
\hline NGO & Non-governmental organization \\
\hline $\mathrm{NPO}$ & Non-profit organization \\
\hline OECD & Organisation for Economic Co-operation and Development \\
\hline ÖVFA & $\begin{array}{l}\text { Österreichische Vereinigung für Finanzanalyse und Asset Management (Austrian Associa- } \\
\text { tion for Financial Analysis and Asset Management) }\end{array}$ \\
\hline PR & Public relations \\
\hline SHV & Shareholder value \\
\hline SME & Small and medium-sized enterprise \\
\hline TBL & Triple bottom line \\
\hline TQM & Total quality management \\
\hline$U G B$ & Unternehmensgesetzbuch (Austrian Commercial Code) \\
\hline $\mathrm{UN}$ & United Nations \\
\hline US-GAAP & United States Generally Accepted Accounting Principles \\
\hline VIF & Variance inflation factor \\
\hline WBCSD & World Business Council for Sustainable Development \\
\hline WWII & World War II \\
\hline
\end{tabular}


Markus A. Höllerer - 978-3-653-01464-8

Downloaded from PubFactory at 01/11/2019 11:31:02AM

via free access 
"While issues concerning the social responsibilities of businesses have long been the subject of debate, today's conception of Corporate Social Responsibility (CSR) marks a new departure."

David Henderson (2001: 15), British academic economist and former head of the Economics and Statistics Department at OECD, in his critique of CSR as a "misguided virtue"

\section{Addressing business' responsibilities toward society}

Stakeholders' views on corporations have shifted radically throughout the last twenty years - as has the way corporations look at society (for empirical evidence, see PricewaterhouseCoopers, 2003; KPMG International, 2008; PricewaterhouseCoopers, 2010, among others). There is growing recognition that corporate ethics have a considerable impact on the economic performance of business organizations nowadays; addressing values, integrity, transparency, and accountability has thus become a requirement in the modern corporate world (Joyner \& Payne, 2002). Despite some skepticism with regard to a redefinition of the business-society interface and the overall beneficial effects of a "socially responsible capitalism" on society (Owen, 2001: 8; see also Beckert, 2006), one has recently been able to witness the emergence of a new way of thinking of, and within, corporate management with regard to the role, purpose, duties, and responsibilities of business organizations. ${ }^{1}$

A variety of labels has been used to account for this novel managerial "creed", the notion of corporate social responsibility (CSR) being the broadest and most

1 In short, capitalism in post-war Europe is seen as having passed through several distinct phases (e.g., Useem, 1996; Owen, 2001): "Managerial capitalism” during the 1950s and 1960s was characterized by executives enjoying a fairly high degree of discretion in deciding how to use the resources at their disposal, whereas shareholders remained generally passive (Owen, 2001). In the public sphere, business organizations were perceived mainly in their role as employers. In the 1970s, and even more decisively in the 1980s and early 1990s, conditions changed considerably and the rise of shareholder activism (Useem, 1993; Davis \& Thompson, 1994) led to another phase referred to as "investor capitalism" (Fligstein, 1990; Useem, 1996), with corporate executives finding themselves under growing pressure from capital markets. However, a core incentive for maximizing shareholder value - the alignment of managers' and owners' interests by, for instance, introducing stock option plans as part of managers' remuneration - did not necessarily result in an improvement of actual management performance (Koslowski, 2000; Dobbin \& Zorn, 2005). In addition, the world of business had to face massive criticism after various cases of corporate malfeasance around the turn of the millennium (e.g., Dobbin \& Zorn, 2005, plus commentaries) as well as in reaction to the events that led to the global financial crisis in 2008. For the last decade, observers therefore have seen antecedents of a change toward a distinct third phase which might be labeled a "socially responsible capitalism" (Owen, 2001), implying a redefined role of business within society. 
prominent - although comparatively vague and in many respects arbitrary construct (Clarkson, 1995; Carroll, 1998; Matten \& Crane, 2005; Crane \& Matten, 2010). ${ }^{2}$ Despite some evidence of "much disorder under the sun" (Sacconi, 2004: 1), the idea of CSR has, as various commentators note, "caught on" (Henderson, 2001: 15) or even "won the battle of ideas" (Crook, 2005: 1; see also Matten \& Moon, 2008). It has been endorsed, as Owen (2001) points out, by a substantial number of corporations and business organizations, by interest groups, nongovernmental organizations (NGOs), academia, capital market actors, governments and inter-governmental organizations (IGOs), as well as by a growing army of consultants.

How corporations affect society seems key to both management practice and scholarship. The phenomenon of CSR has, as the authors of a recently published handbook (Crane, McWilliams, Matten, Moon, \& Siegel, 2008b: 3) put it, "experienced a journey that is almost unique in the pantheon of ideas in the management literature". With core questions being as old as business itself, CSR - as a distinct managerial idea - has been subject to scholarly attention at the theoretical or conceptual level for at least a decade now; however, its global "rise to prominence has not been at all a smooth one" (Crane et al., 2008b: 4). The victory march of CSR has also been characterized by ideological debate, discredit, marginalization, and preference given to "new or supposedly better ways of conceptualizing the business and society interface" (Crane et al., 2008b: 4). Content and scope of CSR, especially as a management concept or instrument, are still contested in the corporate world. Academia, on the other hand, does not even share a common definition of their research object. Overall, scholarly work that has emerged around CSR all too often has to face criticism for not being fully convincing in terms of construct clarity and methodical rigor, as well as for neglecting the "institutional history" in which these practices have emerged (Guthrie \& Durand, 2008). Remarkably, central issues remain unclear: For instance, and despite its dominance in the field, the question of whether CSR is favorable to business and enhances profitability has not yet been consistently answered by empirical research (for an overview, see Orlitzky, 2008, among others).

The study at hand does not claim to address, or even remedy, such broad issues. What it will offer is a thorough examination of the discourse of/on CSR in one particular cultural setting with the overall aim to enhance our understanding of how CSR is spreading throughout the corporate world, and of the contents and implications that are conveyed by this very idea. I will do so by focusing on a specific voice in this discourse, namely that of the societal actors primarily concerned by the notion of CSR - i.e., the perspective of business organizations.

2 Other labels that are frequently used as synonyms of, or that allude to, the notion of CSR are - to name only the most common - corporate responsibility, corporate citizenship, corporate social responsiveness, corporate social performance, corporate accountability, corporate sustainability, corporate ethics, and good corporate governance. 


\subsection{The global rise of CSR as a management concept}

Three distinct observations have informed this research and serve as multiple, yet interdependent, points of departure. First, CSR has developed to become - on a more or less worldwide scale - the trend in corporate governance since the early 2000s. Such an observation raises interesting questions as this global movement spans various national business systems, divergent models of governance, and, thus, also governance systems that incorporate divergent institutional logics (see also Meyer \& Höllerer, 2009). ${ }^{3}$ Second, for empirical contexts like continental Europe, this trend implies a recent shift toward explicitly addressing issues of CSR despite a long and taken-for-granted tradition of adhering to an implicit CSR agenda (Matten \& Moon, 2008). Third, such explicit commitment directly follows a period characterized by the adoption of yet another management concept: shareholder value. Like the majority of contemporary management ideas and trends, shareholder value is of North American origin and therefore also embodies a specific ideology (Djelic, 1998). Especially as a shareholder value orientation is one of the most distinct emblems of the Anglo-American corporate governance model (Meyer \& Höllerer, 2010), which considerably differs from the predominant logic of corporate governance and control in continental European countries, the recent development (i.e., public discredit of the idea of shareholder value) has left corporations in need to explain and justify the renewed shift in orientation (i.e., toward CSR). Hence, business organizations and corporate managements are required to give sense to, rationalize - i.e., theorize on -, and provide legitimate accounts for CSR rhetoric and practice. I will address these issues more succinctly on the following pages.

\subsubsection{CSR as a global trend in corporate governance}

Recently, corporations worldwide have often found themselves in the midst of an intense public debate regarding the responsibilities of business. In Austria, like in the whole of Europe, this debate on a distinct "social" or "societal" responsibility of corporations was triggered by an emerging sustainability movement, by critical voices from new sociopolitical actors like green parties and a variety of NGOs that started to advocate environmental and social concerns, by increased consumer activism and, consequently, increased market pressure, and especially in reaction to criticism of the appropriateness and implications of an exclusive shareholder

3 The literature on national business systems, varieties of capitalism, and divergent systems of governance (e.g., Whitley, 1999; Hall \& Soskice, 2001) mainly juxtaposes an Anglo-American and a continental European system of governance. However, it should be stressed that the worldwide diffusion of CSR also affects, among others, Asia and several developing countries. 
orientation. In order to comprehend the rise of CSR at the turn of the millennium, it is crucial to acknowledge the veritable crisis in corporate control (Dobbin \& Zorn, 2005, plus commentaries) that resulted from a series of corporate malfeasance, fraud, and accounting scandals (for instance, Enron, WorldCom, and Parmalat), shocked the global business community, and facilitated the design of alternative models of corporate governance. The predicted end of the shareholder value ideology (Fligstein, 2005) and its specific conception of corporate control (see also Meyer \& Höllerer, 2009) gave significant momentum to the discussion of one of the most fundamental issues in normative business management: the matter of role and purpose of a corporation, i.e., the question of whose interests a corporation is supposed to serve (e.g., Freeman, 1984; Donaldson \& Preston, 1995; Waddock, 2001).

Corporations are forced to proactively engage in this discourse for two main reasons: First, to reduce risk and to shape the political agenda (i.e., to influence policies actively that might otherwise lead to increased regulation), including national and supranational initiatives on corporate governance and CSR; second, to meet anticipated and actual societal expectations appropriately. Indeed, discursively constructing and managing organizations' legitimacy (see Suchman, 1995; Deephouse \& Suchman, 2008, among others) as well as maintaining their "license to operate" have become key tasks for corporations that are increasingly under pressure to present themselves as valuable members of society that behave with integrity - even more so in the light of instable financial markets and a loss of confidence in corporate executive boards. In this respect, the relevance of CSR rests in its role as a basic orientation model implying considerable consequences on governance and control mechanisms both within corporations and within society at large. Voices that reject the idea of an extended range of corporate responsibilities - i.e., duties exceeding compliance with mere economic objectives (see chapter on CSR below for more) - at all have been rare recently. As Wilson (2003: 3) puts it, "what is in question is not whether corporate managers have an obligation to consider the needs of society, but the extent to which they should consider these needs".

Potential building blocks of how corporations could actually cope with, and rise to, these new challenges in corporate governance already existed "along the path" (Schneiberg, 2007) before the concept itself took off; most of the components of CSR were not invented or designed anew, but rather created by combining established practices and concepts from various contexts (see also Campbell, 2004). Among the most important ones, there is the tradition of a multiple stakeholder orientation governing conceptions of corporate control in continental Europe, as well as the established instruments and rhetoric of corporate social performance: These stem more from the Anglo-American context and embrace the idea of corporate philanthropy, but obviously strike a chord with the paternalistic selfperception of the continental European business elite (see also Meyer \& Höllerer, 
2009). Integrating (and driven by) other, more established issues like, for instance, environmental protection and sustainability (e.g., Löfstedt \& Vogel, 2001, plus commentaries; see also Matten \& Moon, 2008), the notion of CSR soon became a comprehensive label for a "bundle" of related sub-concepts, and a global trend in corporate governance and management. Its advocates have been promoting CSR as a globally theorized solution for a universal problem; nonetheless, they underline the necessity for it to be translated and modified when disseminating into specific local ${ }^{4}$ contexts: As Meyer (2004) points out, even if new management concepts are globally available, and have been theorized to a high degree in their native context (see also Meyer, 2002), they nonetheless need to pass through a powerful filter of local structural and cultural constraints in order to become legitimate in other contexts.

It can be expected that the emergence, the process of translation, and an ongoing institutionalization of CSR are mirrored in public discourse (for instance, in the media coverage of the issue, see also Figure 8 below) as well as in a debate on much broader governance topics. The development described above definitely caused a hype in academic literature (see, for instance, Carroll, 1999; SahlinAndersson, 2006; Aguilera, Rupp, Williams, \& Ganapathi, 2007; Campbell, 2007; den Hond, de Bakker, \& Neergard, 2007b; Scherer \& Palazzo, 2007; Crane, McWilliams, Matten, Moon, \& Siegel, 2008c; Matten \& Moon, 2008; Crane \& Matten, 2010). However, despite its prominence and role as a new orientation model, there are only a few studies empirically analyzing the dissemination and meaning of CSR commitment (e.g., Weaver, Trevino, \& Cochran, 1999; Maignan \& Ralston, 2002; with regard to annual reporting, e.g., de Bakker, Ohlsson, den Hond, Tengblad, \& Turcotte, 2007; Stratling, 2007) or that of CSR-related sustainability practices (e.g., King \& Lenox, 2000; Hoffman, 2001; Aerts \& Cormier, 2009).

\subsubsection{Continental Europe: From implicit to explicit CSR?}

It is important to hold that CSR does not mean the same thing on both sides of the Atlantic Ocean, neither in academia nor in corporate practice. Differences in legislation, sociopolitical and cultural traditions, as well as the broader institutional framework result in remarkably divergent language and vocabulary, action, and overall interpretation of the issue (Maignan \& Ralston, 2002). In one of the most prominent recent publications on CSR, Matten and Moon (2008) raise a number of interesting and important questions. In particular, they provide a powerful conceptual approach that takes into account the institutional framework of the specific local context (see also Doh \& Guay, 2006; Tempel \& Walgenbach, 2007). In continental Europe (and parts of the world other than the United States and Canada), the Anglo-American coined vocabulary of "explicit CSR" - stressing, in

4 Note that "local" here refers to both the field and the organizational level. 
particular, a business or strategic case linked to the idea of corporate giving and philanthropy - has been established only recently, whereas it has been widely used in North America for decades (Matten \& Moon, 2008). The same applies to a tradition of highlighting and documenting voluntary corporate action beyond requirement (see, for instance, Vogel, 2005 and his remarks on a "market for virtue").

However, this does not at all mean that the idea of a social responsibility of business had been alien to continental European countries like Austria, or that corporations in a non-Anglo-American context had in the past neglected their social responsibility (Matten \& Moon, 2008). Being responsible for the wider community and for society in general (i.e., responsibility exceeding the sphere of immediate conduct of business) has been part of a taken-for-granted understanding and thus points to the "indigenous" nature of the concept in continental Europe (see also European Management Forum, 1973; Steinmann, 1973; Ulrich \& Fluri, 1975; European Commission, 2001, among others). What one has actually been witnessing is - at least on a superficial level very much in line with this deeply rooted yet implicit CSR agenda ${ }^{5}$ - a recent shift toward explicitly addressing issues of CSR. After 2000, corporations in continental Europe and their lobbyists ${ }^{6}$ proactively adopted and embraced the concept of CSR within their communication routines; they used their discretion "to engage in firm-specific responsibility practices and to articulate these as CSR, regardless of the fact that responsible business practices have been and continue to be implicitly part of their day-to-day business activities" (Matten \& Moon, 2008: 405). Since then, CSR has not only been a guiding idea in an increasingly complex world (i.e., a tool of "enlightened" corporate governance and control), but has also served corporations' interests as a means of substantiating and managing legitimacy toward the organizational environment, primarily as a reaction to criticism and lobbying activities by interest groups, political parties, or social movements (Holzer, 2008) - and, in particular, by way of preventing increased state regulation. In a similar vein, Matten and Moon (2008) argue that the rise of explicit CSR in Europe is essentially a response to

5 Especially for corporatist countries like Austria the idea of social/societal responsibility of business is by no means anything new. It is firmly anchored and documented in the broader institutional framework and in wider policy arrangements, for instance in laws, legal regulation, established informal forms and practices of organizational governance and political decision making (e.g., in the construct of "social partnership"), or in emphasizing, from a more paternalistic point of view, the business leaders' and industrialists' - as part of a nation's elite - responsibility for the organization, especially the workforce and their families, as well as for the local community at large. Note that especially this paternalistic perspective shows distinct elements of the moral case for CSR (as opposed to a business case framing; see below for details).

6 Compared to the Anglo-American context, explicit CSR in Europe is predominantly driven by large corporations, initiatives of wider industry associations, and also by government programs (Matten \& Moon, 2008). 
changes in the historically grown institutional frameworks of European national business systems.

Drawing on established Anglo-American tools and terminology, explicit CSR soon became an appropriate managerial practice and started its victory march on a more or less global scale, with institutional mechanisms playing a decisive and dominant role. ${ }^{7}$ Thus, the career and dissemination of CSR in Austria - or more precisely, the concept's "translation into Austrian" - only mirrors a global trend that leaves its localized imprints in a wide range of artifacts.

\subsubsection{Assigning meaning to the "new" notion of social responsibility of business}

The trend toward managing legitimacy by directly and explicitly addressing the business-society interface represented a remarkable break with continental European corporations' traditional way of fulfilling their economic responsibility (which tacitly and implicitly covered a broad array of CSR-related issues, moderated through the institutional framework in place). Explicit CSR, as a distinct managerial idea and practice, had been presented as the global solution for tackling problematic business-society relations and as a remedy for the new challenges within the corporate world. However, as with many new ideas and concepts, the very meaning and practical consequences of CSR have remained far from obvious: Depending on perspective, different elements and aspects have been emphasized and integrated into, or excluded from, the CSR agenda and concept. A multiplicity of labels and (sometimes contradictory) meanings assigned by different actors in the arena (Hiß, 2006), a lack of a consistent definition, and an insufficient anchoring in management science or any other academic discipline are just some of the features that still characterize the phenomenon.

While the adoption of explicit CSR in the 2000s has made the conceptual tools, vocabulary, and rhetoric accessible, such ambiguity and the previous - in many cases equally explicit - turn toward shareholder value have led corporations to experience strong pressure to justify, vis-à-vis internal and external audiences, why they adopted and aligned this new concept in corporate governance. Furthermore, they must specify, at least to a certain extent, how this new orientation influences corporate belief systems and activities. They do so by providing accounts. Organizational institutionalism holds that in the course of institutionalization, accounts become increasingly ready-made (e.g., Creed, Scully, \& Austin, 2002; Meyer, 2004). When ideas and objects imbued with cultural meaning spread from one cultural context to the next, they must often be interpreted anew and adapted in order to provide accounts that are legitimate within the new local requirements (e.g.,

7 For instance, Matten and Moon (2008) identify coercive isomorphism, mimetic processes, and normative pressures that have encouraged explicit CSR throughout Europe (see also DiMaggio \& Powell, 1983; Scott, 2008). 
Benford \& Snow, 2000). Thus, even if they use globally available building blocks, actors nonetheless need to assign meaning and, in this respect, theorize CSR once more: ${ }^{8}$ What is it about, and why and how does it represent a viable and enduring solution for a specific social problem? Despite its ongoing institutionalization (Crane et al., 2008b), the socially shared understanding of what CSR actually means, which constituents are to be regarded as addressees, or how corporations can account for appropriate conduct, is still in some state of flux. The process of assignment - or negotiation - of meaning at field level is thus central to this study.

CSR is an accepted managerial practice in most cultural settings nowadays. Nonetheless, it is important to acknowledge that successful CSR rhetoric and practice is dependent on successful field-level theorization (i.e., theorization that resonates in a specific local setting). Meyer (2004) points out that most contemporary management concepts, although shaped by globally prevalent rationalized myths, institutional logics, and theorizations (e.g., Meyer \& Rowan, 1977; Friedland \& Alford, 1991; Strang \& Meyer, 1993; Strang \& Soule, 1998; Benford \& Snow, 2000), and although spread on a worldwide scale, cannot be transferred wholesale from one social context to another. She underlines that whenever such concepts disseminate beyond cultural boundaries to become globally accessible, culturallyresonant modifications of the theorization are a precondition for further diffusion, as the appropriateness of accounts is closely linked to the cultural context in which they are employed. During these translations (Czarniawska \& Joerges, 1996) or "editing" processes (Sahlin-Andersson, 1996), concepts often considerably change their meaning - a characteristic that applies in particular to a concept that stresses the (essentially cultural) dimensions of responsibility and accountability, as well as implying substantial consequences for governance mechanisms both at the corporate and societal level.

\subsection{Focus and research questions: Dissemination and meaning}

This study focuses on corporations' efforts to mobilize and manage legitimacy (Suchman, 1995; Deephouse \& Suchman, 2008) in the face of multiple and potentially incommensurable claims by a variety of constituents. In fact, corporations have been doing just this by increasingly adopting and utilizing the management

8 In assigning and constructing meaning, any social actor essentially refers to, is guided by, and - to a certain degree - reproduces existing cultural constructs in the field (for instance, by drawing on interpretive packages available in field-level discourse; see also Meyer \& Höllerer, 2010); such reproduction also implies the reconstruction of discursively and socially shared categories and symbols. In order to address the more or less simultaneous processes of reconstruction and construction of meaning, one might prefer to make use of the technical term of "(re-)construction"; to a lesser degree, this also emphasizes that any observer is an active - and never perfectly neutral - part of the construction process of the social world (e.g., Lueger, 2001). 
concept of CSR. Building on the understanding that such mobilization of legitimacy is primarily a discursive process (Berger \& Luckmann, 1967), I will analyze corporations' efforts to become identified with values, symbols, and ideas that are perceived as legitimate, and thus to demonstrate alignment with wider societal expectations and cultural context. Processes of institutionalization - and, in particular, diffusion and institutionalization across cultural borders - are covered by this study insofar as management concepts like CSR have been promoted as viable and enduring solutions to social problems on a global scale. As a consequence, discursive theorization activities - regarded as the central prerequisite of any institutionalization - constitute crucial elements of my analysis.

I will lay out in greater detail why the management concept of CSR has become increasingly important to the corporate world, including how CSR works and functions to assist corporations in managing legitimacy. Empirically, I am especially interested in (a) the field-level dissemination - i.e., adoption and indication of commitment - as well as (b) the reconstruction of meaning, and thus in the ongoing theorization of the concept. My research builds on previous work on systems of governance and corporate control as well as on the dissemination and application of various management concepts (for a brief overview see, for instance, Walgenbach \& Meyer, 2008). As I will flesh out, the "tool kit" of organizational institutionalism, supplemented by essentials from discourse analysis, serves as an ideal conceptual background for my empirical study. Given the phenomenon of interest, such a project must be informed by the vast literature in the field of business ethics and CSR.

I will use the genre of annual reports of all Austrian publicly-traded corporations between 1990 and 2005 to provide empirical evidence (for more, see chapter on methodology). Explicit commitment to CSR in these documents - i.e., the "discursive practice" by which the debate on the business-society interface is reproduced by corporations - contains the multiple claims of all stakeholders regarded as "relevant", but nonetheless also represents a key site of struggle over social meaning. ${ }^{9}$ The audience corporations address in annual reports and, hence, the instance to decide upon the appropriateness of corporate policies, is the general public.

Empirically, commitment to corporations' responsibilities can be conceived at various levels (see also Basu \& Palazzo, 2008; for an overview of empirical studies see den Hond et al., 2007b): at the level of actual behavior, at a cognitive level, and at a communicative/rhetorical level. While all have their unique advantages in empirical research, only the latter leaves "time-authentic traces" that provide the

9 Corporations' self-presentation and their efforts to construct legitimacy discursively are the focus of attention, with the position and perspective of corporations being highlighted in particular. These actors represent the most central constituents of the CSR discourse, and can (re-)assign meaning to this management concept by the multiple and divergent ways in which they utilize and employ it (within the limits of the discursive repertoire available). 
opportunity for the researcher to go back in time and construct a solid longitudinal dataset. ${ }^{10}$ The very ways corporations communicate their commitment to CSR and identify areas of responsibility, how they frame their statements, and how they choose to portray the organization's role within society provide a multitude of information - a source of comprehensive data which has yet to be fully exploited by academic literature. In addition, the majority of research into this field has so far focused more on particular sub-topics within the debate on CSR like, for instance, the mutual influence of social and financial performance (for an overview, see Margolis \& Walsh, 2003; Orlitzky, Schmidt, \& Rynes, 2003; Orlitzky, 2008) or social disclosure practices (Epstein \& Freedman, 1994; Brammer \& Pavelin, 2004; Vuontisjärvi, 2006, among others). Large-scale, longitudinal, and field-level studies on the dissemination and meaning of CSR in a continental European context are, to my knowledge, hardly available to date. This study, employing time-series crosssectional data, also facilitates an analysis of temporal dynamics and shifts. Well aware of changes within the genre of annual reports itself, I will track and sketch the most striking developments of the concept over time.

In the following, I will organize my research questions in several clusters, each characterized by specific objectives.

Exploring the Austrian landscape. Before being able to pose and, subsequently, answer any research question, institutional research must explore in greater depth the landscape and empirical stage (i.e., the broader institutional framework in place). As will be argued, Austria qualifies as a potentially interesting setting to study the development or "career" of CSR and to illustrate related processes. An initial bundle of research questions thus aims at mapping divergent interests, institutional pressures, and demands for legitimacy from various "audiences", as well as reactions from the corporate world - that is, also the question of whether CSR can be perceived as a "collective solution" for a "collective problem" in Austria. What are the general conditions ${ }^{11}$ for CSR to go ashore in Austria? What is the relevance of the concept to Austrian business organizations? And how is this specific issue field structured in Austria (for instance, actors in the arena, regulations, explicit and implicit rules)?

Exploring adoption and dissemination. A second bundle of research questions addresses some shortcomings outlined above and is concerned with the dissemination of CSR as a globally diffusing concept and its specific career in the Austrian context. I am especially interested in understanding and explaining the specific characteristics of receptive organizations, or - to put it differently - which corpo-

10 I also assume annual reporting documents to contain manifold discursive traces and thus some reference to all three levels, as corporations must comment, justify, rationalize, and discursively legitimate their behavior to their key stakeholders and the public.

11 This should also reveal the more general opportunity structure (i.e., the broader set of political constraints and opportunities; for details, see Rucht, 1994; McAdam, McCarthy, \& Zald, 1996; Tarrow, 1998, among others) for the dissemination of CSR in Austria. 
rations are "at risk" of indicating adoption and commitment. In order to do so, I will test a broad set of hypotheses comprising both organizational (i.e., contingency) and institutional variables that potentially qualify as drivers of CSR. Moreover, the focus on business organizations' efforts to discursively obtain and manage legitimacy also links with specific discursive practices, and thus also with questions of significance of CSR and its placement on the agenda of today's corporations (see below for details).

Exploring theorization and assignment of meaning. Finally, a third bundle will go beyond existing work and the study of diffusion processes. Recognizing CSR as a comprehensive, dynamic, and discourse-shaped concept, this study also aims at the reconstruction of theorization activities (i.e., the investigation of the definitions and interpretations actors employ when drawing on this particular concept). To this end, one of the main contributions will be to illustrate issues of theorization and to reconstruct the meaning of CSR in Austria. More specifically, this embraces the ways in which corporations respond to pressure (i.e., how they theorize the problem, how they theorize the solution, and how they build a causal relation between the two). Several points merit attention here and will guide my research. First, it will be interesting to see which globally - or locally - available labels for CSR are actually adopted by corporations; a key task will therefore be to disentangle the overall discourse in various sub-discourses. Second, references made to particular groups of stakeholders and/or affected societal actors inform on the relevant social categories of actors in the context of CSR. Third, the topics corporations address when they refer to CSR, as well as the arguments and accounts they provide, communicate on the thematic embeddings of CSR. Fourth, I am especially interested in patterns at field level, in practice variation (e.g., Lounsbury, 2001), and in the heterogeneity of meaning under a common umbrella concept. In this sense, the study aims at detecting and reconstructing the structuring dimensions of meaning within the Austrian CSR discourse.

\subsection{Course of this study}

The course this study follows is largely predefined by the three bundles of research questions described above. After this introductory chapter, which briefly touched upon the overarching theme, outlined central problems and questions, as well as gave a general project outline, I will present, in Chapter 2, the current state of the field of CSR research. In more detail, I will discuss CSR as an essentially contested issue, elaborate on core elements and central framings, and will give a brief overview of existing concepts within the field. Chapter 3 is devoted to organizational institutionalism as the primary theoretical background of my work; the notions most relevant to and used in my research will be addressed. In Chapter 4 I will present methodological considerations and develop the methodical tools necessary 
for carrying out my empirical research. Moreover, I will report precisely on sampling criteria, data, and methods of analysis.

In the empirical part of this study, I will draw on the genre of annual reports of Austrian publicly-traded corporations to analyze commitment to the management concept of CSR. Arguing that such concepts relate to specific models of governance and are thus dependent on the cultural embeddedness of organizations, I will start by presenting the empirical setting of my study (i.e., the Austrian context) in more detail in Chapter 5. A first chapter on findings, then, will be devoted to the career of CSR in Austria (Chapter 6). Here, I will argue and test a number of hypotheses that explain the dissemination and adoption of CSR, as well as central underlying mechanisms and relations. Upon presenting the results of several statistical models, I will discuss the findings in detail and draw initial conclusions. A second chapter on findings (Chapter 7) will focus on the reconstruction of meaning of CSR in Austria. I will present and discuss patterns at field level, dynamics within the discourse, as well as shifts and modifications over time. This will also permit an exploration of field-level processes of theorization and discourse as well as bring forward implications for the social construction of institutions. Both chapters on findings will discuss their specific contributions.

Toward the end of the study, some space will be devoted to a brief synopsis, as well as to key contributions and limitations of my research (Chapter 8). I will then present some thoughts on how this project and its findings can potentially inspire a future research agenda; I will report briefly on areas in which I have already begun research that continues along these lines. A few summarizing remarks will then conclude this doctoral dissertation. 
"The term is a brilliant one; it means something, but not always the same thing, to everybody. To some it conveys the idea of legal responsibility or liability; to others, it means socially responsible behavior in an ethical sense; to still others the meaning transmitted is that of 'responsible for' in a causal mode; many simply equate it with 'charitable contributions'; some take it to mean socially 'conscious' or 'aware'; many of those who embrace it most fervently see it as mere synonym for 'legitimacy', in the context of 'belonging' or being proper or valid; a few see it as a sort of fiduciary duty imposing higher standards of behavior on businessmen than on citizens at large."

Dow Votaw (1973: 11) on corporate social responsibility

\section{Corporate social responsibility (CSR)}

As a field of academic inquiry, CSR is - as Crane et al. (2008a: 568; see also McWilliams, Siegel, \& Wright, 2006b; Windsor, 2006) conclude - "still in an embryonic stage. The study of CSR has been hampered by a lack of consensus on the definition of the phenomenon, unifying theory, measures and unsophisticated empirical methods. Globalization has also added to the complexity of CSR issues." Difficulties of defining the social responsibility of business are partly due to the concept's divergent origins and rationalizations. In the following chapter, I will elaborate on core conceptual elements as well as on the state of the field of contemporary CSR research. Drawing on Matten and Moon's (2008) distinction between explicit and implicit CSR $^{12}$ will provide further information on the institutional embeddedness of this - essentially contested - issue. Very much in line with these authors, I argue that it is "axiomatic" for my empirical analysis not to present yet another definition, especially as the meaning of CSR represents the very core of my empirical research. Nonetheless, I wish to devote appropriate space to elaborate on the most central (meta-)framings of, and accounts for, CSR: the moral versus the business case argument. Finally, I will mark the territory by screening what can and will be considered as CSR in the course of this study - as well as what cannot (thus preparing the ground for my empirical sampling strategy).

\subsection{What is CSR?}

CSR presents itself as an opalescent phenomenon: It takes many different forms and is expressed in numerous ways, varying across wider cultural contexts as well as between individual organizations. A multiplicity of actors cultivating and influencing the field results in diverse imagery associated with the notion of CSR (Hiß,

12 In short, they primarily address "the question why forms of business responsibility for society both differ among countries and change within them" (Matten \& Moon, 2008: 404). 
2006). With the practical implications and relevance of redesigning the businesssociety interface evident, the idea of CSR has attracted scholars from various disciplines and has been studied from different perspectives. Yet the corpus of literature still does not provide a consistent definition of CSR, neither in a descriptive nor in a normative sense (Crane et al., 2008b). Content-related vagueness, ambiguity, and weak alignment with the theoretical foundations of management science have also led to difficulties in empirical research from a management and organization perspective.

Generally speaking, CSR is the vaguely defined term for the broad concept of business conduct that aligns with social expectations of integrity, transparency, fairness, and generally accepted social values (Thompson, 2008). However, while various "concepts, constructs, and theories of CSR [...] are competing with many other concepts, constructs, and theories of CSR [...], we might at least suggest that at the core of these debates is the subject of the social obligations and impacts of corporations in society" (Crane et al., 2008b: 6; see also Matten \& Moon, 2008, among others). ${ }^{13}$ CSR is used to consider and/or evaluate "effects of business on society, beyond the traditional role of seeking to maximize profits" (Crane et al., 2008a: 569). The wording of the World Business Council for Sustainable Development highlights the central role of business within society and might serve as a first approximation to the issue:

"Corporate social responsibility is the commitment of business to contribute to sustainable economic development, working with employees, their families, the local community and society at large to improve their quality of life" (World Business Council for Sustainable Development, 2000: 10).

Also widely quoted is the interpretation of the European Commission which defines the concept of CSR as a template used by corporations - on a strictly voluntary basis, moving beyond mere compliance with legal requirements and market expectations - in order to integrate various social issues, environmental concerns, and stakeholder interests:

"By stating their social responsibility and voluntarily taking on commitments which go beyond common regulatory and conventional requirements, which they would have to respect in any case, companies endeavour to raise the standards of social development, environmental protection and respect of fundamental rights and embrace an open governance, reconciling interests of various stakeholders in an overall approach of quality and sustainability" (European Commission, 2001: 4).

13 Despite the existence of a great variety of different terms, concepts, and interpretations, "all are manifestations of one and the same underlying position, namely that corporate decisions have moral consequences and that therefore corporate decision makers should consider the moral consequences of their decisions" (den Hond, de Bakker, \& Neergaard, 2007a: 3, with reference to Freeman, 1994). 
More from the angle of welfare economics, Salazar and Husted (2008: 140) refer to CSR as a corporation's obligation "to respond to the externalities created by market action." Building on these insights, it is necessary to take into consideration not only objects and topics, but also subjects and means of CSR:

"CSR occurs when a business firm, through the decisions and policies of its executive leaders, consciously and deliberately acts to enhance the social well-being of those whose lives are affected by the firm's economic operations. In this way, CSR blends and harmonizes economic operations with a buman community's social systems and institutions, creating an organic linkage of Business and Society" (Frederick, 2008: 522-523).

Frederick (2008: 523) also reminds us of the dual meaning of CSR, i.e., of the "two distinct ways of determining a company's CSR standing: looking at the company as a whole, or examining the individuals who make decisions and set policies for the company". While the first perspective characterizes a focal corporation's CSR status as a function of "institutional actions" of executives and boards (i.e., the focus here is on the corporation as a legal entity), the latter conceives CSR status more as a function of "personal actions" of individual corporate agents.

Finally, CSR has both an internal and an external perspective (e.g., European Commission, 2001): Within a corporation, socially responsible practices primarily target employees and address issues such as human resource management, occupational health and safety, change management, the management of natural resources, as well as environmental impacts of production processes. However, CSR extends well beyond the doors of the organization and involves a wide range of external stakeholders; in addition to shareholders and staff, corporations must therefore also deal with customers, suppliers, and business partners, public authorities and NGOs representing local and global communities, as well as the environment and society at large (e.g., Freeman, 1984; European Commission, 2001; Werther \& Chandler, 2011).

Definitions of CSR diverge over several dimensions that demand further attention. I will briefly highlight what I regard as the three major points here: motive, voluntariness, and institutional context. First, there is the question of a social motive as an essential foundation for CSR. As Dunfee (2008: 347) puts it: "Should it be considered genuine CSR if in reality the apparent CSR is a disguised business strategy designed to increase earnings, market share, or competitive position?" The answer depends, from a normative perspective, on the ethical theory applied (for an overview, see Kagan, 1998; Smith, 2009; Brenkert \& Beauchamp, 2010): While deontological theories emphasize intention (i.e., the worthiness of action is dependent on the motive and principle behind it), teleological theories focus on the consequences and outcomes (e.g., Dunfee, 2008; Crane \& Matten, 2010). ${ }^{14}$ A wide

14 It is, of course, also possible - and in many cases likely - that both lenses might end up with the same evaluation. 
variety of motives for engaging in CSR have been recognized in the literature. Aguilera et al. (2007), for instance, suggest three main clusters - instrumental, relational, and morality-based motives - also pointing to the possibility of multiple and combined motives. However, motive as an element of a definition of CSR remains tricky, especially as it presents itself as opaque to persons other than the decision maker, or to observers from outside an organization (Dunfee, 2008).

A second important line of conflict in defining CSR revolves around the criterion of voluntariness and whether this feature is a sine qua non for the concept's very definition. While authors like, for instance, Windsor (2006: 93; see also Carroll, 1991, 2004) broadly define CSR as "any concept concerning how managers should handle public policy or social issues", other literature sometimes more narrowly refers to "actions that appear to further some social good, beyond the interests of the firm and that which is required by law" (McWilliams \& Siegel, 2001: 117; McWilliams, Siegel, \& Wright, 2006a). Such reference of surpassing minimum legal requirements might be problematic insofar as it makes it dependent on the respective regulatory context of whether or not a certain type of action qualifies as socially responsible (i.e., behaving in an identical manner could be evaluated quite differently). ${ }^{15}$ On a more abstract and normative level (see, for instance, Kagan, 1998), it is even more questionable as to how to fully reconcile the ideas of voluntariness and responsibility: While living up to someone's responsibility results in a choice of deliberate and discretionary action, the underlying responsibility (or accountability) per se is nothing that can be thought of as essentially voluntary. Moreover (and as with motive), it is difficult to determine what is and what is not voluntary action: While this is, for instance, quite clear in the case of issues settled by specific legislation, the borderline is much more blurred in the case of "soft law" or incentive structures, but also in the case of fundamental institutional pressure (for a general overview, see Dunfee, 2008; see also Edelman, Uggen, \& Erlanger, 1999 on the endogeneity of legal regulation). As indicated above, some definitions of CSR explicitly exclude compulsory action from being able to qualify as CSR by stating that CSR "involves going beyond what the letter and spirit of the law require or the market demands" (Baron, 2001: 12; McWilliams \& Siegel, 2001; see also, for instance, the position of the European Commission, 2001). An alternative approach allows the differentiation of various types of corporate responses to social problems in more detail: Husted and Salazar (2006; Salazar \& Husted, 2008), for instance, make a useful distinction between altruistic, strategic, and coerced CSR.

A third area of divergence in defining CSR is interrelated to those mentioned above and addresses the institutional context in which organizations operate. Matten and Moon (2008), among others, argue that the understanding, scope, and content

15 Campbell $(2006,2007)$ also reminds us that it is not only action but also the abandonment of irresponsible action (i.e., not acting in a harmful way) that qualifies as social responsibility something that is overlooked in most established definitions of CSR. 
of CSR significantly differ between divergent governance and business systems, i.e., especially between liberal market economies (like the United States) and coordinated market economies (various continental European countries; see also Whitley, 1999; Hall \& Soskice, 2001): While the first cultural setting provides greater opportunity and incentives for business to address responsibility through explicit CSR policies, rhetoric, and action, the latter represents a system of wider organizational responsibility (embedded in broader norms and regulation), yielding comparatively narrow opportunities and incentives for business to take explicit responsibility. Matten and Moon (2008) thus denote explicit and implicit as the two decisive attributes for CSR.

'By 'explicit CSR' we refer to corporate policies that assume and articulate responsibility for some societal interests. They normally consist of voluntary programs and strategies by corporations that combine social and business value and address issues perceived as being part of the social responsibility of the company. [...] By 'implicit CSR' we refer to corporations' role within the wider formal and informal institutions for society's interests and concerns. Implicit CSR normally consists of values, norms, and rules that result in (mandatory and customary) requirements for corporations to address stakeholder issues and that define proper obligations of corporate actors in collective rather than individual terms" (Matten \& Moon, 2008: 409).

A primary task in this chapter will be to develop a robust understanding of the concept of CSR that is applicable in empirical research - i.e., that enables a qualified empirical study of CSR discourse in Austria -, yet without imposing an a priori definition on the field that might not resonate, or even lead to distortion. As an initial step, it might be helpful to further our comprehension of the term CSR by shedding some light on its distinguishing elements (see also Hiß, 2006): The types of (a) corporate organizations covered by this attribute comprise stock corporations with separation of ownership and control, corporations with owner-managers (for instance, SMEs or family-owned business), and corporations with ownership by public bodies. These actors are positioned within a complex system of (b) social relations with other societal actors whose interests and claims might vary greatly; additional characteristics like the area of operation (in the case of multinational corporations) or exposure to public scrutiny (such as flagship corporations or those with business activity in sensitive or high impact industries) might intensify this system of multiple interests. Finally, (c) responsibility refers, on the one hand, to the fundamental question of the role and purpose of the corporation within society, and, on the other, to areas of action a focal corporation considers to be relevant, based on the organization's position within society - or, alternatively, core audiences and stakeholders perceive as highly relevant for the focal corporation. In corporate practice, in continental European and Anglo-American contexts alike, social responsibility (soziale Verantwortung in German) has been occasionally interpreted as an act of mere corporate giving, philanthropy, or charity - rather than embracing a more comprehensive approach of responsibility for and accountability 
toward society in general (i.e., societal responsibility, or gesellschaftliche Verantwortung in German; for this distinction, see also Hiß, 2006). Such a narrow understanding is limited to covering only one of the three pillars of the triple bottom line (TBL) of sustainable development, namely the social dimension. However, and especially in recent years, sustainability (Nachbaltigkeit in German) with its focus on environmental issues (i.e., the ecological dimension), as well as long-term value maximization (i.e., addressing the economic dimension) have become essential elements of the understanding of CSR; in addition, strategic stakeholder management made its way into corporations' business policies (e.g., Werther \& Chandler, 2011). Against the backdrop of these multiple understandings, and quite much in line with other research (e.g., Carroll, 1999; Bassen, Jastram, \& Meyer, 2005; Matten \& Moon, 2008), I argue that the idea of CSR is characterized as a comprehensive, dynamic, and discourse-shaped concept consisting of an entire bundle of conceptual subdiscourses. ${ }^{16}$

In order to explore the dissemination of CSR as a management concept, it is indispensable to achieve a comprehensive understanding of the multiple layers of responsibility; it is therefore also essential to include the totality of empirical labels and interpretations, and to pay attention to ambiguous meanings within the concept. The use of various labels that are synonymous with, or clearly allude to, CSR, as well as the struggle over terminology and definition in general, clearly point to the necessity of specification and contextualization. For this study, I have decided to retain CSR as the all-encompassing "umbrella term" (Matten \& Moon, 2008: 405), although literature using new terminology to address business-society relations has recently proliferated (e.g., "corporate citizenship," which draws more attention to the political dimension and to issues of governance; see Matten \& Crane, 2005; Moon \& Vogel, 2008). I have also refrained from "dropping the S" in CSR (see Aguilera et al., 2007) in order to stress the embeddedness of organizations, business, and economic action in the structures of social relations (Granovetter, 1985; Dacin, Ventresca, \& Beal, 1999) that results in strong ties between corporations and their social environment. This being said, I nonetheless wish to break down CSR to its various sub-discourses - both conceptually and empirically.

\subsection{CSR in the academic debate: A brief historical overview}

Like its theoretical foundations, CSR looks back on a rather "long and varied history" in scholarly literature (Carroll, 1999: 268). Some aspects of CSR have created more enthusiasm within academia than in actual corporate behavior (Beaver, 1999; Matten \& Crane, 2005), while other issues that are now part of the CSR agenda (and are thus, for instance, incorporated in standard textbooks) have

16 See below for a detailed description of CSR sub-concepts. 
been anchored in sociopolitical traditions or in corporate practices for a substantial period of time in various institutional contexts, yet without explicitly being thought of as CSR (Meyer \& Höllerer, 2009). Empirical examples used in literature date back as far as times of industrial revolution (e.g., Carroll, 2008). As Frederick (2008: 525) - a researcher whose contributions to the scholarly debate on CSR span more than half a century - points out, the concept currently known as CSR evolved in more or less four chronological phases or stages of development that can be summarized as follows: (a) Corporate social stewardship - corporate managers as public trustees and social stewards (1950s and 1960s); (b) corporate social responsiveness responding to social demands (1960 and 1970s); (c) corporate etbics - fostering ethical corporate culture (1980s and 1990s); and (d) corporate global citizenship - accepting and attaining global citizenship responsibility (1990s and 2000s).

Formal writings on CSR have largely been a product of the second half of the $20^{\text {th }}$ century, with most of the early texts emerging in the United States (for an overview see, for instance, Carroll, 1999, 2008; Frederick, 2008). In Europe, the academic debate is relatively young ${ }^{17}$ and the practices of CSR have become widespread only recently (Matten \& Moon, 2008). Nonetheless, European scholars have significantly contributed to the sizable body of existing literature in the last 15 years, for which reason it must "be acknowledged that CSR and related notions have been developed in practice and thought in a number of [...] countries and at different times" (Carroll, 2008: 20). More recently, countries in other parts of the world have also begun to direct their attention to CSR thinking, policies, and practices. Hence, to outline the development of the concept at length constitutes a considerable challenge. ${ }^{18}$

A number of scholars (Carroll, 1979; Wartick \& Cochran, 1985; Carroll, 1999; Valor, 2005; Lee, 2008, among others) agree that Bowen's (1953) milestone publication entitled Social Responsibilities of the Businessman marked the start of modern literature on CSR within social and management science - and also "CSR's formal birth and growth in the 1950s" (Carroll, 2008: 24). Corporations, so Bowen's (1953: 6) argument, have the obligation "to pursue those policies, to make those decisions, or to follow those lines of action which are desirable in terms of objectives and values of our society". ${ }^{19}$ Drucker was among the first to explicitly address the "public" or "social responsibility of management" in his classic book The Practice of

17 For some early exceptions in continental Europe and in the German speaking community in particular, see, for instance, Steinmann (1973) and Ulrich (1986).

18 For this study (and with regard to the empirical analyses covering an observation period from 1990 to 2005), a summarizing account seems sufficient and favorable.

19 Bowen's treatment of CSR proceeds from the underlying assumption that corporate decision makers constitute a social elite (on value systems and styles of social responsibility of managers, see also Hay \& Gray, 1974). Recently, the responsibility of individual actors has been discussed anew especially under the notion of "accountability" (e.g., Bovens, 2007), whereas the responsibility of the corporation as a legal entity has somehow remained diffuse (see also the remarks on the dual meaning of CSR above). 
Management, presenting many thoughts and ideas (see Drucker, 2007) that prove to be even more relevant and valid today than they were when the book was first published in 1954. In general, while Europe was primarily concerned with efforts to recover and reconstruct its economic infrastructure after WWII, the first explicit theorization of CSR - including the role of corporations within society - mainly took place in the United States. Again, and this is a central point, considerable traces of implicit CSR within the institutional framework of continental European countries must not be neglected. ${ }^{20}$

Following up on some of these early thoughts on CSR, the 1960s were characterized by attempts to define the meaning of CSR (Carroll, 2008), with movement picking up speed throughout the 1970s (for an overview of relevant literature from the 1960s and 1970s see, for instance, Carroll, 1999, 2008). Interestingly, the notion of CSR was extended by reference to corporate social performance (e.g., Sethi, 1975; Wartick \& Cochran, 1985), corporate social responsiveness (e.g., Ackerman, 1973; Sethi, 1975; Ackerman \& Bauer, 1976), and public responsibility (e.g., Preston \& Post, 1981). Many authors at this time began to emphasize the importance of a managerial approach to CSR by applying the traditional management functions, i.e., to "forecast and plan for CSR, organize for CSR, assess social performance, and institutionalize corporate social policy and strategy" (Carroll, 2008: 34).

During the mid-1980s, and in the Anglo-American context, corporations' responsibilities toward society seemed widely recognized; what became more and more important was the question of how to arrange and enact corporate ethics in business practice (Carroll, 2008). Some central theoretical contributions within the discipline (e.g., Carroll, 1979; Zenisek, 1979) - as well as fruitful ideas from the field of strategy and corporate governance (above all the stakeholder theory, see Freeman, 1984), which especially in continental Europe achieved great resonance were followed by a number of studies with diverging foci. Some of this work was devoted to further developing the model of corporate social performance (e.g., Wartick \& Cochran, 1985); another major line of (empirical) research was particularly interested in the relationship of CSR activity and financial performance of a corporation (e.g., Cochran \& Wood, 1984; Aupperle, Carroll, \& Hatfield, 1985; Mackey, Mackey, \& Barney, 2007; for an overview, see Orlitzky, 2008, or the metastudies of Margolis \& Walsh, 2003; Orlitzky et al., 2003).

In the 1990s, new and unique contributions to the concept of CSR were rare; instead, it served rather "as the basepoint, building block, or point-of-departure for

20 For example, as Meyer and Höllerer (2010) point out, in Austria the Aktiengesetz (Austrian Stock Corporations Act) has demanded a distinct stakeholder orientation in corporate control since the 1960s, with the debate on which interests a corporation must take into account dating back to the era of the Austrian-Hungarian Empire (Kalss, Burger, \& Eckert, 2003). Moreover, owners and managers of corporations generally perceived themselves as the societal elite responsible for other members of society - and for the nation at large, thus also engaging in sociopolitical decision making (see chapter on empirical context for details). 
other complementary concepts and themes, many of which embraced CSR thinking and were quite compatible with CSR" (Carroll, 2008: 37). One of the most prominent ones was sustainability - an idea that was originally connected with environmental issues but has been broadened to include other dimensions of organizational environments as well as economic issues ("corporate sustainability", see below). Moreover, the notion of corporate social performance still drew much attention (e.g., Wood, 1991; Swanson, 1995; Wood \& Jones, 1995; Swanson, 1999). Among others, Carroll $(1991,1998)$ revisited his influential CSR definition(s), highlighting the "discretionary/philanthropic" component of CSR that embraces "corporate citizenship", a term that has since become rather popular as an alternative way of framing CSR (Carroll, 2008).

Corporations only more recently realized their responsibilities toward a global business environment, and since the turn of the millennium the CSR movement has become, finally, a global phenomenon, with the rhetorical and practical tool kit of CSR being established as an essential part of business practice. Thus, it is not surprising that the most significant advances and stimuli to the debate on social responsibility have come in the realm of business practice itself (Carroll, 2008). In academia, the 2000s were characterized by a splintering of interests and new scholarly fields in which to think about CSR. Within management research, CSR has doubtlessly created an empirical research agenda of its own which currently seems to aim in particular at reconciling theory and practice (see Habisch, Jonker, Wegner, \& Schmidpeter, 2005; Kotler \& Lee, 2005; Aras \& Growther, 2010). ${ }^{21}$

\subsection{Defining the range of responsibilities for business organizations}

The notion of CSR holds corporations accountable toward society and key stakeholders, and assigns them responsibility for other societal actors and the environment, as well as for society at large. However, the problem of defining a corporation's actual range of responsibilities is a difficult task. While some literature (see above) refers to CSR as exclusively voluntary action, others argue that it must be framed in a way that embraces the entire range of business responsibilities. Carroll (1979) was one of the first to systematize CSR, distinguishing economic, legal, ethical, and philanthropic/discretionary aspects or dimensions of CSR (see also Carroll, 1991; Schwartz \& Carroll, 2003; Carroll, 2004). Specifically, he suggested that the "social responsibility of business encompasses the economic, legal, ethical, and discretionary expectations that society has of organizations at a given point in time" (Carroll, 1979: 500). The derived "pyramid of corporate social responsibility" (e.g., Carroll, 1991) has been particularly predominant (see Figure 1).

21 For an evaluation of the status of CSR research within the management literature see, for instance, Lockett, Moon, and Visser (2006). 


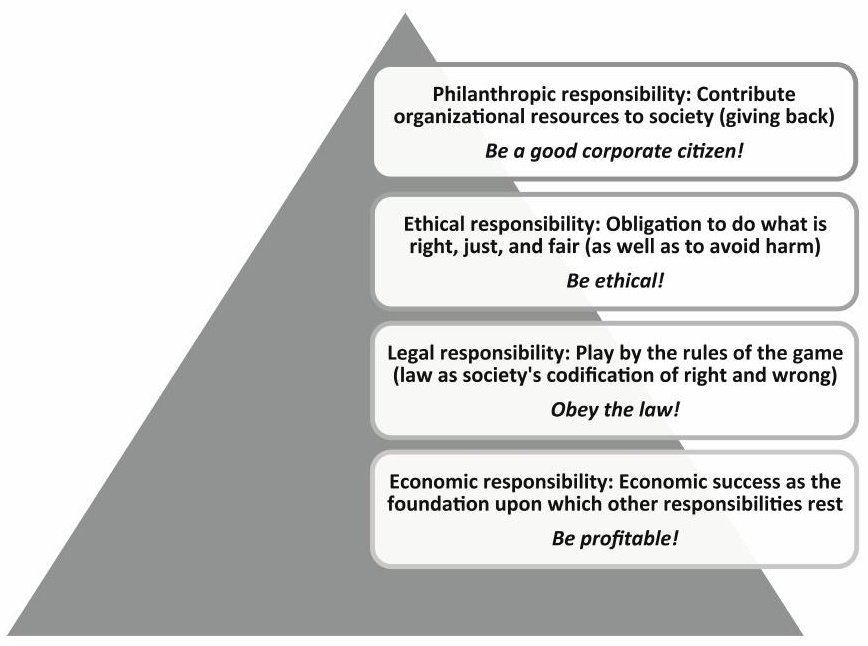

Figure 1: The pyramid of CSR (Source: adapted from Carroll, 1991: 42)

Corporations' primary responsibility is to produce profit and a decent return on investment for its shareholders. Profitability is therefore "a sine qua non of effective corporate citizenship" (Carroll, 1998: 2); or, in the words of Drucker (1984: 62),

"[... the first 'social responsibility' of business is then to make enough profit to cover the costs of the future. If this 'social responsibility' is not met, no other 'social responsibility' can be met.

Decaying businesses in a decaying economy are unlikely to be good neighbors, good employers or 'socially responsible' in any way."

Corporations and their management must also operate within the legal framework of a society - that is, within the society's codified ethics. These two dimensions economic and legal responsibility - are more or less required, while complying with broader ethical standards (i.e., doing no harm and doing what is generally regarded as right, just, and fair) can only be expected by society. Finally, society might desire corporations to live up to their philanthropic/discretionary responsibilities of "giving back" to the community and society at large. ${ }^{22}$ Carroll and Shabana (2010:

22 Carroll's typology is somehow inspired by a ground-breaking contribution to the concept of CSR that also largely reflected the practitioners' view: In its 1971 publication, the Committee for Economic Development suggested three concentric circles to typify CSR: An inner circle that includes basic responsibilities for the efficient execution of the economic function; an intermediate circle that encompasses responsibility to exercise this function with a sensitive 
90; see also Kotler \& Lee, 2005) refer to ethical and philanthropic responsibilities as "the essence of CSR".

While this conceptual framework is still useful today, it is problematic insofar as these clear-cut dimensions do not exist in practice but are intertwined. Werther and Chandler (2006: 9) emphasize that social issues can and do evolve over time, and that societal expectations become increasingly institutionalized. They argue that

"...7 what was ethical, or even discretionary in Carroll's model, is becoming increasingly necessary today due to the changing environment within which businesses operate. As such, ethical responsibilities are more likely to stand on a par with economic and legal responsibilities as foundational for business success [...]. As societal expectations of the firm rise, so the penalties imposed by stakeholders for perceived CSR lapses will become probibitive."

An alternative way to define the range of corporations' responsibilities commences with a differentiation of stakeholders. Basically, corporations have three kinds of stakeholders: organizational stakeholders (i.e., internal stakeholders like employees, management, and shareholders) at its very core, economic stakeholders (i.e., external stakeholders like customers, suppliers, and various business partners) as an interface between organizational stakeholders and society, and societal stakeholders in a more general sense (i.e., external stakeholders like communities, government and regulators, and NGOs). All three sit within the larger context of corporations' global business environment (e.g., Werther \& Chandler, 2006).

These conceptualizations can be summarized and transformed into "spheres of responsibility" (Figure 2; for details see also Hiß, 2006). From the perspective of a corporation, one might distinguish between a minimum sphere (required by society in terms of market mechanisms and legal regulations), an intermediate sphere (voluntary CSR activity within the value chain, for instance, compliance with soft law regulation, which is usually expected by society; e.g., respecting labor standards), and an extended sphere of responsibility (voluntary CSR activity outside the value chain, desired by society; for instance, contributing to and sponsoring civil society).

awareness of changing social values and priorities; and an outer circle that assumes business to become more broadly involved in actively improving the social environment (see also CED Committee for Economic Development, 1971: 17). 


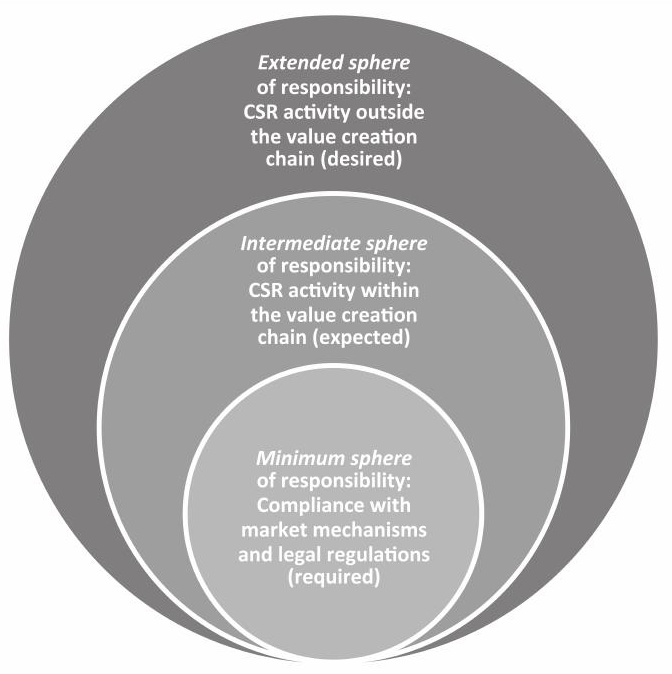

Figure 2: Spheres of CSR (Source: adapted from Hiß, 2006: 38)

\subsection{Institutional context matters: Explicit versus implicit CSR}

I have already briefly referred to the embeddedness of corporations in institutional frameworks, as well as to the question of how these specific contexts influence the perception of and approach to CSR activity. Given that societies have developed divergent governance systems over time (reflecting their institutions, customary ethics, and social relations), it follows "that we might expect some differences in the ways in which corporations express and pursue their social responsibilities among different societies" (Matten \& Moon, 2008: 407). In greater detail, Matten and Moon (2008; see also Hiss, 2009) suggest that these ways can be described as either explicit or implicit (see Figure 3).

The authors make a convincing argument that the institutional framework i.e., the governance and business systems in place - decisively set the scene for corporations' CSR activities (Matten and Moon, 2008): While institutions in liberal market economies encourage individualism and provide considerable discretion to economic actors to explicitly engage with CSR in their corporate policies, CSR is an implicit element of the institutional framework within coordinated market economies (addressed by coordinated approaches to economic and social issues through a partnership of representative socioeconomic actors and government) (see Figure 4). Both systems, however, exhibit explicit and implicit elements to some extent: It 
must not be thought of this model as a "dichotomous distinction [...] but, rather, one of emphasis" (Matten \& Moon, 2008: 410).
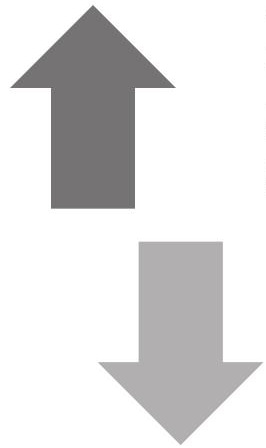

\section{Explicit CSR ...}

... describes corporate activities that assume responsibility for the interests of society.

... consists of voluntary corporate policies, programs, and strategies.

... is motivated by the perceived expectations of different stakeholders of the corporation.

\section{Implicit CSR ...}

... describes corporations' role within the wider formal and informal institutions for society's interests and concerns.

... consists of values, norms, and rules that result in (often codified and mandatory) requirements for corporations.

... is motivated by the societal consensus on the legitimate expectations of the roles and contributions of all major groups in society, including corporations.

Figure 3: Explicit and implicit CSR compared (Source: adapted from Matten \& Moon, 2008: 410)

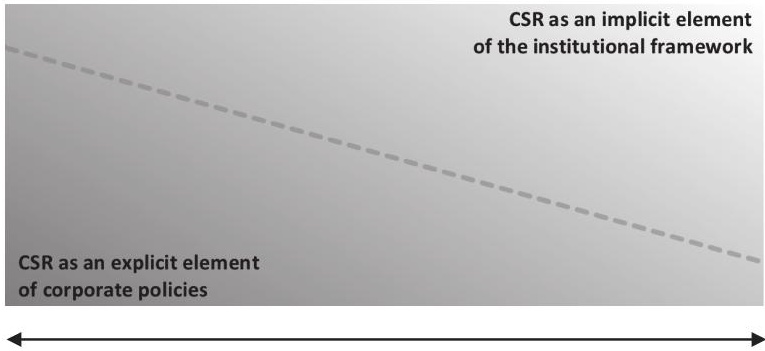

Liberal market economies ...

... with national institutions encouraging:

- Individualism

- Discretionary agency

- Incentivizing responsive actors

- Liberalism

- Network governance

- Policies providing discretion

- Isolated actors
Coordinated market economies ... ... with national institutions encouraging:

- Collectivism

- Systemic/obligatory agency

- Incentivizing program-driven agency

- (Institutionalized) solidarity

- Partnership governance

- Policies providing obligations

- Interlocking/associated actors

Figure 4: A continuum between explicit and implicit CSR (Source: adapted from Matten \& Moon, 2008: 411) 
For corporate stakeholders, the results of CSR activities - as well as their impact on the organization's audiences - do not have to be different at all. On the contrary: Matten and Moon (2008: 410) argue that

\begin{abstract}
"[...] corporations practicing implicit CSR might conduct practices similar to those of corporations practicing explicit CSR [...]. Many of the elements of implicit CSR occur in the form of codified norms, rules, and laws but are not conventionally described explicitly as CSR. It is the societal norms, networks, organizations, and rules that are explicit, rather than their implications for the social responsibilities of business. It is in this sense that CSR in these systems is implicit."
\end{abstract}

However, the interpretation that this important differentiation "also exposes differences in intent" (Matten \& Moon, 2008: 410) is somewhat questionable. While one might agree that implicit CSR is in most cases not "conceived of as a voluntary and deliberate corporate decision but, rather, as a reaction to, or reflection of, a corporation's institutional environment" (although there is much leeway concerning how - and to what extent - codified norms and rules are fulfilled), ${ }^{23} \mathrm{I}$ argue that also explicit CSR is not always "the result of a deliberate, voluntary, and often strategic" decision making process. Expectations from key stakeholders, for example, can prove to be very strong pressures that equally reduce the scope for deliberate decision making. In a similar way, coercive isomorphism in specific industries, for instance, might force corporations to address CSR explicitly.

Still, one major puzzle remains. Why have continental European corporations recently begun to adopt a more explicit commitment to CSR (also reflected in their corporate policies and communication) that largely resembles that of their AngloAmerican counterparts - "regardless of the fact that responsible business practices have been and continue to be implicitly part of their day-to-day business activities" (Matten \& Moon, 2008: 405)? The study at hand will mainly draw on arguments from organizational institutional theory/research in order to explore this phenomenon in more detail. In this respect, another point raised by Matten and Moon (2008: 410) seems important: Corporations practicing explicit CSR "use the language of CSR in communicating their policies and practices to their stakeholders, whereas those practicing implicit CSR normally do not describe their activities this way" - because it is not necessary at all (see also Scott, 2008, on the "cognitive pillar" in institutional theory; for more, see chapter on organizational institutionalism). While some 15 years ago any explicit debate on CSR in Austria was more or less absent due to this issue being, first, taken-for-granted and, second, implicit in the institutional framework, standardized accounts have - after a phase of negotiation of meaning during the decline of classic Austrian institutions and "subsocieties" like the powerful social partnership (e.g., Pelinka, 1998; see also Meyer \&

23 Besides, as Moon and Matten (2008) admit in their statement of limitations, corporations actively shape rather than merely reflect institutional frameworks (see also chapter on the empirical setting of this study). 
Höllerer, 2010) - begun to prevail in the late 2000s (see also empirical findings below).

\subsection{CSR as an essentially contested issue}

The actual scope and content of CSR has been subject to controversial discussion ever since its early appearance, both in practice and theory (see, for instance, the debate surrounding Friedman, 1970). Depending on the position of the actors or speakers involved in the debate, different elements and aspects have been focused on and integrated into the CSR agenda. In the early 1970s, Votaw made a very apt remark on CSR in this respect: "The term is a brilliant one; it means something, but not always the same thing, to everybody" (Votaw, 1973: 11). Drawing on a plurality of literature in - and major contributions to - the field, I have shown above that CSR is far from being easily defined. On the contrary: Few subjects in management research elicit as much controversy and contestation (Crane et al., 2008b). CSR presents itself as both an essentially contested issue and concept (e.g., Okoye, 2009), "being 'appraisive' (or considered as valued), 'internally complex', and having relatively open rules of application" (Matten \& Moon, 2008: 405, with a quote from Moon, Crane, \& Matten, 2005). It appears to be a matter of ideological position whether CSR is argued to be beneficial for business or merely a waste of resources, whether it should remain voluntary action or be determined by legal regulation, ${ }^{24}$ and, finally, which range of activities can be subsumed under the notion of CSR.

Borrowing from institutional theory (see next chapter for more details), CSR discourse can also be understood as an issue field that brings "together various field constituents with disparate purposes" and in which "competing interests negotiate over issue interpretation" (Hoffman, 1999: 351-532; see also Meyer, 2004). Thus, legitimate actors and meaning structures in such contested issue fields - that might themselves be part of even broader societal discourses - are of particular interest. However, meaning - Meyer and Höllerer (2010) refer to a "topographic map" of meaning - is not directly accessible at field level; only manifestations are (for

24 A great deal of the debate centers around the original character of CSR as voluntary action guided by specific (global) standards and "soft law" versus the demand for reinforced legal regulation (Sahlin-Andersson, 2006; for Austria, see Mark-Ungericht \& Weiskopf, 2007; on the expansion of "soft law" and increasing standardization see, for instance, Brunsson \& Jacobsson, 2002; Mörth, 2004). Here, supporters of a more market-based approach argue that externalities must be built into market prices in order to ensure the correct alignment of costs and benefits. Others, however, largely distrust markets as an appropriate modus of control and argue that "soft law" should be replaced by obligatory legal regulations (see also Sahlin-Andersson, 2006). In fact, under certain circumstances (e.g., market failure) increased regulation might be necessary and useful; on the other hand, overregulation reduces the international competitiveness of corporations and might also create considerable market barriers. 
instance, in the media or in other genres of communication like annual reports or corporate websites). ${ }^{25}$

It is noteworthy that the concept of CSR is conceptualized to a large degree from the perspective of corporations (Crane \& Matten, 2004; Hiß, 2006). Thus, corporations themselves - as a core group of actors with considerable sociopolitical influence - dominate the theorization of the concept in the realm of practice, together with the "usual suspects": business schools, consultants, management gurus, IGOs, and business press. However, a wide variety of other societal actors is also involved in field-level discourse on CSR (e.g., various stakeholders, interest groups, politicians, and NGOs). These stakeholder interests are covered insofar as corporations develop strategies to cope with, address, and balance the - often conflicting - claims of these groups: Corporate strategy, corporate communications, and marketing, among others, show distinct traces of such efforts. Moreover, these strategies will also mirror much broader societal discourses and issues that are salient, for instance, in the media. Critical events in the corporations' environment further stimulate the debate surrounding an issue (Meyer \& Höllerer, 2010), contrast perspectives, and contribute to a constantly evolving discourse that sets the CSR agenda for corporations alongside more ethical considerations.

While I shall, in the following, explore central framings of and approaches to CSR in greater detail, it is important to mention critics who more or less reject the notion of a social responsibility of business altogether. These voices are either frequently referring to the classic argument brought forward by Levitt (1958) or Friedman $(1962,1970)$ - generally skeptical of a multi-stakeholder approach ${ }^{26}$ in defining the role and purpose of business (see also Jensen, 2001), or argue that CSR is merely costly rhetoric decoupled from any significant action (e.g., "PR gimmick", "cheap talk", or "managerial speech").

\subsection{Ethical argumentation and business case framing}

CSR can be characterized as a cluster concept with a variety of theoretical foundations that are drawn on in order to substantiate and explain the concept in greater detail. Garriga and Melé (2004) distinguish between four theories, each in itself constituted by various approaches: (a) ethical theories focusing on the right thing to do in order to achieve a good/ideal society; (b) instrumental theories focusing on the

25 Each genre sheds light on different aspects; hence, each approach is selective. While the media debate, for instance, qualifies to cover the entire issue field and overall discourse (notwithstanding that the media play a central role as "gatekeepers"), corporate communication focuses on the most affected actors in the field (i.e., the corporations) and allows for an in-depth exploration of their interpretation of CSR.

26 An extensive body of literature deals with the relationship of shareholder value orientation and stakeholder approach (for an overview see Melé, 2008, among others). 
achievement of core economic objectives through social activities; (c) political theories focusing on a responsible use of status, power, and influence of business in the political arena; and (d) integrative theories focusing on the integration of social demands in business policies.

Of the various interpretive packages to promote CSR, two (meta-) framings appear to be essential in the CSR field: an ethical argumentation (moral case) ${ }^{27}$ and a business case framing. In their textbook on CSR, Werther and Chandler (2006, 2011) build on a moral argument for CSR that is based on a "give-and-take approach" between business and society: Recognizing that generating profit is necessary for the long-term survival of any business organization, it is also important to note that business opportunities for obtaining profit are only possible by enabling an societal environment in which corporations can operate. Thus, the obligations and social responsibilities of business emerge from the reciprocal relationship between corporations and society; they are shaped by individual and collective standards of morality and values. ${ }^{28}$ Such a relationship can be thought of as a "social contract" a series of explicit and implicit contracts between individuals, organizations, and institutions - that ensures an environment of trust and harmony in which corporations receive resources, goods, and the license to operate in exchange for appropriate behavior (Wilson, 2003). In this sense, CSR

"[...] broadly represents the relationship between a company and the principles expected by the wider society within which it operates. It assumes businesses recognize that for-profit entities do not exist in a vacuum and that a large part of their success comes as much from actions that are congruent with societal values as from factors internal to the company" "Werther \& Chandler, 2006: 16).

All societies rest upon a cultural heritage that gives rise to a belief system that also defines the boundaries of socially and morally acceptable behavior of organizations and their agents (Berger and Luckmann, 1967; Werther \& Chandler, 2006). To violate explicit or implicit moral boundaries could result in societal sanctions and a loss of legitimacy ${ }^{29}$ - and, thus, also to constraints on a corporation's freedom to pursue its core interests and strategic objectives (e.g., restrictive legislation, sanctions, fines, and penalties by regulators, or boycotts and social activism that bring

27 The term "moral case" was coined to parallel the "business case", which it either complements or challenges (Lane, 2010).

28 Arguments for the notion that corporations have a moral duty to behave responsibly toward the members of society can be based on several ethical theories such as Kantian ethics and virtue ethics (see below for more).

29 Several scholars highlight, especially from an organizational institutionalism perspective, the need for legitimacy as key for the global spread of CSR (see Hiß, 2006; Matten \& Moon, 2008; Hiss, 2009, among others); they propose a "fundamental shift to moral legitimacy [...] [that] creates a new basis of legitimacy and involves organizations in processes of active justification vis-à-vis society rather than simply responding to the demands of powerful groups" (Palazzo \& Scherer, 2006: 71; see also Palazzo, 2004). 
about limited access to resources and markets). In sum, sanction avoidance represents a rational argument for CSR.

"CSR is a rational argument for businesses seeking to maximize their performance by minimizing restrictions on operations. In today's globalizing world, where individuals and activist organizations feel empowered to enact change, CSR represents a means of anticipating and reflecting societal concerns to minimize operational and financial limitations on business" (Werther \& Chandler, 2006: 18).

The consequences of this rational argument - business acting proactively - lead directly to a strong economic argument for CSR: Incorporating CSR into core business operations and the value chain offers considerable opportunities for differentiation and competitive advantage, especially as corporations increasingly "need to build a watertight image with respect to all stakeholders" (Werther \& Chandler, 2006: 18). In its various roles within the economic system - whether as employer, producer, consumer, supplier, or investment object - the attractiveness and success of a corporation is strongly linked to the strength of its image and brand, as well as to its ability to balance the conflicting interests of multiple stakeholders. Thus,

\begin{abstract}
"...] CSR is an argument of economic self-interest of business. CSR adds value because it allows companies to reflect the needs and concerns of their various stakeholder groups. By doing so, a company is more likely to retain its societal legitimacy, and maximize its financial viability, over the long term. Simply put, CSR is a way of matching corporate operations with societal values at a time when these parameters can change rapidly" (Werther \& Chandler, 2006: 18).
\end{abstract}

\title{
2.6.1 The moral case for CSR
}

CSR can be assigned the status of an objective in itself and positioned at the same level as other goals in the hierarchy of organizational objectives or obligations. While the business case seems to be an increasingly attractive and legitimate framing for corporations to employ the concept of CSR, frequent references to the ethical foundations of the notion of social responsibilities of business are nonetheless to be found.

In general, an ethical approach to CSR contends "defects of morally indifferent business conduct and social advantages of morally-sensitive [...] management practices" (Windsor, 2006: 98). The moral case prescribes action by drawing directly on fundamental standards of morality, values, and other methods of moral reasoning. These principles and values are characterized as essentially intrinsic - as opposed to instrumental values (Lane, 2010). It further seems important to note that such standards concern to a lesser degree the corporation as a legal entity (i.e., institutional action) and more the personal decisions and actions of individual managers and employees as corporate agents (Frederick, 2008). 
Although drawing on a composite of various moral frameworks other than egoism and utilitarianism, ${ }^{30}$ ethical approaches to CSR use "a basic shared principle of impartial moral reflection on tolerating expansive public policy and practicing broad self-restraint and altruism" (Windsor, 2006: 98). From the broad array of normative ethical theories (for an overview see, for instance, Kagan, 1998; Smith, 2009; Brenkert \& Beauchamp, 2010) I will discuss - very briefly - the most important ones. ${ }^{31}$ The focus will be on deontological (non-consequentialist) rather than on teleological (consequentialist) theories (i.e., on theories that are based on underlying principles of decision makers' motivation than on the intended outcomes of action), as well as on virtue ethics.

\subsubsection{Ethics of duties}

The philosophical theory of ethics of duties judges the morality of a specific action based on the action's adherence to a rule or principle, regardless of the desirability of an action's consequences. If an action is not carried out with the motive of duty (deduced from abstract principles), then it is without moral value. Ethics of duties is inevitably related to Kantian ethics and the "categorical imperative" (see, for an overview, Fiesner, 2000, among others) - a "theoretical framework that should be applied to every moral issue regardless of who is involved, who profits, and who is harmed" (Crane \& Matten, 2004: 87). At its very core, the maxims of the categorical imperative reflect the aspects of consistency, human dignity, and universality; hence, these three elements characterize morality (Crane \& Matten, 2004). For CSR, this means that corporate agents first and foremost have a moral duty to respect all stakeholders, as well as mutual rights and obligations; each stakeholder group, conversely, has a moral right to be treated not just as a means to some end but as an end in itself (Evan \& Freeman, 1988; see also Bowie, 1999).

\subsubsection{Theory of rights}

The theory of rights goes back to Locke and his notion of "natural rights" - moral claims to which all humans are entitled, and that should be respected and protected in every single action. Thus, rights of one actor result in corresponding duties of

30 Egoism and utilitarianism - as opposed to deontological ethical theories - address right and wrong according to the consequences and outcomes of a decision, i.e., outcomes for the individual decision maker (egoism) or wider social outcome within a community (utilitarianism) (see Kagan, 1998; Audi, 2010; Crane \& Matten, 2010, among others).

31 Naturally, this can only be a selection of what I regard the most important ethical theories in this context. Crane and Matten (2010), for instance, also discuss alternative perspectives on ethical theory that are based on relationship (e.g., feminist ethics), procedures of norm generation (e.g., discourse ethics), or empathy and moral impulse (e.g., postmodern ethics). 
other actors. Nowadays, the most important rights consist of human rights like the right to life, liberty, freedom of speech, justice, privacy, property, freedom of belief, education, and fair wages, to name just a few (Crane \& Matten, 2004). From a CSR perspective, rights theory essentially addresses the equivalence (or even precedence) of basic human rights and property rights: "While shareholders of a corporation have certain property rights, this does not give them license to override the basic human rights of employees, local community members, and other stakeholders" (Wilson, 2003: 3). Ethical theories based on rights have proven to be very powerful due to their plausibility. However, a substantial limitation - especially for multinational corporations - is that this approach is strongly based in the Western view of morality (Crane \& Matten, 2004).

\subsubsection{Theory of justice}

The issue of justice arises as individual rights must be realized in a way that they are addressed and respected equally and justly: "Justice can be defined as the simultaneously fair treatment of individuals in a given situation with the result that everybody gets what they deserve" (Crane \& Matten, 2004: 92). Fairness, however, can be viewed in two ways that are not always compatible in practice: in terms of fair procedures (i.e., procedural justice) and in terms of fair outcomes (i.e., distributive justice). Notions of justice have been widely applied to questions and problems in business ethics. The problem of a just distribution of wealth has been particularly prominent and has produced two extreme positions (Crane \& Matten, 2004): egalitarian (i.e., justice is the same as equality) and non-egalitarian (i.e., justice within the economic system is a product of the fair process of free markets). A recent and very popular approach toward somehow reconciling these two extremes of equality and liberty is - although not unchallenged - Rawls' (1971) Theory of Justice that suggests two main criteria in order to decide and judge whether an action is just. A first tentative formulation of the two principles - Rawls determines their sense more precisely in the course of his book - reads as follows:

"First: each person is to have an equal right to the most extensive basic liberty compatible with a similar liberty for others. Second: social and economic inequalities are to be arranged so that they are both (a) reasonably expected to be to everyone's advantage, and (b) attached to positions and offices open to all" (Rawls, 1971: 60).

For the notion of CSR, this means that corporate agents should favor social equality, fairness, and justice in the workplace; moreover, a fair society is considered one in which corporations - as key societal actors - consider the needs of all members of society, not only of those with power, status, and/or wealth (see also Donaldson \& Preston, 1995; Wilson, 2003; Frederick, 2008). 


\subsubsection{Virtue ethics}

Yet another ethical approach, rooted in the ancient thinking of Plato and Aristotle, emphasizes the character of an agent or decision maker as the key element of a valid moral judgment. This criterion contrasts with both teleological approaches (i.e., focused on outcomes of actions) and deontological approaches (i.e., focused on the principles underlying an action): Whereas many ethical principles emphasize doing, virtue ethics emphasize being (Carroll, 1998). It contends that virtuous - i.e., morally correct - actions are those undertaken by agents with virtuous characters. Thus, the theory focuses on individuals imbued with intellectual virtues (e.g., wisdom) and moral virtues (e.g., honesty, integrity, courage, mercy, truthfulness, benevolence, or non-malfeasance) that result in habitual patterns of behavior (Solomon, 1993; Carroll, 1998; Crane \& Matten, 2004): Virtuous agents create a good corporation and society (see also Frederick, 2008). For example, the "paternalistic view" on CSR of a corporate/managerial elite - also much in line with Judeo-Christian thinking - points in this direction (see also Meyer \& Höllerer, 2009).

\subsubsection{The business case argument for CSR}

In addition to ethical reasoning, strong rational/economic arguments have been increasingly used to argue for the adoption and implementation of CSR. The business case for CSR is - in business practitioners' terms - a "pitch for investment in a project or initiative that promises to yield a suitably significant return to justify the expenditure" (Kurucz, Colbert, \& Wheeler, 2008: 84). The core idea, predominant both in CSR practice and research, has been that corporations might "do well by doing good" (Zadek, 2000), i.e., they might perform better financially by attending not only to core business operations but also to various societal responsibilities (Joyner \& Payne, 2002; Vogel, 2005; Crane et al., 2008a; Kurucz et al., 2008; Carroll \& Shabana, 2010, among others). ${ }^{32}$ Creating, protecting, and maximizing shareholder value still remains the uncontested and ultimate goal of corporations, however, by means of demonstrating that the focal corporation has a sound ethical stance - and by strategically using this position to enhance business opportunities (see also Höllerer \& Meyer, 2007). As a result, corporations signal their compliance with standards of social responsibility accepted by society in order to increase their attractiveness to potential employees, investors, suppliers, and customers, to reduce their vulnerability to potential damage "irresponsible" conduct can have on profitability, brand image, overall reputation as well as societal legitimacy.

32 For a comprehensive review of concepts, research, and practice with regard to the business case for CSR see, for instance, Salzmann, Ionescu-Somers, \& Steger, 2005; Carroll \& Shabana, 2010). 
The empirical question that lies at the very heart of the notion of a business case for CSR is that of a causal relation of corporations' social and financial performance. ${ }^{33}$ Moreover, a considerable part of the ethical investment movement is built on the belief that a positive correlation exists between these two. However, there is "no single business case for CSR - no single rationalization for how CSR improves the bottom line" (Carroll \& Shabana, 2010: 92). Rather, many different arguments have been assembled to argue the construct of a business case for CSR. Zadek (2000; see also Carroll \& Shabana, 2010) was among the first to present a classification scheme; he argues that corporations pursue CSR activities to defend reputations and avoid potential financial loss ("pain alleviation"), to achieve cost benefits ("traditional business case"), for strategic business reasons ("strategic business case"), and in order to manage risk, innovate, and learn in dynamic and complex environments ("New Economy case").

In order to discuss business case arguments for CSR, I will draw on a framework put forward by Kurucz et al. (2008; see also Carroll \& Shabana, 2010) who identify - partly overlapping with Zadek's (2000) classification - four types of business cases, each embodying a proposition for value creation: (a) cost and risk reduction; (b) competitive advantage by adapting and leveraging opportunities; (c) reputation and legitimacy development by aligning stakeholder interests; and (d) synergistic value creation by integrating stakeholder interests. ${ }^{34}$ These analytical categories are not exclusive, and corporations empirically "may be involved in all four at once through a variety of policies and initiatives" (Kurucz et al., 2008: 86). For each type, the theoretical foundations of these arguments will be outlined.

\subsubsection{Cost and risk reduction}

A first set of justifications of the business case for CSR employs arguments of cost and risk reduction.

"Under the cost and risk reduction perspective [...], the primary view is that the demands of stakeholders present potential threats to the viability of the organization, and that corporate economic interests are served by mitigating those threats through a threshold level of social or environmental performance" (Kurucz et al., 2008: 88).

The cost argument has been widely used - mostly reflecting Friedman's (1962, 1970) neoclassical argument - to oppose CSR activities of corporations, indicating a negative trade-off between CSR expenditures and financial performance of the corporation. Other empirical studies, however, find a neutral or positive correlation

33 Orlitzky (2008) lists a couple of important mediators - causal mechanisms responsible for an observed positive relationship - between corporations' social and financial performance.

34 This triad of adapting, aligning, and integrating - also referring to power relations - strikes an interesting chord with Pfeffer and Salancik's classic book (1978). 
between social activities and financial performance, while again others suggest a relationship that takes the form of an inverted $U$ curve (for an overview see Salzmann et al., 2005): an optimal level of CSR activities, beyond which the corporation incurs unnecessary costs and, consequently, a reduction in profits (Kurucz et al., 2008).

An important means of reducing costs (and, thus, enhance long-term shareholder value) is to adequately manage risk and threats from the organizational environment. Most corporations have established risk management systems in place, and many of these systems incorporate CSR issues within their risk evaluation (Story \& Price, 2006). Instrumental stakeholder theory (Donaldson \& Preston, 1995; Jones, 1995; Berman, Wicks, Kotha, \& Jones, 1999, among others) describes how corporations are affected by stakeholder relations with a view to risk - and thus also cost - reduction by balancing divergent stakeholder interests in processes of corporate decision making: Attention to stakeholder concerns will help to reduce risk by avoiding managerial decisions that could push stakeholders to oppose corporations' objectives (Bowie \& Dunfee, 2002; Kurucz et al., 2008). From such a perspective, developing and fostering trust in the relationship with and between key stakeholders as well as with communities is seen as having the potential to significantly lower costs (Jones, 1995; Berman et al., 1999; Wicks, Berman, \& Jones, 1999; Godfrey, 2005; Godfrey, Merrill, \& Hansen, 2009). As Kurucz et al. (2008) point out, a range of activities and issues directly relate to the reduction of risk and cost: Organizations turn to the managerial idea of CSR influenced by a desire to avoid such conflicts as consumer boycotts and liability suits, increased labor costs (e.g., due to high employee turnover), and/or short-term losses in market capitalization (see Bowie \& Dunfee, 2002). Issues management (also known as social issues management) (e.g., Chase, 1984; Wartick \& Cochran, 1985; Heath, 1997) is an adequate method by which to build stable relationships with stakeholders, to make collaborative decisions, and to avoid critical incidents (such as corruption scandals or environmental accidents) that result in unwanted attention from media, regulators, or the general public (Bowen \& Heath, 2005). ${ }^{35}$ It also assists corporations in preventing extensive legal regulation in favor of a "soft regulatory framework" (Sahlin-Andersson, 2006). Building a genuine culture of awareness within an organization can offset many of these risks.

"Issues management serves the financial viability of organizations by enhancing the quality of relationship with stakeholders in a power arena. Issues management was designed as 'the management process whose goal is to help preserve markets, reduce risk, create opportunities and manage image as an organization asset for the benefit of both an organization and its primary shareholders' [...]. Issues management helps management to understand and implement standards of ethical decision making" (Bowen \& Heath, 2005, with a quote from Tucker, Broom, \& Caywood, 1993).

35 Bowen and Heath (2005) use the case of Enron to exemplify the role of legal standards and ethical principles in decision making in issues management. 
Compliance with national and international CSR standards, the conducting of CSR audits, and the communication of corporate-specific CSR indicators also aim at building confidence among corporations' stakeholders - and thus reduce risk (Kok, van der Wiele, McKenna, \& Brown, 2001; Story \& Price, 2006). In general, a reasonable degree of proactivity on social and environmental issues can lower the risk of a loss of legitimacy among stakeholders (Hart, 1995; Shrivastava, 1995; Carroll \& Shabana, 2010); moreover, it will cut the costs of complying with present or future regulations, thus enhancing firm efficiency and driving down operating costs (Berman et al., 1999).

\subsubsection{Competitive advantage}

CSR activities and initiatives might be conceived strategically as conferring competitive advantage on corporations: Value creation occurs when organizations adapt to their environment in order to realize and/or optimize their competitive advantage in the respective field (see Kurucz et al., 2008).

"Adaptive approaches to building a business case for CSR focus on building firm competitive advantage through strategically orienting and directing resources toward the perceived demands of stakeholders. Stakeholder demands are viewed less as constraints on the organization, and more as opportunities to be leveraged for the benefit of the firm" (Kurucz et al., 2008: 89).

While the previous approach rather illustrated how CSR practices may be used to build competitive advantage in terms of cost leadership, Carroll and Shabana (2010: 98) argue that this one is best understood in the context of a differentiation strategy: It focuses on "how firms may use CSR practices to set themselves apart from their competitors". By meeting demands of key stakeholders, CSR activities enhance the position of corporations to the extent that stakeholder decisions are influenced in their favor, i.e., they lead to favorable stakeholder attitudes and better support behaviors (Du, Bhattacharya, \& Sen, 2010). Including stakeholder positions and interests in the process of strategy-making (e.g., Mitchell, Agle, \& Wood, 1997) thus seems a necessity.

Kurucz et al. (2008) discuss a supply/demand perspective of CSR (e.g., McWilliams \& Siegel, 2001) ${ }^{36}$ as well as "base of the pyramid" approaches (e.g., Prahalad \& Hammond, 2002; Prahalad, 2004) as a means of enhancing business opportunities. Moreover, the resource-based view of the firm (Wernerfelt, 1984; Barney, 1991) and its variations and applications on social and environmental issues (e.g., Hart, 1995; Russo \& Fouts, 1997; Branco \& Rodrigues, 2006; Maurer, Bansal, \& Crossan, 2010; for an overview see also Jones \& Bartlett, 2009) make an especially strong argument that CSR constitutes an important resource (or capability,

36 A supply/demand theory of corporate CSR implies that corporations' ideal level of CSR can be determined by cost-benefit analyses (McWilliams \& Siegel, 2001). 
i.e., an element of strength associated with the focal corporation) that leads to sustainable competitive advantage. From a resource-based perspective, all CSRrelated initiatives should generate resources for the corporations that yield a source of competitive advantage, meaning that create situations in which competitors are unable to deploy equivalent resources and duplicate their benefits (Jones \& Bartlett, 2009). In particular, CSR can help to build and strengthen competitive advantage by strategically adapting to the environment and enhancing relationships with various stakeholders: Customers, for example, demonstrate higher consumer patronage or brand loyalty in the event of customized CSR measures (Baron, 2001; Bhattacharya \& Sen, 2003, 2004; Pivato, Misani, \& Tencati, 2008; Smith, 2008); specific and inclusive CSR policies can be effectively used in helping corporations to win the "war for talents" and to recruit and retain qualified employees from the widest talent pool (Smith, 2005; Bhattacharya, Sen, \& Korschun, 2008); and distinct CSR initiatives also have a positive impact on strategically attracting investment (Smith, 2005; Kurtz, 2008; see below for more).

The business case for CSR can be promoted when it is justified based on an economic rationale, meaning whenever expenditures contribute to increases in shareholders' returns in the end (Carroll \& Shabana, 2010). Porter and Kramer (2002: 59; see also 2006) provide a premise for this argument: Corporations may realize a competitive advantage through their CSR activities when these are directed at causes where there is some "convergence of interests" between financial and social interests (i.e., corporate expenditures simultaneously producing economic and social benefits; see also Carroll \& Shabana, 2010). Strategic philanthropy (e.g., Post \& Waddock, 1995) is very much in line with such an approach. Corporations engage in philanthropic efforts in order to enhance their competitive advantage through combinations of market (i.e., external) and competence (i.e., internal) orientations (Bruch \& Walter, 2005; see also Carroll \& Shabana, 2010): A market orientation helps corporations to design and adapt their CSR activities in order to fit external demands and to meet the expectations of key stakeholders; corporations try to improve their competitive advantage through "improved marketing and selling capabilities, higher attractiveness as an employer or better relationships with governmental and nongovernmental organizations" (Bruch \& Walter, 2005: 50). A competence orientation, on the other hand, brings CSR activities in line with core organizational capabilities and competencies in order to "avoid distractions from the core business, enhance the efficiency of $[\ldots]$ charitable activities and assure unique value creation for the beneficiaries" (Bruch \& Walter, 2005: 50).

\subsubsection{Developing reputation and legitimacy}

A business case is also argued for employing CSR activities in order to create value by enhancing corporations' reputation (and strengthening their societal legitimacy). Such an approach is characterized by a particular "focus on value creation by 
leveraging gains in reputation and legitimacy made through aligning stakeholder interests" (Kurucz et al., 2008: 90).

Under such an aligning perspective, failure to meet crucial stakeholder needs will have a negative impact on corporations' reputation. The social impact hypothesis states that costs of CSR activities are much lower than potential benefits (Kurucz et al., 2008); other studies suggest a positive link between corporations' social performance and their reputation (Fombrun \& Shanley, 1990; Turban \& Greening, 1997; Freeman, 2006). ${ }^{37}$ In crowded marketplaces, corporations strive for association with factors that distinguish them from competitors in the mind of key stakeholders (i.e., for brand differentiation). CSR activities can assist corporations in building a reputation of integrity, and thus enhance the ability of corporations to attract customers, employees, and investors, among others. Here, an organization's reputation and the value of its brand are among its most valuable assets (Smith, 2005; Carroll \& Shabana, 2010). An excellent example of CSR activity that directly targets reputation is cause-related marketing (e.g., Varadarajan \& Menon, 1988; Drumwright, 1996); it highlights the alignment of stakeholder and corporate interests "by linking corporate philanthropy and marketing, showcasing socially and environmentally responsible behavior of the firm in order to generate reputational gains" (Kurucz et al., 2008: 90). Studies on socially responsible or "green" consumerism and ethical purchasing behavior (e.g., Crane, 2001; see also Caruana \& Crane, 2008) consider how reputation and brand differentiation impact financial performance (Smith, 1990; Brown \& Dacin, 1997; Bhattacharya \& Sen, 2003, 2004, among others). The link between corporations' CSR activities, their reputation, and their ability to attract talent is emphasized and explored by various research on the attractiveness of organizations as potential employers (e.g., Riordan, Gatewood, \& Bill, 1997; Turban \& Greening, 1997; Albinger \& Freeman, 2000). Finally, socially responsible investment and ethical sound investing (e.g., Domini \& Kinder, 1986; Kinder, Lydenberg, \& Domini, 1993; Mackenzie \& Lewis, 1999; Domini, 2001; Kurtz, 2008, among others) highlight potential investors' moral positions and expectations of corporate social performance (see also Kurucz et al., 2008).

Corporations are keen to avoid any interference in their business conduct through extensive taxation or legal regulation (see above); even more importantly, they are dependent on maintaining their legitimacy and license to operate granted by the specific society they operate in. This is very much in line with the "iron law" of responsibility (Davis, 1973): As social entities, business organizations must exercise responsible use of power - or they risk having it revoked and thus losing control over decision making and external interactions (Kurucz et al., 2008 with reference to Sethi, 1979). In his seminal definition, Suchman (1995; see also Strandgaard Pedersen \& Dobbin, 2006 as well as the chapter on organizational

37 On the "fit" of corporations' social performance and their specific stakeholder environment see Brammer and Pavelin (2006), among others. 
institutionalism below) characterizes legitimacy as the generalized perception that the actions of an entity are desirable and appropriate within the socially constructed system of values and norms. Fombrun and Shanley (1990) explain that perceptions of business organizations' concerns for issues important to the broader society illustrate their ability to build sustainable relationships, indicating that these organizations are "able to operate while adhering to social norms and meeting expectations of different stakeholder groups" (Carroll \& Shabana, 2010: 99). Corporate philanthropy is just one way to enhance reputation and legitimacy, especially among local communities. Corporations can also enhance their legitimacy by disclosing information with regard to their performance on social and environmental issues (Brammer \& Pavelin, 2004). One such disclosure practice is detailed corporate social reporting linked to the very area of their operations: Aside from building trust, communicating corporate-specific CSR measures and indicators in such media as annual financial reports or stand-alone annual CSR reports ${ }^{38}$ enables corporations to illustrate that their operations are consistent with social norms and expectations and therefore legitimate (Carroll \& Shabana, 2010). Other research inspired by institutional arguments explores isomorphic pressures and their role in motivating CSR-related activities in cases in which organizations can gain firstmover advantage and, consequently, reap the rewards of reputational and legitimacy gains with dominant stakeholders (Bansal \& Roth, 2000; King \& Lenox, 2000; see also Kurucz et al., 2008). Supply chain pressures also push corporations to adopt CSR standards or to seek CSR certification (Cashore, 2002) in order to enhance their legitimacy.

\subsubsection{Synergistic value creation}

Approaches advocating synergistic value creation focus on exploiting opportunities that "unearth, relate, and synthesize" - in short: reconcile - the differing demands and interests of a diverse set of stakeholders (Kurucz et al., 2008: 92; Carroll \& Shabana, 2010). Corporations may create "win-win-win outcomes by seeking out and connecting stakeholder interest, and creating pluralistic definitions of value for multiple stakeholders simultaneously" (Kurucz et al., 2008: 91). In contrast to the "adapting" and "aligning" approaches discussed above, the underlying idea of this perspective is that "creating connections between stakeholders by relating common interests will open up heretofore unseen opportunities for multi-point value creation" (Kurucz et al., 2008: 91).

38 Providing information with regard to corporations' performance on the economic, environmental, and social dimension (i.e., the TBL) has been encouraged by the establishment of the Global Reporting Initiative (GRI) and the United Nations Global Compact toward the end of the 1990s. 
Carroll and Shabana (2010, with reference to Porter \& Kramer, 2002) argue that CSR activities and competitive advantage - appropriate management techniques provided - might become mutually reinforcing and create a "virtuous cycle". On a more general level, one could propose that "the proper 'social responsibility' of business is $[\ldots]$ to turn a social problem into economic opportunity and economic benefit, into productive capacity, into human competence, into well-paid jobs, and into wealth" (Drucker, 1984: 62). The value-based networks conception by Wheeler, Colbert, and Freeman (2003) echoes this contention when describing how communities and social networks united by a sense of what is valuable create new opportunities for mutual benefit (see also Kurucz et al., 2008; Carroll \& Shabana, 2010); related work (Wheeler, McKague, Thomson, Davies, Medalye, \& Prada, 2005) empirically shows how this might result in reinvestment in various types of capital. ${ }^{39}$

In summary, the synergistic value creation perspective on the business case for CSR aims at anticipating and fulfilling stakeholder demands while simultaneously allowing corporations to pursue their own operations and economic/business objectives. By engaging with divergent groups of stakeholders and satisfying their demands, corporations explore new opportunities that enable them to pursue their profitability objective with the consent - and even with the support - of its stakeholder environment. Thus, such a "win-win perspective to CSR practices provides a view in which CSR is perceived as a vehicle that allows both the firm to pursue its interest and stakeholders to satisfy their demands" (Carroll \& Shabana, 2010: 100).

\subsection{Marking out the territory}

Above, I summarized some of the most prominent lines of argument for CSR. The existence of various termini further complicates matters; this complexity also partly explains why conceptual and empirical studies on the social responsibility of business have been handicapped by not being able to share a common understanding or definition. The construct of CSR overlaps with some, and is synonymous with other, conceptions of business-society relations (Matten \& Crane, 2005; Matten \& Moon, 2008). A variety of more or less related concepts - as well as their respective vocabulary - is interchangeably used with CSR (Crane et al., 2008a). In both academic and practitioners' debates, different terms appear within the same

39 At length, Wheeler et al. (2005) empirically revealed that examples of successful sustainable enterprises in developing countries often involve informal networks that include businesses, non-profit organizations, local communities, and other actors. Typically, such sustainable local enterprise networks begin with a range of existing assets that are augmented by some type of external investment functioning as a catalyst for increased growth; positive outcomes can then result in virtuous cycles of reinvestment in human, social, financial, and ecological capital. 
context and are used rather synonymously, while the very same terms are used in significantly different contexts. In sum, this underlines the necessity to thoroughly examine key concepts and terms used in the broad field of CSR. In the following, therefore, I will describe each concept in greater detail, highlighting overlaps and differences.

\subsubsection{Synonyms, interchangeable concepts, and/or distant relatives?}

\subsubsection{Business ethics}

The discipline of business ethics is a form of applied ethics (Pieper, 2000) that explores moral problems and ethical principles that arise in the context of business environments. "In a nutshell, [...] business ethics is the study of business situations, activities, and decisions where issues of right and wrong are addressed" (Crane \& Matten, 2004: 8). It applies to all aspects of business conduct (e.g., issues of human resource management, finance, production, sales and marketing, supply chain management, or use of technology); moreover, it is relevant to both the conduct of individuals and business organizations as a whole (Frederick, 2008). Business ethics as an academic field is both normative and descriptive. It constitutes the theoretical backdrop against which modern management concepts designed to deal with moral and ethical questions are formed and defined. Thus, business ethics represents the wider theoretical framework in which CSR is discussed (see Crane et al., 2008c; Brenkert \& Beauchamp, 2010, among others).

\subsubsection{Corporate sustainability}

Corporate sustainability can be viewed as the evolving management paradigm of the 2000s (as opposed to an orientation toward short-term profit-maximization during the late 1990s). It borrows from various other concepts discussed here, but builds in particular on the notions of sustainable development (e.g., World Commission on Environment and Development, 1987) and TBL reporting (e.g., Elkington, 1999). With increasingly global problems in the environmental and social dimensions, it had been widely suggested that the "goals and consequences of business require radical rethinking" (Crane \& Matten, 2004: 21). The new conceptual frame promoted was primarily the notion of sustainability - an idea strongly influenced by the report of the Brundtland Commission in $1987 .^{40}$ Since then, sustainability has become a common term in the debate and rhetoric surrounding a variety of issues of business ethics. It has been widely adopted by

40 "Sustainable development is development that meets the needs of the present without compromising the ability of future generations to meet their own needs" (World Commission on Environment and Development, 1987: 47). 
corporations, governments, consultants, pressure groups, and academics alike to address the "long-term maintenance of systems according to environmental, economic, and social considerations" (Crane \& Matten, 2004: 24). As a corporate objective, sustainability is embodied most completely in the notion of the TBL. ${ }^{41}$ As Crane and Matten (2004: 26) emphasize, the TBL of sustainability is "less about establishing accounting techniques and performance metrics for achievements in the three dimensions [...] and more about revolutionizing the way companies think about and act in their business". The concept of corporate sustainability ${ }^{42}$ also expands the original notion of social responsibility (for instance, by its focus on the environmental dimension, long-term perspective, or its compatibility with some value-oriented concepts). Nonetheless, and especially in the continental European corporate world, both sustainability and CSR share common characteristics on a large scale.

\subsubsection{Stakeholder approach}

The stakeholder theory of the firm (e.g., Freeman, 1984, 1994; Donaldson \& Preston, 1995; Jones, 1995; Mitchell et al., 1997; Phillips, Freeman, \& Wicks, 2003; Dunfee, 2008; for an state of the art overview see Freeman, Harrison, Wicks, Parmar, \& de Colle, 2010) has, during the last 25 years or so, emerged as a central vehicle of CSR thinking and as the primary organizing framework undergirding all business ethics (McWilliams \& Siegel, 2001; Wheeler et al., 2003). More recently, it has also gained substantive ground as a viable framework in the field of strategic management - the context of its origin (see Freeman, 1984; Werther \& Chandler, 2006, among others). Wheeler et al. (2003: 14) note that "stakeholder 'theory' is not so much a formal unified theory as a broad research tradition that encompasses philosophy, ethics, political theory, economics, law and organizational social science. In its applied form we therefore refer to a "stakeholder approach"'. At its core, the approach concludes that various constituents - and not just shareholders - are affected by the outcomes of business organizations, and therefore should have a voice and rights in corporate decision making (e.g., Donaldson \& Preston, 1995; Crane et al., 2008a). This, obviously, has a massive impact on issues and models of corporate governance. In his seminal book, Freeman (1984: 46) broadly defined stakeholders as "any group or individual who can affect, or is affected by,

41 Elkington (1999) proposes that economic objectives of business organizations are inseparable from the society and environment in which they operate. In particular, he argues that the failure to account for social and environmental impacts will compromise future business opportunities.

42 Corporate sustainability, although often used by practitioners and academics as a synonym for broader sustainability, is focused on a long-term managerial and organizational perspective and thus defined in a more limited sense than sustainability in general (see also Marrewijk \& Werre, 2003, among others). 
the achievement of the organization's objectives". Identifying the range of stakeholders is therefore one of the most crucial challenges of strategic management especially as clear criteria for separating stakeholders from non-stakeholders are somehow lacking. ${ }^{43}$ And, above all: Who actually matters in processes of organizational decision making is a different story altogether:

"The organization is a contested terrain where managers must consider divergent interests and inputs. Shareholders, consumers, employees, and communities all make claims on organizations. A firm must appropriately manage its relationships with its various stakeholders to develop an acceptable corporate social performance [...]. Inherent [...] is the assumption that managers are aware of stakeholder interests and prioritize the value of those interests. As argued by Mitchell, Agle, and Wood (1997), managers respond to stakeholders who have three primary attributes: power, legitimacy, and urgency. Lacking those attributes, stakeholders have relatively little influence over the inner workings of a corporation" (King, 2008: 21).

In summary, while CSR is strongly focused on the corporation and its responsibilities, the stakeholder approach tends to highlight the social environment of business organizations - however, stressing core economic arguments with regard to business-society relationships. It is only through the appropriate management of stakeholder relations and constant dialogue with the stakeholder environment that corporations can perform well on the social dimension, thereby meeting their business objectives and living up to the broad responsibility laid out by the notion of CSR.

\subsubsection{Corporate accountability}

Accountability - understood as "the giving and demanding of reasons for conduct" (Roberts \& Scapens, 1985: 447) - has become a ubiquitous concept in contemporary societies (e.g., Boström \& Garsten, 2008). In such a broad sense, to be held and to hold others accountable is a general characteristic of everyday activities (Giddens, 1979); the accounts actors give point to legitimate and taken-for-granted aspects of society. ${ }^{44}$ Against this backdrop, corporate accountability characterizes the idea that corporations - and corporate decision makers - are not only responsible for business processes but also must explain and justify the wider consequences of their decisions and activities:

43 For example, some authors - broadly and somehow tautologically - suggest "that stakeholders are those that have a stake in the company's activities - something at risk" (Wilson, 2003: 4).

44 Accountability has played a central role in ethnomethodology and structuration theory - and also in organizational institutionalism (Scott \& Lyman, 1968, 1970; Meyer \& Rowan, 1977; Elsbach, 1994; Davis \& Greve, 1997; Elsbach, Sutton, \& Principe, 1998; Creed et al., 2002, among others). 
"Accountability is legal or ethical responsibility to provide an account or reckoning of the actions for which one is beld responsible. Accountability differs from responsibility in that the latter refers to one's duty to act in a certain way, whereas accountability refers to one's duty to explain, justify, or report on bis or ber actions" (Wilson, 2003: 4).

In the world of business, many different accountability relationships exist (for a general overview and conceptual framework see, for instance, Bovens, 2007). Apart from accountability resulting from the relationship between corporate management and shareholders (based on the traditional fiduciary model), corporations are given permits and approvals from regulators (e.g., on environmental issues), or granted a license to operate by society (Wilson, 2003). It has also been argued that the recent shift toward corporate accountability is due to the fact that corporations increasingly take on the role of political actors, triggered by government failure and the increasing power and influence of - in particular multinational - corporations (Crane \& Matten, 2004). All this sets out the arguments why corporations should essentially be accountable for their performance on all three dimensions of the TBL (Elkington, 1999). Corporate accountability is therefore closely linked to transparency, that is, to "the degree to which corporate decisions, policies, activities and impacts are acknowledged and made visible to relevant stakeholders" (Crane \& Matten, 2004: 61) in corporate communication and reporting. In practice, accountability is often used synonymously with other concepts from the field of ethics and governance. I therefore suggest thinking of accountability as a means of reflecting on social relations ${ }^{45}$ with key stakeholders, while responsibility refers to the broader obligation to act in the interest or favor of someone (especially those social groups dependent upon, or in need of, support). However, corporate accountability is an important element that informs us of the political dimension within CSR issues.

\subsubsection{Corporate citizenship}

In recent years, the notion of corporate citizenship - a relatively "new, but potentially important addition to the lexicon" of CSR terminology (Crane \& Matten, 2004: 61) - has become increasingly popular in management practice and literature (e.g., Carroll, 1998; Waddock, 2000; Birch, 2001; Habisch, Meister, \& Schmidpeter, 2001; Waddock, 2001; Windsor, 2001; Wood \& Logsdon, 2001; Matten, Crane, \& Chapple, 2003; Matten \& Crane, 2005; Moon et al., 2005; Valor, 2005). ${ }^{46}$ In their

45 "A relationship qualifies as a case of accountability when: 1. there is a relationship between an actor and a forum 2. in which the actor is obliged 3. to explain and justify 4 . his conduct; 5. the forum can pose questions; 6. pass judgment; 7 . and the actor may face consequences" (Bovens 2007: 452).

46 The worldwide number of research centers and consultancies devoted to the notion of corporate citizenship is remarkable; see Crane and Matten (2004) for an overview of motives as to why business turned toward and adopted this notion at the expense of other terms. 
various literature reviews, Matten and Crane (Matten et al., 2003; Crane \& Matten, 2004; Matten \& Crane, 2005) suggest three different perspectives: the "limited", "equivalent", and "extended view of corporate citizenship". Initially, corporate citizenship is used to denote and identify the voluntary philanthropic role of business organizations within (local) communities; discretionary activity and giving back to society qualifies an organization to become a "good corporate citizen" (e.g., Carroll, 1991, 1998). A second common understanding "consists of a somewhat updated label for CSR (or sometimes stakeholder management), without attempting to define any new role or responsibilities for the corporation" (Crane \& Matten, 2004: 67); essentially, this interpretation is more about a "marketing of academic ideas" and can be also seen in the light of management fashions (Matten \& Crane, 2005). ${ }^{47}$

Matten and Crane (2005; see also Scherer \& Palazzo, 2007) criticize the insufficient conceptual anchoring of the notion of corporate citizenship, and argue rather from the perspective of the notion's origin in political theory (e.g., Moon et al., 2005). They note that corporations have increasingly taken on a political role in society - at the same time when governments have failed to fulfill some of their traditional functions (see also the remarks on accountability above). "Simply said, they [i.e., corporations] can be said to partly take over [...] functions with regard to the protection, facilitation, and enabling of citizens' rights - formerly an expectation placed solely on the government" (Crane \& Matten, 2004: 68). Thus, given the emerging role of corporations in the administration of social, civil, and political rights, Crane and Matten (2010: 78, see also Matten \& Crane, 2005) suggest a novel definition for what they call the extended view of corporate citizenship: It "describes the corporate function for governing citizenship rights for individuals" instead of, or in addition to, state institutions, and in the form of a "providing", "enabling", or "channeling role". In summary, corporate citizenship is, although interchangeably used with CSR in both corporate and academic practice, the broader notion that "considers the role of corporations as social institutions and their ability to respond to non-market pressure, especially in a global context" (Crane et al., 2008a: 570).

\subsubsection{Corporate social performance}

While the responsibilities of business are inherently unobservable, corporations' CSR-related policies, processes, and outcomes can indeed be measured - at least to some extent (Crane et al., 2008a). Wood (1991: 693; for alternative classifications of topics or models of corporate social performance see, for instance, Carroll, 1979; Wartick \& Cochran, 1985; Swanson, 1995, 1999) defines corporate social perfor-

47 Carroll's 1998 adoption of his 1979/1991 model is a clear example of such re-labeling.

48 Note that the recent financial crisis added yet another facet to such distribution of roles. 
mance as the "business organization's configuration of principles of social responsibility, processes of social responsiveness, and policies, programs, and observable outcomes as they relate to the firm's societal relationships". This rather comprehensive definition also hints at the broad range of CSR topics that gather around the term. Above all, the main appeal of the concept is that it enables the empirical testing of the relationship between corporations' financial and social performance (Orlitzky, 2008). However, in many cases, corporate social performance is used as a synonym for CSR or corporate citizenship - or other terms referring to the interaction of business and its social environment (Wartick \& Cochran, 1985; Orlitzky, 2008). In corporate practice, the notion impacts business organizations' communication and reporting on CSR activities, for instance, in encouraging them to issue not only annual financial reports, but also stand-alone annual CSR reports.

\subsubsection{Ethical stakeholder behavior}

Another related area, albeit one not yet characterized by synonymous concepts, is ethical stakeholder behavior. It is "a way for stakeholders to control the socially responsible behavior of managers by determining the incentives for such behavior" (Crane et al., 2008a: 570; see also Crane \& Matten, 2010). One of the most prominent concepts here is socially responsible investing (e.g., Domini \& Kinder, 1986; Kinder et al., 1993; Mackenzie \& Lewis, 1999; Domini, 2001; Kurtz, 2008); another is socially responsible consumerism (e.g., Crane, 2001; Caruana \& Crane, 2008; Smith, 2008). This perspective makes evident that responsibility is not a one-way street; it is also in the hands of key stakeholders to direct business organizations toward CSR. For corporations, on the other hand, this has considerable implications with regard to self-presentation, reporting, and issues management as stakeholders primarily perceive observable proxies for CSR (e.g., CSR indicators, standards, certificates, audits, and reports).

\subsubsection{Good corporate governance}

Corporate governance is best described as the set of regulations, policies, processes, and institutions affecting the way a corporation is directed, administered, and controlled; it addresses the relationships among the various stakeholders (e.g., shareholders, management, supervisory board, employees, customers, creditors, suppliers, and the community at large) and objectives for which a business organization is governed (see European Commission, 2001; OECD, 2001, 2004). "Good" corporate governance, then, adds a normative dimension. The OECD defines good corporate governance as follows:

"Corporate governance is one key element in improving economic efficiency and growth as well as enhancing investor confidence. Corporate governance involves a set of relationships between a 
company's management, its board, its shareholders and other stakeholders. Corporate governance also provides the structure through which the objectives of the company are set, and the means of attaining those objectives and monitoring performance are determined. Good corporate governance should provide proper incentives for the board and management to pursue objectives that are in the interests of the company and its shareholders and should facilitate effective monitoring" (OECD, 2004: 11).

Obviously, some of these issues strike a chord with CSR - especially in modern variants of corporate governance and at the more basic levels of the CSR pyramid. From a shareholder perspective, CSR and corporate governance also share some common objectives - especially the reduction of risk -, although they significantly differ with regard to means employed (Bassen et al., 2005). Corporate governance primarily aims at control and incentive mechanisms in order to prevent misbehavior of management, is limited to bodies within the organization, and emphasizes accountability, transparency, and fiduciary duties; the protection of shareholder interests is the primary and foremost goal (Buchholtz, Brown, \& Shabana, 2008). Thus, I regard good corporate governance as a "distant relative" that can be quite in line with CSR principles in some respect, but that might also be attached to rather contrasting logics. ${ }^{49}$

\subsubsection{A working definition}

In this chapter, I have sorted out basic terminology as well as discussed and assessed several conceptual approaches related to the idea of CSR. Figure 5 summarizes these concepts that feed into, and are intertwined with, the more general issue.

The challenge of adequately designing the business-society interface is, at least currently, mainly addressed by using the wide-ranging label of CSR. However, for the purpose of investigating the discourse on the social responsibilities of business in detail, it is necessary to move beyond examining the development of this umbrella term only and also include other terms that actors in the discursive arena use to denote the same idea. It is important to hold that what belongs to an issue, and what does not, is in itself contested: Inclusion and exclusion are never neutral, but dependent on position. Thus, the issue "should be itself considered as the 'terrain' upon which discourse takes place, a terrain which is itself an (interactive) construction" (Donati, 1992: 161; see also Hoffman's [1999] remarks on the issue field).

49 On divergent models of governance and contesting institutional logics, see also Meyer and Höllerer $(2009$, 2010). 


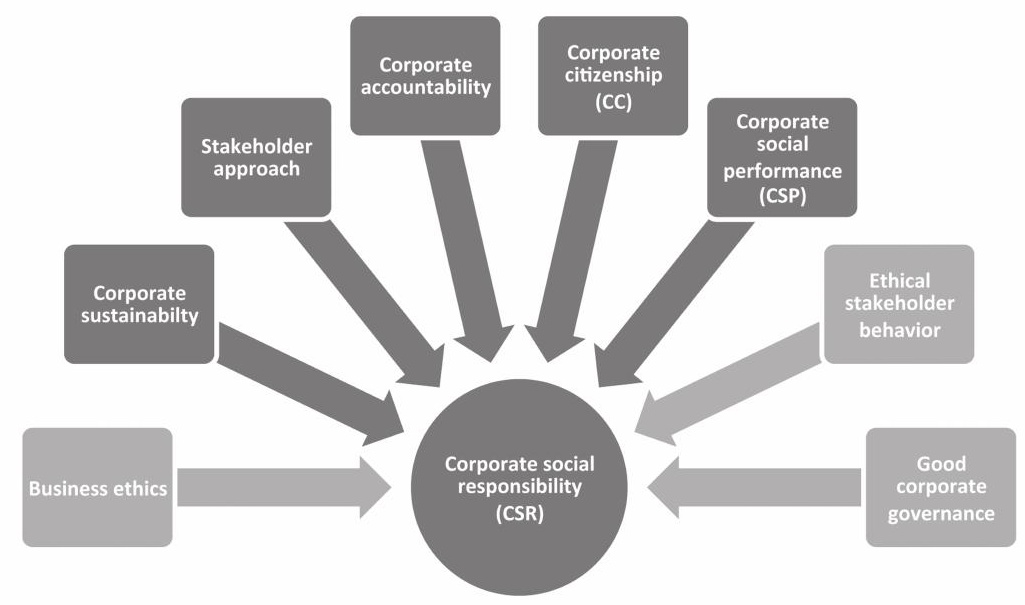

Figure 5: CSR and related concepts

Nevertheless, not all terms and concepts qualify for operationalization ${ }^{50}$ as part of the CSR discourse within my empirical study, and for a number of reasons (see especially the light-blue boxes in Figure 5). I will briefly evaluate the conceptual constructs and frameworks mentioned above against the backdrop of my empirical project.

Business ethics represents the most important theoretical foundation for CSR; nonetheless, it remains far too abstract to be discussed in corporations' statements. ${ }^{51}$ Corporate sustainability and the stakeholder approach, on the other hand, are two central and distinct vehicles of CSR thinking and communication that can also carry ethical considerations; these two definitely must be taken into account. Corporate accountability issues are, at least in the empirical setting of the study at hand, understood as being more or less synonymous with CSR, and they are typically referred to using the identical German label. ${ }^{52}$ Corporate citizenship represents the "youngest" concept in the field of CSR and has been promoted by

50 See also remarks on issue markers in the chapter on methodology.

51 At least for my empirical sample, not even a single direct reference to business ethics was found in the genre of annual reports.

52 With all this multiplicity of labels and terminology, I touch here on a very important point that is highly relevant when investigating discursive traces: In addition to dissemination across divergent cultural/institutional contexts, one has also to deal with language issues (in my case, the spread of Anglo-American terminology into the German-speaking business community which partly adopts these terms, but also partly creates and develops its own vocabulary). In this sense, one has to account for both cultural and linguistic processes of translation. 
its advocates as a potential "heir" to the overall label (albeit with only mediocre success); it nonetheless needs to be included here. Corporate social performance has been a synonym and also an alternative umbrella term ever since, primarily in the Anglo-American context and for the purpose of juxtaposing social and financial performance of business organizations; it is thus strongly linked to quantification and objectification (i.e., to CSR standards and key indicators). Responsible or ethical stakeholder behavior determines a subject of responsibility other than the corporation; therefore, it shall not be included as a decisive part of the CSR discourse in this study. However, responsible stakeholders substantially increase the pressure for business organizations to direct their attention to explicit CSR policies; stakeholders themselves are guided in their actions by corporate social disclosure (alongside, for instance, media coverage, or NGO campaigns). Finally, good corporate governance conceptually embraces elements of CSR and certainly feeds into the broader debate and discourse on responsible behavior of business. However, it refers at the same time to another discourse - corporate governance - that per se does not necessarily imply activities in line with the idea of CSR; it could, for instance, also be restricted to the discourse on shareholder value. In order to ensure a more conservative approach, I have decided not to include issues of corporate governance, ${ }^{53}$ unless they (i.e., mostly their German translations) explicitly allude to responsibility/accountability (for details on the methods used in this study, see below).

53 However, the concept of corporate governance has been recorded as an additional variable and will be employed on several occasions. 
Markus A. Höllerer - 978-3-653-01464-8

Downloaded from PubFactory at 01/11/2019 11:31:02AM

via free access 
"Institutionalization occurs whenever there is a reciprocal typification of babitualized actions by types of actors. Put differently, any such typification is an institution."

Peter L. Berger \& Thomas Luckmann (1967: 54)

\section{Organizational institutionalism}

In this chapter, I will delineate the theoretical background and the conceptual stage in view of my empirical study and also hint at some methodological implications. In short, I argue that organizational institutionalism with its core analytical notions of (in particular) institutions, institutional logics, organizational fields, theorization, legitimacy, institutionalization processes, and institutional change provides appropriate means to address the guiding questions of this project.

Interested in how corporations achieve legitimacy in the face of competing expectations from their environment, I suggest thinking of corporate communication on CSR in annual reports - casual and strategic alike - as one of the multiple loci where social categorization and typification of CSR practices and actors involved become visible. Above, I provided evidence that CSR is still an evolving debate and emerging "issue field" (e.g., Hoffman, 1999; Meyer, 2004), with the concept's very meaning "under negotiation" in ongoing and complex processes within this field. Business organizations - the potential and "typified" adopters - are among the most important actors here: Their statements, assessments, framings, accounts, and the labels they use all feed into the notion and theorization of this management concept. Thus, beyond merely employing analytical constructs from organizational institutionalism to empirically investigate the phenomenon of CSR, it is my objective to further elaborate on the understanding of theorization as has been presented to date. Building primarily on work of Strang and Meyer (1993), theorization should be understood as a dynamic concept that not only serves as a precondition for diffusion (Tolbert \& Zucker, 1996; Greenwood, Suddaby, \& Hinings, 2002) but as an activity that permanently accompanies institutions - their creation, maintenance, and demolition ${ }^{54}$ - through the formation and use of social categories, labels, and content-specific attribution. I argue - drawing, among others, on Berger and Luckmann's (1967) levels of legitimation - that the role of actors adopting specific practices is much more central than is often depicted: By making sense of adopted or adoptable practices in interpretive struggles, they significantly contribute to the ongoing theorization of disseminating concepts and practices.

54 While established and taken-for-granted, there is little need to explicitly address (or even revise and alter) the theorization in place. However, I propose that in phases of institutionalization, deinstitutionalization, or institutional change (i.e., when institutions are challenged), explicit theorization activities will dramatically increase. 
"Actors rarely, if ever, remain silent as they make policy or build regulatory regimes. They think, meet, argue, make claims, define options, conduct studies, tell stories, and generate discursive output, including reports, interviews, minutes, and newspaper commentaries. In producing this output, actors reveal how they perceive problems and make (or fail to make) connections among concepts, objects, and practices. They also articulate models, fairness principles, and criteria for reasonableness or efficiency" (Schneiberg \& Clemens, 2006: 210-211).

In this regard, all actors in an issue field are viewed as active interpreters of practices (Hardy \& Maguire, 2008), and "individuals' interpretations can be seen as part of institutional agency - the social actions that create, reproduce, and change institutions" (Zilber, 2002: 236, with reference to Karnøe, 1997; see also Lawrence \& Suddaby, 2006).

I will develop my argument in several steps within this chapter. First, I will elaborate on the relevance of bringing together the bodies of literature on CSR and organizational institutionalism. Subsequently, I will present a brief review of the tradition of research on diffusing practices and forms within institutional research. The core of the chapter will contain an outline of the tool kit of institutional organizational analysis, thereby setting the scene for the conceptual design of the study at hand; my remarks, however, will be restricted to those central points that seem necessary for my empirical research agenda. As a consequence, I will direct my attention to the very prerequisite for both diffusion and institutionalization: the discursive theorization of a new practice.

A variety of scholars, especially from Scandinavian institutionalism, have emphasized the relevance of local and field-level characteristics that influence the adoption of new concepts, practices, and forms; they have made institutional theory familiar with the notions of "translation" and "editing", describing an adaptation of diffusing practices and their theorizations in order to fit local structures of expectations. I argue that, despite several empirical studies showing such adaptations by actual adopters at the local organizational level, most have so far neglected important consequences of this idea: the influential patterns these multiple adaptations form at field level.

I suggest calling this effect of more local levels informing and influencing more global levels the "repercussion" of adaptation (see below). In such a way, my research aims at taking seriously the hitherto neglected "call to focus on the microprocesses of institutional production at the macro level" (Phillips \& Malhotra, 2008: 718, with reference to the work of Zucker). Finally, I will conclude that theorization and dissemination of managerial ideas and concepts are essentially discursive processes, thus pointing to implications and consequences for the empirical design of my research. 


\subsection{CSR and organizational institutionalism}

Research on CSR embraces, and brings together, a diversity of conceptual approaches, theoretical perspectives, and empirical traditions. The previous chapter outlined that CSR is - as a distinct managerial idea/practice, management concept, issue field, and "field of scholarship" - still in a state of emergence (see also Lockett et al., 2006; McWilliams et al., 2006b; Crane et al., 2008b). However, as Crane et al. (2008b) note, indicators of an increasing institutionalization of CSR are reported both for academia (e.g., journals and special issues devoted to research on CSR, academic conferences facilitating scholarly debate, and CSR as an advancing area of academic teaching) and corporate practice (e.g., explicit statements on corporate websites, corporate initiatives, and CSR reporting). This ongoing institutionalization of CSR, together with the important role of the wider institutional setting and processes of institutional change, has ample implications for my research project - especially with regard to the concept's meaning at field level.

While the literature has to some extent traditionally focused on the consequences of CSR - for instance, the effect of corporate social performance on financial performance (see, e.g., Margolis \& Walsh, 2003; Orlitzky et al., 2003) -, little attention has been paid to understanding the preconditions and empirical causes of CSR (Campbell, 2006). Recently, several scholars (e.g., Aguilera \& Jackson, 2003; Campbell, 2006, 2007; Miller \& Guthrie, 2007; Matten \& Moon, 2008) have shown particular interest in the study of institutions and institutional context - i.e., the wider societal and political frames and arrangements, as well as norms, incentives, and rules - to examine issues of CSR. They suggested that research informed by organizational institutionalism (for an overview, see Greenwood, Oliver, Sahlin, \& Suddaby, 2008) could provide helpful insights and lead to a better understanding of why and how CSR is spreading on a global scale. ${ }^{55}$

Organizational institutionalism posits that organizations make decisions facing multiple pressures defined by the specific organizational field in which they are embedded (DiMaggio \& Powell, 1983) and with an overall objective of maintaining their legitimacy in this field (Suchman, 1995). In addition, this line of theory and research has highlighted how regulative, normative, and cultural-cognitive processes (Scott, 2008) lead to increasingly standardized and rationalized organizational practices and forms even across cultural boundaries. However, organizational institutionalism need not be read as deterministic. As Oliver (1991) points out, organizations - i.e., organizational decision makers - may also proactively and

55 For example, Campbell (2007) evaluates connecting lines between CSR research and organizational institutionalism; he also offers an institutional theory of CSR consisting of a series of propositions specifying the conditions under which corporations are likely to behave in socially responsible ways. For an empirical application of this framework see, for instance, Chih, Chih, and Chen (2010); for some conceptual limitations see Lee (2008), among others. 
strategically respond to institutional pressures in multiple ways. With regard to the institutionalization of CSR and related practices, Miller and Guthrie (2007, with reference to the work of Suddaby \& Greenwood, 2005) suggest that organizations respond proactively to institutional pressures through the use of structure and rhetoric. Matten and Moon (2008) further note that drawing on concepts from organizational institutionalism allows for exploring the ways in which corporations are governed based on motives and interests of multiple stakeholders:

"Contemporary institutional theory illuminates the global spread of [explicit] CSR and its social contextualization beyond its U.S. origins. It enables CSR to be framed in the broader context of organization studies and international management. Thus, the recent worldwide adoption of CSR policies and strategies can be understood as part of the global spread of management concepts, ideologies, and technologies [...], resulting in some sort of 'Americanization' of management practices" (Matten \& Moon, 2008: 406, with reference to Guler, Guillén, \& Macpherson, 2002, as well as to Djelic, 1998).

Matten and Moon (2008) also stress that the assumption of social responsibility of business remains contextualized by the respective institutional framework ${ }^{56}$ - and therefore varies across cultural fields. Their overall explanatory model (reproduced in Figure 6) depicts the corporation as embedded in a historically grown institutional framework (i.e., in a national business system; see Whitley, 1999, among others) as well as exposed to institutional pressures from within an organizational field (e.g., Scott, 2008).

In sum, one could expect research at the intersection of CSR and organizational institutionalism to yield considerable results and insights. Surprisingly enough, the two bodies of literature have to date remained largely isolated from each other (Campbell, 2006; but see, for instance, Aguilera \& Jackson, 2003; Doh \& Guay, 2006; Campbell, 2007; Miller \& Guthrie, 2007; Guthrie \& Durand, 2008; Matten \& Moon, 2008; Jackson \& Apostolakou, 2010).

56 Schneper and Guillén (2004: 289), for instance, note that "the power of various stakeholders characterizes countries in fundamental and momentous ways". 


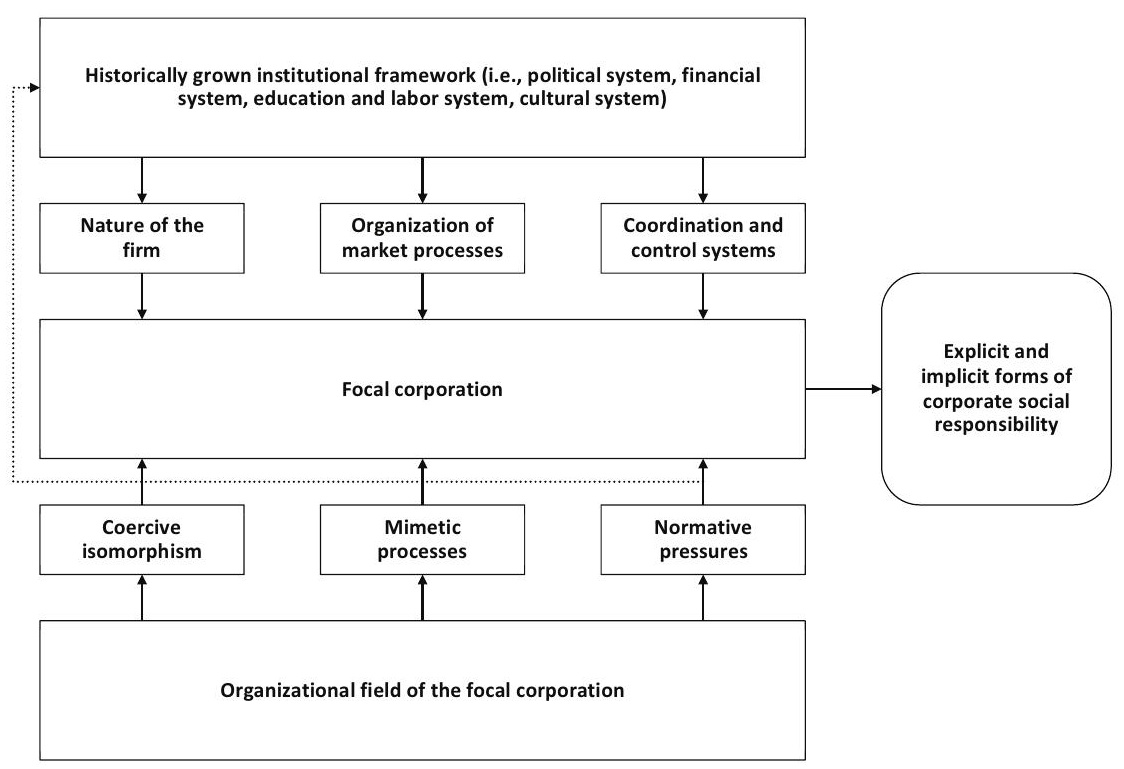

Figure 6: CSR and the institutional context (Source: adapted from Matten \& Moon, 2008: 413)

\subsection{Research on the diffusion of organizational and managerial practices}

Studies investigating the diffusion of organizational and managerial practices, including normative concepts and institutional rules, are prominent in empirical institutional research. According to one of the fundamental assumptions of organizational institutionalism, such diffusion - on a global scale - shapes the structures and practices of organizations in the same manner and to the same extent as they are exposed to similar environments; this inevitably leads to organizational isomorphism (DiMaggio \& Powell, 1983). An extensive body of literature has significantly enhanced our understanding of diffusion mechanisms, offering "a variety of rational, boundedly rational, and social explanations for the adoption and diffusion of practices across time and space" (Ansari, Fiss, \& Zajac, 2010: 67). Such studies also "provide an opportunity to observe the cultural construction of meaning, where we learn how practices are locally and globally interpreted, and ask why some practices flow while others languish" (Strang \& Soule, 1998: 266).

The relevant academic literature is especially characterized by highlighting two sets of explanations regarding the processes that lead to the adoption of organiza- 
tional and managerial practices and forms (Ansari et al., 2010; see also Strang \& Macy, 2001): Rational accounts typically emphasize a technical imperative for adoption (e.g., efficiency and effectiveness), whereas social accounts typically emphasize a cultural imperative for adoption (e.g., imitation, legitimacy); both are assumed to explain diffusion under different conditions (Ansari et al., 2010). The degree of dissemination of a specific organizational and managerial practice within a field is interpreted as an indicator for its institutionalization. Empirical research applies multivariate methods and a broad range of variables in order to detect and/or test patterns of the adoption of practices (for an overview see Rogers, 1995; Strang \& Soule, 1998; Scott, 2008, among others).

Green (2004: 653) points our attention to the outstanding role of language and rhetoric $^{57}$ in processes of diffusion: Any dissemination of organizational practices and forms depends on "discursive justifications" used to explain and rationalize them up to a point when justifications are taken-for-granted, and practices and forms reach a state of institutionalization. Green (2004: 654) thus argues for greater integration of rhetoric and discourse in diffusion studies:

"A rhetorical perspective suggests that managers play an active role in the diffusion process, because what managers say and how they say it matter a great deal [...]. This perspective reconceptualizes diffusion as a product of rhetoric, because rhetoric can influence the motives driving firms to adopt innovations and shape the social structure through which those practices diffuse. [...] This view emphasizes the linguistic origins of rationality and institutions. To rationalize is to give discursive reasons for actions; to institutionalize is to accept and take these reasons for granted. This makes language central to understanding variations in the diffusion and institutionalization of managerial practices and suggests a more active conceptualization of discourse and social action."

Recently, conventional diffusion research has faced substantial criticism. One major concern (see below for more details) is that scholars might have overestimated the ability to export and import organizational and managerial practices across cultural borders: Such objects have been theorized and are embedded in specific fields as well as in social contexts and thus have a specific cultural meaning that might not be transferable (e.g., Brunsson, 1989; Czarniawska \& Joerges, 1996; SahlinAndersson, 1996; Strang \& Soule, 1998; Snow \& Benford, 1999; Sahlin-Andersson \& Engwall, 2002a; Meyer, 2004). Another significant concern addresses the fact that within a general trend of organizational isomorphism and homogeneity, a substantial degree of practice variation and heterogeneity can be recorded (e.g., Westphal, Gulati, \& Shortell, 1997; Lounsbury, 2001, 2008). Organizational institutionalism, consequently, sees itself confronted with the challenge to provide

57 The role of language and discourse within organizational institutionalism in general and for diffusion processes in particular is emphasized in various studies (e.g., Strang \& Meyer, 1993; Phillips, Lawrence, \& Hardy, 2004) and often falls back on the seminal work of Berger and Luckmann (1967; see also Luckmann, 2006). 
the appropriate tools to capture such heterogeneity (Walgenbach \& Meyer, 2008). Lounsbury (2001: 53) is among the first to point in this direction:

\begin{abstract}
"In general, we need more studies that connect institutional change to variation in the content of organizational practices. To uncover institutional sources of practice variation, however, researchers may have to employ more eclectic methodologies that combine large-scale archival analysis with more grounded ethnographic research strategies. By understanding how the content of organizational practices is shaped by broader institutional forces, we may develop new insights about the sources of organizational heterogeneity and gain significant leverage in identifying why organizational diversity exists in some fields but not in others."
\end{abstract}

For research focusing on the dissemination of organizational and managerial practices, the requirement to take such variation - i.e., heterogeneity not only across, but also within specific local contexts - into account is inevitably linked to a thorough investigation of the very meaning of practices.

\title{
3.3 A conceptual tool kit for organizational institutional analysis
}

Modern organizational institutionalism discusses a broad variety of conceptual approaches and theoretical perspectives, implying various analytical strategies that could be viewed as "theoretical resources in an institutional tool kit" (Lounsbury, 1997: 465; Swedberg, 2006). Providing the "typical tools for the job" (Schneiberg \& Clemens, 2006), they facilitate an analysis of the dissemination and institutionalization of organizational and managerial practices. ${ }^{58}$ I will briefly outline - against the backdrop of the empirical study to follow - what I regard as the most important conceptual tools provided by the domain of organizational institutionalism.

\subsubsection{Institutions}

It goes without saying that institutions are at the very core of all versions of institutional theory. According to Berger and Luckmann (1967: 54), an institution is the "reciprocal typification of habitualized actions by types of actors". In a similar vein, Barley and Tolbert (1997: 96) define institutions as "shared rules and typifications that identify categories of social actors and their appropriate activities or relationships". Consequently, such a definition of institutions also implies, for certain types of actors, a certain sequence of typical actions - generally referred to as "scripts". Institutions should therefore also be understood as (consolidated) structures of expectation. They are, by definition, of relative permanence, and thus

58 Such analysis focuses on notions or topics such as the field, "embeddedness", processes and trajectories of diffusion, theorization, institutional logics, isomorphism, homogeneity and heterogeneity of practices, hybridization of logics, bricolage, translation, or decoupling. 
a bridge across time and space (Meyer, 2004), even though they are themselves subject to change - be it evolutionary or revolutionary ${ }^{59}$ (e.g., Greenwood \& Hinings, 1996; Clemens \& Cook, 1999; Greenwood et al., 2002; Amis, Slack, \& Hinings, 2004; Campbell, 2004; Greenwood \& Hinings, 2006; Schneiberg, 2007).

A standard - "omnibus" - definition of institutions is presented by Scott (2001: 48; see also Scott, 2008):

- "Institutions are social structures that have attained a high degree of resilience."

- "Institutions are composed of cultured-cognitive, normative, and regulative elements that, together with associated activities and resources, provide stability and meaning to social life."

- "Institutions are transmitted by various types of carriers, including symbolic systems, relational systems, routines, and artifacts."

- "Institutions operate at multiple levels of jurisdiction, from the world system to localized interpersonal relationships."

- "Institutions by definition connote stability but are subject to change processes, both incremental and discontinuous."

Scott $(1995,2008)$ also introduces a model defining the "three pillars of institutions" that serves as a central and widely accepted "lowest common denominator" in organizational institutionalism (see Table 1 below). It is, however, important to hold that the three pillars are represented to varying degrees in the different forms of institutions: They are not "types" of institutions, but represent relevant dimensions to access institutions analytically (Walgenbach \& Meyer, 2008).

\begin{tabular}{|c|c|c|c|}
\hline & Regulative & Normative & Cultural-cognitive \\
\hline Basis of compliance & Expedience & Social obligation & $\begin{array}{l}\text { Taken-for-grantedness, } \\
\text { shared understanding }\end{array}$ \\
\hline Basis of order & Regulative rules & Binding expectations & Constitutive schema \\
\hline Mechanisms & Coercive & Normative & Mimetic \\
\hline Logic & Instrumentality & Appropriateness & Orthodoxy \\
\hline Indicators & Rules, laws, sanctions & $\begin{array}{l}\text { Certification, } \\
\text { accreditation }\end{array}$ & $\begin{array}{c}\text { Common beliefs, shared logics } \\
\text { of action, isomorphism }\end{array}$ \\
\hline Affect & Fear guilt/innocence & Shame/honor & Certainty/confusion \\
\hline Basis of legitimacy & Legally sanctioned & Morally governed & $\begin{array}{l}\text { Comprehensible, recognizable, } \\
\text { culturally supported }\end{array}$ \\
\hline
\end{tabular}

Table 1: The three pillars of institutions (Source: adapted from Scott, 2008: 51)

59 "Revolutionary and evolutionary changes are defined by the scale and pace of upheaval and adjustment. Whereas evolutionary change occurs slowly and gradually, revolutionary change happens swiftly and affects virtually all parts of the organization simultaneously" (Greenwood \& Hinings, 1996: 1024). 
In a nutshell, what are the implications of this conceptualization for the study at hand? In Austria, social responsibility has been a deeply rooted institution for large business organizations for many years; moderated by the historically grown institutional framework, it has been related to a variety of actions more or less expected from corporations (see chapter on empirical context for more). Such presumed understanding has been anchored in the Austrian - and more broadly: in the continental European - interpretation of corporate governance and control. As a consequence, these taken-for-granted activities were neither addressed explicitly nor used strategically by the corporate world: They were, however, implicitly addressed in the way in which corporations conducted their daily business. As I will show, the claim to talk about, report on, and account for corporations' social responsibility has been a fairly novel, yet increasingly institutionalized practice in this specific empirical context. Especially with advancing globalization and a worldwide spread of management concepts - mainly incorporating an AngloAmerican ideology or logic of corporate governance and control (see also Meyer \& Höllerer, 2010) - corporations have felt increasing pressure to (re-)define their role, and ensure their legitimacy, within society.

\subsubsection{Institutional logics}

Beyond the regulating, coordinating, and organizing capacity of institutionalized practices it is, as Meyer and Höllerer (2009) emphasize, important to highlight the expressive character of all institutions that is also at the very heart of Selznick's (1957) classic definition. Institutions are embodiments of a "Leitidee" (Lepsius, 1997) or "substance" (Friedland, 2009) that guides the organizing principles of an institutional order - i.e., they are symbolic formations that serve as signifiers for this guiding orientation, which is in turn knowable and perceivable only by being materialized and given shape (Meyer \& Höllerer, 2009). As Friedland stresses, such "an institutional logic is a bundle of practices organized around a particular substance" (2009: 61) and depends "on making the invisible substance visible" (2009: 65). ${ }^{60}$

The notion of institutional logics is one of the most opalescent and widely used in organizational institutionalism. Originally introduced and subsequently further developed by Alford and Friedland (1985; Friedland \& Alford, 1991) to describe the central contradictory practices and beliefs inherent in institutions of modern

60 An alternative, albeit related, conception is provided by Thornton and Ocasio (1999: 804) who define institutional logics as "the socially constructed, historical patterns of material practices, assumptions, values, beliefs, and rules by which individuals produce and reproduce their material subsistence, organize time and space, and provide meaning to their social reality". 
societies, ${ }^{61}$ it has been applied to a diversity of research topics and empirical contexts (for an overview and thorough discussion, see Thornton \& Ocasio, 2008). Rejecting "both individualistic, rational choice theories and macro structural perspectives", Friedland and Alford "posited that each of the institutional orders has a central logic that [...] provides social actors with vocabularies of motive and a sense of self (i.e., identity)" (Thornton \& Ocasio, 2008: 101). ${ }^{62}$

Various empirical studies focusing on institutional change, hybridization of practices, and institutional orders or practice variation emphasize the competition between alternative institutional logics within an organizational field (e.g., Greenwood \& Hinings, 1993; Haveman \& Rao, 1997; Thornton \& Ocasio, 1999; Scott, Ruef, Mendel, \& Caronna, 2000; Lounsbury, 2002; Townley, 2002; Rao, Monin, \& Durand, 2003; Reay \& Hinings, 2005; Haveman \& Rao, 2006; Meyer \& Hammerschmid, 2006a, 2006b; Lounsbury, 2007; Marquis \& Lounsbury, 2007; Meyer \& Höllerer, 2009). As Friedland and Alford (1991: 232) succinctly point out, social actors are generally exposed to multiple institutions and institutional orders

"[...] that shape individual preferences and organizational interests as well as the repertoires of bebaviors by which they may attain them. These institutions are potentially contradictory and bence make multiple logics available to individuals and organizations. Individuals and organizations transform the institutional relations of society by exploiting these contradictions."

\subsubsection{Organizational fields}

The organizational field is - both as a primary unit and level of analysis (Scott, 2008) - "the central construct" for research anchored in organizational institutionalism (Wooten \& Hoffman, 2008: 130; see also DiMaggio, 1986; Walgenbach \& Meyer, 2008). Introduced in the seminal article of DiMaggio and Powell (1983), it was soon criticized for a number of reasons (for an overview see, for instance, Walgenbach, 2002). Scott (2008: 181) notes that "like so many concepts in institutional theory, the conception of organizational fields is a work in progress. [...] It is, at one and the same time, widely accepted and hotly contested." According to Scott (1994: 207-208),

"[...] the notion of field connotes the existence of a community of organizations that partakes of a common meaning system and whose participants interact more frequently and fatefully with one another than with actors outside of the field."

61 Friedland and Alford (1991) list for modern Western societies the capitalist market, the bureaucratic state, families, democracy, and religion.

62 Against the backdrop of the study at hand, and as Nigam and Ocasio (2010: 826, with reference to Ocasio \& Joseph, 2005; Zilber, 2006, among others) point out, institutional logics are also "embodied in vocabularies and communication [...]. Both the prevalence of specific words, phrases, or signs and their use to denote specific meanings can serve as indicators of societal and field-level institutional logics". 
Such an understanding partly corresponds with DiMaggio and Powell's (1983: 148) original definition of the organizational field as a social space that encompasses "those organizations that, in aggregate, constitute a recognized area of institutional life": Organizational fields constitute a social space delimited by a particular distribution of institutionalized rules, positions, and resources (Phillips, Lawrence, \& Hardy, 2000; see also Oakes, Townley, \& Cooper, 1998).

Another, more recent approach conceptualizes organizational fields that have not been formed around markets or technologies but have emerged around central disputes and "issues that bring together various field constituents with disparate purposes" (Hoffman, 1999: 352). Organizational fields are thus "centers of debates in which competing interests negotiate over issue interpretation" (Hoffman, 1999: 351). In this way, the organizational field also includes the relevant organizations from the point of view of actors (Fligstein, 1991). Summarizing in his study on corporate environmentalism, Hoffman (1999: 352; see also 2001) suggests

"[...] that a field is formed around the issues that become important to the interests and objectives of a specific collective of organizations. Issues define what the field is, making links that may not have previously been present. Organizations can make claims about being or not being part of the field, but their membership is defined through social interaction patterns [...]. Field membership may also be for a finite time period, coinciding with an issue's emergence, growth, and decline."

In a parallel vein, but with a different emphasis, Meyer (2004; see also Meyer \& Höllerer, 2010) defines the "totality of relevant actors" (DiMaggio \& Powell, 1983: 148) of an issue field as those actors that engage in the "politics of signification" (Benford \& Snow, 2000: 625); she also reveals the striking interface with social movement research as she conceptualizes fields as the social space in which actors have to mobilize support and legitimacy.

Finally, Scott (2008: 209) reminds us of why the field concept represents such a useful analytic framework and valuable tool in organizational institutional research:

"Although it would appear that a field-level focus would detract attention from our attempt to understand the behavior of individual organizations, I believe that this is far from being true. Just as the attributes and actions of a character in a play are not fully comprehensible apart from knowledge of the wider drama being enacted - including the nature and interest of the other players, their relationships, and the logics that guide their actions - so we can better fathom an organization's behavior by seeing it in the context of the larger action and meaning system in which it participates."

\subsubsection{Legitimacy}

"Organizations require more than material resources and technical information if they are to survive and thrive in their social environments. They also need social 
acceptability and credibility" (Scott et al., 2000: 237). Legitimacy - one of the fundamental concepts in organizational and management studies and in organizational institutionalism in particular (for an overview, see Deephouse \& Suchman, 2008; note also the relevance for the field of CSR) - has been made "into an anchor-point of a vastly expanded theoretical apparatus addressing the normative and cognitive forces that constrain, construct, and empower organizational actors" (Suchman, 1995: 571). A helpful and thus widely cited reference and definition has been coined by Suchman (1995: 574):

"Legitimacy is a generalized perception or assumption that the actions of an entity are desirable, proper, or appropriate within some socially constructed system of norms, values, beliefs, and definitions."

Awarded on the principle of a comprehensive, generalized evaluation of an organization rather than in an event-specific manner, legitimacy is "possessed objectively, yet created subjectively" (Deephouse \& Suchman, 2008: 574): It is "conferred when stakeholders - that is, internal and external audiences affected by organizational outcomes - endorse and support an organization's goals and activities" (Elsbach \& Sutton, 1992: 700). Hence, an organization is regarded as legitimate if its objectives and activities appear appropriate within a specific institutional framework. ${ }^{63} \mathrm{It}$ might be important to stress that legitimacy is more "a relationship with an audience rather than [...] a possession of the organization" (Suchman, 1995: 594).

Berger and Luckmann (1967: 93) already hold that "legitimation 'explains' the institutional order by ascribing cognitive validity to its objectivated meanings. Legitimation justifies the institutional order by giving a normative dignity to its practical imperatives." Especially in cases when organizations are exposed to environments characterized by the existence of multiple or even contradictory/competing institutional logics, proactive legitimacy management ${ }^{64}$ becomes increasingly important to establish or maintain legitimacy of the organization and its activities in the face of divergent stakeholder interests and expectations. A mismatch of social expectations and organizations' activities can often be observed during the initial phases of institutionalization or de-institutionalization processes. Berger and Luckmann (1967) also refer to the outstanding role of language in such processes. For them, the mobilization of legitimacy is essentially a social and discursive process (for details, see below; see also Meyer \& Rowan, 1977; Suchman, 1995; Lounsbury \& Glynn, 2001; Phillips et al., 2004, among others): Organizational actors must present "accounts" (Scott \& Lyman, 1970: 93) ${ }^{65}$ to justify and

63 See also Scott (2008: 59-62), who refers to (bases of) legitimacy within the "three pillars of institutions" model.

64 See also the remarks on the business case for CSR in the previous chapter.

65 For an overview, see Meyer (2004); for empirical studies, see the work of Elsbach and colleagues (Elsbach \& Sutton, 1992; Elsbach, 1994; Elsbach et al., 1998), Lamertz and Baum (1998), or Creed, Scully, and Austin (2002), among others. 
explain deviant behavior and activities. With increasing institutionalization, however, such justifications become standardized and included in the theorization of an institutional concept, practice, or form: It is in this sense that Zucker (1977: 728) notes that "when acts have ready-made accounts $[. .$.$] , they are institutionalized".$

\subsubsection{Processes of institutionalization and deinstitutionalization}

Institutional theories had been, in their early days, more concerned with institutions and their central character of reducing uncertainty by establishing stability and continuity (see also Berger \& Luckmann, 1967). Per definitionem - and this feature is common to the divergent definitions of institutions - this implies relative duration and relative order (e.g., Walgenbach \& Meyer, 2008). However, critique has reproached organizational institutionalism for its tendency to investigate effects and outcomes of institutionalization rather than the very processes of institutionalization (DiMaggio, 1988; Powell, 1988; Brint \& Karabel, 1991; Powell, 1991; Zucker, 1991; Hirsch \& Lounsbury, 1997; Kondra \& Hinings, 1998; Beckert, 1999, among others). Consequently, more recent publications (particularly those from the 1990s and early 2000s) have established a new line of research focusing on processes of institutionalization and deinstitutionalization (e.g., Tolbert \& Zucker, 1996) and thus on various forms of institutional change (e.g., Greenwood \& Hinings, 1996; Clemens \& Cook, 1999; Greenwood et al., 2002; Kraatz \& Moore, 2002; Amis et al., 2004; Campbell, 2004; Streeck \& Thelen, 2005; Greenwood \& Hinings, 2006; Schneiberg, 2007). Such changes in the institutional framework can be caused either by exogenous or endogenous factors (for an overview, see Campbell, 2004; Scott, 2008, among others).

The most significant attempt to conceptualize the process of institutionalization is summarized by Tolbert and Zucker (1996; see Table 2 below) and is reflected in a myriad of studies testing the so-called two-stage institutional model of diffusion (e.g., Baron, Dobbin, \& Jennings, 1986; Fligstein, 1991; Westphal et al., 1997; Dobbin \& Sutton, 1998). This perspective focuses on a two-stage process with early adopters of a specific practice driven more by technical and economic considerations, while late adopters tend to "imitate each other in a contagion-like process that is decoupled from rational calculation" (Lounsbury, 2007: 289). 


\begin{tabular}{lccc}
\hline & $\begin{array}{c}\text { Pre-institutionalization } \\
\text { stage }\end{array}$ & $\begin{array}{c}\text { Semi-institutionalization } \\
\text { stage }\end{array}$ & $\begin{array}{c}\text { Full-institutionalization } \\
\text { stage }\end{array}$ \\
\hline $\begin{array}{l}\text { Processes } \\
\begin{array}{l}\text { Characteristics of } \\
\text { adopters }\end{array}\end{array}$ & Habitualization & Objectivation & Sedimentation \\
Impetus for diffusion & Homogeneous & Heterogeneous & Heterogeneous \\
$\begin{array}{l}\text { Theorization activity } \\
\text { Variance in } \\
\text { implementation } \\
\text { Structure failure rate }\end{array}$ & None & Imitative/normative & Normative \\
\hline
\end{tabular}

Table 2: Stages of institutionalization (Source: adapted from Tolbert \& Zucker, 1996: 185)

Taking into account the ambiguities surrounding the definition and conceptual identity of CSR, as well as first impressions of the empirical data from Austria, characteristics of a semi-institutionalized stage (i.e., an institutionalization "in the making") in the late 1990s and early 2000s can be observed. During this phase of objectivation, and in order for the innovative practice to gain legitimacy and be successfully established, adopters and advocates must provide a convincing theorization of both the problem tackled and the solution proposed (e.g., Strang \& Meyer, 1993; Greenwood et al., 2002). This rather high degree of theorization activity goes hand in hand, according to Tolbert and Zucker (1996), with a more heterogeneous group of adopters and a change from imitation toward a normative impetus for diffusion.

Despite the model's "triple significance in institutional theory" (for details, see Scott, 2008: 132), the depiction of late adopters as passive and "a-rational" provides a limiting conceptualization (Strang \& Macy, 2001; Lounsbury, 2007), "reinforcing the misguided notion that neoinstitutionalism is a theory of isomorphism and stability" (Lounsbury, 2007: 289, with reference to Hirsch \& Lounsbury, 1997). As a consequence, the classic model of institutionalization has faced fundamental criticism and has recently been enhanced by rethinking the role of motivations in the diffusion of practices. Kennedy and Fiss (2009: 914), in their study on TQM adoption and implementation, argue that logics of efficiency and legitimacy might be more compatible than has been generally assumed in previous work: "Both legitimacy and efficiency factor into the moves of both early and later adopters that is, wanting to look good does not preclude wanting to do well." For no other debate than the one on CSR could these words be more appropriate. 


\subsection{Theorization as a prerequisite for institutionalization}

A mainstream line of empirical research in the domain of organizational institutionalism has dealt with processes of diffusion of practices and forms into new fields. According to Rogers (1995: 5), diffusion is "the process by which an innovation is communicated through certain channels over time among the members of a social system". However, grasping diffusion simply as a "spread of something within a social system" (Strang \& Soule, 1998: 266) leaves an essential question unanswered: What is it that is actually disseminating? Hence, a number of institutional and social movement scholars have pointed out that one must to understand how social consensus is built around the meaning of practices before one can go about understanding the ways they spread (Jennings \& Zandbergen, 1995; SahlinAndersson, 1996; Benford \& Snow, 2000; Meyer, 2004, among others; see below for more). At its very core, institutional research has only little to say about how practices become imbued with meaning (Bartley, 2004). Research on framing activity (e.g., Benford \& Snow, 2000) and "field frames" (e.g., Lounsbury, Ventresca, \& Hirsch, 2003), however, highlights ways in which practices take on more abstract meanings and connotations, and how these develop over time.

Before new practices or forms are likely to diffuse beyond the confines of local contexts, they must be given broader cultural significance, such as a set of meanings about what they are good for and where else they might be appropriate (Clemens, 1997; Bartley, 2004). Strang and Soule (1998; see also Sahlin-Andersson, 1996) argue that, rather than practices, specific framings of practices are imitated and therefore diffuse; or, in the words of Strang and Meyer (1993: 499),

\footnotetext{
"[...] what flows is not a copy of some practice existing elsewhere [...], it is the theoretical model that is likely to flow. Such models are neither complete nor unbiased depictions of existing practices. Instead, actual practices are interpreted as partial, flawed, or corrupt implementations of theorized ones."
}

In organizational institutionalism, such "strategy for making sense of the world" (Strang \& Meyer, 1993: 493) is commonly referred to as theorization. ${ }^{66}$ Successful theorization basically requires two steps in order for a practice to achieve moral or pragmatic legitimacy: First, a generic definition of an organizational problem or organizational failing must be created; second, it must be made apparent as to how a particular, abstract solution will remedy the previously specified problem (Strang \& Meyer, 1993; Greenwood et al., 2002). ${ }^{67}$

66 Bartley (2004) notes that, despite the fact that successful theorization is a precondition for the diffusion process - it enables and accelerates diffusion -, the concept of theorization has not received nearly as much attention as have the dynamics of diffusion.

67 Note the link to "diagnostic", "prognostic", and "motivational framing" in social movement literature (e.g., Snow \& Benford, 1988). 
Building on the understanding of accounts as justification provided for unanticipated activities that "are likely to be routinized within cultures" (Scott \& Lyman, 1968: 52), Strang and Meyer (1993) argue that established or habitualized social practices are accompanied by theorized, ready-made accounts actors may use to explicate reasons for their conduct. Such routinization of accounts is essentially part of the theorization of a practice and goes hand in hand with an increasing degree of institutionalization (e.g., Tolbert \& Zucker, 1996; Strang \& Soule, 1998). For Berger and Luckmann (1967: 54),

\section{"[...] institutionalization occurs whenever there is a reciprocal typification of habitualized actions by types of actors. Put differently, any such typification is an institution. What must be stressed is the reciprocity of institutional typifications and the typicality of not only the actions but also the actors in institutions. [...] The institution itself typifies individual actors as well as individual actions."}

Any theorization of a practice, defined as the "self-conscious development and specification of abstract categories and the formulation of patterned relationships such as chains of cause and effect" (Strang \& Meyer, 1993: 492), essentially contains such abstract typification of adopters and actions involved, as well as of suggested effects of the practice. Hence, the theorization of a practice implies the construction of cultural categories of actors - as either the subject or the object of the theorized practice - as well as of actions that directly or indirectly link these categories. $^{68}$ Theorization, however, is not only significant by means of social construction of actors and actions involved in a specific practice: As a discursive process, theorization in itself is an essential part of the diffusion mechanism; the higher the degree of abstraction and theorization, the more rapid the diffusion and the less dependent on relational networks. As Strang and Meyer (1993: 498-499) conclude,

"[...] the very aim and character of theories means that they are less tied to concrete actors than are the practices they describe. Where potential adopters internally reproduce and act on the basis of the theoretical model, we might describe theorization itself as the diffusion mechanism."

For the study at hand, the analytical concept of theorization is highly relevant: The very same practice - CSR - is spreading based on rather different theorizations and their underlying logics. For instance, an economic logic supports a business case for CSR, while a moral case is suggested by theories more closely linked to the realm of ethics. Yet diversity exists within such logics as well: For example, within an

68 It is important to hold that not only the categorization of potential adopters affects diffusion, but also the social categorization of other social entities and actors influencing or being influenced by the diffusing practice. In the case of organizations, "standardized categories make it plausible [...] to provide recipes for successful management" (Strang \& Meyer, 1993: 491). 
economic logic, a neoliberal framing of market primacy, a primacy of politics and public interest, or a primacy of ownership is conceivable. While the consequences of divergent diagnostic framings are rather minor for actual practice, they are essential for legitimation and rationale: Corporations may basically do the same things, but they do those things based on very different motives (see chapter on CSR for more).

\subsection{Adaptation, translation, and bricolage in local contexts}

Several scholars emphasize the "structural and cultural bases of diffusion" (Strang \& Soule, 1998: 266) as well as the assignment of cultural meaning to diffusing practices. Meaning - the term refers to interpretations, understandings, and shared beliefs that are produced and processed through social action (Zilber, 2002, 2008) does not reside somewhere "out there" but is instead socially constructed (Berger \& Luckmann, 1967). Consequently, several authors stress that objects imbued with cultural meaning cannot spread wholesale or be imported "ready-to-wear" but must be interpreted, adapted, and related to existing legitimating accounts for a specific local setting (Elsbach, 1994; Benford \& Snow, 2000; Lounsbury \& Glynn, 2001; Creed et al., 2002, among others). In a similar vein, Meyer (2004) empirically shows that even if ideas are globally available, regarded as modern, and have been theorized to a high degree in their native context (see Meyer, 2002), they nonetheless need to pass through a powerful filter of local structural and cultural constraints in order to become legitimate in other contexts.

With regard to the dissemination of organizational practices it is important to note that interpretation must be done in an active manner by the actors and social entities involved (Benford \& Snow, 2000): "Unlike infection, however, 'the object' of the diffusion cannot spread by itself - it must be actively adopted by some actor or other" (Brunsson, 1989: 262). Therefore, on their path of diffusion and during adoption, practices and concepts are also subject to interpretation and modification. Building on Latour's (1986) earlier work, Czarniawska and Joerges (1996) suggest the metaphor of "translation" for this "travel of ideas" and the process of disseminating practices and structures across organizations; this notion clearly alludes to transformation and reshaping in a specific empirical context. SahlinAndersson (1996: 78; see also Sahlin \& Wedlin, 2008) refers to such translation as editing processes and argues that most organizations actually imitate rationalizations (rather than practices and structures): These are "stories constructed by actors in the 'exemplary' organization, and their own translation of such stories. The distance between the supposed source of the model $[\ldots]$ and the imitating organization forms a space for translating, filling in and interpreting the model in various ways." 
Campbell (2004) highlights path-dependency and the fact that diffusing practices usually meet a structured field with a variety of already existing and institutionalized concepts, practices, and forms. He suggests that institutional change can be thought of as either (a) "bricolage" or (b) translation. Bricolage is the mere recombination of existing and locally given institutional elements (Campbell, 2004: 67; see also Streeck \& Thelen, 2005; Scott, 2008):

"Institutions provide a repertoire of already existing institutional principles and practices that actors can use to innovate. The key is to recognize that actors often craft new institutional solutions by combining elements in their repertoire through an innovative process of bricolage whereby new institutions differ from but resemble old ones."

While "substantive bricolage" follows a "logic of instrumentality" in order to solve coordination problems, "symbolic bricolage" involves a "logic of appropriateness" - much akin to framing activities in translation (Walgenbach \& Meyer, 2008) - so as to create acceptance and legitimacy within the broader social environment (Campbell 2004: 69-70, quoting March \& Olsen, 1989).

On the other hand, as Campbell (2004: 80) points out, translation always entails a combination of new ideas and preexisting institutional elements:

"New ideas [...], therefore, are translated into local practice in varying degrees and in ways that involve a process very similar to bricolage. The difference is that translation involves the combination of new externally given elements received through diffusion as well as old locally given ones inherited from the past."

Much in line with these arguments, a considerable number of publications (e.g., Lounsbury, 2001; Kraatz \& Moore, 2002; Maguire, Hardy, \& Lawrence, 2004; Marquis, Glynn, \& Davis, 2007; Marquis \& Lounsbury, 2007) has recently pointed to a new direction of institutional research that focuses less on isomorphic diffusion and more on practice variation and on the "heterogeneity of actors and activities that underlie apparent conformity" (Lounsbury, 2007: 289). This implies the need to conceptualize institutional environments as more fragmented, contested, and influenced by multiple and competing logics (e.g., Schneiberg \& Soule, 2005; Lounsbury, 2007; Schneiberg, 2007; Meyer \& Höllerer, 2009; Reay \& Hinings, 2009), necessarily redirecting the study of institutional diffusion toward the translation of symbolic systems of meaning (e.g., Czarniawska \& Sevón, 1996; Sahlin-Andersson \& Engwall, 2002b; Sahlin \& Wedlin, 2008; Zilber, 2008).

\subsection{Theorization activity across various levels}

Before I conclude this chapter with some summarizing remarks that highlight the discursive dimension of all processes of institutionalization, I wish to stress three aspects that have hitherto drawn little attention in research inspired by organiza- 
tional institutionalism: First, the theorization of concepts, practices, and forms does not only depend on abstract typification by legitimated theorists (e.g., Tolbert \& Zucker, 1996), but essentially builds on sense-giving and categorization by other actors at micro level, and thus on an active interpretation and (re-)construction of meaning by the actual adopters during translation into, and enactment in, local contexts (see also, e.g., Hardy \& Maguire, 2008). Berger and Luckmann (1967) have already emphasized that it is - analytically - possible to distinguish between several different levels of legitimation of practices. Especially the first three levels, as well as their dynamic interplay, are relevant against the backdrop of my study:

"Incipient legitimation is present as soon as a system of linguistic objectifications of buman experience is transmitted [...]. The fundamental legitimating 'explanations' are, so to speak, built into the vocabulary [...]. This level, of course, is pretheoretical. But it is the foundation of selfevident 'knowledge' on which all subsequent theories must rest - and, conversely, which they must attain if they are to become incorporated in tradition [...7. The second level of legitimation contains theoretical propositions in a rudimentary form. Here may be found various explanatory schemes relating sets of objective meanings. These schemes are highly pragmatic, directly related to concrete actions [...]. The third level of legitimation contains explicit theories by which an institutional sector is legitimated in terms of a differentiated body of knowledge. Such legitimations provide fairly comprehensive frames of reference for the respective sectors of institutionalized conduct. Because of their complexity and differentiation, they are frequently entrusted to specialized personnel who transmit them through formalized initiation channels" (Berger \& Luckmann, 1967: 94-95).

While prior studies have stressed, in particular, the role of legitimated theorists (i.e., the third level of legitimation), my research emphasizes the largely neglected first and second levels, which are more concerned with the actual adopters of a concept, practice, or form.

Second, theorization is an ongoing, never-ending process that does not only occur ex ante (i.e., prior to diffusion) or during diffusion (e.g., Tolbert \& Zucker, 1996; see also Table 2), but also to a considerable extent ex post - and at local level. Even in cases when practices are widely institutionalized and their theorization is taken-for-granted, they nonetheless must constantly prove themselves against exogenous events and challenges. In order to maintain the "empirical credibility" (e.g., Snow \& Benford, 1988) of a theorization - i.e., its fit with real-world events -, it is in need of constant adaptation and alignment to local contexts; it should be easily related to experiences of the adopters or audience.

Third, I argue that theorization might take place simultaneously at various - not necessarily always clearly hierarchically organized - levels. Broadly speaking, these levels are a more or less global level, a local (field or organizational) level, and an individual level. They are not isolated from each other, but are in a constant state of mutual influence. I suggest the notion of repercussion to account for such effects, particularly for effects of local theorizing on the more global forms. I will elaborate on these three points in greater detail below. 


\subsubsection{Micro-level categorization and sense-giving}

Strang and Meyer (1993: 493) point out that theorizing as a "strategy for making sense of the world" is, as such, "employed in individual-specific ways by the potential adopters themselves" ${ }^{99}$ In this sense, they hold that individual theorizing matters. Yet they also argue that these

'[...] forms of 'bottom up' theorizing should impact diffusion, but in rather local ways. Individual-specific theories affect the individual's adoption patterns, but not those of other adopters. Shared understandings [...] may homogenize the actors involved, but not larger populations. Ideas about adopter-level theorizing thus provide a mechanism motivating arguments about the individual rationality of adoption."

At the core of their influential article, Strang and Meyer (1993) criticize shortcomings of relational models of diffusion while highlighting cultural linkages and institutional conditions that avail further knowledge on the flow of social elements. In order to be able to explain broader diffusion and, hence, adoption, the authors shift their focus from "everyday theorizing" by actual adopters toward legitimated theorists: "Rather than stressing ubiquitous theorizing by potential adopters, we emphasize globally available models imported into local situations" (Strang \& Meyer, 1993: 494). The mainstream of institutional literature on diffusion (see above) has picked up this argument: Academia and scientists, intellectuals, policy analysts, think tanks, professions, and a wide variety of other "knowledge entrepreneurs" like consultants and media (for an overview, see Abrahamson, 1996; Kieser, 1997; Abrahamson \& Fairchild, 1999, among others) produce complex and highly integrated theorizations. These groups are, unlike actual adopters, "free of pressing needs to apply their theories to concrete problems, which increases not only foolishness but also abstraction" (Strang \& Meyer, 1993: 494).

69 Theorization necessarily and essentially entails the construction of social categories - it is the "self-conscious development and specification of abstract categories and the formulation of patterned relationships” (Strang \& Meyer, 1993: 492). Categories developed in individualspecific theorization, however, go beyond the individual actor: They are culturally informed, mirror broader meaning structures within the field - and possibly become institutionalized at field level. As Spector and Kitsuse (1977: 72) note, "if the subject matter is definitions of social problems, then it is definitions that are socially processed. In this sense, we can say that definitions have careers, one aspect of which is their institutionalization as official categories".

70 As Strang and Meyer (1993; see also Tolbert \& Zucker, 1996; Greenwood et al., 2002) note, an idea or concept must be presented in a way that can persuade an audience that it is more appropriate to tackle social problems or meet needs than do existing ones. Unless an idea or concept is adequately theorized - essentially by means of the typification of problem, solution, adopters, core practices, etc. - and regarded as legitimate, it is unlikely to be widely adopted by an audience. 
Such emphasis on knowledge entrepreneurs leaves various questions unanswered (see Strang \& Meyer, 1993: 508-509, Footnote 27). In particular, the complex relationship between individual theorizing and collective theorization as well as the mobilization of legitimacy remain vague and underexplored. ${ }^{71}$ Also, there seems to be a discontinuity between the diffusion of theorized practices at a more global level and micro-level sense-making activities in a twofold way: First, at the pre-diffusion stage, how is theorization by legitimated theorists linked to bottom-up theorization by actual adopters? Theories on innovative practices and concepts usually do not emerge out of the blue; fundamentally, they are built on acknowledged problems - and on practical solutions. Further, "if bottom-up theorization should impact adoption patterns in a localized manner then how does this process of theorizing fit into our overall understanding of the theorization process" (Gondo \& Amis, 2007: 8)? Second, what is the role of actual adopters in a post-diffusion stage with regard to the theorization of concepts, practices, and forms? While a more general typification (and matching) of adopters and practices is a condition sine qua non for diffusion (e.g., Strang \& Meyer, 1993), a more finegrained categorization of core activities and social entities involved (e.g., addressees of a concept or practice) will only be possible during enactment and translation in specific empirical contexts. Also, the translation of imported concepts, practices, and forms - editing and modification - cannot be accomplished by knowledge entrepreneurs alone but also relies on actual adopters rationalizing their behavior and practice: The ongoing adaptation and further development is only possible through the constant theorization in the local context by the social entities involved. Local actors will pick up on the theorizations offered by knowledge entrepreneurs, but they will modify and adapt these theorizations, just as they remodel the practices. A theorization must therefore be "baptized by fire": The chances of readjustment and modification of the overall theorization nevertheless remain fairly high. ${ }^{72}$

\subsubsection{Theorization as an ongoing process}

At this point, it is also necessary to question the role assigned to theorization in standard models of institutionalization (e.g., Tolbert \& Zucker, 1996) when applied to empirical research: While it goes unchallenged that the most crucial phase of

71 Strang and Meyer (1993: 495) also note that "diffusion obviously requires support from other kinds of actors as well: state authorities, large corporate actors, grassroots activists. In some way, models must make the transition from theoretical formulation to socials movement to institutional imperative."

72 Examples of frame alignment and amplification are plentiful (see Snow, Rochford, Worden, \& Benford, 1986; Benford \& Snow, 2000, among others). For example, many managerial practices originally crafted for private business management have been translated into public sector organizations; in reverse, their theorization has been altered to a considerable degree. 
theorization activity occurs in a semi-institutionalized stage prior to broad diffusion, I argued above that in many cases individualized and fragmentary theorization already happens before knowledge entrepreneurs and legitimated theorists even adopt an idea or concept. ${ }^{73}$ In most cases, new organizational practices and forms must also be argued for, justified, explained, and linked to existing ones as well as to their underlying theories (Campbell, 2004). Moreover, for legitimacy reasons, adopters that champion innovative practices and forms need to put effort into convincing others that these are relevant, effective, and appropriate. As specific solutions to specific problems, they need the "aura" of rational action and thus also need to be rationalized by their early adopters. One might even propose that the "quality" of ex ante theorization is essentially linked to the degree of individualspecific theorizing.

Yet theorizing is also essential during and after diffusion, when ideas are locally enacted. It seems important to note that the translation and diffusion of practices are accompanied and followed by what I refer to as ex post theorizations: Contextualized categories, their deviation from the original theorization, or freshly integrated elements stemming more from local contexts ${ }^{74}$ are once again directed toward abstraction and reshape the original theorization when aggregated at field level. Theorization is necessary even in a full-institutionalization stage: With increasing institutionalization, justifications decline (see Green, 2004); nonetheless, theorization is further developed in residual discourse with actual adopters playing a decisive role. While taken-for-granted concepts, practices, and forms do not need extensive backing from theorists at the global level, a certain degree of "maintenance work" is necessary at a more local one for the purpose of holding up a concept's empirical credibility. To a lesser extent than in phases of growth, concepts and ideas are in need of support and extensive theorization when it comes to phases of saturation and decline. Moreover, the abandonment of a practice must be argued appropriately. At a more general level, concepts, practices, and forms must be defended in light of newly emerging ones or against a change in the broader institutional environment; adopters and advocates will usually explain and give accounts as to why they retain, modify, or abandon established concepts, practices, and forms. Thus, I suggest thinking of theorization as an ongoing and never-ending process throughout the entire "life cycle" of an idea.

73 In the two-stage model of diffusion, however, it remains unclear as to which theorization early adopters of a practice draw on.

74 In very extreme cases, only local elements are at play: A globally diffusing practice might not be implemented at all, but rather initiate a recombination of already existing elements (see also Campbell, 2004, and remarks on bricolage above).

Markus A. Höllerer - 978-3-653-01464-8 


\subsubsection{Repercussion}

While these considerations per se are not entirely new and to some extent addressed by literature on translation, organizational institutionalism research to date has largely neglected the effects of ex post theorization (i.e., especially the "echo" of various local variants at field-level or global theorization) ${ }^{75}$ Little attention has also been paid to the fact that theorization might take place simultaneously at various levels that are not isolated from each other, but are in a constant state of mutual influence. In order to conceptually account for such effects that could potentially alter the "master theorization" of a concept, practice, or form, I suggest making use of the notion of repercussion. ${ }^{76}$

I argue that theorization is a dynamic and circular process that involves active adopters: Early adopters act as innovators and are on the forefront of theorizing; knowledge entrepreneurs at field or global level integrate these early framings and elements in their own abstract model and theorization of a practice. Once equipped with an abstract theory, ideas may spread on a more or less global scale. During this travel of ideas (Czarniawska \& Joerges, 1996; Czarniawska \& Sevón, 2005), practices and their theorizations are constantly adapted in divergent local contexts. It is important to note that "local" has a twofold meaning here: the local field level (like the continental European or Austrian cultural field, for instance) and the local organizational level (such as the individual corporation). During all these processes of modification, framing activity and readjusting theorization remain crucial (see also Meyer \& Höllerer, 2010). At this point, I wish to propose that all levels are in a constant state of mutual influence. For instance, a field-level theorization is - in addition to the meaningful contributions on the part of field-level actors and knowledge entrepreneurs - as much influenced by more local (in the words of Strang and Meyer [1993]: bottom-up) theorizations by local adopters as it is shaped by more global (top-down) ones. In this way, theorization does not simply occur

75 For instance, one might think of innovative conceptions of management accounting practices in public sector organizations (e.g., new key performance indicators or controlling instruments) that - often with very local origins and through distinct bottom-up rationalization/theorization - gradually change field-level practices and their theorization; notwithstanding, the more global and institutionalized practice of management accounting, at its core, has never been questioned. Another example is Kelly and Dobbin's (1998) work on employers' responses to antidiscrimination law. Finally, for the subject of my empirical study it might be interesting to see how the encounter of the Anglo-American management concept of explicit CSR (which can be regarded as an institutionalized practice in its native setting) and the continental European tradition of more implicit CSR will reshape the global notion of CSR in the long run.

76 The term alludes to processes in which meaning is (re-)negotiated and theorizations are altered. The field (i.e., meso level) here serves as a Resonanzraum - as a broker/mediator between the different levels and aggregates of theorizations: On the one hand, a lowest common denominator is needed for the more local, individual variants; on the other, field-level theorizations never develop in isolation, but are linked to more global theorizations. 
exclusively top-down or bottom-up, but is indeed a complex process involving theorization activity across various levels (see Figure 7).

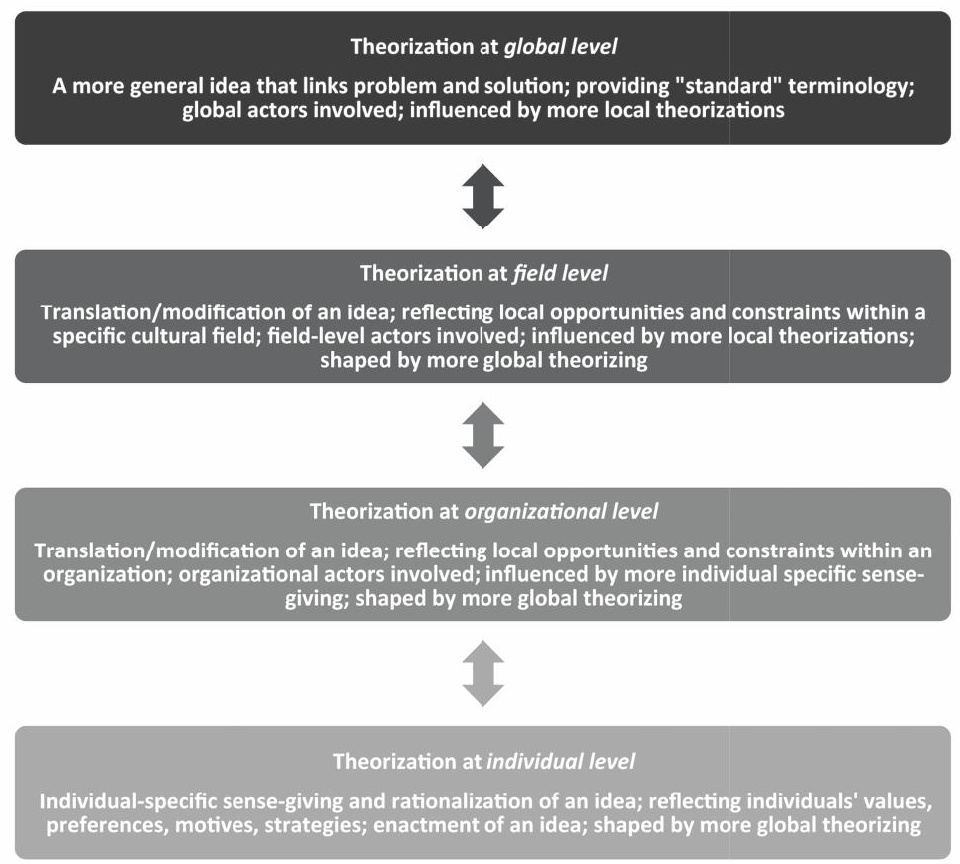

Figure 7: Theorization at and across various levels

Such an approach accounts for the mutual influence of theorization activity across various levels, and especially for the phenomenon of repercussion - both from a local (organizational) level to the field level, and from a local (field) level to the global level. Put differently: If more local variants of a concept (including related scripts and ceremonies) with deviating theorizations exist, what implications does this have for the master theorization? And how is an institution that is represented - due to translation - by a variety of forms further developed, whetted, and adjusted over time without losing its "identity"? What are the mechanisms that hold together such variety as a kind of "umbrella"? Knowing that practice variation exists, one must investigate how divergent local meanings impact a globally available concept. Meyer and Höllerer (2010) stress a general point with regard to translation studies and questions of isomorphism or heterogeneity in organizational fields: With the multiplicity of labels used to denote an idea and the heterogeneity of framings and meanings attached, how does one recognize that he or she is 
analyzing variations of the very same theme? "How long can we think of a concept as transformed or translated, and when is it to be regarded as 'different' altogether? What characteristics constitute 'family resemblance', what is the genotype of an institution that is held constant during all the transformations" (Meyer \& Höllerer, 2010) $?^{77}$

\subsection{Exploring the discursive dimension}

In sum, this chapter briefly introduced and outlined the conceptual approaches and theoretical perspectives within organizational institutionalism that are most central to my study. I also presented some potential extensions that might be helpful to discuss emerging issues like the one studied here, including the role and significance of activities at local level: Mainstream organizational literature often refers to local settings at organizational level (for instance, when empirically investigating translation). However, and as, for instance, Meyer (2004) has shown for the translation of shareholder value "into Austrian", the diffusion, negotiation of meaning, and editing of global ideas sometimes takes place primarily at local field level, with discrete field-level variants of the spreading practice being critical as well.

I have noted that processes of institutionalization require legitimacy (and thus extensive theorization) of a concept, practice, or form to establish themselves in a specific local context. Legitimation - i.e., the mobilization and management of legitimacy - and theorization rest on communication and are therefore essentially discursive processes (Berger \& Luckmann, 1967; Suchman, 1995; Luckmann, 2002). A number of scholars in the domain of organizational institutionalism have highlighted the role of such linguistic or communicative processes: organizational vocabulary (e.g., Meyer \& Rowan, 1977), rhetoric and meaning (e.g., Zilber, 2002, 2006), storytelling (e.g., Lounsbury \& Glynn, 2001), rhetorical strategies (e.g., Suddaby \& Greenwood, 2005), and framing activities (e.g., Meyer, 2004; Fiss \& Zajac, 2006; Kaplan, 2008; Meyer \& Höllerer, 2010).

In a similar vein, Luckmann (2006) argues that the human social world is mainly constructed in communicative interaction: As communicative actions become institutionalized like any other form of social action, this requires "examining the formats in which it is produced - the communicative genres" (Meyer, 2008: 531). One of these genres - corporate annual reports - is the subject of my empirical research on the ongoing institutionalization of CSR. I will follow earlier

77 Although more concerned with the perspective of adopters (and other key actors) involved in the diffusion process, Ansari at al. (2010: 86) point to the very same "intriguing questions regarding the identity of a diffusing practice" and the scarce research existing in this area to date: "If corporate practices are frequently adapted, at what point do they become a different entity and should no longer be thought of as the same practice?" 
work that has outlined central methodological implications (Meyer, 2004) and will highlight the crucial role of communicative practices, starting from the assumption that institution-building processes may be analyzed by tracking discursive traces of theorization activity, modification of meaning, and mobilization of legitimacy. 
"Our stakeholders are informed, mature, and critical. They are not impressionable, neither by glossy brochures nor by the note that our documents are printed on non-chlorine bleached paper. It is the content that matters. Thus, [...] we organized a round table with stakeholders, as it is of importance for us to elaborate on the topics they expect, and not on those that we are fond of communicating. CSR is not a project in the conventional sense but rather an attitude that is worth campaigning for."

Wolfgang Ruttenstorfer, CEO of OMV, Central Europe's leading oil and gas producer and Austria's largest corporation (in: OMV Corporate Social Responsibility Performance Report 2003/2004: 3, December 2005; translation by the author)

\section{Methodology: Tracking discursive traces}

The following pages will expand on methodological considerations and their implications for my empirical research. I will provide insight into the processes of data collection and describe methodical tools (for both data collection and analysis).

\subsection{Empirical design}

\subsubsection{Some basic methodological considerations}

At the methodological level, this study is inspired by, and committed to, a social constructionist view - and its fundamental assumption of an essentially communicative construction of social reality in particular (Berger \& Luckmann, 1967; Luckmann, 2002, 2006). I argue that processes of institutionalization and deinstitutionalization - but also institutions and institutional practices themselves are fundamentally based on language. Also, as Berger and Luckmann (1967: 64) note in their seminal work The Social Construction of Reality, "the edifice of legitimation is built upon language and uses language as its principal instrumentality": Institutionalization occurs due to the establishment of shared definitions of reality among social actors, and it is through linguistic processes that such definitions of reality are constituted, gain legitimacy, and are disseminated (see also Phillips et al., 2004).

A major objective of such a social constructionist perspective is to uncover ways in which individual and collective actors participate in the - inter-subjective creation of their social world and reality. This especially involves investigating ways in which social phenomena are established and subsequently stabilized in a process of habitualization and institutionalization (Berger \& Luckmann, 1967). Social construction of reality is seen as an ongoing and dynamic process formed - not 
only, but primarily - in communicative action (see Luckmann, 2006): Reality is (re-) produced by action as well as by the multiple interpretations of affected actors. Acknowledging the outstanding role of discourse, recent literature (e.g., Keller, 2005; see also Keller, Hirseland, Schneider, \& Viehöver, 2005) refers - alluding to Berger and Luckmann's notion - to the "discursive construction of reality" ${ }^{78}$

It is exactly this "view of rhetoric as involved in all processes of human communication and reality construction" (Watson, 1995: 807) that allows the investigation of meaning and structuring dimensions of meaning. Institutions and institutional practices in social fields, as well as their transformations, are portrayed in discourse and manifested in various forms of text - and are therefore trackable and accessible for research. The analysis of the manifold communicative and discursive traces is thus the foundation upon which meaning is constructed (Meyer, 2004). However, from a methodological point of view, this also makes evident a more general dilemma of humanities and social sciences that is referred to as "double hermeneutic": Not only is knowledge a social product, but the same holds true for the very object of knowledge itself. ${ }^{79}$

Social meanings are closely tied to the socio-historical fields in which they were constructed. The study at hand particularly focuses on the investigation of patterns of dissemination of CSR as well as on the assignment of meaning within the Austrian corporate world. However, the empirical story here is rather complex as an incumbent understanding - or, more precisely, a deeply ingrained logic or Leitidee (Lepsius, 1997) - has already occupied the "territory" of social responsibility when confronted with an Anglo-American "challenger" (see below for more details). Against the backdrop of the questions guiding this research, it became evident that a reconstruction of meaning can only be achieved by also integrating some qualitative elements into the methodology in order to account for field characteristics - yet without compromising the analysis of structures at field level that can only be revealed by a more quantitatively-oriented research design.

All this essentially implies a reconstruction of sense-making/giving, categorization, and theorization activities by corporations when translating the management concept of CSR into the Austrian context. I argue that the managerial/corporate discourse is a crucial element in the institutional and cultural environment of individual business organizations, as it transfers legitimacy to specific ideas and

78 Along these lines, an emerging strand in sociological research makes an attempt at integrating sociology of knowledge (in the tradition of Berger and Luckmann) and discourse analysis (which has been especially influenced by a range of French sociologists and philosophers); see also Meyer (2008).

79 Among others, Giddens (1986: 374) directs our attention to the "intersection of two frames of meaning as a logically necessary part of social science, the meaningful social world as constituted by lay actors and the metalanguages invented by social scientists". In fact, the quote stated at the beginning of this chapter effectively illustrates this point: Alluding to "expected expectations" in the context of CSR, it makes us aware of the many "interpretive filters" that are inherent in such discursive traces - and that need to be considered in research. 
practices - and also describes the prevailing "legitimated vocabularies" (Meyer \& Rowan, 1977: 377). In my research, I am especially interested in the multiple meanings of CSR, including shifts and modifications within discourse over time. The empirical design suggested below is assumed to provide fruitful insights into how corporations, differently or similarly, assign meaning to the notion of CSR and also how they interpret their role within society. At a more macro level, it delineates the legitimate accounts and discursive opportunity structure available to corporate actors to respond to societal expectations.

\subsubsection{Empirical access: Social disclosure in corporations' annual reports}

Empirically, institutions and their underlying Leitidee are never directly accessible (Berger \& Kellner, 1984). Any empirical research on these topics must therefore rely on particular manifestations, which can range from artifacts and practices to the language used. Interested especially in corporations' attempts to mobilize legitimacy in an environment characterized by multiple interests (on rhetorical strategies of legitimacy, see also Suddaby \& Greenwood, 2005), I focus on texts that delineate corporations' verbal interpretation of CSR. As socially assigned meaning must be established through the use of language (Luckmann, 2002, 2006; see above), these texts will allow for the analysis of indications of institutionalization processes.

Annual reports are a central genre of corporate communication that qualify for analysis as they also serves as an important vehicle of issues management and social disclosure (i.e., of corporations' self-perception and identity, self-presentation, and addressing "expected expectations" of stakeholders as well as of wider ethical concerns; see also Cheney \& Christensen, 2001). With respect to the interpretation of new organizational concepts and novel managerial practices, they are an important site of meaning negotiation: They simultaneously serve as a mirror for broader societal discourses and as a stage for the multiple claims of business organizations. However, annual reports are themselves an institutionalized communicative genre or a "communicative institution" (Meyer, 2008: 531; for comments on communicative genres and genre rules, see Knoblauch \& Luckmann, 2004). Annual reports are directed at the public, but unlike mass media or business press, they are directed to a more qualified audience.

Nonetheless, the reasons and backgrounds for reading annual reports may vary greatly. ${ }^{80}$ Annual reports not only cover financial details but elaborate on corporations' relationships with various stakeholders and, therefore, also tackle a variety of

80 The audience includes, but is not limited to such diverse groups as financial analysts, shareholders, investors, banks and creditors, employees and employee interest groups, NGOs, media, customers and suppliers, governmental institutions - especially the state in its regulatory role -, and society in general. 
social and environmental issues. In annual reports, corporations mirror the expectations they assume relevant stakeholders have. Thus, whether followed by actual practices or not, annual reports contain the common basis of beliefs, the "agreed language or currency of discourse about conduct and performance, and the criteria that should be used in assessing them" (Day \& Klein, 1987: 2).

Therefore, in order to empirically reconstruct how corporations account for their social responsibility, I draw on corporations' annual reports, ${ }^{81}$ as they represent the predominant means for "officially" disclosing corporate information and communicating with relevant groups of stakeholders (for an overview, see Hopwood, 1996; Stanton \& Stanton, 2002; see also Fiss \& Zajac, 2004, 2006; de Bakker et al., 2007, among others). Moreover, they are the most significant formal communication a corporation has with its stakeholders (Epstein \& Freedman, 1994), also depicting its responsibility and accountability. ${ }^{82}$ Texts and statements in annual reports are collectively crafted by executive management and communication experts from inside and outside the organization - often a team from within the organization supported by a public relations agency - on behalf of the corporation. As Weber (2005: 230) states, it is "important to note that the actor to which the cultural toolkits in those reports can be attributed is the company and not individual executives. The authors of the text explicitly speak on behalf of an abstract entity, not as their private selves." Therefore, one can expect annual reports to transport "official" interpretations of the concept of CSR in the face of multiple and possibly contradictory claims. These interpretations represent a crucial part of the overall discourse on the role and responsibilities of business.

With regard to their basic structure and content, annual reports are to some extent predetermined by national corporate law (i.e., especially in terms of minimum requirements) or international standards; this implies a rather high degree of

81 Annual reporting documents have been used as a source of information in various earlier studies on social responsibility, social responsiveness, and/or social disclosure practices (e.g., Beresford, 1973, 1974; Bowman \& Haire, 1975, 1976; Ingram, 1978; Abbott \& Monsen, 1979; Anderson \& Frankle, 1980; Trotman \& Bradley, 1981; Cowen, Ferreri, \& Parker, 1987; Vyakarnam, 1992; Tsang, 1998; Abu-Baker \& Naser, 2000; Idowu \& Towler, 2004; Thompson \& Zakaria, 2004; Vuontisjärvi, 2006; Branco \& Rodrigues, 2008; Dawkins \& Ngunjiri, 2008; Tengblad \& Ohlsson, 2010).

82 I do, of course, acknowledge that during the last decade another genre - corporate websites - has joined annual reports in fulfilling this role; nonetheless, annual reports are still a major and dominant genre to disseminate "official" information. An analysis of CSR commitment on corporate websites (e.g., Maignan \& Ralston, 2002; Fukukawa \& Moon, 2004; McMurtrie, 2005; Capriotti \& Moreno, 2007; Basil \& Erlandson, 2008; Paul, 2008) might serve as an alternative or complementary source of data. The main advantage of annual reports - compared to websites - is that they represent time-authentic archival data (see also Ventresca \& Mohr, 2002). A longitudinal study of CSR within the genre of websites is not feasible, mainly due to its young age, the speed and extent of developments in IT (resulting in a lower degree of institutionalization of this communicative genre), and the non-existence of comprehensive archives of websites. 
comparability across corporations and years. In Austria, reporting on CSR was not compulsory within the period of observation; however, as the issuance of standalone CSR reports has also been a rather scarce practice in this empirical setting (see below), financial annual reports are presumed to have been the stage where corporations would make public their commitment to social responsibility - with websites increasingly joining the scene toward the end of the observation period.

However, to draw on annual reports also has some limitations. In Austria, issuing publicly available annual reports is only obligatory for corporations listed on the Vienna Stock Exchange; I am quite aware of the fact that the concept of CSR might appeal to a slightly different set of organizations as well. Changes in reporting practices can further be influenced by new international guidelines and schemes (e.g., by the Global Reporting Initiative GRI) or by a general shift in the development of the genre (see also Hopwood, 1996). Moreover, corporations do not design their annual reports from scratch each year; on the contrary: they strongly rely on their own previous reporting practices and existing templates.

In addition to mere rhetoric, annual reports are also expected to contain some reference to the cognitive level as well as to the level of actual behavior. Beyond argument, the rhetorical claim of being committed to a management policy is not necessarily equal to actual adoption - let alone implementation of the concept as announced. Analyses in the scope of this project can therefore cover the communicative/rhetoric level and capture actual practices only to the extent that they are reflected in corporate reporting. Consequently, the question of decoupling, for instance, cannot be answered on this basis, but, as Meyer (2008: 530) notes, "decoupling and symbolic window-dressing activities, merely rhetorical adoptions of practices, etc. are not necessarily antagonistic to institutions $[\ldots]$. On the contrary, they might point to socially powerful expectations that cannot be neglected." Hence, my research will grasp a very central part of the discourse on the role and responsibilities of business, focusing on one specific voice in this discourse (i.e., the perspective of the corporate world) and stressing its legitimatory efforts.

\subsubsection{Implications for data collection and analysis}

As scholars such as Mohr (1998; Mohr \& White, 2008) point out, the recollection that institutions are essentially meaningful constructs - whose existence, distribution, spread, or change cannot be fully explained unless their social meanings are understood - has resulted in an increasing interest in qualitative methods and interpretive methodologies capable of capturing the underlying structures of meaning. While such micro-level reconstruction of meaning generally builds on hermeneutic procedures (for an overview, see Flick, von Kardoff, \& Steinke, 2004), the mapping of field-level phenomena requires a certain degree of standardization that must go beyond finer differences and individual nuances. In line with Meyer 
and Höllerer (2010), I wish to propose not only the simultaneous use of qualitative and quantitative methods, but rather their integration: It is impossible to understand patterns at field level without reconstructing the underlying web of meaning that unfolds in a research design that in turn substantially incorporates qualitative elements.

The call for combining qualitative and quantitative methods as well as for utilizing multilevel analyses in research in the domain of organizational institutionalism has been echoed by various scholars (e.g., Mohr, 1998; Schneiberg \& Clemens, 2006). In their influential article on institutional work, Lawrence and Suddaby (2006) express their hope that future institutional research will incorporate archival analyses, qualitative field work, and ethnographic observation in combination with quantitative techniques - such as social network analysis and correspondence analysis - in order to capture the substantial cultural and structural embeddedness of institutional work. In a similar vein, Mohr and White (2008) point out that the essence of an institution is precisely that it links the agentic with the structural, the symbolic with the material, and the micro-, meso-, and macro-level of social organization - and that this is what makes the disentangling of institutional processes so complex and challenging (see also Meyer \& Höllerer, 2010).

My study, in its methodological positioning, follows these lines of argument and argues for a combination of quantitative and qualitative methods in the generation of data (e.g., quantitative and qualitative content analysis) and subsequent analyses (e.g., regression models, network analysis, multiple correspondence analysis). I will employ and analyze data in two major steps: First, I will focus on the dissemination of CSR and identify central characteristics of adopters - as well as factors related to their technical and institutional environments - by testing a broad set of hypotheses in various regression models. Second, I will use more qualitative data and exploratory tools of multivariate statistics to gain a better understanding of patterns at field level. Descriptive statistics will be used to consolidate analyses throughout the entire study.

\subsection{Data and methods}

\subsubsection{Sample and collection of empirical material}

The empirical sample for this study consists of the entire population of Austrian publicly-traded $^{83}$ corporations (defined as those having their corporate headquarters

83 In German-speaking countries like Austria and Germany, publicly-traded corporations are referred to as börsennotierte Aktiengesellschaften. I prefer the term "publicly-traded corporation" over "public corporation" in order to avoid confusion, as the latter is used to denote both corporations listed on a stock exchange and state-owned businesses; alternatively, one might refer to publicly-traded corporations as "listed corporations". 
in Austria) listed within the equity segment either on the Vienna Stock Exchange or on any major foreign stock exchange. In order to build my dataset, I collected information on these corporations covering an observation period from 1990 through $2005 .{ }^{84}$ I opted for a longitudinal design of data - comprising a total of 16 years - in order to capture dynamics over time and to adequately account for changing external and internal parameters.

The list of corporations was drawn from the yearly statistics of the Vienna Stock Exchange, from annual handbooks, and published listings throughout the observation period. ${ }^{85}$ All publicly-traded corporations per year ${ }^{86}$ are represented which does not necessarily entail the same cohort of corporations over the whole observation period: Over time, the set and number of corporations per year vary due to some corporations going public during the observation period, and others going private or being delisted due to mergers, takeovers, bankruptcy, or other reasons. ${ }^{87}$

The unit of analysis is the fiscal year of the corporation; all variables are measured for each corporation - exceptions are, obviously, field-level variables for each year. ${ }^{88}$ In total, the sample comprises 1,636 observations (i.e., annual reports) retrieved from 179 different corporations. The average number of corporations included per year is 102 with 30 corporations having been observed throughout the entire observation period. Measurement points per year range from 87 to $113($ mean $=102.3)$, measurement points per corporation range from 1 to 16 (mean $=9.1)$. In the event of missing values in any of the variables used for

84 Such an observation period seems appropriate given that the vocabulary of explicit CSR emerged in the German-speaking corporate world only recently and not prior to the early 1990s (see also Matten \& Moon, 2008).

85 Specifically, data sources for sampling decisions comprised the Vienna Stock Exchange's yearly statistics for cash and derivatives market, the Wiener Börse Jahrbücher published by $\ddot{O} V F A$, and listings published in the economy and finance section of the two most important Austrian quality newspapers - Die Presse and der Standard - with information based, varying over time, on data from Reuters, APA Austria Press Agency, and TeleTrader. While not all of these sources were accessible for the entire observation period, at least two sources were available for each year.

86 Observations from corporations that filed for bankruptcy in a specific year (and therefore were suspended from trading) were excluded from my sample; the same applies to corporations listed for a period of less than one year. Nor was I able to include observations from corporations that had not published an annual report due to a pending merger or due to their removal from listings for other reasons.

87 I am well aware of the fact that longitudinal data from an unbalanced panel has implications. Although these should ultimately be dealt with in a statistically appropriate manner, I see considerable advantages in using the whole population that represents the entire discourse in the field over drawing a random sample.

88 In cases in which the fiscal year and calendar year did not correspond, a simple rule was applied: For fiscal years ending in the first quarter of a calendar year, the previous year was ascribed; otherwise, the current year was assigned. 
individual regression models or other analyses, I conducted list-wise deletion (yet present pair-wise correlation coefficients in the descriptive statistics). All variables employed in the study as well as their operationalization, measurement, and relevant data sources used are presented in greater detail below.

An initial task for the data collection process, one that indeed enabled this study, was to assemble a complete collection of annual reports of Austrian publiclytraded corporations for the entire observation period. Annual reports were gathered from corporations in 2005 (mostly in hard copy, as publicly available electronic versions were not typically available at that time) as well as in a follow-up in early 2007; some missing documents could also be obtained from the archives of the Vienna Stock Exchange and the Austrian National Library. ${ }^{89}$ In a second step, I collected a wide range of data on corporate characteristics as well as a variety of institutional and context factors by analyzing the content of annual reports and examining various databases. In a third step, discursive traces of CSR were detected within the texts by coding for specific CSR issue markers throughout all annual reports (see below for details). Finally, a more qualitative approach examined the text fragments forming around CSR issue markers, yielding important data for the reconstruction of meaning.

\subsubsection{Generating data: Archival research and content analysis}

Corporations' annual financial reports constitute a rich mine of information for the purpose of my study. ${ }^{90}$ I extracted data on corporations' commitment to, and interpretation of, the concept of CSR as well as more basic data on individual corporations (e.g., financial data, ownership structures) by way of quantitative and qualitative content analyses (for an overview on content analysis see Früh, 2004; Krippendorf, 2004, among others). For variables not covered in annual reports, other sources were used (for all sources, see below). Since annual reports are written in the year following the events they report on, there is a natural lag present within the data; to account for this phenomenon, the study refrains from additionally lagging any variable.

In conducting content analyses, it is necessary to distinguish between coding procedures at the level of the entire annual report (e.g., for a focal corporation's commitment to CSR in a specific year) and at the level of text fragments (e.g., for reference to actors or thematic embeddings in the immediate context of CSR). A text fragment is defined as a set of related sentences - for instance, sentences connected

89 I am grateful for the generous help of these institutions in completing my sample. I also wish to thank Otto Janschek from WU Vienna University of Economics and Business for allowing access his personal collection of annual reports.

90 The existence of annual stand-alone CSR or sustainability reports was recorded, but not considered any further (primarily in order to maintain comparability among the sample).

Markus A. Höllerer - 978-3-653-01464-8 
by a causal relation - that forms around one or several CSR issue markers. Here, it is important to note that although data coding took place within identified text fragments for some variables, the unit of analysis is - for each and every variable the annual report (i.e., the fiscal year); this, in turn, warranted the aggregation of data to some extent.

\subsubsection{Dependent variable(s): Commitment to CSR}

Coding for commitment to CSR - the dependent variable - represented the most crucial step, as this variable was subsequently used to select passages in annual reports for more in-depth analyses.

In short, in a first step, I developed a hierarchically structured dictionary of phrases that identify the concept of CSR (see also Table 4) and indicate the presence of a coding category: From the academic and scholarly debate (see above) I derived various hyponyms that work as markers or labels for the issue of CSR. In written text, they occur in the form of specific verbal codes and explicit vocabulary. ${ }^{91}$ I tested the approach for a random sample of annual reports and made only minor adjustments (primarily due to unconventional wording or translation into German language). In a second step - and with the assistance of two trained coders $^{92}$ - I worked through all annual reports of the sample, each coding statements that indicated corporations' espousal of a CSR orientation according to the dictionary of phrases; for the later years, the procedure was supported by a full-text search of annual reports available in electronic format. ${ }^{93}$ As I followed a rather conservative approach - i.e., included only those statements that relate to the specified verbal codes listed in the dictionary - and the additional coders were provided with clear instructions, the coding scheme contained very little ambiguity and thus resulted in high inter-coder reliability. Differences between the coders almost exclusively resulted from passages in the text being overlooked in the manual search. However, all cases of disagreement were reviewed and resolved. In total, I measure 259 annual reports that feature corporations' commitment to CSR through the use of issue markers.

91 I refer to these as "issue markers" (see also Donati, 1992; Meyer, 2004; for literature on "issue", "issue culture", and "issue field" see Gamson, 1992; McAdam et al., 1996; Hoffman, 1999; Meyer \& Höllerer, 2010, among others).

92 All coders were German native speakers with an educational background in social and economic sciences.

93 The methodology applied captures text around specific issue markers in any part of the annual reports - also including, for instance, the cover, blurb, preface, and glossary. 


\begin{tabular}{lll}
\hline $\begin{array}{l}\text { Dependent } \\
\text { variable(s) }\end{array}$ & Operationalization & Measurement and data sources \\
\hline $\begin{array}{l}\text { Commitment to } \\
\text { CSR (or CSR sub- } \\
\text { discourse) }\end{array}$ & $\begin{array}{l}\text { Content analysis of annual reports, coding for } \\
\text { specific CSR issue markers (i.e., verbal codes) }\end{array}$ & $\begin{array}{l}\text { Binary measure (0/1 = not } \\
\text { existing/existing) } \\
\text { Source: Annual reports }\end{array}$ \\
\hline
\end{tabular}

Table 3: Dependent variable(s): Operationalization, measurement, and data sources

The dependent variable (Table 3) was constructed as a binary measure set one if a corporation espoused commitment to the concept of CSR in the respective annual report, and zero otherwise. More precisely, while I used an aggregated variable comprising all groups of issue markers (e.g., for regression models), individual conceptual sub-discourses (i.e., groups of issue markers) were retained in separate codes to allow for further analysis later on.

Although the cluster-concept of CSR is characterized by a variety of terms and contested definitions, my literature review (see chapter on CSR above) suggested that a set of six sub-discourses accurately captures the overall CSR discourse. In more detail, this set comprises (a) the Anglo-American terminology of CSR: a label that is homonymic with the overall issue/discourse; (b) sustainability and its German translation; ${ }^{94}$ (c) corporate citizenship, yet another Anglo-American sub-discourse emphasizing the political dimension of corporate responsibility; (d) CSR indicators \& standards, comprising a variety of social performance standards used to anchor and foster corporations' commitment to CSR by linking up with national and international standards, best-practice models, and more abstract guidelines issued by legitimate standard setters; (e) explicit reference to multiple stakeholders and a stakeholder approach in corporate governance; and finally, (f) Germanizations: German equivalents of CSR and CC. ${ }^{95}$ The coding scheme is laid out in Table 4 below.

94 As corporations have used the English and German terminology of sustainability rather jointly and synonymously ever since, I refrained from coding differences in language separately.

95 German translations of CSR and CC are coded separately, as they might be used in different ways than the English terms. Even more importantly, the German wording has existed for decades, but has not been explicitly used in corporate communication. Although I expect a considerable shift in meaning since the Anglo-American concepts were introduced in the Austrian business world, I nonetheless assume Germanizations to remain somehow linked to a more indigenous institutional logic of responsibility of business. 


\begin{tabular}{|c|c|}
\hline $\begin{array}{l}\text { Conceptual CSR } \\
\text { sub-discourses }\end{array}$ & Examples of text coded for (all semantic variations) \\
\hline CSR & $\begin{array}{l}\text { Corporate (social) responsibility, corporate responsibility, CSR, corporate } \\
\text { social accountability, responsible corporation, corporate social } \\
\text { responsiveness, ... }\end{array}$ \\
\hline Sustainability & $\begin{array}{l}\text { Sustainability, corporate sustainability, sustainable development, } \\
\text { Nachhaltigkeit, nachhaltiges Wirtschaften, nachhaltige } \\
\text { Unternehmensführung, ... }\end{array}$ \\
\hline CC & Corporate citizenship, corporate citizen, $\mathrm{CC}, \ldots$ \\
\hline CSR indicators \& standards & $\begin{array}{l}\text { Social performance indicators; SA } 8000 \text {, AA1000, ISO 26000; UN Global } \\
\text { Compact, GRI, EU Green Paper, CSR Europe, respACT austria; various } \\
\text { sustainability indices and ethical investment funds, ... }\end{array}$ \\
\hline Stakeholder approach & Stakeholder, Anspruchsgruppe(n), ... \\
\hline Germanizations & $\begin{array}{l}\text { Gesellschaftliche/soziale Verantwortung, gesellschaftliches/soziales } \\
\text { Engagement (von Unternehmen), verantwortungsvolle } \\
\text { Unternehmensführung, Unternehmen als guter Bürger, ... }\end{array}$ \\
\hline
\end{tabular}

Table 4: Conceptual CSR sub-discourses: A structured dictionary of phrases and codes

It may be interesting to note that (good) corporate governance has not been included in this coding scheme, notwithstanding some extremely important conduits: Focusing on a principal-agent model of shareholder-management relations, and integrating issues that resonate more with the concept of shareholder value, it might refer to yet another discourse (see also OECD, 2004). ${ }^{96}$ A similar point holds true for the environmental discourse: Statements referring to environmental concerns are captured only insofar as they - via constructs as the TBL (e.g., Elkington, 1999) - address sustainability issues. ${ }^{97}$

\subsubsection{Independent and control variables used in regression models}

A multiplicity of variables ${ }^{98}$ related to the focal corporation, institutional context, reporting year, and/or annual report has been added to my dataset and employed as independent or control variables for regression modeling (as well as for various other analyses). While the relevance of each variable is argued in detail in the

96 Good corporate governance that explicitly addresses the balancing of multiple stakeholder interests is, however, indirectly captured by stakeholder approach. Also, Germanizations might include some terminology broadly alluding to good governance (verantwortungsvolle Unternehmensfübrung, among others).

97 The decision not to include the environmental discourse is also corroborated by empirical evidence: For instance, some stand-alone environmental reports issued by corporations completely eschew the term "responsibility" or its German equivalents.

98 Not all variables are applicable within the confines of this study. Nonetheless, many of them were of importance while specifying and testing first statistical models. In the following, I will only report on the ones actually used. 
hypotheses for regression models (see below), their "technical construction" is of interest here. For each variable, Table 5 and Table 6 describe operationalization, measurement, and data sources.

Control variables. To control for the level of economic activity and development, I used the development of the Austrian Traded Index (ATX) as a proxy. Data were retrieved from statistics of the Vienna Stock Exchange; the year 1990 constitutes the origin with 1,000 index points. Leverage is a first indicator of a corporation's financial situation - and especially reliance on capital market financing: Processing data from the financial statements in annual reports, it was constructed as the debtequity ratio. The involvement of public relations agencies is measured as a binary variable set one in cases where the annual report was co-edited by one of the "big players" from the Austrian PR industry. More precisely, a public relations agency is defined as a major player if it supports at least five different corporations in the sample. Data were recorded by analyzing the publishing information in corporations' annual reports. The variable timeline is introduced as a year-count variable (since the observations begin in 1990) based on the fiscal year of the annual report. Table 5 presents an overview of control variables.

\begin{tabular}{|c|c|c|}
\hline $\begin{array}{l}\text { Control } \\
\text { variables }\end{array}$ & Operationalization & Measurement and data sources \\
\hline $\begin{array}{l}\text { Economic activity } \\
\text { and development }\end{array}$ & $\begin{array}{l}\text { Development of the Austrian Traded Index } \\
\text { (ATX) }\end{array}$ & $\begin{array}{l}\text { Index points ( } 1990=1,000 \text { index } \\
\text { points as the origin) } \\
\text { Source: Statistics of the Vienna Stock } \\
\text { Exchange }\end{array}$ \\
\hline Leverage & Debt to equity ratio & $\begin{array}{l}\text { Debt / equity } \\
\text { Source: Financial statements in } \\
\text { annual reports }\end{array}$ \\
\hline $\begin{array}{l}\text { Public relations } \\
\text { agencies }\end{array}$ & $\begin{array}{l}\text { Annual report co-edited by a major PR agency } \\
\text { in the field (defined as one supporting at least } \\
\text { five different corporations among the sample) }\end{array}$ & $\begin{array}{l}\text { Binary measure }(0 / 1=\text { no/yes }) \\
\text { Source: Publishing information in } \\
\text { annual reports }\end{array}$ \\
\hline Timeline & $\begin{array}{l}\text { Year-count based on fiscal year of annual } \\
\text { report }\end{array}$ & $\begin{array}{l}\text { In (number of years since start of } \\
\text { observation) } \\
\text { Source: Annual reports }\end{array}$ \\
\hline
\end{tabular}

Table 5: Control variables: Operationalization, measurement, and data sources

Independent variables. I prefer to measure firm size in terms of staff (i.e., number of employees) over sales in order to account for the sociopolitical perspective that is relevant for my research. Where available, I collected data directly from the annual reports; as a backup and to avoid a large number of missing values, I also utilized the Wiener Börse Jahrbücher - annual publications issued by the Austrian Association for Financial Analysis and Asset Management - as well as the AURELIA database (managed by Bureau van Dijk Publishing). ${ }^{99}$ Firm age is a year-count variable based

99 Wiener Börse Jahrbücher, AURELIA database, and AlacraStore.com were also used to gather data for other variables; see Table 6. 
on the year of foundation; where available, information from annual reports was used, otherwise I consulted profiles (company snapshots) retrieved from the AlacraStore.com website. Profitability can be measured in various ways. For this research, I decided to refer to return on assets (ROA) to account for invested capital: The variable is constructed as earnings before tax (EBT) to total assets ratio, processing data from the financial statements in annual reports. Concentrated (private) ownership is defined as an individual investor directly holding more than $25.0 \%$ of shares, which - according to the Aktiengesetz. (Austrian Stock Corporation Act) - entitles this shareholder to veto rights in a number of governance issues. ${ }^{100}$ Public sector influence is constructed by taking direct and indirect blockholdings (more than $25.0 \%$ of shares) by public bodies into consideration. I gathered data with regard to corporations' listing on a foreign stock exchange and listing on the Austrian Traded Index (ATX) by examining statistics of the Vienna Stock Exchange and various foreign stock exchanges and by consulting listings issued by capital market information providers reproduced in pertinent print media (see also footnote 85). Relative importance of workforce is constructed as a labor (number of employees) to capital (total assets) ratio. High impact industries are based on the primary SIC code assigned to a corporation (see Table 6 for more).

In order to depict visibility and cultural resonance of the issue in the local context, I also employ media-related variables. My data stem from the two most widely read Austrian quality newspapers ${ }^{101}$ that I expect - both being published on a daily basis nationwide - to also have inter-media agenda setting functions. All data were extracted from a full-text media archive. ${ }^{102}$ Following Wartick (1992: 34), who defines media exposure as "the aggregated news reports relating to a specific company within a prescribed period", I measured visibility of the corporation in the media as the total number of articles mentioning a specific corporation. To operationalize CSR in the media discourse, I combined two factors: volume and tenor of media coverage. First, I determined the volume of media coverage as the total number of articles referring to the new umbrella label of CSR. Second, to assess the evaluative tenor of the public debate in the media, I followed previous work by Deephouse (1996, 2000; Deephouse \& Carter, 2005), Pollock and Rindova (2003), Bansal and Clelland (2004), and others and used the Janis-Fadner coefficient of imbalance (Janis \& Fadner, 1965). ${ }^{103}$ For this purpose, full-text articles referring to

100 Blockholdings by public bodies, however, were not considered here but are covered by the next variable.

101 These are Die Presse, a conservative paper with a long tradition, and der Standard, although founded only in 1988, as its left-liberal counterpart.

102 I wish to express my appreciation for the free-of-charge access to Austria Press Agency's APA DeFacto full-text media archive.

103 This measure ranges from -1.0 (all negative coverage) to 1.0 (all positive coverage) and is calculated by using the following formula to process the number of positive, neutral, and negative articles: 
CSR were coded as positive, negative, or neutral by a team of two coders. ${ }^{104}$ All inter-coder disagreements were discussed and completely resolved. Nonetheless, I randomly selected $10.0 \%$ of the articles and conducted an inter-coder reliability check; the results of which indicate a high level of inter-coder agreement $(90.9 \%$ agreement, Cohen's $\kappa=0.841){ }^{105}$

In order to measure prevalence of CSR among model corporations in $t_{-1} \mathrm{I}$ suggest that highly visible corporations in the field qualify as particularly relevant models for other organizations. ${ }^{106}$ Commitment to CSR in $t_{-1}$ is based on the dependent variable in the previous year. Also, reference to corporate governance is constructed in the same way as the dependent variable (i.e., by coding for the issue marker "corporate governance"). Table 6 presents an overview of all independent variables.

$\frac{\left(\text { positive }{ }^{2}-\text { positive } * \text { negative }\right)}{(\text { positive }+ \text { neutral }+ \text { negative })^{2}}$ if positive $>$ negative

$\frac{\left(\text { positive } * \text { negative }- \text { negative }{ }^{2}\right)}{(\text { positive }+ \text { neutral }+ \text { negative })^{2}}$ if negative $>$ positive

104 A neutral rating was given when evaluative qualifiers were missing in an article or if the positive and negative aspects were roughly in balance.

105 Generally, a Cohen's $\kappa$ larger than 0.7 is considered satisfactory (Lauf, 2001; Früh, 2004; StataCorp LP, 2007a); see also the comments on the kappa command in STATA 10 (StataCorp LP, 2007a).

106 In greater detail, this variable is operationalized as the percentage of the most visible corporations nationwide - the largest corporations in terms of sales and those included in the ATX - espousing commitment to CSR in the previous year. 


\begin{tabular}{|c|c|c|}
\hline $\begin{array}{l}\text { Independent } \\
\text { variables }\end{array}$ & Operationalization & Measurement and data source \\
\hline Firm size & Number of employees & $\begin{array}{l}\text { In (number of employees); } \\
\text { Sources: Annual reports; Wiener } \\
\text { Börse Jahrbücher; AURELIA database }\end{array}$ \\
\hline Firm age & Year-count based on year of foundation & $\begin{array}{l}\text { In (number of years) } \\
\text { Source: Annual reports; } \\
\text { http://www.alacrastore.com } \\
\end{array}$ \\
\hline Profitability & Return on assets (ROA) & $\begin{array}{l}\text { Earnings before tax / total assets } \\
\text { Source: Financial statements in } \\
\text { annual reports }\end{array}$ \\
\hline $\begin{array}{l}\text { Concentrated } \\
\text { (private) ownership }\end{array}$ & $\begin{array}{l}\text { Direct blockholdings ( }>25.0 \% \text { ), with } \\
\text { blockholdings by public bodies excluded }\end{array}$ & $\begin{array}{l}\text { Binary measure }(0 / 1=\text { no/yes }) \\
\text { Sources: Annual reports; Wiener } \\
\text { Börse Jahrbücher; AURELIA database }\end{array}$ \\
\hline $\begin{array}{l}\text { Public sector } \\
\text { influence }\end{array}$ & $\begin{array}{l}\text { Direct or indirect blockholdings ( }>25.0 \% \text { ) by } \\
\text { public bodies }\end{array}$ & $\begin{array}{l}\text { Binary measure }(0 / 1=\text { no/yes }) \\
\text { Sources: Annual reports; Wiener } \\
\text { Börse Jahrbücher; AURELIA database }\end{array}$ \\
\hline $\begin{array}{l}\text { Listing on a foreign } \\
\text { stock exchange }\end{array}$ & $\begin{array}{l}\text { Additional or exclusive listing on any of the } \\
\text { major foreign stock exchanges (e.g., New } \\
\text { York, London, Frankfurt, Zürich) }\end{array}$ & $\begin{array}{l}\text { Binary measure }(0 / 1=\text { no/yes }) \\
\text { Sources: Statistics of various } \\
\text { international stock exchanges, same } \\
\text { sources as used for sampling }\end{array}$ \\
\hline $\begin{array}{l}\text { Listing on the } \\
\text { Austrian Traded } \\
\text { Index (ATX) }\end{array}$ & Listing on the Austrian Traded Index (ATX) & $\begin{array}{l}\text { Binary measure }(0 / 1=\text { no/yes }) \\
\text { Sources: Statistics of the Vienna } \\
\text { Stock Exchange, same sources as } \\
\text { used for sampling }\end{array}$ \\
\hline $\begin{array}{l}\text { Relative importance } \\
\text { of workforce }\end{array}$ & Labor to capital ratio & $\begin{array}{l}\text { In (number of employees / total } \\
\text { assets) } \\
\text { Source: Annual reports; } \\
\text { http://www.alacrastore.com }\end{array}$ \\
\hline $\begin{array}{l}\text { High impact } \\
\text { industries }\end{array}$ & $\begin{array}{l}\text { Main business within the following industries: } \\
\text { mining, oil; textile, wood, paper, and allied } \\
\text { products; chemicals, plastic, leather, and } \\
\text { allied products; electricity, gas, sanitary }\end{array}$ & $\begin{array}{l}\text { Binary measure }(0 / 1=\text { no/yes }) \\
\text { Source: Based on SIC codes from } \\
\text { http://www.alacrastore.com }\end{array}$ \\
\hline $\begin{array}{l}\text { Visibility of the } \\
\text { corporation } \\
\text { in the media }\end{array}$ & $\begin{array}{l}\text { Number of articles mentioning the focal } \\
\text { corporation }\end{array}$ & $\begin{array}{l}\text { In (number of articles) } \\
\text { Source: Die Presse and der Standard } \\
\text { in APA DeFacto }\end{array}$ \\
\hline $\begin{array}{l}\text { CSR in the } \\
\text { media discourse }\end{array}$ & $\begin{array}{l}\text { Volume and tenor of media coverage of CSR in } \\
\text { quality press }\end{array}$ & $\begin{array}{l}\text { In (number of articles) * Janis- } \\
\text { Fadner coefficient of imbalance * } \\
1000 \\
\text { Source: Die Presse and der Standard } \\
\text { in APA DeFacto }\end{array}$ \\
\hline $\begin{array}{l}\text { Prevalence of CSR } \\
\text { among model } \\
\text { corporations in } t_{-1}\end{array}$ & $\begin{array}{l}\text { Percentage of most visible corporations } \\
\text { nation-wide (top } 10 \% \text { in terms of sales or } \\
\text { those included in the ATX) espousing } \\
\text { commitment to CSR in the previous year's } \\
\text { annual report }\end{array}$ & $\begin{array}{l}\text { Percentage of publicly-traded } \\
\text { corporations indicating commitment } \\
\text { in } \mathrm{t}_{-1} \\
\text { Source: Annual reports, see above }\end{array}$ \\
\hline $\begin{array}{l}\text { Commitment to } \\
\text { CSR in } t_{-1}\end{array}$ & Commitment to CSR in the previous year & $\begin{array}{l}\text { Binary measure }(0 / 1=\text { no/yes }) \text {, } \\
\text { equals the value in } t_{-1} \\
\text { Source: Annual reports, see above }\end{array}$ \\
\hline $\begin{array}{l}\text { Reference to } \\
\text { corporate } \\
\text { governance }\end{array}$ & $\begin{array}{l}\text { Content analysis of annual reports, coding for } \\
\text { specific issue markers (i.e., for the verbal code } \\
\text { of corporate governance in all semantic } \\
\text { variations) }\end{array}$ & $\begin{array}{l}\text { Binary measure }(0 / 1=\text { not } \\
\text { existing/existing) } \\
\text { Source: Annual reports }\end{array}$ \\
\hline
\end{tabular}

Table 6: Independent variables: Operationalization, measurement, and data sources 


\subsubsection{Other variables used}

In addition to this set of more or less standard variables for an institutionally inspired investigation of the dissemination of CSR, and in order to track theorization activity, I examined CSR issue markers - as well as the discursive context in which they are embedded - in greater detail (see Table 7). ${ }^{107}$ Data on the dependent variable are organized in a way that allows for an exploratory analysis of the structuring dimensions of discourse. To facilitate insights on dynamics over time, especially as it is not feasible to present individual "snapshots" for all 16 years, I introduced distinct time periods: A first period covers the early years of the concept (1990 through 2000) until a series of fraud and financial scandals shocked the global and Austrian business community alike around the turn of the millennium; these events also sparked a broad public debate on how to best prevent corporate malfeasance. In this sense, a second period covers the years from 2001 through $2005{ }^{108}$ These two periods will also be applied to "split" the full model in regression analysis and thus account for time-related effects.

I will also contrast the dissemination of CSR in annual reports with CSR media coverage (i.e., dissemination of CSR in print media). Unlike the more evaluative variables used above that take into account the inter-media agenda setting function, this variable was operationalized as the number of articles on CSR and its equivalents in German covering quality press and tabloids alike. ${ }^{109}$

Obviously, there is a considerable difference between mentioning CSR in only one line and reporting at some length on several occasions throughout an annual report. I considered this in two ways: first, by exploring the level of text in annual reports in which I recorded the occurrence of CSR issue markers, thereby also taking into account features of text superstructure (see van Dijk, 1980); and second, by assessing the extent of reporting on CSR issues (operationalized as a relative line count). ${ }^{110}$

107 To control for general trends in reporting activities of corporations over time, the original data also cover - at the level of the annual report - characteristics like extent (e.g., number of pages, or share of the "narrative" part of the report), layout features (e.g., use of visualization, "general glossiness", or homogeneity of text layout), and comprehensive publishing information (e.g., detailed information on the involvement of internal organizational units and of public relations/graphic design agencies in drafting/producing the report). While these data contributed to a better overall understanding of the development of the communicative genre, not all were used for analytical purposes within this study.

108 In addition, for some analyses, I will single out the last year of observation (2005) to highlight the most recent trends within the sample and data.

109 I am able to draw on data collected by one of my students in the course of her master thesis.

110 The extent of reporting is measured as the proportion of space of the annual report devoted to CSR issues, based on a line count of all respective text fragments within the annual report. The total number of pages, the average number of lines per page, and the amount of space assigned to the annual statement of accounts were considered here in order to standardize between divergent formats and layouts. A low extent of reporting was recorded if less than 
The last three variables in Table 7 constitute the core of the more qualitative part of this study; all point at the framing of CSR, and provide first answers to the question "CSR is about ...". In order to track such sense-making/giving, (bottomup) theorization, and/or translation activity, I coded for anchorage in annual report sections, for reference to relevant stakeholders and other societal actors (both as subjects and objects of CSR), and - as primary "framing cues" - for thematic embeddings of CSR issue markers. For each variable of interest, a coding scheme was developed inductively from the texts (see below for details). ${ }^{111}$

\begin{tabular}{|c|c|c|}
\hline Variables & Operationalization & Measurement and data source \\
\hline Time periods & $\begin{array}{l}1990-2000 \text { versus } 2001-2005 \text { based on the } \\
\text { fiscal year of annual report; for some analyses } \\
\text { the last year } 2005 \text { is singled out }\end{array}$ & $\begin{array}{l}\text { Categorical measure } \\
\text { Source: Annual reports }\end{array}$ \\
\hline CSR media coverage & $\begin{array}{l}\text { Number of articles in the most important } \\
\text { Austrian quality press and tabloids } \\
\text { mentioning the issue of CSR }\end{array}$ & $\begin{array}{l}\text { Number of articles } \\
\text { Source: Die Presse, der Standard, } \\
\text { Kurier, and Kronen Zeitung in APA } \\
\text { DeFacto }\end{array}$ \\
\hline Level of text & $\begin{array}{l}\text { Anchoring at the level of plain text, lead, title } \\
\text { (of a section), preface, or cover/blurb }\end{array}$ & $\begin{array}{l}\text { Categorical measure } \\
\text { Source: Annual reports }\end{array}$ \\
\hline $\begin{array}{l}\text { Extent of } \\
\text { reporting }\end{array}$ & $\begin{array}{l}\text { Low }(<1.0 \% \text { of space available in annual } \\
\text { report used for reporting on CSR issues), } \\
\text { medium (between } 1.0 \% \text { and } 3.0 \%) \text {, or high } \\
(>3.0 \%)\end{array}$ & $\begin{array}{l}\text { Categorical measure } \\
\text { Source: Annual reports }\end{array}$ \\
\hline $\begin{array}{l}\text { Annual report } \\
\text { sections }\end{array}$ & $\begin{array}{l}\text { Main sections of a standard annual report in } \\
\text { Austria (inductively developed from the } \\
\text { documents; see below for details) }\end{array}$ & $\begin{array}{l}\text { Categorical measure } \\
\text { Source: Annual reports }\end{array}$ \\
\hline Actors & $\begin{array}{l}\text { Categories of actors referred to in the } \\
\text { immediate context of CSR, i.e., within } \\
\text { identified text fragments (inductively } \\
\text { developed; see below for details) }\end{array}$ & $\begin{array}{l}\text { Categorical measure } \\
\text { Source: Annual reports }\end{array}$ \\
\hline $\begin{array}{l}\text { Thematic } \\
\text { embeddings }\end{array}$ & $\begin{array}{l}\text { Categories of thematic embeddings in the } \\
\text { immediate context of CSR, i.e., within } \\
\text { identified text fragments (inductively } \\
\text { developed; see below for details) }\end{array}$ & $\begin{array}{l}\text { Categorical measure } \\
\text { Source: Annual reports }\end{array}$ \\
\hline
\end{tabular}

Table 7: Other variables used: Operationalization, measurement, and data sources

A first approximation toward the thematic context - at annual report level - can be achieved by investigating the anchorage of CSR issue markers in the divergent sections of a "standard" annual report in Austria - i.e., to some extent, also the placement of the issue on the corporation's agenda (for instance, CSR primarily concerning investor relations, human resource management, or as a mere add-on). Categories were inductively developed from the texts; Table 8 below presents an

$1.0 \%$ of text referred to CSR issues, a high extent in the case of more than $3.0 \%$; a medium extent was coded for those in between.

111 For some categories, clustering seemed appropriate to enable more dense categories and proper analysis without compromising accuracy in details. 
overview of categories and section and sub-section titles ${ }^{112}$ that contributed to their creation.

\begin{tabular}{|c|c|}
\hline Report sections & Section titles included (plus variations) \\
\hline Preface & $\begin{array}{l}\text { Vorwort des Vorstandes, Vorwort des Aufsichtsrates, Interview mit dem } \\
\text { CEO, sonstiges Vorwort, Gastkommentar }\end{array}$ \\
\hline Presentation of the corporation & $\begin{array}{l}\text { Mission statement, Leitbild, Unternehmensportrait, Ziele des } \\
\text { Unternehmens, Unternehmensphilosophie, Organisationsstruktur, } \\
\text { Geschäftsbereiche, Darstellung von Produkten und Märkten }\end{array}$ \\
\hline Strategy & $\begin{array}{l}\text { Strategie, Geschäftspolitik, business policy, Analyse des } \\
\text { Unternehmensumfeldes }\end{array}$ \\
\hline Review of operations & $\begin{array}{l}\text { Lagebericht, Analyse des Geschäftsverlaufs, Geschäftsergebnis, } \\
\text { Finanzübersicht (Vermögens-, Finanz- und Ertragslage), Ausblick, } \\
\text { Prognosebericht }\end{array}$ \\
\hline Investor relations & $\begin{array}{l}\text { Investor relations, Aktie, Beteiligungsverhältnisse, shareholder value, } \\
\text { value management }\end{array}$ \\
\hline Corporate governance & Corporate governance \\
\hline Human resources & Human resources, Mitarbeiter, Sozialreport \\
\hline Sustainability, environment, CSR & $\begin{array}{l}\text { Nachhaltigkeit, sustainability, Umwelt, corporate social responsibility, } \\
\text { Verantwortung, corporate citizenship }\end{array}$ \\
\hline Other functional areas & $\begin{array}{l}\text { Forschung \& Entwicklung, Produktion, Organisation, supply chain } \\
\text { management, Marketing und Verkauf/Vertrieb, Investitionen, } \\
\text { Risikomanagement, IT management, Unternehmenskommunikation }\end{array}$ \\
\hline Annual accounts & $\begin{array}{l}\text { Bilanz, Gewinn- und Verlustrechnung, cash flow statement, } \\
\text { Segmentberichterstattung, Anhang und Erläuterungen, Bericht des } \\
\text { Aufsichtsrates, Bestätigungsvermerk }\end{array}$ \\
\hline Key indicators & Kennzahlen, Leistungsindikatoren \\
\hline Glossary & Glossar \\
\hline Special placements & Other special placements (e.g., cover page, blurb, insert) \\
\hline
\end{tabular}

Table 8: Report sections: Construction of variable

Interested in the reference to societal actors and constituents (for a detailed discussion, see chapters on findings below), I examined the immediate context of CSR issue markers (i.e., identified text fragments). The individual categories of the variable actors subsume various closely related lexical labels (see Table 9): I initially ended up with a total of over 50 actor categories which I, in a second step, clustered into 27 object categories and 4 subject categories for further analysis. Note that the unit of analysis is the individual annual report; in this respect, data from different text fragments are aggregated.

112 Only those section and sub-section titles that were also included in the table of contents of the annual report qualified for analysis. 


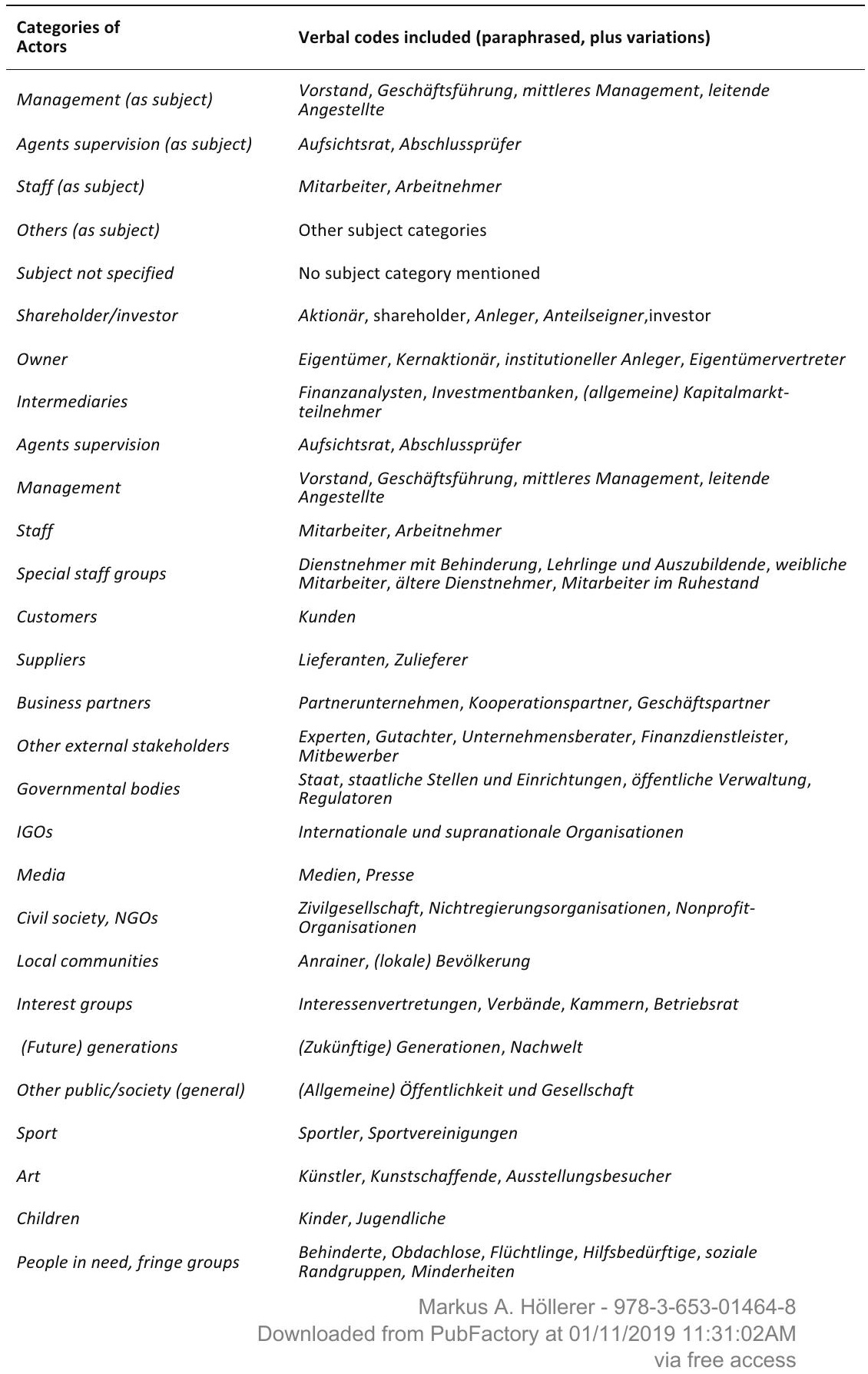




$\begin{array}{ll}\begin{array}{l}\text { People third world/crisis context } \\ \text { Education, universities, research }\end{array} & \text { Bildungseinrichtungen, Schulen, Universitäten, Forschungseinrichtungen } \\ \text { Other supported groups } & \text { Sonstige förderungswürdige Akteursgruppen } \\ \text { Stakeholder (general) } & \text { Stakeholder, Anspruchsgruppen } \\ \text { Object not specified } & \text { No object category mentioned }\end{array}$

Table 9: Categories of actors: Construction of variable

In essence, the same procedure was applied to the topic codes, resulting in 18 distinct categories of thematic embeddings (see Table 10).

\author{
Categories of \\ thematic embeddings \\ Statements included (paraphrased, plus variations) \\ Role and values \\ Mission/self-image \\ Strategy \\ Management concept/instrument \\ Indicators, controls, internal \\ standards \\ Financial/management \\ accounting \\ Value chain, primary activities \\ Economic responsibility \\ Transparency \\ Gesellschaftliche Verantwortung als Unternehmen, soziale \\ Verpflichtung, Rolle des Unternehmens in der Gesellschaft, \\ unternehmerische und gesellschaftliche Werte, Wertordnung \\ Bekenntnis, Leitbild, mission, vision, Unternehmensphilosophie, \\ Unternehmenskultur, Selbstverständnis, and various related topics such \\ as the postulation of intrapreneurship \\ Strategie, (strategische) Unternehmensziele, (strategische) \\ Unternehmensführung, strategische Allianzen, Wachstum(-sstrategie), \\ merger \& acquisition \\ Managementinstrument, Managementkonzept, Managementmethode, \\ Steuerungsinstrument, Unternehmenssteuerung, management \\ information system, (Re-)Organisation, Restrukturierung \\ Kennzahlen, Messgrößen, Indikatoren, unternehmensinterne Standards, \\ unverbindliche Richtlinien \\ Kosten, Kostenstruktur, Investitionsentscheidung und Finanzierung, \\ Risikomanagement, Geschäftsergebnis, Ertrag und Unternehmenserfolg, \\ betriebswirtschaftliche Nutzenentscheidung \\ Forschung \& Entwicklung, Produktion und Logistik, Produkt und Marke, \\ Preispolitik, Qualitätsmanagement \\ Primat der unternehmerischen/ökonomischen Verantwortung, \\ unternehmerische Verpflichtung \\ Transparenz
}

Balancing stakeholder interests

$T B L$, environment

Support, sponsoring

Human resources

Shareholder interests
Ansprüche verschiedener Stakeholder-Gruppen, Interessenausgleich zwischen Anspruchsgruppen, Stakeholder-Dialog, StakeholderManagement

Triple bottom line, Umgang mit Ressourcen, Umwelt, Umweltschutz

Sponsoring, Engagement, Unterstützung, Patenschaften, Entwicklungshilfe

Human resources, Mitarbeiter, Arbeitsplatz, Verhältnis UnternehmenMitarbeiter, diversity management, Aus- und Weiterbildung, Anreizsysteme, erfolgsabhängige Entlohnung

Investor relations, Aktie, Dividende, Börsenperformance, Anlegerinteressen, Kapitalrentabilität, Kapitalmarkterfordernisse, Eigentumsverhältnisse, Beteiligungen 
Ethical investment

Hard and soft law

Image, external and public relations

Other topics
Ethisches Investment, Ethikfonds, Nachhaltigkeitsindizes

Gesetzliche Bestimmungen, verbindliche Richtlinien und Standards, Corporate Governance (Kodex)

Unternehmensimage, Außenwirkung und -kontakt, Auszeichnungen, Awards, externe Berichterstattung

Definitions, glossary, other topics

Table 10: Categories of thematic embeddings: Construction of variable

\subsubsection{Methods of analysis}

Throughout the study, I will rely on basic methods of analysis including descriptive statistics, graphs, and figures - e.g., bar, column, line, and radar charts - plotted with standard software (Microsoft Office Excel 2007) in order to explore features and dynamics within the CSR discourse. Second, I will apply binary logistic regression routines with STATA 10 (see below for details) in order to identify characteristics of adopters as well as factors related to their technical and institutional environments. Third, the exploratory social network analysis tool PAJEK 1.23 will be used (see below for details) in order to reveal at a more fine-grained level relational structures within my data. Finally, aiming at a reconstruction of the prevalent system of meaning within the CSR discourse, I will conduct several correspondence analyses computed and plotted with STATA 10 (see below for details): I will hereby also demonstrate that (multiple) correspondence analysis is a powerful method to advance my endeavor.

\subsubsection{Binary logistic regression}

Patterns of adoption and thus dissemination of CSR can be captured by employing multivariate statistics on organizational and technical/institutional variables: To test various hypotheses, I will predict the likelihood of a corporation proclaiming commitment to CSR by using binary logistic regression models estimated by maximum-likelihood techniques (see Long \& Freese, 2006; StataCorp LP, 2007a, among others). ${ }^{113}$ The structure of my data (i.e., representing time-series cross-

113 In contrast to structural features like the establishment of investor relations departments (e.g., Rao \& Sivakumar, 1999), the introduction of corporate positions (e.g., Zorn, 2004), or the implementation of new incentive structures (e.g., Sanders \& Tuschke, 2007), the rhetorical claim to be committed to a normative orientation or policy is not necessarily equal to actual adoption or implementation. In addition, corporations do not completely redesign their annual reports each year, but instead rely strongly on their own previous reporting. Yet they may decide to report commitment in one year, drop the subject in the following year's annual report, and take it up again in the next. Since a corporation can thus shift back and 
sectional data with a binary dependent variable) caused me to deal with an unbalanced panel and repeated observations on corporations, resulting in observations from the same unit not being independent - a common phenomenon for data applied in diffusion studies. Therefore, it is advisable to make use of the cluster option when estimating models using binary logistic regression routines in STATA $10 .{ }^{114}$ I will cluster data by corporation ID and use robust variance estimation that takes into account within-group dependence and resulting possibilities of heteroscedastic standard errors. ${ }^{115}$ All variables used were subject to the usual diagnostic procedures, with no problems having been revealed. ${ }^{116}$

\subsubsection{Exploratory social network analysis}

Social network analysis is a powerful methodological tool used in a broad range of disciplines and fields within the social sciences (for a brief overview and introductory remarks see de Nooy, Mrvar, \& Batagelj, 2005, among others). A social network, generally speaking, is a social structure consisting of entities (so-called nodes) linked by one or more specific types of interdependency: While traditionally focusing on ties between individuals or organizations, social network analysis can also be applied to other entities (like, in my case, ties between sub-discourses or social categories). Social network analysis offers a methodology to analyze such social relations: Its main objective is to detect and interpret structures and patterns of social ties among actors or other entities. For the purpose of this study, I adopt an exploratory approach, "which assumes that the structure or pattern of ties in a social network is meaningful to the members of the network and, hence, to the researcher. Instead of testing prespecified structural hypotheses, we explore social networks for meaningful patterns" (de Nooy et al., 2005: 5).

forth between commitment and non-commitment, my dataset contains all observations. An exclusive focus on the first appearance of CSR in a focal corporation's annual report - which would suggest employing an event-history design - would only grasp part of the story (see also Meyer \& Höllerer, 2009 for more on this point).

114 I use the logit command in STATA 10; binary logistic regression is based on the following equation (see also Backhaus, Erichson, Plinke, \& Weiber, 2000; Long \& Freese, 2006; StataCorp LP, 2007a):

$\ln \left(\frac{p\left(y_{i}=1\right)}{1-p\left(y_{i}=1\right)}\right)=\alpha+\sum_{j} \beta_{j} x_{i j}$

115 Here, traditional standard errors are replaced by robust standard errors, also known as Huber/White (or "sandwich") standard errors (Long \& Freese, 2006); variance is estimated in a way that relaxes assumptions about independence within groups.

116 The following prerequisites exist for specifying logistic regression models: (a) meaningful coding (no ordinal or nominal independent variables); (b) inclusion of all relevant, and exclusion of causally irrelevant, independent variables; (c) N > 100; and (d) no multicollinearity (see below for detailed scores on multicollinearity). 
I will make use of the software PAJEK 1.23 to map out and analyze social networks. ${ }^{117}$ Information and a full technical account is provided in standard manuals, handbooks, and existing literature on this method (for PAJEK see, for instance, de Nooy et al., 2005; for social network analysis in general see Wasserman \& Faust, 1994; Scott, 2000; Carrington, Scott, \& Wasserman, 2005).

\subsubsection{Multiple correspondence analysis}

Correspondence analysis has not been established as a standard method in (at least Anglo-American) organizational and management research yet, although it is firmly anchored in the domain of social sciences: For instance, it looks back on a long history in sociology (and in French sociology in particular). ${ }^{118}$ The main purpose of the multivariate statistical technique of correspondence analysis is to reveal the structure within complex data by replacing the raw data with a simpler matrix, yet without losing essential information (i.e., by removing "noise" and redundant information); moreover, the method enables the researcher to visualize and more easily interpret results (Clausen, 1998). It is important to hold that correspondence analysis is first and foremost an exploratory technique that allows for the illustration and investigation of the structuring features of meaning as well as the context within which meaning is embedded (Harcourt, 2002). ${ }^{119}$

Conceptually similar to principal component analysis, it is applied to categorical data and, essentially, visualizes contingency tables. Correspondence analysis decomposes the $\chi^{2}$ statistics associated with such tables into orthogonal factors and portrays the associations between two categorical variables by graphically representing the categories of the variables as label points within a two-dimensional

117 However, the graphical output is refined using CorelDRAW X4 in order to optimize printing quality.

118 In social sciences, (multiple) correspondence analysis has earned a reputation mainly through its application by sociologist Pierre Bourdieu who - notably in his books La Distinction and Homo Academicus - stressed that social structure is a system of relations and differences rather than a set of attributes (de Nooy, 2003). Outside Europe, and especially in the Anglo-American academic environment, correspondence analysis has been received more reluctantly and is only slowly becoming known as a way of more rigorously measuring meaning structures (Mohr, 1998; Breiger, 2000). Hence, this method has scarcely been used in management research to date, with exceptions in marketing (e.g., Inman, Shankar, \& Ferraro, 2004; Penz \& Stöttinger, 2008), or in meta-studies (e.g., Furrer, Thomas, \& Goussevskaia, 2008). Examples in fields related to this study include Anheier, Gerhards, \& Romo, 1995; Breiger, 2000; Harcourt, 2002; Owen-Smith, Riccaboni, Pammolli, \& Powell, 2002; Hsung \& Breiger, 2009; Meyer \& Höllerer, 2010, among others).

119 Correspondence analysis has occasionally been criticized for being merely descriptive or "model-free" as it does not test hypotheses - whereas its proponents praise exactly this very aspect as its greatest virtue, in that it "lets the data speak without imposing any preconceptions" (Harcourt, 2002: 1001; Breiger, 2000). 
space; the dimensions of such a correspondence map are defined - to varying degrees - by the individual categories (Le Roux \& Rouanet, 2004; Greenacre, 2007). Generally speaking, categories co-occurring relatively often are plotted closely together, while those in opposition are plotted apart (de Nooy, 2003). Multiple correspondence analysis is an extension of simple correspondence analysis and applicable to a set of more than two variables. For a full technical account, refer to standard literature (e.g., Greenacre, 1984; Weller \& Romney, 1990; Greenacre, 1991; Greenacre \& Blasius, 1994; Clausen, 1998; Le Roux \& Rouanet, 2004; Greenacre \& Blasius, 2006; Greenacre, 2007; StataCorp LP, 2007b; Le Roux \& Rouanet, 2010).

"Plotting several types of entity [...] in the 'same' space" (Breiger, 2000: 99) thus creating what one might call a "topographic map" (see Meyer \& Höllerer, 2010) -, the key analytical objective is to identify more profound and more overarching principles that account for the spatial arrangement of categories and thereby help to understand how a cultural system of meaning is structured (Mohr, 1998). It is important to note, however, that a merely visual assessment of such a map might lead to false conclusions, as the individual categories contribute to the dimensions to differing extents and are themselves explained to varying degrees by these dimensions. An integration of the statistical output into the interpretation is therefore essential.

Generally speaking, several complementary ways of interpreting two-dimensional correspondence maps exist (Meyer \& Höllerer, 2010): One focuses primarily on the dimension and the categories that are most expressive of it, while another interprets the angle and location of label points with respect to the origin - or center - of the graph (for details on interpretation, see Greenacre, 1991; Greenacre \& Blasius, 1994, 2006; Greenacre, 2007; StataCorp LP, 2007b, among others). Interpreting the relationship of dimensions and label points works both ways: On the one hand, the contribution of a label point to a dimension indicates the percentage of inertia, or variance, of a dimension explained by this particular label point; by focusing on the most substantive label points, one may induce the very meaning of a dimension or axis. On the other hand, the contribution of a dimension to a label point (squared correlations) is a measure of quality and reflects how well a particular label point is described by a dimension. Here, a standard analysis particularly stresses label points that have a high contribution of dimension to label point; those not well described by the model merit less analytic focus.

While interpreting the distance between label points in a correspondence map is not always accurate, simple rules dictate how to construe the angle between two label points: Taking the origin as the summit, if the angle between two label points is acute $\left(<90^{\circ}\right)$, the two characteristics are positively correlated; if the angle is obtuse $\left(>90^{\circ}\right)$, the label points are negatively correlated; finally, if the angle is approximately $90^{\circ}$, the label points do not interact and are rather independent. In addition, label points near the origin are more or less rather conventional categories 
with no significant differences in distribution. More interesting and relevant for analysis are those that are plotted far from the origin as they appear in specific constellations.

Together, this allows the exploration of a topographic map and the detection of distinct patterns. In this study, with regard to computing and plotting techniques, I rely on STATA 10 and its multiple correspondence analysis module. ${ }^{120}$ I will provide some statistical information along with the interpretation of the individual correspondence maps in the chapters on findings.

120 In more detail, I used the joint correspondence analysis option of the mca command as well as related post-estimation routines in STATA 10. Again, the graphical output has been refined in order to optimize printing quality. 
Markus A. Höllerer - 978-3-653-01464-8

Downloaded from PubFactory at 01/11/2019 11:31:02AM

via free access 
"Eureka! - Finally we have another Anglo-Saxon term for something so self-evident: 'Corporate social responsibility' is the magic word that means nothing but the fact that corporations must also take into account the public good (something that, by the way, the wise architects of the Austrian Stock Corporations Act formulated decades ago with enduring validity)."

Herbert Krecji, former Secretary General of the Austrian Federation of Industrialists and member of the board of directors in various Austrian corporations, (in: Gewinn 12/02: 180, December 4, 2002; translation by the author)

\section{CSR in Austria}

For many reasons, Austria is an excellent and unique setting to study the career of CSR - or, more precisely, and in Matten and Moon's (2008) terms: of explicit CSR - in greater detail. The quote at the beginning of this chapter points out several elements that characterize this uniqueness. First and foremost, and as a common feature of the majority of continental European countries and their governance system, social responsibility of business is per se nothing new. On the contrary: The implicit notion of CSR has been firmly anchored in such an institutional framework - an indigenous, taken-for-granted idea that had already existed (e.g., European Management Forum, 1973; Steinmann, 1973; see also Ulrich \& Fluri, 1975; Ulrich, 1986, among others) before it was "discovered" as a strategic instrument and rhetorical tool. What certainly is new is the fact that corporations have started to pick up the explicit vocabulary of CSR in their corporate communication over the last decade; in doing so, they aim to manage legitimacy and maintain their license to operate by demonstrating sound management practices vis-à-vis various stakeholders.

Such a deeply ingrained understanding also expresses the consensus of powerful societal actors and is materialized in various ways from legal regulation to informal means of political decision making (see below for more details). For instance, and as early as 1965, the Aktiengesetr. (Austrian Stock Corporation Act) stipulated that the management of corporations must act, above all, in the best interest of the corporation itself. At the same time, it must also take into account the interests of key stakeholders; the law explicitly mentions shareholders and employees as well as the public interest. ${ }^{121}$ Another characteristic and key feature of this specific empirical context is the strong corporatist tradition in Austria that has been manifested in a range of informal forms and practices of political decision

$121 \int 70$ (1) - the guiding principle for the executive board - reads as follows (translation by the author): "The executive board shall have sole responsibility for managing the corporation in a way that best serves the corporation's interest and thereby shall endeavor to take into account the interests of the shareholders and the employees as well as the public interest." 
making: Austria has consistently been portrayed as the "country of corporatism" (Traxler, 1998) - as an icon of corporatist and stakeholder governance in post-war Europe (on the Austrian context, see also Meyer \& Höllerer, 2009, 2010).

On the following pages, I will systematically explore these and other characteristics describing the continental European context and the Austrian empirical setting in particular. Moreover, I will portray the Austrian CSR arena and its key actors. Toward the end of the chapter, I will present first empirical data in order to illustrate the genre of annual reports in Austria; I will also briefly discuss social disclosure practices in Austrian corporations' annual reports.

\subsection{Cultural conditions}

\subsubsection{A continental European model of corporate governance}

Much scholarly work has highlighted the cultural embeddedness and sociopolitical aspects of governance models (see, for instance, Fligstein, 1990; Hollingsworth \& Boyer, 1997; Whitley, 1999; Hall \& Soskice, 2001; Aguilera \& Jackson, 2003; Aguilera \& Cuervo-Cazurra, 2004; Schneper \& Guillén, 2004; Fiss, 2008). The differences between the governance models prevailing in the Anglo-American context and those in continental European countries have especially been discussed at length in literature (see Djelic, 1998, among others). In comparative research across cultural borders, two theoretical frameworks in particular deserve attention: the varieties of capitalism approach (e.g., Hall \& Soskice, 2001) and the (national) business systems perspective (e.g., Whitley, 1999). While the first approach identifies two ideal types of economies (i.e., liberal market economies versus coordinated market economies), the latter refers to business systems as the "distinctive patterns of economic organization that vary in their degree and mode of authoritative coordination of economic activities, and in the organization of, and interconnections between, owners, managers, experts, and other employees" (Whitley, 1999: 33). As Fiss (2008: 401) points out, the business systems perspective offers "an intriguing framework for those who aim to study corporate governance through an institutional lens" (see also Djelic \& Quack, 2003; Djelic \& Sahlin-Andersson, 2006; for a detailed discussion of linkages with organizational institutionalism see, for instance, Tempel \& Walgenbach, 2007).

Following Matten and Moon (2008: 407), I argue that national differences in CSR issues - i.e., "ways in which corporations express and pursue their social responsibilities" - can be explained by historically grown institutional frameworks that shape business systems. I will employ the dimensions used by Matten and Moon (2008) - they themselves borrow from Whitley (1999) - to outline the Austrian case. I will especially stress specifics relevant for CSR, but also contrast the more general continental European model with the Anglo-American one to illustrate the empirical context of my study. 


\subsubsection{Institutional framework in Austria}

In general, four key features characterize the historically grown institutional framework for business organizations within any country: the political system, the financial system, the education and labor system, and the cultural system. These features inform national business systems, especially in terms of the nature of the firm, the organization of market processes, and the coordination and control system (Whitley, 1999; see also Matten \& Moon, 2008).

\subsubsection{Political system}

The political system in Europe, compared to that of Anglo-American nations, has historically been characterized by a relatively powerful state and by governments engaged in economic and social activity throughout various policy fields (Matten \& Moon, 2008). Very much in line with the European welfare state tradition, many welfare services in Austria are provided or at least financed by the state, consequently resulting in a rather high tax and contribution ratio. At the core of Austria's social model rests a nationalized insurance system for health, unemployment benefits, and pensions, as well as for other social commodities.

Numerous topics now regarded as part of the CSR agenda have been anchored in Austrian governmental policies for a considerable period of time. As in other European countries, environmental issues stimulated an at times - especially during the 1970 s and 1980 s - highly emotional political debate ${ }^{122}$ that also gave rise to the establishment of the Austrian Green Party in 1986. ${ }^{123}$ Deviating from other European countries, the Austrian federal government - at that time composed of a grand coalition of social democrats and conservatives - explicitly proclaimed the so-called öko-soziale Marktwirtschaft (eco-social market economy) ${ }^{124}$ as an essential part of its political program at the beginning of the 1990s.

122 For instance, a negative plebiscite prevented the first Austrian nuclear power plant from going on line in 1978. In 1984/1985, severe clashes between police and protesters (the junior elite from literally all political parties were among the demonstrators) prevented the construction of a hydropower plant on the Danube river and led to the creation of the DonauAuen National Park; the areal preserves the last remaining major wetlands environment in Central Europe.

123 The Austrian Green Party was formed by merging of two individual parties each founded in 1982. Although to date not part of any federal government but represented in the Austrian Parliament since 1986, the Austrian Green Party has been part of various local governments at state/Länder and municipal level, and has thus participated in setting the political agenda.

124 The term öko-soziale Marktwirtschaft was coined by the Austrian conservative politician and later Austrian Vice-Chancellor Josef Riegler in the late 1980s (see, for instance, Riegler, 1990). Based on a strong and innovative market economy, it is a holistic model that aims at balancing free market economy and strives for social fairness as well as the sustainable use and protection of natural resources. 
As Meyer and Höllerer $(2009,2010)$ expound in great detail, it is important to acknowledge the very close link between economic and political elites that can be attributed to the corporatist tradition characterizing Austria after WWII. The construct of the Sozialpartnerschaft (social partnership) has been built upon a tacit and informal agreement between the government, major employers' associations, and various employee interest groups, and has dominated the socioeconomic environment to an extent that Austria is generally top-ranking in empirical studies on corporatism (e.g., Lehmbruch \& Schmitter, 1982; Molina \& Rhodes, 2002; see also Schmitter \& Lehmbruch, 1979). ${ }^{125}$ This type of policy-making is not based as much on pluralistic interest groups' efforts to lobby and/or pressure the government as it is on actually integrating these groups into the policy-making process (Meyer \& Höllerer, 2009). Until 2003, and for a period of several decades, no social or economic law in Austria had been passed by the Austrian Parliament without consulting the social partners in advance. Their predominant strategy of regulating conflicts by way of institutionalized bargaining and compromise - secluded from the public - resulted in social peace and the post-war Austrian "economic miracle". In turn, democratic legitimacy deficits resulting from the secrecy and informality of political decision making and a politicization of the economy were the price to pay (Meyer \& Höllerer, 2009, 2010).

At the end of the 1990s, several traditional Austrian institutions began to erode: Pelinka (1998) calls it the "end of subsocieties" and a "farewell to corporatism". Among other things, the influence of the social partnership was thought to have come to an end, not least due to the increasing importance of international financial markets and the fact that, for the first time since the 1960s, the Social Democratic Party of Austria was not part of the federal government between 2000 and 2007. However, and as several political observers and the media noted in 2008, the aftermath of corporate malfeasance and the financial crisis - which once again changed the global role of the state within the economic system - together with a newly elected federal government was fertile ground for a resurgence of the traditional corporatist system in Austria (see also Meyer \& Höllerer, 2010).

\subsubsection{Financial system}

Another important criterion in describing business systems is the configuration of the financial system, especially the role of the capital market. In North America, a high degree of transparency and accountability toward investors is due to the fact that the stock market is the central financial source for corporations (Whitley, 1999); widely spread shareholdings are common (Gourevitch \& Shinn, 2007). In

125 Using the Hicks-Kenworthy index as a measure of corporatism, Austria (0.96) - in a near-tie with Sweden (0.97) - and the United States (0.02) represent the extreme values (Gourevitch \& Shinn, 2007: 154). 
European corporations, however, shareholding can generally be characterized as relatively less dispersed and tending toward a considerable concentration of ownership (see also Barca \& Becht, 2002; Gourevitch \& Shinn, 2007): A small network of fairly large shareholders - i.e., mutually interlocking owners with banks and insurance companies playing a major role - strive for long-term preservation of influence and power (Matten \& Moon, 2008). Also, in the continental European model, groups of stakeholders other than shareholders play an equally important role in corporate governance (see above). Nevertheless, several studies ${ }^{126}$ have documented recent shifts toward a more shareholder-focused orientation (e.g., Fiss \& Zajac, 2004, 2006; Sanders \& Tuschke, 2007; Meyer \& Höllerer, 2010).

Meyer (2004; see also Meyer \& Höllerer, 2009, 2010) notes that in Austria an external market for corporate control - manifested through hostile takeovers or takeover attempts - has been practically non-existent. Apart from the growing importance of institutional investors, a distinct shareholder movement is still in its infancy today. ${ }^{127}$ The corporate landscape of post-war Austria has been dominated by formerly nationalized industries and, more recently, subsidiaries of foreign multinational corporations. It is further characterized by long-established industrialist families and a high degree of small and medium-sized enterprises, often referred to as the "backbone" of Austrian economy. In their study on the separation of ownership and control in Austria, Gugler, Kalss, Stomper, and Zechner (2002: 58; see also Gourevitch \& Shinn, 2007) conclude that, "by European standards, Austria seems to be the country with the highest concentration of ownership and voting power. State ownership and control dominates among large firms, while families prevail as majority owners of small firms. Banks and foreign investors play a significant role as owners and holders of voting blocks in all sizeclasses."

An analysis of ownership data reveals that in 2000, for instance, $86.5 \%$ of Austrian publicly-traded corporations showed considerable blockholdings (i.e., more than $25.0 \%$ of shares held by an individual investor). Moreover, for $27.4 \%$ of publicly-traded corporations, Meyer and Höllerer (2010) measure significant influence of the public sector (i.e., direct or indirect blockholdings by governmental entities). Market capitalization, on the other hand, is comparatively low: In 2000, over 50 European stocks on the Dow Jones STOXX each had a market capitalization greater than that of the entire Austrian stock market (European Central Bank, 2002). At the Vienna Stock Exchange, with an average of 102 domestic corporations listed between 1990 and 2005, the top five corporations accounted for $42.2 \%$

126 Fiss and Zajac (2006: 1175), for instance, note that "a shareholder-oriented strategy, by placing the interests of shareholders above those of other constituents, represents a clear and highly controversial break with the traditional German stakeholder model of corporations and a major shift in firms' priorities."

127 It was only recently that, for the first time in Austrian corporate history, a rebellion of minority shareholders forced an executive board to resign. 
of market capitalization in 2000. Likewise, the equity segment displays rather low liquidity with the top five corporations generating $52.3 \%$ of stock exchange turnover (Meyer \& Höllerer, 2010). The structure of the pensions system - according to Gourevitch and Shinn (2007), Austria is among those countries with the lowest private pension assets in relation to GDP -, a tradition of debt financing rather than venture capital, and a strong preference for conservative forms of private savings add to the overall modest role and activity of the capital market in Austria (Meyer \& Höllerer, 2009, 2010).

Furthermore, the specific legal tradition of a nation strongly influences the governance model in place as well as the activity on and of the capital market (see La Porta, Lopez-de-Silanes, Shleifer, \& Vishny, 1998; Aguilera \& Jackson, 2003). Austria's civil law tradition is typically considered to lag behind common law countries with regard to financial investor protection and to provide a less favorable environment for shareholders and the capital market in general (Meyer \& Höllerer, 2010). ${ }^{128}$ This is also reflected in the comparatively small number of stock corporations: In 2001, only 1,096 corporations of this legal type (equaling $0.5 \%$ of all business organizations) employed $15.6 \%$ of the Austrian workforce compared to, for instance, $21.6 \%$ companies with limited liability and $64.6 \%$ with sole proprietorship (Statistik Austria, 2001; for an overview of legal forms according to Austrian law, see Gugler et al., 2002).

\subsubsection{Education and labor system}

There are substantial differences between national contexts in terms of regulation and qualification of human resources at the post-secondary education level: Europe is characterized by publicly led training and active labor market policies, whereas corporations in the United States have developed distinct strategies of their own (Matten \& Moon, 2008).

In Austria, with the social democrats being in power for most of the time since WWII (either alone or as part of a coalition), labor issues were given highest priority in almost every government program with the explicit objective of full employment. The Arbeitsmarktservice (Austrian Public Employment Service), an agency under public law since 1994 and formerly known as the Labor Market Administration Authority affiliated with the Austrian Federal Ministry of Employment, Health, and Social Affairs, has assumed its role as the leading provider of all labor-related services - including financial assistance - in close cooperation with labor union and employers' associations. Labor market policies have also been

128 In this context, it is important to note that minority shareholder protection in Austria is among the lowest of all Western countries. Gourevitch and Shinn (2007: 48) indicate a minority shareholder protection index of 30.0 for Austria compared to 97.0 for the United States. 
highly influential vis-à-vis decision making processes in corporations, especially in those organizations with significant public sector influence.

As outlined above, a number of European countries, and Austria in particular, are characterized by relatively integrated, nationwide, and hierarchical structures of both business and labor interest in a corporatist tradition (Molina \& Rhodes, 2002). High levels of union membership - the Österreichischer Gewerkschaftsbund (Austrian Trade Union Federation), although nonpartisan, is a social democratic-dominated association subdivided into nine smaller affiliated trade unions - and employers organized in business associations and federations, together with the highly influential and taken-for-granted construct of social partnership, resulted in the negotiation of labor-related issues at national rather than at corporate level (Lehmbruch \& Schmitter, 1982; Molina \& Rhodes, 2002; see also Matten \& Moon, 2008). Strikes also during collective bargaining - have been fairly uncommon in Austria. Hence, the Austrian model is appropriately referred to by the catchphrase of a "class struggle on the green table" (Meyer \& Höllerer, 2010).

\subsubsection{Cultural system}

Anglo-American and continental European cultural systems have, as Matten and Moon (2008: 408, quoting various sources) summarize,

"[... generated very different broad assumptions about society, business, and government. Compared to Europeans, Americans are regarded as having a relative capacity for participation [...], a relative capacity of business people for philanthropy [...], relative skepticism about big government [...], and relative confidence about the moral worth of capitalism. Thus, there is a much stronger American ethic of stewardship and 'giving back' to society [...]. This contrasts with the greater European cultural reliance on representative organizations, be they political parties, unions, employers' associations, or churches, and the state."

In general, these findings hold true for the Austrian context as well: Leaving aside conventional stereotypes, a distinct identity in terms of professional and status groups, firm ties with the political base and thus a clear political identity, a traditionally strong Catholic Church, and universal trust in a powerful state and other authorities have been central characteristics of the nation. On the other hand, dichotomies (i.e., building on an American versus European debate) ${ }^{129}$ can never capture all details of post-war society in Austria: Over several decades, it was primarily the economic elite, with industrialist families playing a crucial role, that felt responsible for the socioeconomic architecture of the nation - "an idea that [...] frequently comes with a flavor of patriarchy or with the fragrance of Christian ethics" (Meyer \& Höllerer, 2009: 11). Such a paternalistic perspective involves the

129 For critical remarks on the "American/European debate about corporate governance", see Donaldson (2008). 
balancing of different stakeholders' claims and interests not only to navigate the corporation through troubled waters, but due to the conviction, claim, and also obligation to know better what is good for stakeholders - perhaps better than the stakeholders themselves - and society as a whole (Meyer \& Höllerer, 2009). ${ }^{130}$ It is in this regard that an implicit understanding of social responsibility, firmly anchored as "good Austrian entrepreneurship with responsibility", has left its imprint in public discourse and in Austrian society. It was also among the most vividly recalled accounts against shareholder value when this new management concept went ashore in Austria (see, for details, Meyer \& Höllerer, 2010).

\subsubsection{Nature of the firm}

The broader institutional framework also influences structural features of corporations. Matten and Moon (2008; see also Whitley, 1999), in this respect, refer to the degree to which private hierarchies control economic processes, the level of discretion owners grant corporate managers in running business operations, and the organizational capabilities available with which to respond to changing demands.

As Meyer and Höllerer $(2009,2010)$ point out, a key aspect that expresses underlying logics and makes cultural differences visible is the dominant image, or metaphor, of what a corporation is and ought to do (see also Fiss \& Zajac, 2004; Weber, 2005, among others). Similarly, Jensen (2001: 8) states that "at the heart of the current global corporate governance debate is a remarkable division of opinion about the fundamental purpose of the corporation". While the Anglo-American model typically goes hand in hand with a contractarian view of the corporation as a "nexus of contracts" designed to maximize the investors' return (e.g., Jensen \& Meckling, 1976; see also Davis, 2005), the mainstream continental European perspective evokes quite different imagery. Here, the corporation is regarded as a social entity with interests of its own (often interpreted as its continued existence or survival) that must be protected and thus rank highest in a hierarchy of interests (Meyer \& Höllerer, 2009, 2010).

In Austria, this perspective is also codified in the Austrian Stock Corporations Act. In the guiding principle for the executive board (for the exact wording, see footnote 121), the law stresses interests of the corporation itself alongside those of

130 Meyer and Höllerer (2009) refer to one of the most influential German-speaking scholarly authors on management throughout the 1970s and 1980s who sums up this point well: "Executives in all areas of society are, with regard to role and power, part of the elite that can be expected to recognize better and earlier than others which objectives and types of behavior are appropriate in order to safeguard the future. The fact that corporate management takes on social responsibility thus implies that it makes great efforts not only to pursue the interests of the corporation, but also to do what is best for society at large" (Ulrich, 1980: 16, translation by Meyer \& Höllerer, 2009). 
shareholders, employees, and the general public. As Meyer and Höllerer (2009, 2010) discuss in greater depth, the various comments on this codification, originally drafted in the 1950s, provide an interesting insight into the debate at the time: While it was, for instance, undisputed that the public interest had to be taken into account, it was seen as problematic to make management explicitly its agent; a contested passage that allowed for the dissolution of a corporation by act of state authority in case the corporation acted against the public interest was dropped during this debate (Kalss et al., 2003).

It is also worth noting that corporate governance varies across countries, especially with regard to the board system. Austria, like Germany, is an example of a corporate governance system in which the control of managing directors (i.e., the executive board) lies in the hands of a separate supervisory board (two-tier system) - as opposed to the Anglo-American system where such control is an additional task of the board itself (one-tier system; for a detailed discussion see Hopt, Kanda, Roe, Wymeersch, \& Prigge, 1998; du Plessis, McConvill, \& Bagaric, 2005; Mäntysaar, 2005, among others). In addition, in Austria, employees have substantial rights of co-determination that grant their representatives seats and voting rights on the supervisory board, as well as a voice in far-reaching areas of corporate decision making.

In terms of ownership, continental European countries have a "large amount of direct ownership or alliance ownership, most notably through networks of banks, insurance companies, or even governmental actors" and public entities, whereas the Anglo-American model has been "more reliant on market-based forms of contract-based ownership" (Matten \& Moon, 2008: 408, with reference to Coffee, 2001). For Austria, financial markets under significant state control (practically all large banks were controlled by public bodies or the social partners until the mid-1990s) as well as the crucial importance of nationalized industries (with largescale privatization starting only in the early 1990s and the state remaining a core owner in many of these corporations) have been characteristic features of the socioeconomic landscape for decades. For a substantial number of (publicly-traded) corporations, the literal meaning of the synonymously used term "public corporation" perfectly mirrors - as Meyer and Höllerer (2009: 10) put it - their role in Austria: "owned by a public entity". As a result, Austria has been witnessing a high level of public engagement, investment, and influence in private sector industry, resulting in corporations having a range of embedded relations with a relatively wide set and variety of societal actors.

\subsubsection{Organization of market processes}

Matten and Moon (2008: 408-409; see also Whitley, 1999) emphasize the way economic relations between actors are organized and coordinated as a "decisive feature" of business systems, with markets and alliances representing the two 
extreme positions: "Characteristic features include the extent of long-term cooperation between firms within sectors, the role of intermediaries in establishing market transactions, the role and influence of business associations, the role of personal relations, and trust in establishing market transactions."

While in North America greater prominence has been given to market self-organization, the continental European system tends to be characterized more by organized markets, either reflecting a mediation of labor and capital or strong governmental leadership (Matten \& Moon, 2008). In Austria, at political and legislative level, the system of social partnership has been of outstanding influence and, with its strategy of negotiation and coordination between central interest groups, has clearly dominated the socioeconomic environment (see remarks above). Consumer protection (i.e., legal regulation that safeguards the interests of consumers and is designed to ensure fair competition and a free flow of truthful information in the marketplace) also has a fairly long tradition in Austria. Together with topics such as product stewardship or liability for production and products, it touches on core CSR and sustainability issues. Alongside various NGOs, consumer protection $^{131}$ in Austria has been administered at federal governmental level for many years.

\subsubsection{Coordination and control system}

Business systems may also differ in the way in which individual corporations are governed (Whitley, 1999; see also Whitley, 1992; Whitley \& Kristensen, 1996; Barca \& Becht, 2002; Gourevitch \& Shinn, 2007), including the degree of integration and interdependency of economic processes, and especially employer-employee relations (e.g., the degree of delegation, level of employee discretion with regard to duty fulfillment, and the degree of trust governing relationships). As Matten and Moon (2008) note, employee representation and participation in continental Europe (and thus in Austria as well) are covered by dense employment regulation and protection covering a significant number of issues which, in an Anglo-American context, would be part of explicit CSR.

To recapitulate, and following Gourevitch and Shinn (2007: 51), it becomes clear that corporate governance patterns vary substantially due to a host of other socioeconomic features within specific contexts (see the remarks above), exhibiting what Milgrom and Roberts (1992) call institutional complementarity - "a logic of fit that

131 This policy field is currently assigned to the Austrian Federal Ministry of Labor, Social Affairs, and Consumer Protection. Interestingly, the current minister is the former head of the Austrian Trade Union Federation, with his "counterpart" in the Austrian Federal Ministry of Economy, Family, and Youth being the former Secretary General of the Austrian Economic League and Deputy Secretary General of the Austrian Economic Chamber. Again, this is just another example of the regained importance of traditional social partnership in Austria. 
causes each to contribute to the other". Measuring institutional complementarity for different countries leads to a dichotomous result (see also Hall \& Soskice, 2001): Generally speaking, a liberal, outsider- and market-oriented capitalism of Anglo-American provenance that gives priority to shareholders, and the coordinated, insider- and relationship-oriented continental European variant that favors a stakeholder-oriented view of the corporation are juxtaposed (Meyer \& Höllerer, 2009, 2010). In this respect, Austria provides an excellent case: In Gourevitch and Shinn's (2007: 53) comparative study, for instance, the United States (1.0) and Austria (0.0) represent the extreme ends of a coordination index that measures institutional complementarity among 20 countries.

\subsubsection{The Austrian CSR arena: Activities and key actors involved}

Austria has a long tradition of broad stakeholder involvement in sociopolitical decision making as well as a comparatively high level of public awareness in environmental concerns (see remarks above). Explicit activities and policies aiming at the institutionalization of issues of CSR and sustainability can be traced back to the late 1990s and early 2000s (see also Strigl, 2005) and for the most part mirror wider European trends and/or global initiatives. The configuration of the "CSR arena" in Austria is built on three main pillars, each with rather different worldviews, interests, and motives to engage with the issue: (a) the world of business (i.e., especially employers' and business associations); (b) labor associations and various actors of civil society; and (c) governmental organizations. In addition, each of these groups makes use of a broad range of consultants, think tanks, and/or academic experts: A rather diverse industry of CSR consultancies and public relations agencies in this field has been established over the past ten to fifteen years.

Hence, the public debate on CSR is - not too surprisingly - "a paradigmatic example of political discourse" (Mark-Ungericht \& Weiskopf, 2007: 285). I will comment on the three main perspectives of how actors in the field observe and interpret the issue of social responsibility - and how they construe the pressures on corporations in this respect - in more detail in the following paragraphs. ${ }^{132}$

\subsubsection{The world of business}

A first and major event with regard to CSR in Austria was the foundation of the CSR Austria Initiative in 2002: As one of the main instruments of Austrian CSR policy, it was founded by the Österreichische Industriellenvereinigung (Federation of

132 For an overview - and for authors representing divergent perspectives in Austria -, see a volume edited by Köppl \& Neureiter (2004), among others. 
Austrian Industries) and the Austrian Federal Ministry of Economic Affairs and Labor. ${ }^{133}$ Other key business players and large employers' associations like the Wirtschaftskammer Österreich (Austrian Federal Economic Chamber) joined in early 2003. The initiative is characterized by Strigl (2005: 125) as a "concerted action to promote CSR in Austria" as well as the most important "private sector contribution to the Austrian Sustainability Strategy and, at a European level, a major Austrian contribution to the Lisbon Strategy". Between 2003 and 2005, it operated with the main purpose of proactively addressing the issue of CSR and fostering dialog between business, politics, and society at large.

After a relaunch and rebranding in mid-2005, the association respACT austria continued with the same portfolio of activities. In 2007, the organization merged with the Austrian Business Council for Sustainable Development (ABCSD, established in the mid-1990s) and - as the leading CSR platform in Austria - has since operated under the title respACT - austrian business council for sustainable development. The organization is predominantly financed by membership fees (i.e., from business organizations) as well as by support from the Federation of Austrian Industries, the Austrian Federal Economic Chamber, the Austrian Federal Ministry of Economy, Family and Youth, the Austrian Federal Ministry of Labor, Social Affairs and Consumer Protection, and the Austrian Federal Ministry for Agriculture, Forestry, Environment and Water Management (respACT, 2010).

The initial objectives of CSR Austria/respACT were to initiate a broader discussion on CSR and to create a common understanding of the concept's meaning and benefits, as well as to identify feasible CSR models for Austrian corporations by screening international initiatives (Strigl, 2005). Further progress made during my observation period includes the development of the "CSR Austria Guiding Vision" and, mostly in collaboration with various partner institutions, several tools of implementation: These include, among others, guidelines for sustainability reporting, the TRIGOS prize for excellence in CSR (awarded since 2004), the Austrian Business Academy for Sustainable Development that provides practicaloriented qualification programs for the private business sector, and - led by the Austrian Standards Institute - the Austrian CSR guidelines ("Guidance for the Implementation of Corporate Social Responsibility") issued in 2004.

Some specifics of the business perspective on CSR might be worth mentioning in more detail (see also Mark-Ungericht \& Weiskopf, 2007 for critical remarks). First, one of the most important aspects is - similar to the EU Green Paper - an emphasis on the voluntary character of CSR; every tendency to move beyond soft law regulation is fiercely opposed. From the perspective of business, the idea of CSR can only fully unfold within a voluntary rationale, simultaneously enabled and constrained by a proper legal framework. For instance, Leitl (2004) stresses that CSR must not be misunderstood as a substitute for existing (or new) social and

133 Note that at that point in time, a single ministry/minister assumed responsibility for both policy fields (i.e., economic affairs and labor interests). 
environmental regulation. ${ }^{134}$ Second, another main concern is about creating competitive advantage, both for individual corporations and for Austria as a business location. By proactively addressing CSR topics and reporting on their CSR activities, business organizations aim to build trust with various audiences, thereby creating a win-win situation for all parties involved. Third, and closely related, CSR is depicted as an important tool of stakeholder management to enhance a corporation's reputation and image - and thus, indirectly, its legitimacy. In sum, as MarkUngericht and Weiskopf (2007) note, these activities from the world of business might also represent a reaction to first tentative attempts to regulate corporate activities; moreover, they criticize that the business associations' perspective masks the more international dimension of CSR (which is, however, due to the fact that the overwhelming majority of Austrian corporations are small and medium-sized enterprises not engaging in large-scale international business), and that the CSR initiatives might imply too much rhetoric and only little relevance for core business.

\subsubsection{Labor associations and civil society}

In late 2003 - soon after CSR Austria had been launched by employers' associations with the support of the then conservative government -, a broad coalition of labor associations, NGOs, and other civil society actors published a position paper entitled Die gesellschaftliche Verantwortung von Unternehmen (CSR) aus zivilgesellschaftlicher Perspektive (CSR from a civil society perspective) (see also Strigl, 2005; MarkUngericht \& Weiskopf, 2007). This declaration was signed by Amnesty International, AGEZ (an umbrella organization for 29 Austrian NGOs dedicated to social and developmental activities), the Austrian Federal Chamber of Labor (which already opposed corporate self-regulation in previous statements), ÖKOBÜRO (a coordinating body for various Austrian environmental organizations including, among others, Greenpeace Austria, WWF Austria, and GLOBAL 2000), as well as the Austrian Trade Union Federation. The position paper was intended as a reaction to, and critical reflection on, the CSR Austria Initiative. It especially demanded the inclusion of labor associations in the discussion process; the addressing of ecological, social, and human rights issues detached from economic considerations; the introduction of binding social and ecological minimum standards on a global scale; and the involvement of employee interest groups and civil society actors during the development, implementation, and monitoring of specific CSR measures. Additional points brought forward by civil society actors encompassed a focus on core business as the central area of CSR, on corporations' responsibility for the global supply chain, on increased transparency, and on the possibility of sanctions in case of deviance from socially accepted CSR standards.

134 Christoph Leitl is the President of the Austrian Federal Economic Chamber and President of the Association of European Chambers of Commerce and Industry. 
In recent years, while pressure from consumer associations has remained surprisingly moderate, ${ }^{135}$ a variety of civil society actors has been very active in the field of CSR. The Netzwerk Soziale Verantwortung (NeSoVe, Austrian Network Social Responsibility) - building on the alliance of NGOs and organizations representing labor interests that also issued the above-mentioned position paper - has established itself as a major adversary of resp ACT. Initially designed as an information and communication platform, it interprets its role as representing a wider stakeholder and civil society perspective, serving as a watchdog in cases of corporate malfeasance, and promoting legal standards in areas relevant for CSR (NeSoVe, 2010). Religious organizations - traditional and fairly legitimate speakers on social issues - are also present in the debate, although clearly in a subordinate role: Projekt Sozialwort (the social mission statement of the Ecumenical Council of Churches in Austria) is an initiative of the 14 Christian churches in Austria that speak out on issues of social concern, honoring their responsibility toward society at large (Sozialwort, 2010).

\subsubsection{Governmental organizations}

Governmental organizations - Strigl (2005) lists five Austrian federal ministries have been actively involved in developments in the CSR arena. However, due to various interlocks and the institution of social partnership, but also due to various changes in the administrative responsibility for policy fields, the specific interests are not always clear and partially intermingled. Especially in the more recent past, the field has seen a high degree of consolidation. Very active players, like the Austrian Federal Ministry of Labor, Social Affairs, and Consumer Protection, are collaborating with various other actors in the field and are, for instance, currently supporting organizations from both "camps" like resp $A C T$ and Netzwerk Soziale Verantwortung. Beyond the previously mentioned activities, this ministry has also been involved in issues of work-life balance (e.g., family and career audits, womenand family-friendly employer awards) and various issues of social security (see also Austrian Federal Ministry of Labor, Social Affairs, and Consumer Protection, 2010). Also the Austrian Federal Ministry of Economy, Family, and Youth is among the most important players in the arena and supportive of numerous initiatives, albeit traditionally with a bias toward business-related activities (see also Austrian Federal Ministry of Economy, Family, and Youth, 2010).

At the same time it is important to note that expertise and voice in one key dimension of CSR - sustainability - has long been claimed not so much by the world of business or labor organizations, but in particular by the Austrian Federal Ministry for Agriculture, Forestry, Environment, and Water Management (also

135 As was mentioned above, this policy field has been widely administrated at the federal government level, but it has also been embraced by the Austrian Federal Chamber of Labor. 
branded as Lebensministerium - in English: "Ministry of Life"). It oversaw the "Austrian Strategy for Sustainable Development" (2002) and has supported a broad number of initiatives devoted to sustainable development (see also Austrian Federal Ministry for Agriculture, Forestry, Environment, and Water Management, 2010).

Still other ministries like the Austrian Federal Ministry of Transport, Innovation, and Technology have been active in and supportive of projects like the "Austrian Program on Technologies for Sustainable Development" (initiating and supporting trend-setting R\&D projects as well as implementing pilot projects) and the establishment of specific Austrian guidelines on sustainability reporting (Strigl, 2005). With regard to issues of good corporate governance, the Austrian Federal Ministry of Finance, among others, supported the Austrian Working Group for Corporate Governance. The organization, composed of representatives of the Austrian Institute of Certified Public Accountants, the Austrian Association for Financial Analysis and Asset Management (ÖVFA), the Vienna Stock Exchange, and various other actors, drafted the Austrian Code of Corporate Governance (2002) that covers both the international standards (e.g., OECD, 2004) as well as the most important provisions of the Austrian Commercial Code (see also Österreichischer Arbeitskreis für Corporate Governance, 2002).

\subsection{Social disclosure in Austrian corporations' annual reports}

\subsubsection{Genre characteristics}

Annual reports are, with regard to their basic structure, more or less standardized documents that comprehensively depict individual organizations' business activities throughout the previous financial year. Originally directed toward shareholders and potential investors with the goal of reporting on financial performance, they now cover a variety of topics and address a much broader - and more diffuse - audience (see chapter on methodology for more). All Austrian Aktiengesellschaften (stock corporations) must prepare and publish annual reports - with annual accounts and other mandatory information being filed in the Firmenbuch (Austrian Commercial Register). Corporations listed on the Vienna Stock Exchange are, in addition and according to the Börsegesetz (Austrian Stock Exchange Act), required to report more frequently - e.g., biannually and quarterly - and must make their annual reports available to all stakeholders interested.

At the core of an annual report lies the Jabresabschluss (annual accounts), i.e., the financial statement; this document encompasses, among others, the Bilanz (balance sheet), the Gewinn- und Verlustrechnung (income statement), a cash flow statement, Erläuterungen (notes) on these sections as well as on accounting policies, and a Prïfvermerk (auditor's certificate). Typically, the remainder of the annual report usually at the front - includes forewords from both the CEO and the chairman of the supervisory board, a mission statement and general presentation of the corpo- 
ration, the legally required Lagebericht (review of operations), a statement of compliance with corporate governance standards, some social and environmental disclosure, and a range of other topics that might vary greatly among individual corporations and industries.

Annual reports fulfill a purpose both as a controlling instrument (for executive and supervisory boards) and as an important public relations tool. The need to manage legitimacy has been one of the biggest considerations for a substantial change of the genre during the last decades - especially for large corporations exposed to a broader audience. Originally characterized as documents dominated by numbers, annual reports have turned into colorful and high-gloss publications with novel formats (in terms of both discourse and layout). As Preston, Wright, and Young (1996) point out, visualization and imagery are also central elements of modern annual reports. In crafting these documents, executive management and communication experts from inside the organization receive support from professions like public relations agencies and graphic designers. Most annual reports within my sample, however, state the names of the responsible organizational members, as well as external assistants involved in creating the respective document, in the publishing information. ${ }^{136}$

In order to deepen the understanding of the development of the genre over time I analyzed for selected years some formal-descriptive variables ${ }^{137}$ that might serve as a backdrop for further interpretation of social disclosure: Extent (i.e., total number of pages), percentage devoted to annual accounts (i.e., the share of an annual report devoted to balance sheet, income statement, cash flow statement, notes, and auditor's certificate), use of visual elements and imagery, and - as a proxy for professional layout and design - layout consistency. Table 11 shows a distinct development and trend over the years: For 2005, with the total number of pages on average almost 2.5 times higher than in 1990, I observe a decrease of the relative space devoted to annual accounts (i.e., to numbers) since the mid-1990s, and with it a clear increase of verbal text. ${ }^{138}$ For both the use of visual elements and for layout consistency I measure a continuous rise over the years, pointing at an increasingly professional design of this genre.

136 Major public relations agencies are also considered relevant in the regression model of my study (see chapter on methodology).

137 Note that these are not mentioned in the chapter on methodology, but in the footnotes below.

138 Due to new legal regulations in the early 1990s, the first row in Table 11 is comparable only to a limited degree (especially in terms of relative importance of annual accounts). 


\begin{tabular}{lcccc}
\hline Year & $\begin{array}{c}\text { Total number } \\
\text { of pages (average) }\end{array}$ & $\begin{array}{c}\text { Percentage } \\
\text { devoted to annual } \\
\text { accounts (average) }\end{array}$ & $\begin{array}{c}\text { Use of } \\
\text { visual elements } \\
\text { (average) }\end{array}$ & $\begin{array}{c}\text { Layout consistency } \\
\text { (average) }\end{array}$ \\
\hline 1990 & 39.59 & $41.12 \%$ & 1.71 & 2.34 \\
1995 & 58.49 & $48.32 \%$ & 1.84 & 2.53 \\
2000 & 70.57 & $46.88 \%$ & 2.01 & 2.64 \\
2005 & 97.23 & $45.04 \%$ & 2.16 & 2.67 \\
\hline Overall & 63.56 & $46.52 \%$ & 1.91 & 2.55 \\
\hline
\end{tabular}

Table 11: Selected formal-descriptive variables for annual reports

\subsubsection{Reporting on CSR issues: A recent phenomenon}

In the international context, reporting on corporate social performance has been debated for several decades (for an overview see Owen \& O'Dwyer, 2008). While it more or less fell off the corporate agenda during the 1980s, corporations have increasingly paid attention to this topic within their annual reporting practices since the 1990s (Gray, 2001); especially after 2000, social disclosure became an essential part of corporate reporting and thus likewise of annual reports (KPMG International, 2008; Owen \& O'Dwyer, 2008). Alongside a wealth of literature, a substantial body of guidelines and schemes for reporting on social performance has been developed (e.g., the Global Reporting Initiative, or AccountAbility's AA1000 framework), yet hardly any compulsory regulation has been established to date (Villiers, 2006).

In Austria, explicit social disclosure is definitely a rather recent phenomenon and restricted to a small number of corporations (Denkstatt, 2004). Before 2000, it had been addressed infrequently - and even when it was, it was viewed as more of a natural process and as occurring only in passing, with corporations gradually learning to deal with the terminology of CSR throughout the 1990s (Strigl, 2005). The absence of detailed regulation has consequently left leeway for corporations to

139 For the use of visual elements, I examined the relative degree to which corporations employ visual elements (e.g., pictures, images, figures, diagrams, but also colors) in their annual reports in order to support the communication of messages (e.g., through the symbolic power of visual metaphors and the latent dimension of visual elements). The scale was structured as follows: $0=$ no use of visual elements; $1=$ scarce/infrequent use; $2=$ high quantity of visual elements with low symbolic power, or low quantity of visual elements with high symbolic power; 3 = high quantity of visual elements with high symbolic power.

140 For layout consistency, I examined typeface, consistency of color use, coherence of text superstructure, and integration of figures and tables. The scale was structured as follows: $0=$ hardly consistent; 1 = low to medium; 2 = medium to high; 3 = high to very high. 
deliberately pick issues from the CSR agenda and voluntarily disclose selected information to the public. However, and mainly following changes in EU regulation, the Unternehmensgesetzbuch (UGB, Austrian Commercial Code) has been recently modified with regard to annual reporting requirements (see also AFRAC Austrian Financial Reporting and Auditing Committee, 2006, 2009). ${ }^{141}$ According to $\int 243 \mathrm{UGB}$, large corporations are obliged to present essential non-financial indicators in their review of operations. These indicators are not further specified in detail but must depict information on environmental as well as on employee issues, and must be evaluated in relation to (future) financial performance. The regulation, however, only became effective at the very end of my observation period (in 2005): While this legal change - due to its vagueness - did not impact on reporting too much in 2005, Austrian corporations have increasingly begun to adjust their reporting behavior to international standards like the Global Reporting Initiative (GRI) in the last years.

Stand-alone annual CSR or sustainability reports only recently emerged as an additional and interesting sub-genre. ${ }^{142}$ Their content is, generally speaking, inspired by the TBL approach of reporting on economic, environmental, and social performance - although ties between these three pillars remain loose, and integration into management information systems remains fragmentary. Like more extensive social disclosure in mandatory parts of annual financial reports, the emergence of standalone CSR reports has been supported by key actors in the Austrian arena promoting a vision of "modern entrepreneurship" (Österreichisches Institut für nachhaltige Entwicklung, 2003). The main motives for publishing such a standalone report are, according to Denkstatt (2004), to position the focal corporation as a CSR leader and pioneer, respond to the increasing demand for social disclosure from (international) financial markets, communicate with internal and external stakeholders, and use such reports as a management tool.

141 As Brom and colleagues highlight in their current study (Institut für Ökologische Wirtschaftsforschung, 2008), the European Commission had hitherto postulated CSR primarily as voluntary action (see also, for instance, European Commission, 2001). In this respect, the recent changes in regulation also represent a highly notable change in EU policy.

142 Note that, due to sampling reasons, these reports are not covered in my research. 


\begin{abstract}
"EVN is much more than a business organization that merely supplies electricity, gas, heat, and water. It is a reliable and strong partner with regard to all issues of energy supply [...]. The corporation also stands for environmental protection, safety, proximity, and solidarity with all citizens [...]. We are prond to contribute our share and to live up to the responsibility of one of the largest corporations [...]. Increasing shareholder value and an attractive dividend are by no means the only criteria by which we have to judge our conduct of business these days."

Rudolf Gruber, CEO of EVN, Lower Austria's leading utilities corporation (in: EVN Umwelt- und Sozialreport 2000/2001: 3, December 2001; translation by the author)
\end{abstract}

\title{
6 The career of CSR
}

So far, I have argued that corporate responsibility beyond the bottom line has been a taken-for-granted notion in the Austrian context for a considerable period of time. Although firmly anchored in the institutional framework of the country something Matten and Moon (2008) call the "implicit" notion of CSR - the concept has been recently adopted by business organizations as a strategic instrument and rhetorical tool for managing and enhancing their legitimacy. ${ }^{143}$ As indicated above, the empirical study at hand is concerned with CSR as a managerial idea - i.e., with explicit CSR commitment as a distinct rationale for corporate decision making and organizational behavior. Against the backdrop of the increasingly stressed "problem" of societal responsibility/accountability of businesses I am especially interested in the local dissemination of the corresponding, and globally theorized, "solution": the management concept of CSR.

At field level, this raises a number of interesting questions. First of all, business organizations make social investments in the face of compelling and undeniable economic reasoning not to do so (but see my remarks on the business case for CSR above). As Margolis and Walsh (2003: 285) point out, this "discrepancy between actual practice and the theoretically espoused purpose of the firm prompts a quest for explanation". In order to make sense of corporations' adoption of CSR, one first needs to understand which organizations are susceptible and respond to pressures from their environment. Thus, the chapter to follow will focus, at its very core, on an investigation of drivers and influence factors of CSR commitment among corporations. In addition, I will address various characteristics of the career of explicit CSR in Austria, among them the concept's dissemination, significance, as well as its placement on the corporate agenda.

143 Implicit understandings are, however, not explicitly reported in corporate communication, the media, or elsewhere - which makes CSR difficult to measure prior to it becoming explicit, rationalized, and equipped with distinct labels. 


\subsection{Dissemination}

The empirical design of this research qualifies for the precise measurement of the adoption rate of CSR at discursive level, but it is limited in gauging its actual practice. Questions about decoupling, for instance cannot be dealt with here adequately (see chapter on methodology for more). Nonetheless, rhetoric and the corporations' explicit declaration of being committed to CSR, especially within such a prominent genre of corporate communication as annual reports, point to socially powerful expectations that may not be neglected by business organizations (see also Meyer, 2008). It thus allows for substantiated speculation on the increasing practical relevance of this management concept.

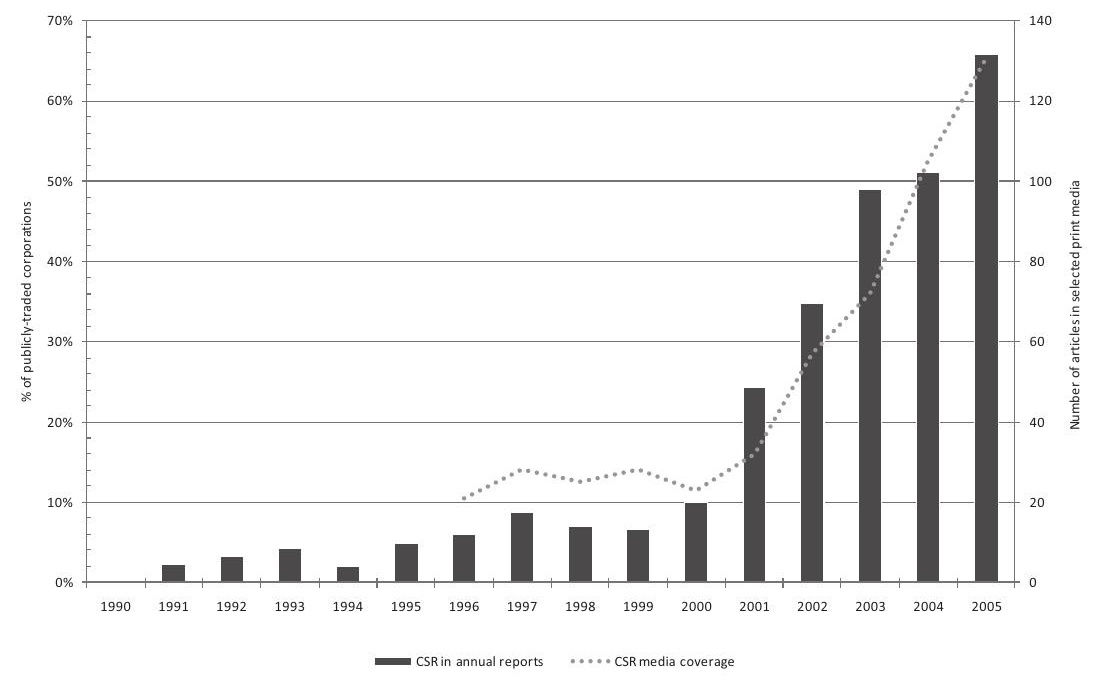

Figure 8: Dissemination of CSR in Austria

In total, I measure 259 annual reports from 69 different corporations that feature explicit CSR commitment through the use of issue markers. ${ }^{144}$ Figure 8 indicates the development of the main dependent variable - espoused commitment to CSR in

144 I will use the full count of 1,636 annual reports - corrected for missing values in variables (list-wise deletion) - for some of the following analyses (in particular, for the regression models). For others, however, I will employ a reduced sample that comprises only those annual reports that explicitly espouse corporations' commitment to CSR through the use of specific issue markers (i.e., the sampling criterion is that the binary dependent variable commitment to CSR equals 1). 
annual reports, measured in percentage of publicly-traded corporations in Austria per year - over time. This assault reveals a clear trend: Following rather low discursive activity throughout the 1990s, reference to the concept gains significant momentum after the turn of the millennium. While in 2000 only $10.0 \%$ of publiclytraded corporations referred to CSR in their annual report $(0.0 \%$ in $1990,4.9 \%$ in 1995), this figure increased to $65.9 \%$ in 2005.

Several developments and events might explain why explicit CSR appeared on the Austrian stage at that specific point in time. First, during the 1990s, various international documents on sustainability and CSR (for an overview, see Tully, 2005) set the tone on a more global scale. For Austria, like for other European countries, international standard setting activities - in particular the EU Green Paper (for details, see European Commission, 2001) and various other initiatives (e.g., CSR Europe [established 1995], World Business Council for Sustainable Development [1995], or United Nations Global Compact [2000]) - were highly influential for the national CSR agenda. Second, the period of emergence of CSR strongly corresponds with a series of corporate malfeasance, fraud, and accounting scandals (e.g., Enron, WorldCom, and Parmalat) that shocked the global business community and triggered a debate on issues of accountability and good corporate governance. CSR is therefore also regarded as a reaction to criticism and lobbying activities by interest groups, political parties, or social movements - and also an attempt to prevent further legal regulation. Third, one might argue that the rise of explicit CSR in Europe is (among other things) a response to changes in the historically grown institutional frameworks of European national business systems. Matten and Moon (2008), for instance, refer to changes in the European political system (e.g., regarding the capacity of the welfare state and corporatist policy making), the financial system (e.g., corporations increasingly using stock markets as a source of capital), the labor system (e.g., the weakening of the position of trade unions and industry associations), and the cultural system (e.g., increased awareness of the global impact of European MNCs and growing societal expectations regarding health, safety, the environment, and human rights issues).

The trend toward CSR is also perfectly mirrored in public discourse and CSR media coverage. For the years between 1996 and 2005, the dotted line in Figure 8 reflects the number of articles in selected Austrian daily newspapers employing CSR terminology. ${ }^{145}$ The overall tenor of CSR media coverage is overwhelmingly positive. Thus, and as in other continental European nations, CSR can be regarded a rather consensual issue in the Austrian context - although there is considerable

145 The media sample is extended for this illustration and comprises statistics from both quality press and tabloids. For each group, the two most important Austrian daily newspapers in terms of circulation are used: Die Presse and der Standard as well as Kronen Zeitung and Kurier. The samples date back as far as 1996. The data do not contain the issue markers sustainability and stakeholder approach, but they do contain the Anglo-American terminology CSR and CC as well as selected German equivalents. 
disagreement among its proponents with regard to the concept's actual design (see chapter on empirical context).

\subsection{Emergence of CSR in annual reports}

\subsubsection{Significance: Anchorage at different levels and extent of reference}

For the specific genre analyzed here, one could take into consideration not only the presence or absence of CSR, but the significance of reference. In this respect, the anchoring of CSR issue markers within the hierarchical superstructure of text (van Dijk, 1980) ${ }^{146}$ represents a first crucial piece of the puzzle. Figure 9 reports, as a proxy for significance, the appearance of CSR issue markers on divergent hierarchical levels of text (i.e., text, lead, title, preface, or cover/blurb). In addition, the overall extent of reference is measured as the proportion of space of the annual report devoted to CSR issues (based on a line count of all respective text fragments within the focal annual report). In order to illustrate developments and dynamics over time, data are divided by means of two time periods (1990-2000 versus 2001-2005); to depict the most recent trend, the last year (2005) is singled out.

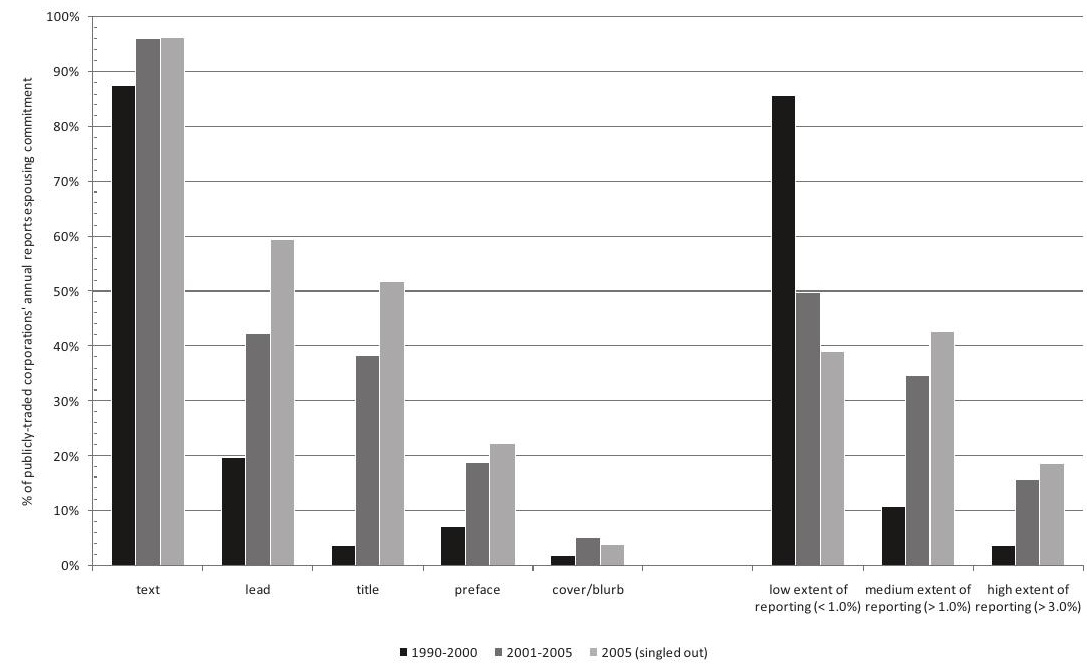

Figure 9: Significance and extent of CSR in annual reports

146 Note that thematic content is usually organized by an abstract hierarchical schema, consisting of conventional categories that specify what the overall function of the topics of the text is. Van Dijk (e.g., 1980, 1985, 1988) calls such a schema the superstructure of text. 
For the entire observation period, and with regard to hierarchical levels of text, in $94.2 \%$ of annual reports in which commitment to CSR is espoused, the level of text is used to position CSR issue markers. In 37.5\%, these keywords can be found as a lead, while in $30.9 \%$ even the title of a section within the report is used to refer to the concept. The preface $(16.2 \%)$ and the cover/blurb $(4.2 \%)$ are used to a much lesser degree. In sum, this contradicts the frequent assumption that CSR is just another modern concept or "management fad" referred to only in passing (e.g., in the introductory address by the CEO). Over time, one witnesses a clear increase of CSR at all text levels. Particularly toward the end of the observation period, CSR becomes more and more prominently positioned (title, lead, and, to a lower degree, preface).

On average, in $57.4 \%$ of annual reports in which commitment is espoused, less than $1.0 \%$ of space is devoted to text fragments that explicitly employ CSR issue markers, thus indicating a low extent of reporting on CSR issues. ${ }^{147}$ In $13.2 \%$ of annual reports, more than $3.0 \%$ of space is devoted to CSR issues, thus showing a relatively high extent of reporting, while for another $29.4 \%$ I measure a medium extent of reporting (between $1.0 \%$ and $3.0 \%$ of space available). Over time, one recognizes a significant increase in the extent of reporting - although, in sum, still a rather small proportion of the text corpus is assigned to, and explicitly addresses, CSR issues.

\subsubsection{Placement on the agenda: Anchorage in annual report sections}

This more formal description of references to CSR in annual reports should be complemented by an initial and brief look at content. In this vein, it is important to understand the ways corporations position this issue. A starting point is to examine the annual report sections in which corporations primarily anchor CSR.

Like all genres of communication, annual reports have specific genre rules. In addition to hierarchical levels of text (see above), one can think of the standard template of an annual report - i.e., of the typical sequence of more or less standard sections - as another superstructural feature of the genre. As van Dijk (1985; see also footnote 146) notes, the "schematic superstructures organize thematic macrostructures, much in the same way as the syntax of a sentence organizes the meaning of a sentence" (van Dijk, 1985: 69; see also van Dijk \& Kintsch, 1983).

In assigning CSR issues and vocabulary a specific place within a text, corporations also tentatively locate them on their agenda (e.g., as part of investor relations, human resource management, strategic considerations). Figure 10 illustrates -

147 The variable is measured as the proportion of text directly devoted to CSR issues, and is based on a line count of all respective text fragments within the annual report. Therefore, my approach yields rather conservative results. For more details, see also the chapter on methodology as well as genre characteristics for the annual reports included in my sample (presented in the chapter on empirical context). 
based on the main sections of a standard annual report (for coding, see chapter on methodology) - those sites that are most likely to serve as a "mooring" for CSR issue markers. It thus describes both the sequential superstructure of annual reports and, in a sense, the thematic macrostructure relevant for issues of CSR. On average, more than two report sections are used to refer to, and link up with, CSR.

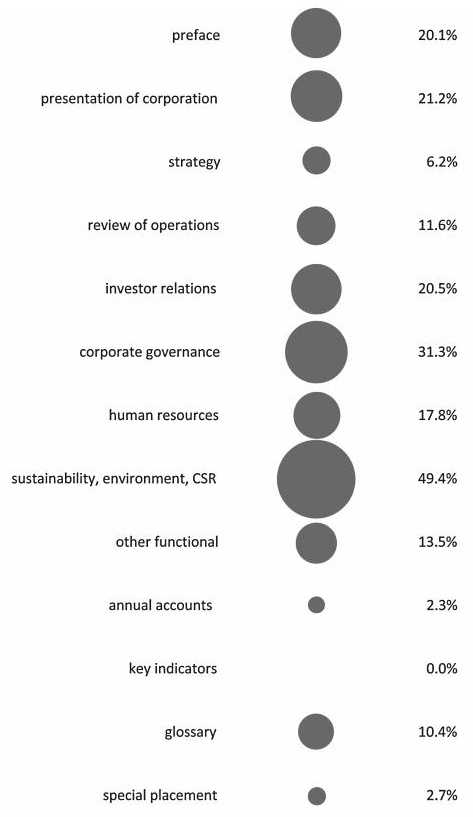

Figure 10: Anchorage of CSR in annual report sections

In $49.9 \%$ of annual reports in which commitment to CSR is espoused, a specific additional and novel - section refers to CSR; this section is usually labeled "sustainability" or "corporate responsibility", or, in a more traditional way, alludes to environmental issues or the TBL. Such sections on sustainability, environment, CSR first emerged in my sample in the year 1995 and throughout the 1990s are only to be found in annual reports of large corporations listed on the ATX; activity in high impact industries (see above), however, does not differentiate.

I also measured a rather high level of presence of the issue in the corporations' self-presentations - preface and interviews with corporate executives or board members $(20.1 \%)$, and presentation of the corporation $(21.2 \%)$ - that are usually positioned at the start of the annual report. Against the backdrop of "strategic corporate social responsibility" (Werther \& Chandler, 2011) and the business case for 
CSR, it somehow comes as a surprise that the data indicate a rather low level of presence of CSR in strategy (only 6.2\%) and other sections that report on the primary processes within the value chain: review of operations $(11.6 \%)$ and other functional areas $(13.5 \%)$.

On the other hand, the concept is often referred to in communication with shareholders and investors - i.e., in corporate governance (31.3\%) and investor relations (20.5\%). With CSR historically being strongly related to employer-employee relations (see also the tradition of HSE reports in the Anglo-American context), I would have expected a more frequent anchoring within the section on buman resources (only 17.8\%); yet it might be important to add that human resource management has also recently been integrated in the CSR or sustainability section. On the whole, CSR issues virtually do not exist in terms of figures, that is, in the annual statements of accounts (2.3\%, mainly as notes/comments) or in key indicators $(0.0 \%)$. A glossary is often used to clarify terms and acronyms (10.4\%). In $2.7 \%$, another section than those mentioned here refer to the concept (special placement).

In sum, this analysis identifies three major thematic moorings of CSR and thus strategies of addressing the issue: First, to create a new, specific, and exclusive section within the annual report to communicate CSR commitment, which could also be interpreted as an attempt to tailor accounts in the face of competing claims and pressures (see also Meyer \& Höllerer, 2009); second, to integrate CSR in the section most likely to be read by shareholders and financial market constituents (i.e., IR and corporate governance), and thus to aim at the reconciliation of competing claims and pressures; and third, to utilize CSR mainly for public relations and corporate self-presentation.

\subsection{Who espouses commitment to CSR?}

\subsubsection{Some basic considerations}

\subsubsection{Model overview}

In order to make sense of the adoption of the new managerial rationale referred to as CSR, a central objective of this empirical study is to explore which corporations are likely to espouse commitment. Here, I build on previous research on the diffusion of policies, practices, and forms. Scholars inspired by work in the domain of organizational institutionalism have placed special emphasis on various factors that mediate the ways an innovation and its underlying logic spread within a field. In more detail, prior studies have investigated the diffusion of new practices by focusing on organizational characteristics on the one hand, and on institutional variables that cause, impede, or go hand in hand with a move toward a new practice on the other. 
In the following, I will study these influence factors from various angles by formulating a series of hypotheses. A first cluster of hypotheses is linked to organizational characteristics and contingency factors. The second and third clusters examine key stakeholders' power and the nature of environment to which organizations must relate. A fourth cluster looks at classic arguments of institutional research: exposure to public scrutiny, prevalence of the concept in the field, and processes of mimetic isomorphism. The fifth and sixth clusters carry some thoughts on normative orientation and broader discourse further, while a final hypothesis explores period effects. In sum, the binary logistic regression models in this study comprise 15 hypotheses, testing a total of 18 variables in eleven different models. All variables, and especially the operationalization of these variables, were explained in greater detail in the chapter on methodology (see above).

\subsubsection{Controls}

To account for alternative explanations and to provide a more conservative test for my hypotheses, I include, in addition to a range of independent variables, a number of control variables that I believe to be potentially relevant for the phenomenon studied here.

General economic development. The commitment to modern management concepts, such as CSR, might also be influenced by the more general economic development and activity within a field, or by global economic cycles (e.g., Barley \& Kunda, 1992). Analyzing publicly-traded corporations, I use the index development of the ATX to control for the overall level of economic activity and development, though without proposing any direction of effect.

Dependence on capital market financing. The debt-equity ratio - also called leverage is included as an indicator for a corporation's reliance on capital market financing. Since my sample is limited to publicly-traded corporations - and thus might include a sampling bias with regard to the capital market - this will also serve as an important control for sampling issues. Generally, the literature argues that a high level of dependence will put corporations under greater pressure to conform to the expectations and logics of financial markets; several empirical studies have tested the impact of leverage on social and environmental disclosure (e.g., Richardson \& Welker, 2001; Cormier \& Magnan, 2003; Cormier, Magnan, \& van Velthoven, 2005; Aerts \& Cormier, 2009), albeit with mixed results. Thus, I refrain from postulating any a priori assumptions about the direction of effect.

Influence of professions. A management concept is further reinforced if key actors in the arena link up with it and actively promote it. In this context, the role of professions as carriers of diffusion has been highlighted in several studies (Greenwood et al., 2002; Sahlin-Andersson \& Engwall, 2002a, among others). As corporations seek and receive essential support from external communication experts in editing annual reports, large and renowned public relations agencies might play a 
substantial role in spreading new concepts: by mediating field and corporate levels, they regulate a vital intersection in the diffusion process of innovative practices. Hence, I control for whether or not a corporation's annual report is co-edited by one of the "big players" from the Austrian PR industry. As this variable addresses specifics within the production process of annual reports, it is - at the same time also a control for genre issues. A positive effect is expected.

Development over time. Timeline is introduced as a year-count variable to control for a secular trend and for an overall shift in the Austrian business environment. As explicit commitment to CSR is, as illustrated by Figure 8, on a constant rise, the expected positive effect of timeline seems obvious. ${ }^{148}$

\subsubsection{Hypotheses}

\subsubsection{Organizational characteristics}

Research in - more or less - related fields suggests that an array of organizational characteristics is crucial for the adoption of novel practices within an organization. I will be more specific on these variables in the following.

\section{Hypothesis 1: Larger corporations are more likely to show explicit commitment to CSR.}

Firm size affects corporate behavior in the context of various issues and in multiple ways and has thus been included as an independent or control variable in the majority of studies on the diffusion of new organizational practices (e.g., Fiss \& Zajac, 2004, 2006; Sanders \& Tuschke, 2007; on the relationship of firm size and CSR, see McWilliams \& Siegel, 2001; Campbell, 2007; Matten \& Moon, 2008; Udayasankar, 2008; Chih et al., 2010). Large corporations are frequently reference models for other organizations, are more visible to external stakeholders, and therefore are also under closer public scrutiny than smaller, less visible corporations. In addition, they are usually diversified to a higher degree, thus facing a more diverse range of stakeholders. In this study, I prefer to measure size primarily in terms of staff over a measurement in terms of sales in order to account for the sociopolitical perspective that is relevant here. ${ }^{149}$ Corporations with a high number

148 As I am more interested in a secular trend and overall shift in the field - and in order to actually depict this - I refrain from using year dummies as controls. Since annual reports are written and issued in the year following the events they report on, there is a natural lag present within the dataset.

149 Firm size is also considered in hypothesis 7, which focuses on large corporations that are flagships of the Austrian stock market in terms of market capitalization and stock exchange turnover (i.e., corporations listed in the ATX). In this way, it is possible to include a second variable that measures different aspects of organizational size without encountering any statistical problems of multicollinearity. 
of employees are regarded as bearing a greater degree of responsibility (for instance, as local employers; i.e., they provide jobs for the working population of a region) - and are thereby more likely to become the target of political intervention. Following prior research, I expect firm size to have a positive effect on the explicit commitment to CSR.

\section{Hypothesis 2: Older organizations are more hesitant to adopt the idea and terminology of explicit CSR.}

A hypothesis for firm age is included, as prior research has stated that corporations become more inert and develop resistance to change as they age (e.g., Sanders \& Tuschke, 2007; see also Meyer \& Höllerer, 2009); they prove to be less likely to link up with new management concepts that are regarded as modern. In Austria, older corporations are often owned by industrialist families. These businesses refer to shareholders that have long-established associations with the organization they originally founded or built up. Thus, these owners have also accumulated a considerable amount of power over time, based on the social influence that they develop through regularly occurring interactions in the context of formal organizational roles; through repeated interactions with managers; and through rich histories of relationships that have developed between employers and employees over several generations (Kang \& Sørensen, 1999). Furthermore, given the strong paternalistic approach toward CSR in Austria (see chapter on empirical context), such corporations might have been practicing, for decades, what Matten and Moon (2008) characterize as implicit CSR - without explicitly talking about or reporting on it. Consequently, I hypothesize that old and well-established corporations are more unlikely to adopt the modern idea and terminology of explicit CSR.

\section{Hypothesis 3: The bigher the financial performance of the focal corporation, the more} likely its explicit commitment to CSR.

One of the most vibrant lines in empirical CSR research focuses on the relationship, and mutual influence, of financial and social performance (e.g., McGuire, Sundgren, \& Schneeweis, 1988; Waddock \& Graves, 1997; for an overview, see Orlitzky, 2008, as well as the meta-studies of Margolis \& Walsh, 2003; Orlitzky et al., 2003). In order to assess a corporation's financial situation, I follow prior research (e.g., Chih et al., 2010) and include the return on assets as a profitability measure. While in existing studies profitability is an established indicator for the operative performance of a corporation, the association between profitability and CSR is inconclusive; decisive empirical evidence for a direct relationship between corporate social and financial performance is lacking. However, in line with, for instance, Waddock and Graves (1997), I propose a positive effect of slack resource availability and corporate social performance. In addition, more profitable corpora- 
tions might find themselves under greater moral pressure to "give back" to society. Non-profitable corporations, on the other hand, aside from lacking funds for corporate giving and philanthropy, are likely to encounter difficulties when required to justify such social investments vis-à-vis their shareholders.

\section{Hypothesis 4: Concentrated (private) ownership decreases the likelihood of explicit com-} mitment to CSR.

Ultimate power over an organization lies with ownership (Kang \& Sørensen, 1999). Consequently, a great number of studies have pointed to the crucial role of ownership structures - especially of concentrated ownership - and related power constellations for the adoption and implementation of management concepts (e.g., Aguilera \& Jackson, 2003; for CSR, see Atkinson \& Galaskiewicz, 1988, among others). This should especially hold true for concepts that touch on the legitimacy of vested interests. For instance, Fiss and Zajac $(2004,2006)$ and Sanders and Tuschke (2007) show that the divergent political and social interests of different types of owners affect the extent to which a shareholder value orientation is pursued in the corporations they control. With regard to CSR, Aguilera et al. (2007) argue that blockholders in a continental European governance system will push for CSR as they tend to prioritize long-term benefits for the corporation and to include the interests of a broader set of constituents. At the same time, however, Cormier et al. (2005) find a significant negative relation between blockholdings and the extent of environmental disclosure in German annual reports. High ownership concentration is one of the most central features of the Austrian corporate world (e.g., Gugler et al., 2002). Thus, my model includes the existence of concentrated ownership (see chapter on methodology for details). I expect corporations with concentrated (private) ownership - often in the hands of established industrialist families - to be less inclined to disclose their governance philosophy to the public (hypothesis 5 will clarify why I focus on private investors but exclude public entities here). Moreover, blockholdings are characteristic and a prerequisite for the traditional paternalistic approach toward CSR and hence run counter to the explicit commitment to CSR (see hypothesis 2 above). Consequently, I expect a negative effect of concentrated (private) ownership.

Hypothesis 5: Public sector influence decreases the likelihood of explicit commitment to CSR.

In Austria, a considerable number of corporations were nationalized in 1946 and 1947. ${ }^{150}$ Playing a substantial role during Austria's post-war economic resurrection, privatization of these corporations only began in the late 1980s. Since then, several

150 Austria was de facto annexed to the German Third Reich in 1938 and, after the end of WWII, saw a ten-year presence of Allied Forces on its territory. 
corporations have been sold to private investors directly or via IPO, with, in most cases, only part of the shares being offered and the rest remaining in public ownership. This way, a number of corporations - among them several included in the ATX - have been, directly or indirectly, partly owned by public entities at federal, state/Länder, or municipal level throughout my observation period. Corporations with significant public influence in corporate control will (or will even have to) attend to the interests of several groups of stakeholders and are thus perceived as acting more or less in line with general societal expectations. Therefore, a certain degree of social responsibility is an implicit feature of the governance policies within such organizations: I propose that corporations with a high level of public sector influence will experience less pressure to explicitly indicate their social responsibility as well.

\subsubsection{Pressure from financial market constituents}

The classic resource dependency argument (Pfeffer \& Salancik, 1978) states that the greater an organization's dependence on the resources provided by a particular stakeholder group, the greater this group's relative power is: When forced to decide, corporate decision makers will turn to the most influential groups (Meyer \& Höllerer, 2009). Given that explicit CSR, like the majority of modern management concepts, is of North American origin and, therefore, incorporates specific ideology (Djelic, 1998, among others), and that the financial markets - which are globally shaped by precisely this Anglo-American system of governance - play an important role in the diffusion process of CSR (see, for instance, the notion of ethical investment, or various sustainability indices), one cannot neglect to include the capital market in a study like this.

\section{Hypothesis 6: The relevance of the international capital market increases the likelihood of explicit commitment to CSR.}

For a long time, Austria's domestic stock market has been characterized by mediocre activity on the national stock exchange in Vienna, as well as by low liquidity, underperformance, and little interest from international institutional investors (Meyer, 2004). This became a substantial burden to the Austrian corporate world during the 1990s: Corporations increasingly had to address the international financial market in order to raise capital. The pressure to conform to AngloAmerican corporate governance and reporting principles rises to about the same degree to which these corporations are exposed to an international market for financing. Consequently, I propose that dependence on foreign investors and international financial capital - I use listing on a foreign stock exchange as a proxy here increases the probability of explicit commitment to the global trend of CSR. 
Hypothesis 7: The significance of the focal corporation for the national stock market increases the likelihood of explicit commitment to CSR.

In a similar vein, such considerations also apply to corporations that are regarded as flagships of the Austrian stock market in terms of market capitalization and stock exchange turnover. Compared to less central corporations, they are particularly dependent on the (national and international) financial market and consequently are under closer scrutiny by both national and international capital market actors. It is, in turn, more appropriate and conclusive for them to accommodate expectations of financial market constituents. With explicit CSR being increasingly important for consideration by investment funds and other institutional investors that adhere to an ethical investment strategy, or to appear on one of the various sustainability index lists, I expect a positive effect here. In addition - and as discussed in footnote 149 - listing on the Austrian Traded Index (ATX) is an additional measure of a corporation's size, and thus importance.

\subsubsection{The role of labor and industry}

Unlike shareholder value, for instance, the primary addressees of CSR are less obvious (Meyer \& Höllerer, 2009): Environments to which corporate managers must be responsive in terms of CSR activities are both internal and external. Historically and in terms of its current foci, contemporary CSR reporting is derived from, or goes hand in hand with, health and safety (i.e., employee-related) as well as with environmental issues.

Hypothesis 8: The higher the relative importance of the workforce for a focal corporation, the more likely its explicit commitment to CSR.

Employer-employee relations have been stressed as an important determinant of CSR by various research projects (Campbell, 2007). From a resource-based perspective (see chapter on CSR for more), one might assume that corporations that are more dependent on - and thus also more exposed to - the labor market will put more effort into demonstrating their ethical orientation toward the workforce and unions. Some researchers also draw on a labor cost argument (e.g., Navarro, 1988) or regard CSR as an institutional response to labor environments (e.g., Miller \& Guthrie, 2007). In this study, however, I expect the relative importance of workforce i.e., the labor-capital ratio - to have a positive effect on explicit commitment to CSR.

Hypothesis 9: Activity of the focal corporation in high impact industries increases the likelihood of explicit commitment to CSR. 
Corporations within high impact industries - i.e., in industries where production processes consume large amounts of resources and energy and/or cause considerable pollution - are under greater scrutiny and pressure from state regulators as well as from environmental and consumer organizations (in particular the latter in the case of direct business-to-consumer links) or from other social movements. In this context, it is important to hold that CSR has developed as a response to increasing environmental awareness and a distinct eco-movement within society. In Austria, the notion of sustainability has been an important and early part of discourse (see chapter on empirical context for more). I expect a positive effect of business activity in high impact industries on explicit commitment to CSR.

\subsubsection{Institutional pressures: Public scrutiny and prevalence of the concept}

As mentioned above, business organizations are vulnerable to pressures from their environment (Pfeffer \& Salancik, 1978). Organizational institutionalism states that organizations must gain legitimacy by signaling compliance with rationalized myths and with expectations of relevant audiences in the social context in which they are embedded (Meyer \& Rowan, 1977; DiMaggio \& Powell, 1983). However, the various organizations within an institutional field are not equally subjected to these audiences' attention - and neither are issues, practices, or concepts (Meyer \& Höllerer, 2009).

Hypothesis 10: The higher the visibility of the focal corporation in the media, the more likely its explicit commitment to CSR.

Prior research has suggested that a key indicator for the general public's awareness is the degree of visibility of the corporation in the media (e.g., Meznar \& Nigh, 1995; Fiss \& Zajac, 2006; Meyer \& Höllerer, 2009). Generally speaking, the higher a corporation's level of visibility, the greater the external expectation that the focal corporation employs professional and state-of-the-art management concepts. Media coverage affects a firm's reputation and legitimacy, at the same time making it an object of public attention and scrutiny (Fombrun \& Shanley, 1990; Deephouse, 1996; Brown \& Deegan, 1998; Deephouse, 2000; Pollock \& Rindova, 2003). Several empirical studies (Bansal \& Clelland, 2004; Bansal, 2005; Cormier et al., 2005; Branco \& Rodrigues, 2008; Aerts \& Cormier, 2009, among others) have shown that public pressure in the form of media exposure enhances corporations' disclosure of social and environmental issues. Consequently, I expect - somewhat similar to firm size or listing on the Austrian Traded Index (ATX), but here with another conceptual focus - a positive effect of visibility of the corporation in the media.

Hypothesis 11: A high volume of and positive tenor toward CSR in the media discourse increases the likelihood of explicit commitment to CSR. 
As Meyer and Höllerer (2009) note, public pressure is not only tied to the visibility of the corporation, but also to the attention certain issues receive. Agenda-setting indeed lies at the beginning of all diffusion processes (Rogers, 1995), with the media being one of the most influential arenas in which the relevance and legitimacy of innovative practices are negotiated: ${ }^{151}$ Media coverage of issues influences the awareness of the general public and significantly raises the salience of an issue on the public agenda (McCombs \& Shaw, 1972). Both corporate decision makers and audiences draw on the media to assess the relevance of an issue. Thus, the higher the level of media coverage of a certain management concept, the higher the expectation that this concept - representing state of the art of modern, professional management - is used in the corporate world. ${ }^{152}$ As Gamson (1992) points out, the media are not only a mirror of reality, but also constitute a "resonance chamber" that serves as a mediator between the locally prevailing cultural belief system and new ideas. More than merely raising the audiences' attention, the media can also promote evaluations of an issue by either endorsing or challenging it (see also Meyer \& Höllerer, 2009). Thus, while the volume of media coverage is an indicator for the flow of public attention, the tenor of media coverage influences the perceived level of appropriateness (e.g., Fombrun \& Shanley, 1990). One will expect favorable media coverage to positively influence the extent to which corporations espouse commitment to a specific management concept. In this study, I depict CSR in the media discourse by combining the volume and tenor of media coverage (see chapter on methodology for details).

\section{Hypothesis 12: The prevalence of commitment to CSR among model corporations' an- nual reports in the previous year increases the likelihood of explicit commitment to CSR in a focal corporation's current report.}

One of the fundamental arguments in organizational institutionalism has been that corporations follow - i.e., imitate - other organizations in the field (DiMaggio \& Powell, 1983). As an innovation diffuses and the number of its adopters grows, a threshold will be reached beyond which non-adopters increasingly risk reputation and legitimacy losses ("institutional bandwagon", according to Abrahamson \&

151 Especially where innovations spread among structurally equivalent actors rather than via inter-organizational ties, the media also play a central role in the theorization as they are both the stage and the leading actor in these processes (Meyer \& Höllerer, 2009). Several scholars (Hirsch, 1986; Abrahamson, 1991; Kieser, 1996, 1997; Strang \& Soule, 1998; Lounsbury, 2001; Fiss \& Zajac, 2006, among others) have pointed to the media as the broadcaster of success/failure stories or best practices as well as to their role as a promoter of new policies and strategies.

152 A "rhetorical bandwagon pressure", according to Abrahamson and Fairchild (1999: 732), "occurs because managers read discourse telling them that many organizations are adopting (or rejecting) this technique". 
Rosenkopf, 1993) or fall behind their competitors ("competitive bandwagon"). ${ }^{153}$ Despite considerable criticism with regard to an overly passive conception of adopters and over-optimistic assumptions concerning transferability of concepts from one social context into another (e.g., Sahlin-Andersson, 1996; Strang \& Soule, 1998; Snow \& Benford, 1999; Lounsbury, 2007), this model is still very prominent in institutional research. One of the main questions here is how organizations establish the relevant reference category. Frequency-based imitation (e.g., Haunschild \& Miner, 1997) builds on the assumption that potential adopters are receptive to the number of prior adopters; empirical support for this effect has been shown in several studies (Burns \& Wholey, 1993; Palmer, Jennings, \& Zhou, 1993; Kraatz, 1998; Rao \& Sivakumar, 1999; Zorn, 2004; Sanders \& Tuschke, 2007, among others). Trait-based imitation holds that not the sheer number but rather specific characteristics of prior adopters are influential for a decision to follow suit. Previous arguments have pointed to a variety of "traits" that single out high status or otherwise outstanding roles of model organizations; size (as an indicator for general visibility) and success (as an indicator for qualifying as role model for others) are among the most prominent (e.g., Burns \& Wholey, 1993; Haveman, 1993; Davis \& Greve, 1997; Kraatz, 1998; Strang \& Soule, 1998; Rao, Greve, \& Davis, 2001). For this study, I suggest that highly visible corporations within the field (largest corporations in terms of sales and/or listing on the ATX) serve as models for other corporate actors. Thus, the prevalence of CSR among model corporations in $t_{-1}$ is expected to have a positive effect on a focal corporation's explicit commitment to CSR. ${ }^{154}$

\subsubsection{Normative orientation and/or copy-paste effect}

While the hypotheses in the previous subsection focus more on the field level, the following hypothesis will investigate, in greater detail, how individual corporations deal with the situation.

Hypothesis 13: A focal corporation's explicit commitment to CSR in the previous year's annual report is relevant and increases the likelihood of explicit commitment to CSR in the current report.

Models of governance - at field level as well as at organization level - are highly normative constructs. For CSR, in proclaiming organizational values and beliefs as

153 Based on individually varying thresholds, the well-known S-curve of diffusion comes into play (Granovetter, 1978; Rogers, 1995).

154 I had to drop an original measure for prevalence at the field level (i.e., among all publiclytraded corporations) due to a multicollinearity problem with the media variables. I also refrained from using industry as a referent category due to the fact that some industries in Austria consist of a very small number of corporations. 
well as addressing issues of corporate ethics, this remains true to a greater extent. One might argue that commitment to CSR partly involves features of a quasireligious creed. However, even in the case of management originally intending the commitment to be merely rhetorical and decoupled from actual practice, substantial effects might occur as internal and external audiences start to take this published information at face value and come to expect a certain type of behavior from the focal corporation (Meyer \& Höllerer, 2009). This, then, makes it difficult for a corporation to switch back and forth between commitment and non-commitment without losing its credibility toward audiences in the long run (although corporations obviously can, and do, alter their positions)..$^{155}$ However, I expect an overall positive effect of commitment to CSR in $t_{-1}$ on commitment in the current year. In addition, this hypothesis controls for any copy-paste effect that may occur in periodically issued communication genres.

\subsubsection{Part of a discursive bundle? CSR and corporate governance}

Meyer and Höllerer (2009) argue that CSR moves in tandem with other management concepts concerned with questions of corporate control. It is in this regard that CSR is part of a broader discursive bundle. The authors, in line with Drori (2006), among others, point at the important role of the meta-discourse of corporate governance.

Hypothesis 14: Reference to the meta-discourse on corporate governance issues increases the likelihood of explicit commitment to CSR.

In modern societies, corporations often find themselves confronted with competing demands and expectations from divergent audiences. For the case of shareholder value and CSR, Meyer and Höllerer (2009) illustrate, that the very same corporations simultaneously claim to be committed to different management concepts - even at the price of inconsistency. As the normative contradiction between such concepts cannot be removed, and subordination is not convincing, there is a strong demand to create other, higher-level concepts that are able to function as an "umbrella" or "bridge" to integrate divergent interests, at least to some extent. Invoking corporate governance - a concept that has existed since the late 1980s and early 1990s (Aoki, 2004; for a study of the global institutionalization of corporate governance see, for instance, Drori, 2006) - represents a practicable solution. Relabeled as "good corporate governance", and positioned as a remedy and preventative measure against unintended or harmful behavior of executive

155 Meyer and Höllerer (2009), for instance, empirically investigate rhetorical strategies of corporations referring to, and switching between, several management concepts - even at the price of normative inconsistency. 
managers, it has a highly positive connotation and has been regarded as a rather consensual issue since the early 2000s. Like in most other countries, the call for general standards and soft law regulation in Austria was a direct consequence of corporate malfeasance; this also led to the formulation of a formal Austrian Code of Corporate Governance in 2002 (after two years of consultation, and with involvement of - among others - the social partners and board members of major corporations). Corporate governance, I hypothesize, fuels and enables - in particular for publicly-traded corporations - explicit commitment to CSR. I expect a positive effect of reference to corporate governance. ${ }^{156}$

\subsubsection{Period effects}

In all processes of diffusion and institutionalization, dynamics over time play an important role. While a secular time trend is, as a control variable, included in the models specified above, period effects are not.

Hypothesis 15: Early adopters of explicit commitment to CSR will differ from late adopters.

A core assumption of organizational institutional research postulates that early adopters of innovative practices or of new concepts differ from late adopters; moreover, that adopters' organizational characteristics are of decreasing relevance as the respective practice or concept spreads widely within an organizational field (Tolbert \& Zucker, 1983, 1996). Above all, empirical research on the so-called twostage model of diffusion (e.g., Abrahamson \& Rosenkopf, 1993) or institutionalization (e.g., Dobbin \& Sutton, 1998) goes in that direction (for an overview, see also Walgenbach \& Meyer, 2008, among others). In order to test this assumption, I eventually drop the variable timeline and split the dataset according to two relevant time periods: the early years from 1990 through 2000 versus the late years from 2001 through 2005 (see chapter on methodology for details). For both periods, a comprehensive model - including control and all independent variables according to hypotheses 1 to 14 - will be estimated.

\subsubsection{Results}

Empirical data (14 independent variables and four control variables) are employed in eleven binary logistic regression models (see chapter on methodology for details). Table 12 presents basic descriptive statistics and correlations for all

156 In a sense, adding corporate governance to my statistical model should also improve explanatory value and control for a very prominent - separate but nonetheless closely related - concept. 
variables involved. Table 13 then reproduces the different models that test my hypotheses. The anticipated direction of effect is indicated in the first column. I also report important indicators and measures for overall quality at the bottom of the table. ${ }^{157}$ In particular, and despite occasionally high correlation coefficients stated in the descriptive statistics, there is no indication of multicollinearity problems: Variance inflation factors (VIFs) range between 1.10 and 4.71 (mean VIF = 2.10), with a condition number of 5.31 for the full set of (centered) variables. ${ }^{158}$ As another technical note: For some variables, my results imply a change of sign when comparing different models. As multivariate regression models implicate mutual interdependencies of variables, such changes happen regularly when moving from less specified models (i.e., hypothesis testing) to more specified models (i.e., various full models) and are thus of no real consequence (StataCorp LP, 2007a). In all cases, however, no move from a significant positive to significant negative prediction occurs; the results rather point to a clear trend that can be interpreted in a meaningful way (see below).

In Table 13, model I presents results for control variables. Models II to V test the first four clusters of hypotheses as outlined above, with model VI providing an overall outline. All hypotheses but one are supported by these models; the variable tested for the non-confirmed hypothesis is also significant - however, with a contradicting direction of effect. Models VII and VIII add additional variables stepwise (i.e., hypotheses) that are both strongly supported by my data. In sum, the comprehensive model (model VIII) shows seven independent variables and two controls significant with the anticipated direction of effect, and one independent variable significant, but with a contradicting sign. This highly explanatory comprehensive model can be reduced and optimized, maintaining almost the same level of quality (see $\log$ likelihood, Mc Fadden's adjusted $\mathrm{R}^{2}$, Wald $\chi^{2}$ ): I therefore conduct a step-by-step elimination of the least significant variable (i.e., for variables with $\mathrm{p}$ values below significance) in each case. This way, I end up with a lean, parsimonious/optimized model (model IX, comprising a total of only eight significant variables). Finally, models X and XI test the comprehensive model for the two time periods identified, demonstrating that a different set of variables is significant for each period.

157 Alongside basic information, like the degrees of freedom, or the number of observations for each model, I report Wald $\chi^{2}$ and - as a global measure of fit - McFadden's adjusted R2 (for details on interpretation of these measures, see, Long \& Freese, 2006, among others).

$158 \mathrm{I}$ used the collin command in STATA 10 to analyze the magnitude of multicollinearity. A common rule of thumb states that multicollinearity is not a concern if individual VIFs are below 10.0 and condition number is below 15.0 (see Kutner, Nachtsheim, \& Neter, 2004; StataCorp LP, 2007a, among others). 


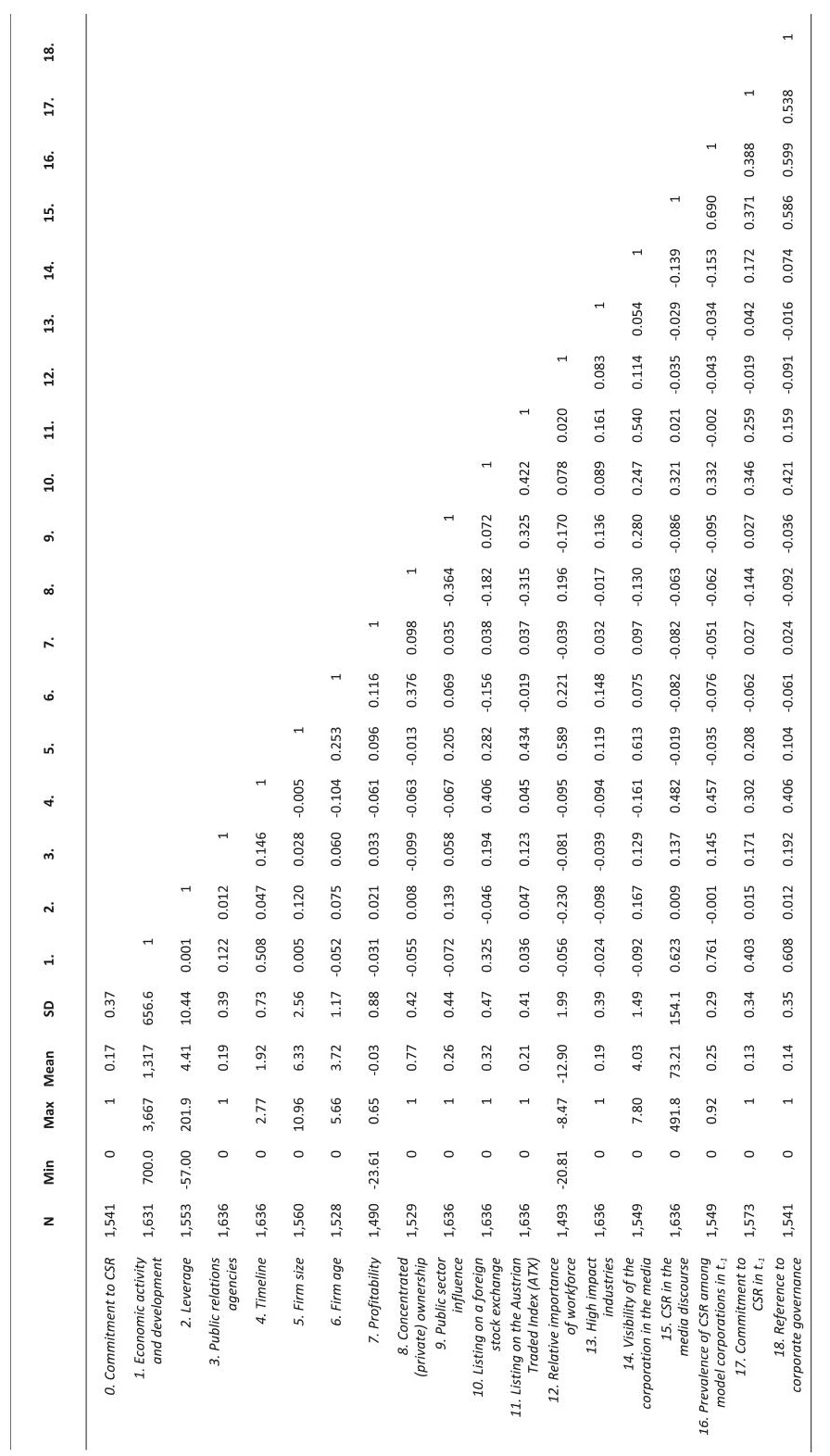

Table 12: Descriptive statistics 


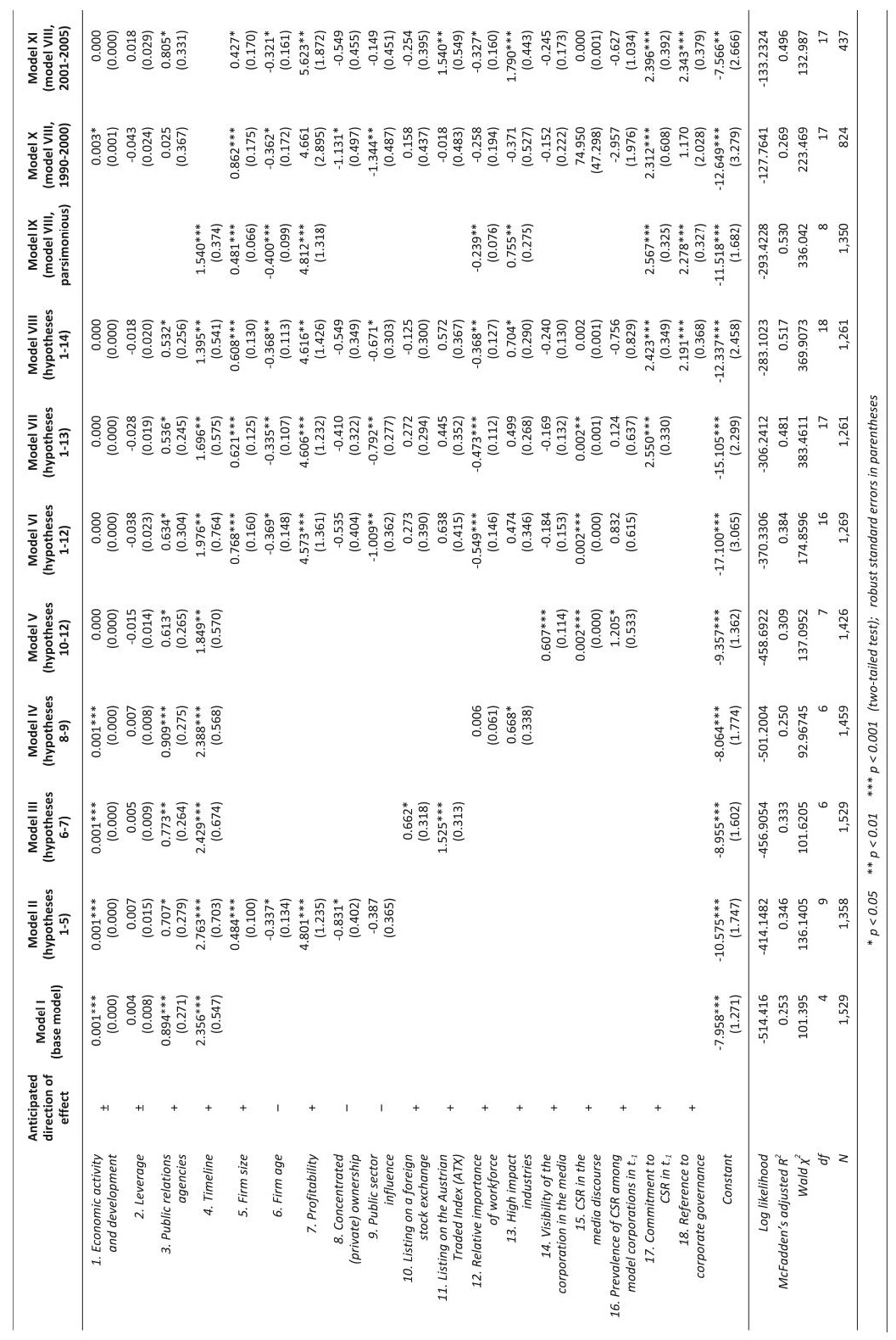

Table 13: Regression models I-XI 


\subsubsection{Interpretation and discussion}

I will interpret and discuss, in the following, the individual models presented in Table 13 - or, more precisely, the variables introduced and added by each model. I will thereby comment on the result for the respective variable and, in addition, give an outlook on its performance throughout the various models to follow. Period effects (models X and XI) are dealt with separately.

\subsubsection{Model I (base model)}

To begin with, I will offer some remarks on the control variables introduced by model I. Economic activity and development has a clear positive effect on CSR commitment throughout models I to IV, but drops below significance as soon as the variables on institutional pressures are taken into consideration. I find no evidence that leverage - a corporation's reliance on the capital market as opposed to debt financing - is a significant predictor. The positive effect of involving major public relations agencies in crafting reports is confirmed throughout almost all models (with the exception of the parsimonious/optimized model ${ }^{159}$ ), emphasizing the influence of this profession on the genre and/or management concept analyzed in this empirical study. As expected, timeline is highly significant; the fundamental importance of the linear time trend as a control variable is displayed throughout all the models.

\subsubsection{Model II (bypotheses 1-5)}

Model II adds the cluster of organizational characteristics that are supposed to influence a focal corporation's likelihood to espouse explicit commitment to CSR. Among those predictors (which are most commonly referred to in related studies; see above), firm size is of highest significance, and its positive relationship is clearly confirmed. The same statement holds true for profitability. My study thus provides additional affirmation that CSR is especially carried forward by large and successful corporations.

Firm age, on the other hand, is also a very powerful independent variable, yet one that is significantly negatively related to explicit commitment to CSR: Older corporations are obviously much more hesitant to adopt the concept. But does this mean that these corporations do not feel socially responsible at all? Drawing on

159 Note that, for the parsimonious/optimized model, I conducted a step-by-step elimination of the least significant variable in each case (i.e., for variables with p-values below significance); due to interdependencies, public relations agencies and public sector influence (see below) drop below significance during this process and are thus eliminated from the parsimonious/optimized model. 
Matten and Moon (2008), I would not necessarily argue in this direction. Considering a continental European tradition of implicit CSR and the specific context of Austria, the opposite might be true. For long-established organizations, especially those with stable relationships with a broad range of stakeholders, the social responsibility of business is something that is taken-for-granted - and thus certainly nothing they need to explicitly discuss: It is something that is simply done and fulfilled in day-to-day business activities.

To a lesser degree (i.e., significant only in hypothesis testing, but not throughout the full models), such findings hold true for corporations with private blockholdings. As argued above, long-established corporations in Austria are, in many cases, characterized by concentrated (private) ownership, often with the second, third, or even fourth generation of an industrialist family in charge of corporate decision making. Among this socioeconomic elite, a paternalistic approach toward CSR as well as borrowing from Christian-ethical thinking with regard to social obligations is not uncommon. Moreover, concentrated ownership results in a rather low number of shares owned by anonymous/dispersed shareholders to whom annual reports particularly cater, whereas other and more direct communication channels qualify for the exchanging of information between corporate decision makers and core owners.

Public sector influence - by means of ownership - is another variable that negatively influences corporations' explicit commitment to CSR. Although not confirmed in hypothesis testing, it gains significance in the various full models. As argued above, corporations with considerable influence of public entities in corporate control - often, these corporations are also characterized by large blockholdings of public entities - are perceived as acting in line with broader societal expectations. They are organizations "owned" by agents of the general public and should thus reflect its multiple interests in their behavior. My results indicate that, for corporate decision makers, this reduces the need to emphasize such alignment of interests by espousing explicit commitment to CSR.

\subsubsection{Model III (bypotheses 6-7)}

A second cluster of hypotheses predicts the influence of financial market constituents. Both listing on a foreign stock exchange and listing on the Austrian Traded Index (ATX) are confirmed in hypothesis testing but lose significance in the full models. ${ }^{160}$ In this way, my study illustrates that corporations' need to attract international financial capital is of less importance for the commitment to CSR than often argued. The role of being among the flagships on the national stock exchange simultaneously a measure of visibility and size - is also put into perspective. ${ }^{161}$

160 Note that I will comment on period effects separately below.

161 These results also have implications at the methodological level. Together with the non- 


\subsubsection{Model IV (bypotheses 8-9)}

Model IV introduces two interesting variables that allude to the historic roots of CSR reporting: the role of labor (as opposed to capital) and industry. Relative importance of workforce shows the expected sign in hypothesis testing but remains below the significance mark. Most interestingly, this radically changes for the more specified models: A highly significant and negative prediction of CSR becomes evident in the full models. Relative importance of workforce thus marks the only hypothesis in this study that is not confirmed and must even be rejected entirely. This insight urges us to make sense of the fact that explicit CSR in Austria is not as, for instance, Miller and Guthrie (2007) argue - a response to the focal corporation's dependence on labor markets, but, to the contrary, that CSR commitment increases with decreasing relevance of this means of production.

One possible explanation is that corporations that rely more on capital instead of labor (i.e., human capital) to produce economic value seem to be forced to legitimate their role and position within society to a much higher degree. For instance, in the case of fully automated production, corporations might wish to undergo somewhat of an image change replacing the negative perception of a factory full of machinery and "robots" with the positive imagery of a modern workplace (essentially displaying a human face in creating, designing, and maintaining it for the good of society). This, however, corresponds well with interests at play in the recent debate on the taxation of the factor capital analogous to the factor labor. ${ }^{162}$ So, contrary to my expectations, commitment to CSR is not so much directed at labor markets but at civil society and state authorities in order to prevent further regulation. An alternative explanation comes to mind when recalling the construction of the underlying variable: the relation of staff number to total assets. Its reciprocal ${ }^{163}$ - i.e., total assets per staff - in some manner depicts the dependence of the corporation on the single employee as it indicates the amount of capital that is to be "cultivated" by the individual employee. Admittedly, this is a speculative thought insofar as my empirical design cannot capture structural elements of workforce composition; nonetheless, it is very tempting to think of the indispensability of the individual employee - and thus of human capital - as a

significant results for leverage, they provide ample argument against potential reservations of a financial market bias in sampling decisions (i.e., the criticism that my sample comprises only publicly-traded corporations).

162 See also the German catchphrase of the so-called Maschinensteuer (i.e., - loosely translated "taxation of tangible fixed assets": a controversially discussed sociopolitical term for the introduction of a supplementary social insurance payment to offset a loss in contributions caused by the increased rationalization of jobs through automation) as well as the discussion centering on the high level of non-wage labor costs, both aiming at mitigating the "unfair taxation of labor".

163 Note that this will change the sign of coefficients, with all other the values (coefficients, standard errors, p-values) remaining the same. 
predictor for CSR in less-labor-intense corporations. Seen this way, explicit commitment to CSR in annual reports is a clear signal decision makers send to existing staff. This is also manifested in the actual wording within annual reports, playing with the metaphor of "being one family": the family (i.e., organization) is dependent on its members, and family members (i.e., human capital) cannot be dismissed at will.

I refrained from using industry dummy variables in my study as some industries in Austria consist of a rather low number of corporations. Defining high impact industries, however, seems an appropriate way to integrate this aspect in the regression models. The positive effect of environmentally high impact industries is confirmed in hypothesis testing and in the comprehensive (and also in the parsimonious/optimized) model, but reported below significance in the other models. Nonetheless, it provides evidence that corporations from these industries are more susceptible to explicit CSR policies and activities. It is also important to note that a strong environmental discourse has been established in Austria which constitutes yet another rationale and terminology under which references may have been made to the environmental dimension of social responsibility. I will return to this point later in greater detail.

\subsubsection{Model V (bypotheses 10-12)}

Finally, I introduce and test a number of classic institutional hypotheses for my data. I argue that the cultural and social embeddedness of governance issues together with the broad variety of addressees of annual reports - links issues of overall public visibility and a focal corporation's explicit commitment to CSR. I assume the visibility of corporations to be a factor that increases public exposure and scrutiny, and the media discourse (i.e., volume and tenor of media coverage) to be an indicator of cultural resonance and legitimacy of the concept within the field. I also argue, drawing on core institutional arguments, that corporations follow and imitate leading organizations in the field.

Visibility of the corporation in the media proves to be a highly significant predictor for CSR during hypothesis testing. However, the variable loses its significance in the full models: As soon as firm size and other organizational characteristics are added, I even witness a change of sign with values, albeit still below the significance mark. Aside from corroborating the strong explanatory value of these organizational variables, I also interpret this as evidence that public scrutiny of corporations, in the context of rather consensual issues like CSR (see above), is less influential than individual characteristics of adopting organizations.

CSR in the media discourse - a combined measure of volume and tenor of media coverage - determines the visibility and resonance of the concept of CSR at field level. It is important to note that CSR did not receive much media attention until it became explicit around 2000, and that the tenor of media coverage is almost 
unanimously positive - critical statements thrive exclusively on the admonishment that it is much ado about something that should be self-evident. Consistent with my assumption, the rising and overwhelmingly favorable media coverage has a positive effect on CSR commitment in annual reports. The variable remains highly significant, even after adding other clusters of hypotheses; only at the point when introducing corporate governance, I witness a reduced effect (i.e., below significance). Obviously, CSR is part of a broader discourse on corporate governance issues, with the latter being more relevant for indicating conformance with socially agreed values and norms than media discourse.

Hypothesis testing in model $\mathrm{V}$ also suggests mimetic pressures at work: The prevalence of CSR among model corporations in $t_{-1}$ significantly increases the likelihood that a focal corporation will also indicate commitment. This effect, however, ceases and actually turns negative (albeit below significance) when other variables complete the picture. Although I find - as suggested by the broad literature on diffusion - evidence for some mimicry, its relevance is less important in the case studied here.

\subsubsection{Model VI (bypotheses 1-12, full model)}

Model VI presents a first full model that integrates the previous hypotheses in one single picture. Overall, I witness considerable influence of almost all organizational characteristics - firm size, firm age, profitability, and public sector influence - as anticipated, a significant negative effect of relative importance of workforce, and a significant positive effect of CSR in the media discourse. From the controls, public relations agencies and timeline are reported as significant. All variables were also addressed, and interpreted, in more detail above. In the sections to come, I will add two important variables to the full model in order to eventually obtain a comprehensive model. I will then present a parsimonious/optimized model that contains the most essential variables. Finally, I will test my data for distinct time periods to account for period effects.

\subsubsection{Model VII (bypotheses 1-13)}

It is not only organizational characteristics and field level pressures that influence a focal corporation's commitment to CSR. Management concepts are highly normative constructs, especially with their underlying governance models referring to normative belief systems. As argued above, this makes it difficult for organizations to switch back and forth between commitment and non-commitment without losing credibility. However, examining my data I witness - especially for the early years of CSR in Austria - a substantial amount of casual commitment. Model VII introduces an additional variable that statistically tests, and confirms, the assump- 
tion that commitment to CSR in $t_{-1}$ is highly significant for commitment in the current annual report.

This variable also controls for another organizational practice that is relevant here: namely the fact that organizations potentially copy-paste texts from one document to another (i.e., from the previous year's issue of an annual report to the current one). ${ }^{164}$

\subsubsection{Model VIII (bypotheses 1-14, comprehensive model)}

Finally, a hypothesis is devoted to the meta-discourse on corporate governance issues; results show a significant positive effect of reference to corporate governance on the dependent variable. More generally speaking, these findings indicate that management concepts are not singular points of orientation but rather deeply linked with related issues and/or concepts and therefore also integrated in complex discursive bundles (see also Meyer \& Höllerer, 2009).

Figure 11 illustrates the relationship between CSR and corporate governance over time - and depicts a rather simultaneous diffusion process within my sample. While explicit CSR existed to some extent throughout the 1990s, the label "corporate governance" entered the genre of annual reports for the first time in 1999 and skyrocketed in the following years, surpassing commitment to CSR only three years later when the formal Austrian Code of Corporate Governance was published in 2002. Over time, I also notice increasing joint appearance of CSR and corporate governance issue markers in a corporations' annual reports: In 2005, 63.4\% of publicly-traded corporations refer to both CSR and corporate governance, while $2.5 \%$ refer to CSR exclusively, and another $14.6 \%$ to corporate governance exclusively; however, this leaves a remarkable number of corporations $(19.5 \%)$ that do not fall in line with these global trends at all.

164 However, while this certainly may apply for specific parts of an annual report (such as the mission statement, statement of corporate values, and glossary), and annual reports follow certain templates, most parts of the text are altered and drafted anew each year. 


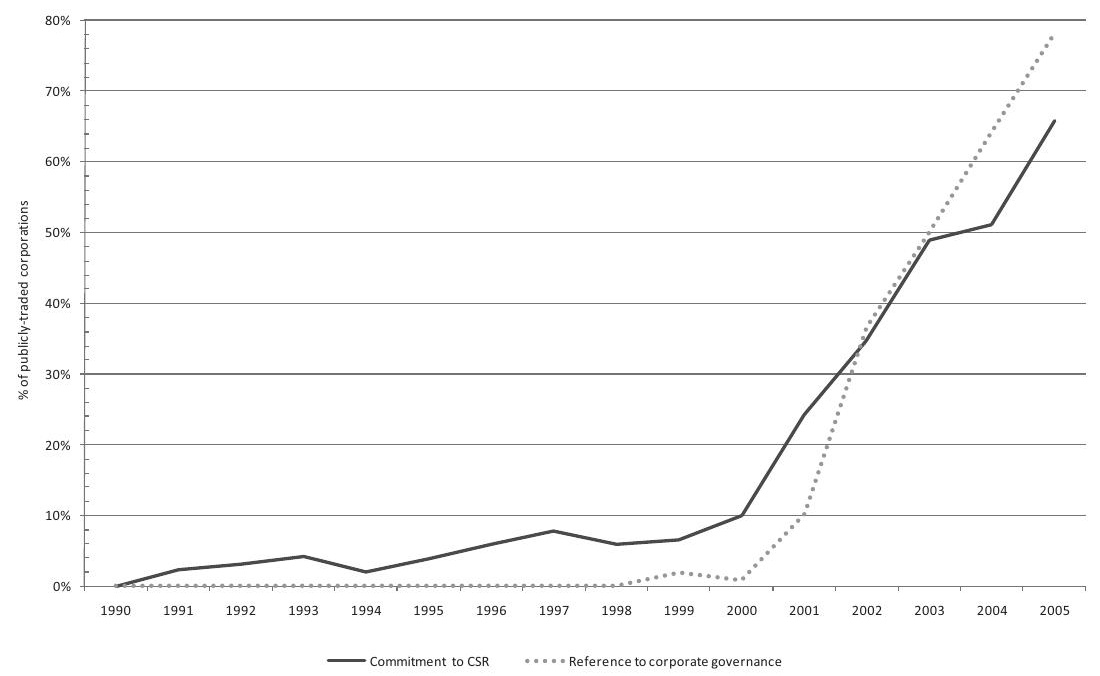

Figure 11: CSR and corporate governance over time

For both concepts, the events around 2000/2001 (i.e., corporate malfeasance that shocked the global business community) boost relevance and dissemination, with corporate governance being the more direct answer addressing the problematic nature of principal-agent relations. Framed as good corporate governance, however, the link between corporate governance and CSR becomes evident for reestablishing trust in corporations and reassuring business' role within society.

Nonetheless, I suggested a causal relationship. My argument is twofold: On the one hand, corporate governance, in particular, has offered the rhetorical tools "to reframe issues in institutionally-consistent terms" (Miller \& Guthrie, 2007: 2; Suddaby \& Greenwood, 2005) in the face of divergent institutional environments, global and local alike. Only this has enabled the implicit understanding of CSR to metamorphose into an explicit commitment in an arena characterized by a focus on shareholder interests. ${ }^{165}$ On the other hand, good corporate governance, despite its global theorization, remains rather abstract. For the continental European as well as for the Austrian context, CSR has provided an existing, indigenous solution at hand. For this reason, the reference to corporate governance might provide an important piece of the puzzle within this study.

165 Note that this study investigates publicly-traded corporations and financial annual reports addressing a national and international capital market. Meyer and Höllerer (2009) show how corporate governance, as a conceptual and discursive mediator, is able to link the - at normative level opposing - concepts of shareholder value and CSR. 


\subsubsection{Model IX (parsimonious model)}

The parsimonious/optimized model IX carries forward the previous model and by means of a step-by-step elimination of non-significant variables - reduces complexity without compromising statistical quality. Two variables that are flagged as significant in the comprehensive model drop below significance during this process due to interdependencies: public relation agencies and public sector influence. For all other values included in model IX, results corroborate previous interpretation: I witness the same or an improved level of significance (at least $\mathrm{p}<0.01$ ), thus presenting very strong evidence.

\subsubsection{Models X and XI (period effects)}

Finally, the comprehensive model is tested for two selected time periods in order to shed some light on dynamics over time: specifically, the years before and after the corporate malfeasance scandals. In this manner, I am empirically able to confirm a core assumption of institutional and diffusion research, namely that early adopters of an innovative practice differ from late adopters in terms of organizational characteristics (see Table 13 for details). Beyond demonstrating for each period that a distinct set of variables characterizes corporations indicating explicit commitment to CSR, I also show that field-level pressures gain significance over time while organizational characteristics tend to lose relevance with an increasing institutionalization of the practice.

Some variables retain their level of importance throughout the whole observation period: firm size, firm age, and commitment to CSR in t. . Other characteristics, like leverage and listing on a foreign stock exchange, or institutional factors like visibility of the corporation in the media, CSR in the media discourse, or prevalence of CSR among model corporations in $t_{-1}$ are not significant in any particular period.

In more detail, early adopters - corporations espousing explicit commitment to CSR in the period 1990 through 2000 - can be portrayed as large (firm size, positive effect) and rather young (firm age, negative effect) organizations, with dispersed ownership - i.e., without blockholdings or substantial state influence (concentrated (private) ownership and public sector influence, both negative effect). In the case of a focal corporation indicating commitment in the previous year, this significantly raises the odds for commitment in the current annual report (commitment to CSR in $t_{-1}$, positive effect).

In the period 2001 through 2005, proponents of CSR are again large (firm size, positive effect) and young (firm age, negative effect) organizations that espoused commitment in the previous year (commitment to CSR in $t_{-1}$, positive effect). My data also suggest that for late adopters, the slack resource argument is valid as they are, to a significant degree, profitable corporations (profitability, positive effect). These business organizations also draw considerably on support from major public 
relations agencies (public relations agencies, positive effect): PR agencies (like other knowledge entrepreneurs including consultants and professions), fulfill an important role in the dissemination of new ideas, practices, and forms. Ownership structures, on the other hand, are not significant for late adopters.

Compared to the 1990s, however, distinct field-level pressures come into play: pressure from national capital market constituents (listing on the Austrian Traded Index (ATX), positive effect), business activities within environmentally ${ }^{166}$ high impact industries (bigh impact industries, positive effect), and consequences of capital-intense production technologies (as opposed to labor-intensity; relative importance of workforce, negative effect). In sum, this clearly points to broader societal implications and an ongoing institutionalization of explicit CSR within the business community and society. Linkage with the meta-discourse of corporate governance also proves to be a significant predictor for commitment to CSR (reference to corporate governance, positive effect), despite the fact that it did not exist at all in Austria during the 1990s.

\subsection{Summary}

This - more quantitative - part of the study conveys a clear idea of the emerging CSR discourse in Austria during the 1990s and early 2000s. First, both for the genre of annual reports as well as for print media, it was possible to witness a rapid dissemination of explicit CSR after the turn of the millennium. I briefly discussed several possible triggers for this development: international standardization on CSR-related issues, a series of corporate malfeasance in the aftermath of shareholder value euphoria (also leading to the increased relevance of issues of good corporate governance), and changes in the historically grown institutional framework in Austria.

Second, I empirically illustrated the increasing significance of CSR within the genre of annual reports, both in terms of anchoring in text superstructure, as well as in terms of extent of reference. The picture was completed by a first examination of the concept's content: I showed that the three major thematic moorings and strategies of addressing the issue of CSR in annual reports were either to create a new and exclusive section, to integrate CSR with issues concerning investor

166 One might have expected corporations within high impact industries to be among the CSR pioneers - however, they are late adopters: A plausible explanation is the existence of yet another, and well established, discourse in Austria: the discourse on environmental issues. A negative sign for the variable in the first period (although below the significance mark), and a highly significant positive effect in the second period, can be interpreted such that corporations in these industries continued to adhere to the specific environmental discourse, and only with increasing institutionalization of explicit CSR shifted attention to the CSR subdiscourse of sustainability (including notions like sustainable development, or the TBL, for instance). 
relations and corporate governance, or to utilize CSR for public relations and marketing purposes.

Third, at the very core of this chapter, I examined which corporations would be likely to espouse explicit commitment to CSR. Testing a broad range of organizational characteristics and institutional variables, I presented and discussed results from various binary regression models, with a parsimonious/optimized model providing a compact overview. Generally speaking, I found large, young, and profitable corporations that employ capital-intense technologies and operate in high impact industries to be more inclined to espouse explicit commitment to CSR policies and activities. This very much corresponded with my initial proposition that it was not the typical Austrian corporation (i.e., medium-sized, traditional, family-owned) that primarily linked up with, and adopted, explicit CSR policies and practices. Such corporations were already seen, by their owners and executives alike, as being in line with societal expectations, and as behaving responsibly within the broader institutional framework of the country. In other words: Business organizations that have actually practiced CSR implicitly for a long time - mainly as part of their self-understanding and identity - picked up the explicit terminology rather late. For them, CSR was "something you do - but that you don't talk about too much". A media quote illustrates this point well:

"It is true that corporate social responsibility [...] is being practiced, but it is not recognized as a strategic instrument and is thus not employed as profitably as it could be. And, above all, it is not being communicated" (Roman Mesicek, managing director of the platform respAct/CSR Austria, cited in: Die Presse, page R4, September 15, 2005; translation by the author).

In sum, several pieces of evidence clearly point to broader societal implications and an ongoing institutionalization of explicit CSR, both within the business community and society: the normative aspect of uttering a "CSR creed" in the past, the cooccurrence of CSR with issues of corporate governance, the insight that early adopters of CSR differed from late adopters in terms of organizational characteristics, and the fact that field-level pressures gained significance with the increasing institutionalization of explicit CSR. 
Markus A. Höllerer - 978-3-653-01464-8

Downloaded from PubFactory at 01/11/2019 11:31:02AM

via free access 
"Both social actors and patterns of action they engage in are institutionally anchored. The particular types of actors perceived by self and others and the specific forms their activity takes reflect the institutionalized rules of great generality and scope."

John W. Meyer, John Boli, \& George M. Thomas (1994: 18)

\section{Reconstructing meaning}

While the study at hand has so far been concerned with the question of which corporations adopt the terminology of CSR within their annual reports, the following chapter is devoted to what these corporations actually perceive CSR to be. This question is inextricably linked to a thorough investigation of how they actively construct and assign meaning to the concept - and thus to an investigation of categorization and theorization activities. In order to examine how the issue and discourse of CSR is organized and structured in the Austrian corporate world, data are extracted from texts in corporations' annual reports by a combination of qualitative and quantitative elements of content analysis. I argue that such an approach allows the exploration of how corporations respond to the "problem" of socially expected responsibility of business, and how they make sense of - and thus, at rhetorical level, theorize - problem and solution simultaneously.

I will proceed in several steps that guide my research: First, I will show that one does not observe - as the literature sometimes (implicitly) suggests - a single and coherent discourse. The phenomenon of social responsibility of business rather gathers under the umbrella term of CSR, and may be more thought of as a bundle of various and nuanced conceptual sub-discourses. ${ }^{167}$ Second, I will focus on the social categories of actors that are referred to - hence constructed - in those sections of annual reports devoted to CSR issues; both subject and object categories of social responsibility are of interest here, as well as the ways in which these categories are interlinked. I argue that by exploring such cultural categories, I will be able to reconstruct what is established as a socially "agreed language or currency of discourse" (Day \& Klein, 1987: 2). A third line of investigation will then address (categories of) themes and topics in which corporations embed and integrate CSR issues. These thematic categories can also be interpreted as first and tentative framing cues. Finally, I will examine practice variation and identify distinct patterns within the discourse on CSR in Austria: Making use of multiple correspondence analysis, I will reveal the essential structuring dimensions of meaning. Dynamics over time will be addressed throughout all parts of this chapter.

167 Note that I derived several conceptual CSR sub-discourses from broader academic debate (see chapter on corporate social responsibility above) and operationalized these as specific sets of issue markers (see chapter on methodology). However, it will be one of the major contributions of this study to explore whether they are also distinct sub-discourses at empirical level. 


\subsection{CSR: An umbrella term for a bundle of conceptual sub-discourses?}

\subsubsection{Development over time}

A decisive feature of CSR as a discourse and management concept is that it builds on a broad array of themes and issues that imply highly normative connotations. Among others, these encompass the nature and general purpose of the corporation, the role of business within society, the primacy of a stakeholder orientation, various sustainability issues, environmental protection, and corporate philanthropy. It will be interesting to see which issues from this global menu are selected by Austrian corporations - and the extent to which they are integrated into the substance of their approach toward CSR.

Studies on theorization and legitimating accounts have highlighted that multiple interpretations of a concept may coexist within a field (e.g., Strang \& Meyer, 1993; Elsbach, 1994; Davis \& Greve, 1997; Lamertz \& Baum, 1998; Creed et al., 2002; Zilber, 2007). Meyer and Höllerer (2010) emphasize that in such cases - and especially when global ideas diffuse into cultural contexts in which another language is spoken - a certain range of keywords and lexical items is used to denote a concept. This also creates opportunities for redefining its meaning: Research on editing and translation activities (for an overview, see Sahlin \& Wedlin, 2008) has found that a variety of meanings may be covered under one and the same label; equally, different labels may convey the very same meaning. In a similar vein, this study argues that what is generally referred to as the CSR discourse potentially breaks down - both conceptually and empirically - into divergent streams. I propose that each of these CSR sub-discourses is characterized by, and draws on, specific vocabulary (i.e., issue markers). However, such issue markers may be used synonymously - or in order to invoke a rather different imagery and theorization: They resemble the rhetorical strategies of how corporations address and tackle relevant issues (see also Meyer \& Höllerer, 2010).

Before going into more detail here, one might be first interested in the relevance of individual sub-discourses (i.e., their contribution to the overall discourse as well as their development over time). For this purpose, I will break down the dissemination chart (Figure 8) and individually plot the six groups of issue markers that - as an aggregate - resulted in my dependent variable (i.e., explicit commitment to CSR). Figure 12 shows that the six groups (or sets) of issue markers contribute to the overall CSR discourse to a rather divergent degree. The uneven distribution and the different developments of conceptual sub-discourses represent yet another indicator for why CSR is not a monolithic discourse. It is evident prima facie that the Anglo-American labels of CSR and CC do not resonate overly well in the Austrian context: While corporations' reference to $C C$ in their annual reports is appropriate, for clearly less than $10.0 \%$ of publicly-traded corporations throughout the entire observation period, CSR exceeds this mark only in the last two years. By contrast, Germanizations make up the most important sub-discourse, with $54.9 \%$ of 
corporations employing this group of issue markers in 2005. With notions in the 1990s more tied to traditional ideas of social responsibility of business organizations - i.e., the implicit understanding of CSR in the Austrian context -, such early explicit reference can also be interpreted against the backdrop of issue management and agenda-setting. Later notions also include the translation of the AngloAmerican terminology of CSR and CC (and elements of these sub-concepts) into the German language and the Austrian context. Sustainability is the runner-up within the overall discourse and entails a strong link to the prominent ecology debate of the late 1980s and early 1990s (as whose "legitimate" successor it was increasingly positioned after 2000). Moreover, the stakeholder approach is surprisingly strong in this period and complements a leading triad of conceptual CSR sub-discourses. Finally, CSR indicators \& standards definitely rose during the final years of my observation period, reflecting standardization and anticipating the growing pressure to report on non-financial performance.

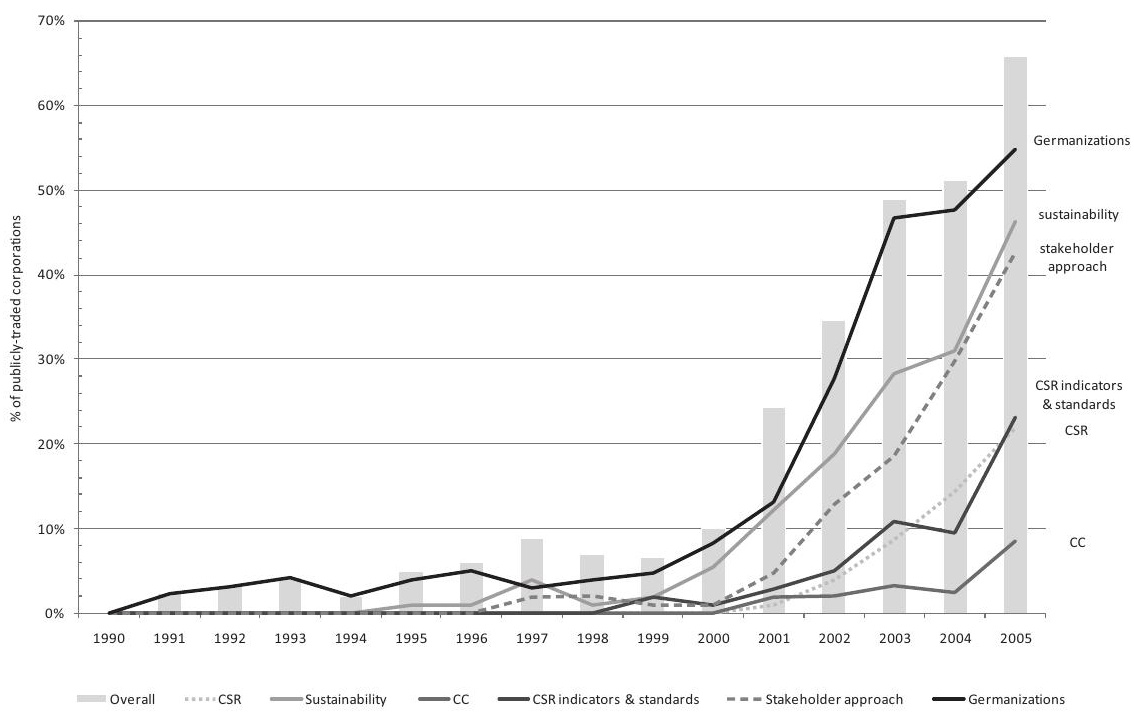

Figure 12: Conceptual CSR sub-discourses over time

It might be worth further unraveling and examining the composition of the overall CSR discourse. While Figure 12 shows the dissemination of the various conceptual sub-discourses among the total number of Austrian publicly-traded corporations, Figure 13 is based on the same data but zooms in on - and makes more distinct - the relative importance of individual CSR sub-discourses for the overall discourse per year $(=100.0 \%)$ over time. 


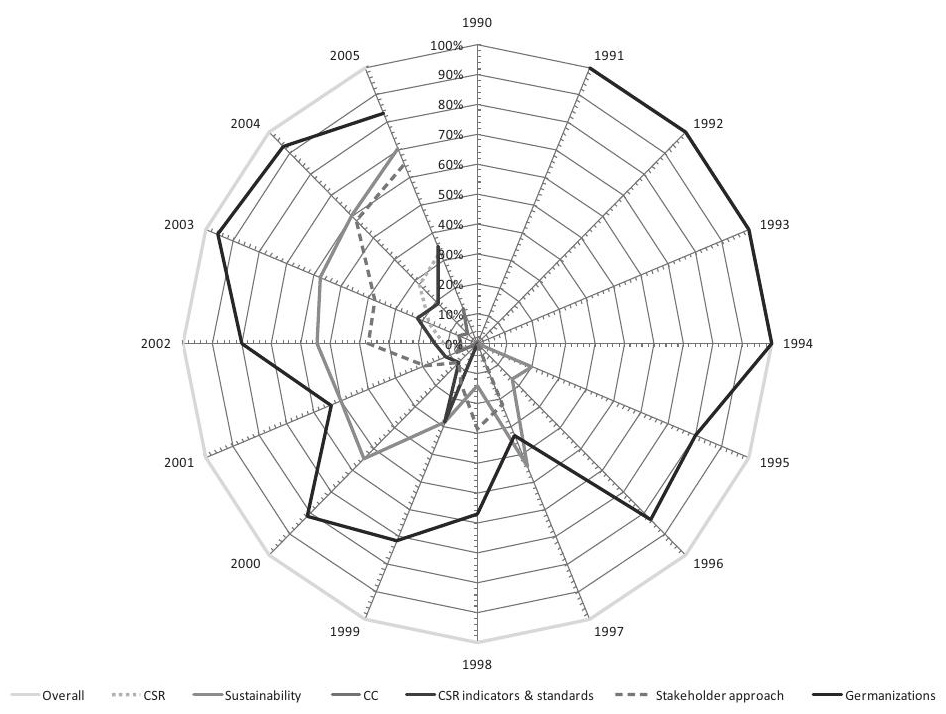

Figure 13: Relative importance of conceptual CSR sub-discourses

The first thing to recognize is that Germanizations impressively dominate the overall discourse, especially throughout the first six years (it is the exclusive label between 1991 and 1994), but also in 2000 and again between 2002 and 2005. With sustainability entering the stage in 1995, the years between 1997 and 1999 mark a period where corporations are obviously in search for the appropriate rhetoric tools and vocabulary to address CSR issues: In 1997, sustainability temporarily outweighs Germanizations, in 1998, the stakeholder approach is relatively strong ${ }^{168}$ while sustainability falls behind, and finally in 1999, sustainability returns to the stage and CSR indicators \& standards peak for the first time. This period also marks a crucial turning point in the CSR discourse in Austria: an estrangement from the tradition of an implicit understanding of business' social responsibility, and a change in direction toward new concepts and terminology, as well as a proactive alignment with the explicit CSR discourse of Anglo-American origin - nonetheless accompanied by substantive translation efforts. ${ }^{169}$ From 2000 onward, all conceptual sub-discourses

168 This corresponds well with the findings of Meyer and Höllerer (2010), who identify a period of contestation of shareholder value in the Austrian media discourse between July 1996 and December 1998. It is not surprising that publicly-traded corporations, in the aftermath of this conflict evolving around the case of the Austrian tire manufacturer Semperit and rather critical media coverage, increasingly refer to the direct counter concept of shareholder value: the stakeholder approach.

169 The re-strengthened role of Germanizations after 2001 supports such an interpretation: 
increase more or less proportionally with their order remaining unchanged (only CSR indicators \& standards fall back behind CSR once in 2004).

\subsubsection{Network of conceptual sub-discourses}

In the 2000s, a differentiation of the CSR discourse in Austria is documented by the average number of conceptual sub-discourses simultaneously employed in corporations' annual reports: The figure rises from 1.0 in 1996, 1.4 in 1999, and 2.0 in 2002 to 3.0 in 2005. This increasing co-occurrence directs my attention toward exploring the links between CSR sub-discourses in greater detail. For this purpose, I do not measure simultaneous commitment to divergent sub-discourses within an entire annual report, but - as a more qualified measure - within an identified text fragment (albeit aggregated at the level of the annual report; see chapter on methodology for further details). I also include - although not contained in the dependent variable of this study, but as a central point of reference - the meta-concept or "linking pin" (Drori, 2006) of corporate governance due to its strong effect indicated by the regression models above, as well as its subsumption under the CSR agenda by some literature (e.g., Bassen et al., 2005; see also Aras \& Growther, 2010).

The tool of network analysis provides for the description and exploration of the links of groups of CSR issue markers to each other and, in addition, to the related concept of corporate governance. Figure 14 illustrates the network over the entire observation period. The size of each node depicts the importance of the respective conceptual sub-discourse (i.e., its frequency), while the strength of lines between two nodes indicates the extent of co-occurrence; all relations are shown in the graph. Based on the position of nodes within the network, one can make clear statements with regard to structural features like center and periphery.

Interestingly, the overall CSR discourse in the last years of my observation period again shows - despite the use of multiple groups of issue markers - a similarly high level of Germanizations as in the early years (see Figure 13). 


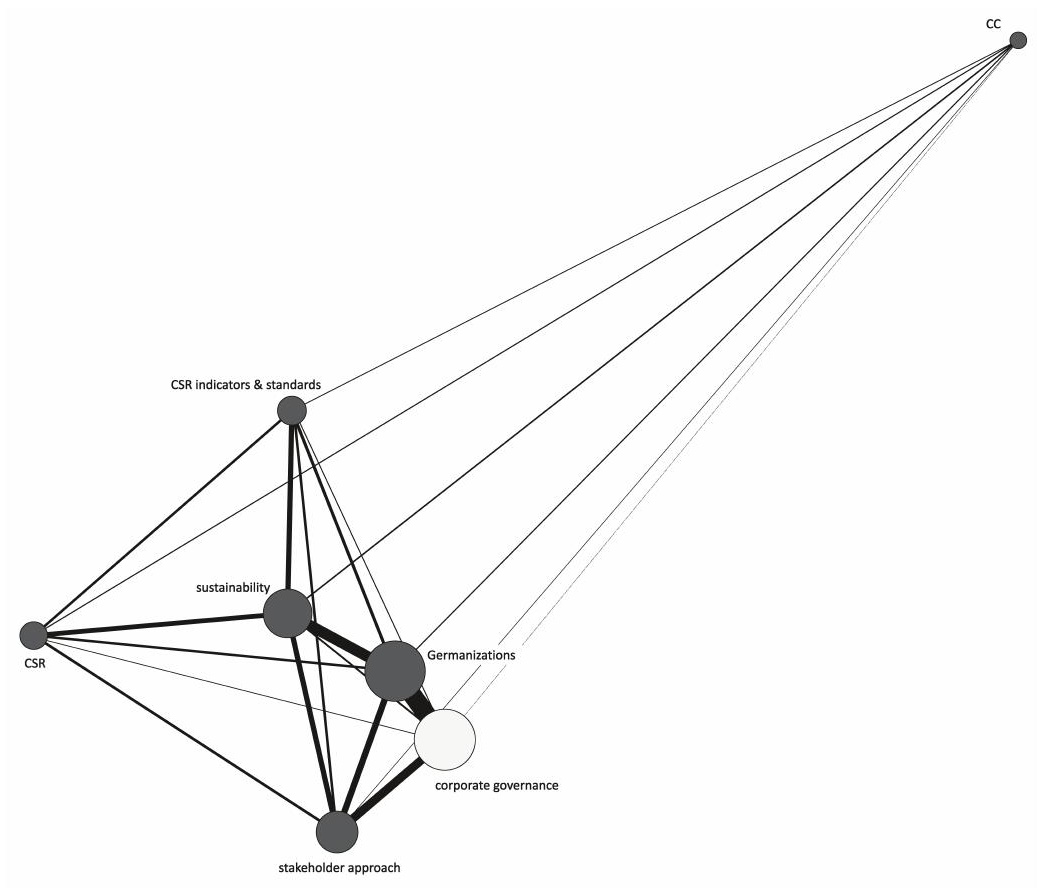

Figure 14: Network of conceptual CSR sub-discourses plus corporate governance

The most important conceptual CSR sub-discourses (see above) naturally dominate the network, with Germanizations being the focal point in Figure 14 - they are strongly linked with corporate governance on the one hand and sustainability on the other; within the exclusive CSR discourse (i.e., leaving aside corporate governance), the connecting line between Germanizations and sustainability is, indeed, the central axis. The stakeholder approach frequently links with Germanizations, sustainability, and corporate governance, whereas CSR and CSR indicators \& standards are more related to sustainability. CC, however, remains very peripheral.

In sum, sustainability shares the most even and proportional ties with all other conceptual sub-discourses and thus can be interpreted as a core underlying idea of CSR. However, sustainability almost does not link with corporate governance. A central bridging function here lies with Germanizations - and partly with the stakeholder approach. Another striking feature of the network is that it provides some evidence that CSR and Germanizations are not necessarily used side by side (i.e., they are not just synonyms and vocabulary translated from one language to another, but obviously also imbued with divergent meaning and thus positioned differently within the overall discourse). 
Table 14 helps to further the understanding of relations between groups of issue markers. In contrast to Figure 14 it states, for any given group, the relative probability of co-occurrence of another group (again, corporate governance is included here as an additional category). As a matter of fact, conceptual subdiscourses with a larger mass are common points of reference, but can themselves only link to other sub-discourses to a lesser degree.

\begin{tabular}{|c|c|c|c|c|c|c|c|}
\hline Link to ... & $\begin{array}{c}\text { CSR } \\
(N=43)\end{array}$ & $\begin{array}{c}\text { Sustain- } \\
\text { ability } \\
\text { (N = 137) }\end{array}$ & $\begin{array}{c}C C \\
(N=16)\end{array}$ & $\begin{array}{l}\text { Link from ... } \\
\text { CSR } \\
\text { indicators \& } \\
\text { standards } \\
\text { (N = 48) }\end{array}$ & $\begin{array}{l}\text { Stake- } \\
\text { holder } \\
\text { approach } \\
(N=101)\end{array}$ & $\begin{array}{l}\text { German- } \\
\text { izations } \\
(\mathrm{N}=\mathbf{2 1 1})\end{array}$ & $\begin{array}{l}\text { Corporate } \\
\text { governance } \\
(\mathrm{N}=\mathbf{2 1 5})\end{array}$ \\
\hline$C S R$ & - & $25.5 \%$ & $43.8 \%$ & $37.5 \%$ & $18.8 \%$ & $9.5 \%$ & $1.9 \%$ \\
\hline Sustainability & $79.5 \%$ & - & $62.5 \%$ & $89.6 \%$ & $38.6 \%$ & $32.2 \%$ & $6.0 \%$ \\
\hline$C C$ & $15.9 \%$ & $7.3 \%$ & - & $10.4 \%$ & $2.0 \%$ & $3.3 \%$ & $0.5 \%$ \\
\hline $\begin{array}{l}\text { CSR indicators \& } \\
\text { standards }\end{array}$ & $40.9 \%$ & $31.4 \%$ & $31.3 \%$ & - & $19.8 \%$ & $10.4 \%$ & $2.8 \%$ \\
\hline $\begin{array}{l}\text { Stakeholder } \\
\text { approach }\end{array}$ & $43.2 \%$ & $28.5 \%$ & $12.5 \%$ & $41.7 \%$ & - & $20.9 \%$ & $26.0 \%$ \\
\hline Germanizations & $45.5 \%$ & $49.6 \%$ & $43.8 \%$ & $45.8 \%$ & $43.6 \%$ & - & $45.1 \%$ \\
\hline $\begin{array}{l}\text { Corporate } \\
\text { governance }\end{array}$ & $9.1 \%$ & $9.5 \%$ & $6.3 \%$ & $12.5 \%$ & $55.4 \%$ & $46.0 \%$ & - \\
\hline
\end{tabular}

Table 14: Relative probability of co-occurrence of conceptual CSR sub-discourses

Both Anglo-American coined issue markers - CSR and CC - seem to be in need of contextualization. One notices a very strong link of CSR with sustainability $(79.5 \%)$, as well as considerable co-occurrence of Germanizations, the stakeholder approach, and CSR indicators \& standards. Further, CC links especially with sustainability (62.5\%), but also quite often with CSR and Germanizations.

CSR indicators \& standards themselves almost exclusively co-occur in the immediate context of sustainability (89.6\%); again Germanizations and stakeholder approach are relevant to some degree. For the stakeholder approach and sustainability, Germanizations are the major point of reference; however, note the considerable difference in the linkage with corporate governance $(9.5 \%$ versus $55.4 \%)$. Finally, Germanizations as the largest conceptual sub-discourse in my empirical sample is obviously also the most independent one: Within the overall discourse, only sustainability is somehow relevant - to a lesser degree than the link to corporate governance, though.

For corporate governance, the data corroborates the decision not to subsume this concept under the notion of CSR in this study: The very low relative probability of co-occurrence - with the notable exceptions of Germanizations and stakeholder approach - strongly denotes corporate governance as a separate (or meta-) discourse. 


\subsection{Responsible for and accountable to whom? Social categorization of actors involved}

A dominant line of CSR literature has addressed challenges of legitimacy created and potentially resolved - by organizational responses to divergent stakeholder concerns (see chapter on CSR). Also, research inspired by organizational institutionalism has long investigated the role the relations between organizations and their central audiences play in the assignment of legitimacy: As Suchman (1995) points out, any management of legitimacy rests, like most cultural processes, heavily on communication between the organization and its various audiences (see also Ginzel, Kramer, \& Sutton, 1992; Elsbach, 1994, among others). Suchman (1995: 594) further emphasizes the fact that "legitimacy represents a relationship with an audience, rather than being a possession of the organization". Studies building on a resource-based view theorize CSR - and especially its strategic value - as truly facilitating such relationship management (e.g., Jones \& Bartlett, 2009).

In order to reconstruct the meaning of CSR, it is essential to understand how corporations frame their social responsibility as a social relation. By discursively specifying and interpreting (and thus effectively assigning meaning to the concept of CSR), corporations simultaneously construct categories of relevant actors (human beings and/or legal entities) as subjects and objects of CSR, as well as by defining relationships between them. Consequently, such typification of actors involved in CSR issues (i.e., of potentially legitimate stakeholders) provides for the exploration of this particular management concept ratione personae (Ruwet \& Tamm Hallström, 2007): Interested in an understanding of how CSR - as an increasingly institutionalized practice - is linked and directed to different categories of other societal actors, my research also implies an investigation of the culturally defined social relationships between organizations and actors from their environment in the context of CSR. Going beyond a mere evaluation of which actor categories dominate the overall CSR discourse, I will demonstrate that the different labels employed to refer to this management concept are not used synonymously but are signifiers to denote different ways of theorizing the range of actors involved in responsibility issues. Illustrating that specific sets of actor categories are relevant for specific sub-discourses, I will be able to strengthen my point made above: CSR is rather a discursive bundle than a monolithic discourse. I will also show how actor categories are placed in relation to each other, and - in a subsequent section - how they are embedded in divergent thematic contexts.

\subsubsection{The construction of social categories as bottom-up theorization}

Building on the sociology of knowledge (Berger \& Luckmann, 1967; Schutz \& Luckmann, 1973; see also Meyer, 2006, for recent developments), organizational 
institutionalism holds that organizations, like all social actors, organize their experiences through typifying (i.e., by assigning, for instance, actions, other actors, relations, or events to certain cultural categories). Such typifications - or social categorizations - are at the heart of all institutions and processes of institutionalization: Theorization of practices essentially contains abstract typifications of adopters and practices involved (Strang \& Meyer, 1993), and thus also builds on the construction of cultural categories of actors - either as subjects or objects of the theorized practice.

For this reason, the examination of the social categorization and typification of actors plays a crucial role in this study. While most prior research has highlighted the role of knowledge entrepreneurs such as science, consultants, media, and professions (e.g., Strang \& Meyer, 1993; Abrahamson, 1996; Kieser, 1997; Abrahamson \& Fairchild, 1999; Sahlin-Andersson \& Engwall, 2002b), I emphasize here bottom-up theorization by the actual adopters of a practice (Strang \& Meyer, 1993) - i.e., theorizing by corporations as the social entities mainly concerned by CSR ${ }^{170} \mathrm{I}$ will analyze to whom corporations actually pay attention when they talk about their social responsibilities: Exploring the "web of relevant actor categories" lies at the very core of the social construction of legitimacy of constituents' claims and also addresses essential issues of power (Mitchell et al., 1997).

The core idea of CSR, in holding corporations accountable and assigning them responsibilities for other societal actors, for the environment, and for society at large, is highly congruent with the conceptualization of "modern actorhood" as presented by Meyer and Jepperson (2000). According to them, modern actors individuals, organizations, and national states alike - are historical and ongoing cultural constructions. Apart from acting for themselves i.e., managing their own goals and legitimate interests, ${ }^{171}$ "agentic actors" can serve as agents for other actors. ${ }^{172}$ Organizations, for instance, may act on behalf of their own individual

170 It is important to hold that corporations are themselves categorized as falling under the specific type of social entities that is expected to publicly display such an orientation (i.e., CSR).

171 A great deal of standardization and scripting is involved here: "Modern cultural formulations defining $[\ldots]$ organizational $[. .$.$] entities and interests are highly standardized, and evolve$ and expand in similar ways over time" (Meyer \& Jepperson, 2000: 106). In order to be regarded as legitimate agents for underlying interests, they incorporate "highly standardizing responsibility to enact imagined moral and natural principles” (Meyer \& Jepperson, 2000: 107).

172 Modern actors are expected not only to pursue their interests in a rationalized way, but to contribute to the well-being of others - or the society at large - in corresponding with broader, rationalized rules (Hasse \& Krücken, 2005) as well. They can, "mobilized in standardized and stylized ways, supported by a host of external cultural definitions and social structures $[\ldots]$, easily shift from agency for the self to agency for other actors $[\ldots]$ [since they] incorporate an enormous amount of standardizing rationalized material" (Meyer \& Jepperson, 2000: 107). 
members, their shareholders, other central stakeholders, or for an imagined interest of non-actor entities categorized in the cultural system, and even for potential actors: In the name and under the banner of sustainability and CSR, they are expected to mobilize their agency for the eco-system or for future generations. ${ }^{173}$ Finally, actors can assume responsibility to act as an agent of the imagined natural and moral law. ${ }^{174}$ This is the case when organizations or corporations assume tasks that were previously tied to the national state and governmental authorities (for examples in the context of the notion of corporate citizenship, see Matten \& Crane, 2005, among others), or when owners of corporations express their social responsibility from a more paternalistic point of view or employ a Christian ethical rationale.

Financial accountability and traditional stakeholder approaches (for an overview see Freeman et al., 2010) are originally based on more direct relationships where entitled groups of actors (i.e., especially key stakeholders like, for instance, owners, shareholders, employees, customers, suppliers, or other business partners) expect the corporation to act in their interest or to comply with legal regulations. With the global spread of CSR, one notices a much broader definition of responsibility that forces corporations to assume an additional advocacy role and act on behalf of other groups of actors (or on the basis of abstract moral and ethical principles; see above). However, compared with key stakeholders who possess power and/or social legitimacy and are, therefore, able to voice their claims (Mitchell et al., 1997), an implication of the notion of advocacy is that beneficiaries are generally passive and lack the knowledge, skill, ability, or standing to speak for themselves. In addition, while the legitimacy of constituents who base their claims on contractual or legal grounds is fairly uncontested, the legitimacy of groups that have to base their status on moral or ethical obligations is subject to definition (and negotiation). In the context of CSR, corporations may, for instance, also be expected to act on behalf of children in third-world countries they operate in, civilsociety, the eco-system and natural resources, or the common good and public interest. It is somehow obvious that these diverse actor categories - ranging from key stakeholders to rather diffuse beneficiaries - are structurally unequally positioned in terms of power and ability to sanction the corporation for non-compliance.

173 "The capacity to do so arises from the modern actor's imagined competence in applying natural and moral law, competence that can be put to the service of the widest variety of legitimated entities, whether the entities are themselves actors or not" (Meyer \& Jepperson, 2000: 108).

174 Meyer and Jepperson (2000: 108) note that another "principal is in practice always involved: in becoming an authorized agent (of the self, or of any other), the proper modern actor assumes responsibility to act as agent of the imagined natural and moral law. Otherwise the actor risks either incompetence or corruption". 


\subsubsection{Responsible conduct of business and relevant actor categories}

In a fairly straightforward manner, Figure 15 presents the actor categories referred to in the immediate context of CSR; the percentages relate only to those corporations that espouse commitment to the concept in their annual reports. ${ }^{175}$ While subject categories are depicted in light blue and marked with $[s]$, object categories are in blue and marked with [0]; the categories not specified are the only exclusive ones here and are calculated independently for both subjects and objects (i.e., they indicate annual reports that refer to CSR but do not name a specific subject/object category). In this way, Figure 15 provides a first overall picture of which actor categories corporations regard as relevant within the discourse on CSR.

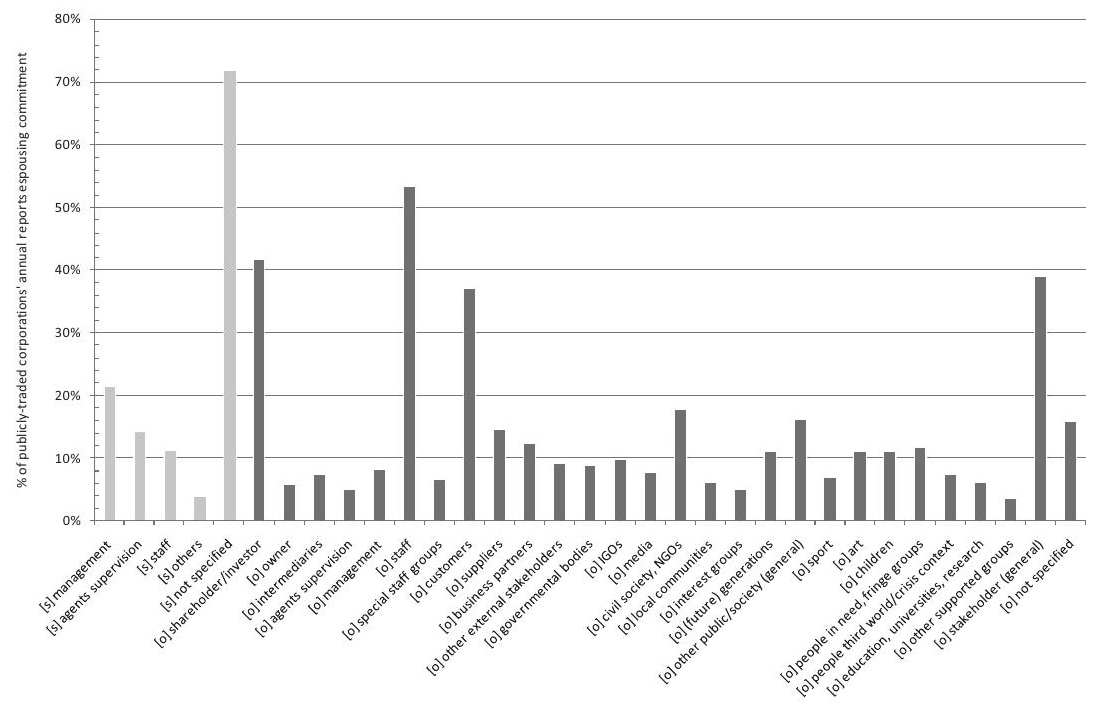

Figure 15: Reference to specific actor categories in the context of CSR

The subjects of CSR seem to be obvious a priori: the corporations themselves. However, such responsibility remains rather unspecified for collective actors, as long as no distinct and more individual actors are named (such as, for instance, the management board, the supervisory board, executive management, or staff). Be it to make use of the conceptual vagueness or because the genre rules - i.e., the

175 The unit of analysis is still the annual report (see the chapter on methodology for details); $\mathrm{N}=259$. 
understanding that an annual report speaks on behalf of the corporations as legal entities - are taken-for-granted, the main subject category is a rather diffuse "we" or the name of the corporation: Thus, for $71.8 \%$ of annual reports that indicate commitment to CSR, the subject is not specified. Much more interesting, however, are cases in which subjects are explicitly named as representatives of the corporation. I find that the main subject category is management $(21.2 \%)$ - here especially executive management - followed by bodies supervising management's conduct of business (agents supervision, e.g., the supervisory board, or the auditor of the annual accounts, $14.3 \%$ ). While top management has been a rather natural subject category for responsibility issues ever since, supervising bodies enter the stage based on the close relationship of responsible conduct of business and good corporate governance. However, more than $11.2 \%$ of annual reports explicitly hold that CSR is also a task of all employees of a corporation.

On the other hand - and as highlighted above -, the actor categories referred to as objects of CSR activities serve as first important and crucial indications for the framing of this management concept. I find great variation concerning these categories. The four most frequently mentioned groups are staff $(53.3 \%)$, shareholder/investor (41.7\%), customers (37.1\%), as well as the generalized but not further specified stakeholder (39.0\%). ${ }^{176}$ Suppliers (14.7\%) and business partners (also including various partner organizations, $12.4 \%$ ) complement this rather traditional picture that is characterized by a priority orientation toward market-related groups of stakeholders. Other categories from the public sphere - like civil society, NGOs $(17.8 \%)$, (future) generations $(11.2 \%)$, or other public/society (which includes society in general, $16.2 \%$ ), but also the prominent position of various beneficiaries and supported groups like people in need, fringe groups $(11.6 \%)$, art $(11.2 \%)$, children $(11.2 \%)$, among others - point to a new role of corporations within society that exceeds management of primary stakeholders and underscores the relevance corporations assign (or must assign) to a much broader variety of constituents. At the same time, however, one witnesses a surprisingly high number of annual reports that do not specify the objects of the corporation's responsibility in the immediate context of CSR issue markers at all (not specified, 15.8\%).

In sum, Figure 15 depicts, invokes, and manifests the imagery of a distinct stakeholder orientation in a continental European tradition, strongly corresponding to the explicit stakeholder approach in corporate control in Austria (see, for instance, the Austrian Stock Corporation Act dating back to 1965). Here, the first and foremost social responsibility of the corporation and its representatives ${ }^{177}$ is toward primary stakeholders and particularly toward its employees, while categories more important for the Anglo-American theorization of the concept (especially

176 Usually, the English term "stakeholder" is used by Austrian corporations in their annual reports; only very few use the German term "Anspruchsgruppe" or variations thereof.

177 Interestingly, owners (or shareholders) are not mentioned as a relevant subject category but merely as an object category. 
with its focus on philanthropy and local communities; see Carroll, 1991, among others) seem to be of rather low relevance for Austrian corporations.

\subsubsection{A web of relevant actor categories}

Actor categories are, of course, not referred to as being isolated from each other, but appear jointly in statements related to CSR; this calls for an examination of the co-occurrence of various categories. Figure 16 not only shows their importance the size of nodes indicates the visibility of individual actor categories in annual reports (like in Figure 15) - but also depicts the web of actor categories that is relevant from the perspective of corporations in greater detail: It is this very combination of categories that business organizations include in their CSR statements. Here, the links indicate the degree to which actor categories are referred to together in the immediate context of CSR (i.e., within identified text fragments) within one annual report. ${ }^{178}$ It is important to hold that - in order to carve out the most interesting features - I calculated a relative network (technically speaking, the link between nodes is divided by the number of appearances of the smaller node) and, in addition, removed links at less than 0.60 from the analysis. One of the most striking features of the network analysis in Figure 16 is that it locates the actor categories in the center or on the periphery depending on their relevance for corporations' construction of CSR.

I present actor categories in several clusters: (a) subjects of CSR (in red); (b) internal stakeholders (blue for staff and special staff groups, lilac for management, light blue for agents supervision); (c) market-related external stakeholders (dark blue for shareholder/investor and owner, lime for customers, suppliers, business partners, and other external stakeholders, yellow for intermediaries on the financial market); (d) a public/society cluster also comprising sociopolitical actors (orange for governmental bodies, IGOs, civil society, NGOs, local communities, interest groups, (future) generations, media, and other public/society); (e) beneficiaries (green for sport, art, education, universities, research, children, people in need, fringe groups, people in third world/crisis context, and other supported groups within society); and (f) reference to the generalized stakeholder (violet).

178 Co-occurrences are again aggregated at the level of the annual report (see chapter on methodology for details). 


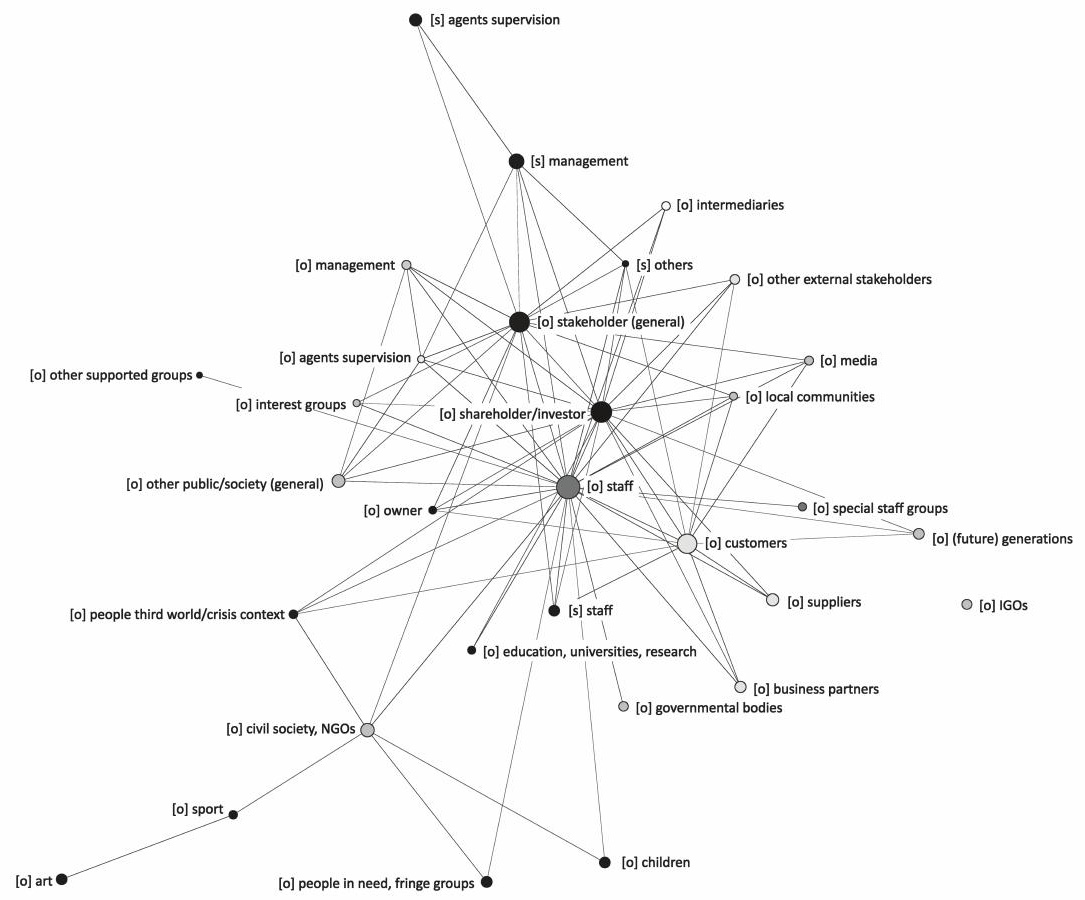

Figure 16: Web of relevant actor categories

Unsurprisingly, the most visible actor categories are also the backbone of this network. On the object side, staff and market-related external stakeholders (especially shareholder/investor and customers) are at the center of discourse; these are complemented by the generalized stakeholder and exhibit a high degree of joint appearance with various other actor categories. However, categories used to refer to responsibility for societal groups other than the primary stakeholders are more fragmented; also, the vocabulary used to denote them still seems to be much less agreed upon (or routinized). For instance, various supported groups and beneficiaries - although named together, but relatively seldom with primary stakeholders - are not well represented, as they obviously do not fit the traditional stakeholder approach in place in this empirical setting; consequently, they are positioned at the periphery of the CSR discourse. ${ }^{179}$ The actor categories that belong to the society cluster are then located somewhere in between. Looking at the individual categories, I find that some appear jointly with internal and market-related stakeholders (especially the more general other public/society, local communities, or media). Others, in

179 I use a correlation table to corroborate all interpretations drawn from the network analysis. 
particular civil society, $N G O s$, are often associated with various supported groups. This emphasizes the fact that corporations regard civil society, NGOs as the agentic actors that primarily act on behalf of various beneficiaries. Including civil society actors in corporations' CSR policies obviously seems more appropriate (and compatible with simultaneously addressing other stakeholders) than referring directly to individual supported groups. Another interesting category is owner - a label that is generally eschewed by publicly-traded corporations and therefore peripheral within the discourse, most likely as it makes a clear statement on principal-agent and thus power relations; shareholder/investor seems to be a more neutral term in this respect. However, owner co-occurs relatively often with primary stakeholders, but is only loosely related to beneficiaries and supported groups (which somewhat goes against the traditional image of the paternalistic owner in the empirical context of this study).

Focusing on the (specified) subjects of CSR, I find management, agents supervision, and staff to be of relevance. Especially management and agents supervision (for instance, the supervisory board) are strongly linked and likely to be named simultaneously as subject categories (see also comments on the two-tier system in corporate governance in the chapter on empirical context). In terms of subject-object relations, management is more frequently pointed out as the subject when annual reports highlight the duties concerning the object categories of shareholder/investor, the generalized stakeholder, staff, and agents supervision. Staff as the subject goes well together with all major object categories (shareholder/investor, the generalized stakebolder, customers, and staff as the object), while agents supervision as a subject category primarily focuses on the generalized stakeholder. Interestingly, one does not notice any considerable subject-object relations toward any category of either beneficiaries or the public/society cluster.

Overall, these findings suggest an interpretation of CSR that closely mirrors the traditional continental European stakeholder approach in corporate control. For Austria, such an understanding is documented in the wording of the Austrian Stock Corporation Act (as early as 1965; see above) or the Austrian Code of Corporate Governance issued in 2002 (which basically replicates the original wording). It also indicates that the core ideas of the Anglo-American version of CSR and, in particular, of CC - both heavily based on business-society relations and philanthropy are not the predominant features of the translation of CSR into the Austrian context.

\subsubsection{Specifying subjects and objects: Dynamics over time}

Exploring how diverse the CSR discourse is in terms of reference to actors, I observe - as a general development - a considerable increase in those actor categories being explicitly named. Relative frequencies (i.e., the number of catego- 
ries per annual report) give a first impression: For the overall sample, the average annual report of a corporation espousing commitment refers to 0.5 subject and 3.8 object categories (as defined above) in the immediate context of CSR issue markers. Over time, these numbers rise from 0.1 (1990-2000) to 0.6 (2001-2005; 0.7 for 2005 only) for subject categories, and from 2.3 (1990-2000) to 4.2 (2001-2005; 4.8 for 2005 only) for object categories.

In Figure 17, the same periods are used to illustrate the trends for the individual categories (in percentage of publicly-traded corporations' annual reports espousing commitment). One notices that as the statements become more frequent within reports over time, they also become much more detailed and specific in terms of naming subjects and objects.

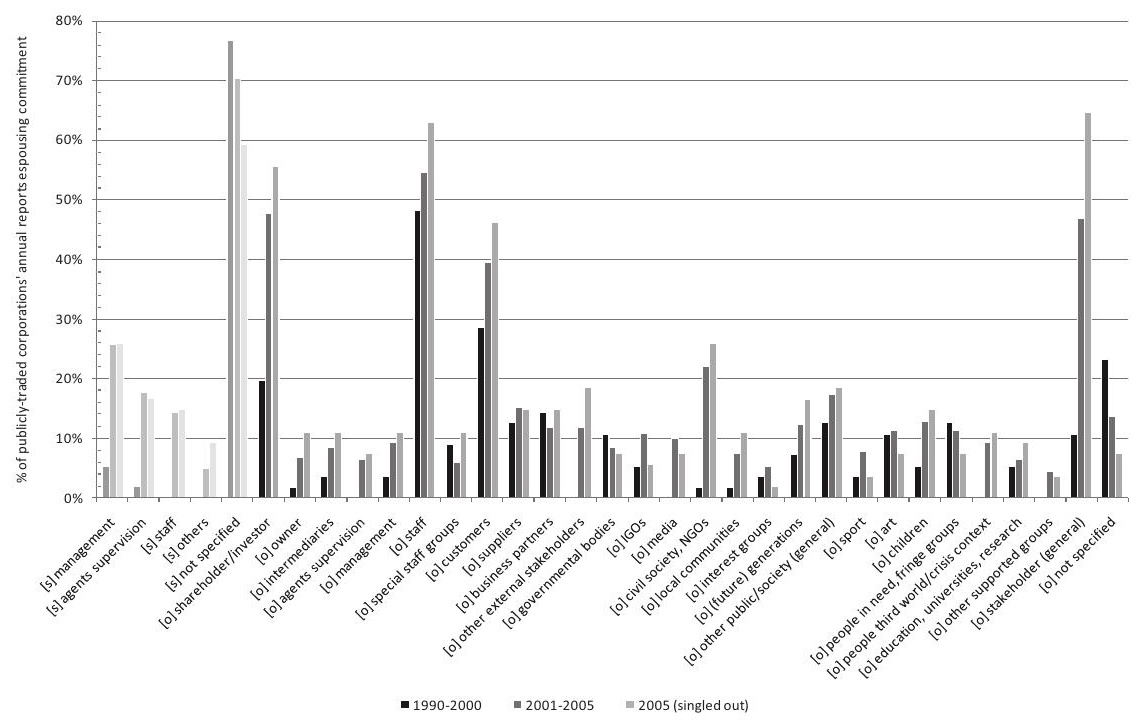

Figure 17: Reference to actor categories over time

Specific subject categories for CSR virtually do not exist in annual reports in the 1990 s and emerge as explicit references only after the debate on corporate governance gained momentum around 2000. This also indicates a certain degree of responsibility (and even more: accountability) attributed ad personam as a consequence of various corporate scandals.

On the object side, due to the overall increasing visibility of CSR as an issue over time, and the tendency to accept a larger amount of stakeholders, almost all 
categories of actors are on the rise. However, a correlation table ${ }^{180}$ provides a more detailed view: While I find no significant increase over time for actor categories that are primarily targeted by strategic stakeholder management (staff, customers, suppliers, business partners, among others), the increasing relevance of shareholder/investor - i.e., a group that is especially targeted by the debate on accountability and good corporate governance - becomes obvious. Also, some more abstract and/or heterogeneous categories are significantly on the rise, like the generalized stakeholder or other external stakeholders (including experts, consultants, and competitors), as well as a range of actors from the public sphere and society (civil society, NGOs, media, people in third world/crisis context, among others). ${ }^{181}$ The picture is rather mixed for supported groups. Overall, the trend in the last year (2005, singled out) suggests that there is still a great deal of momentum within the CSR discourse and that its development has not stabilized in terms of specifying actors involved in this nonetheless increasingly institutionalized organizational practice.

Interested in dynamics over time, I also wish to shift the focus slightly and examine the relative importance of actor categories. In this sense, Figure 18 explores how reference to actor categories shapes the CSR discourse at different points in time (relative percentages, calculated independently for subject and actor categories).

180 Due to space restrictions, the correlation table is not presented here.

181 The rise and increasingly legitimate use of more abstract categories like the anonymous/generalized stakeholder also points at the trend to invoke addressees of CSR without naming each group individually; over the years, addressing traditional stakeholders increasingly comes ready-made. 


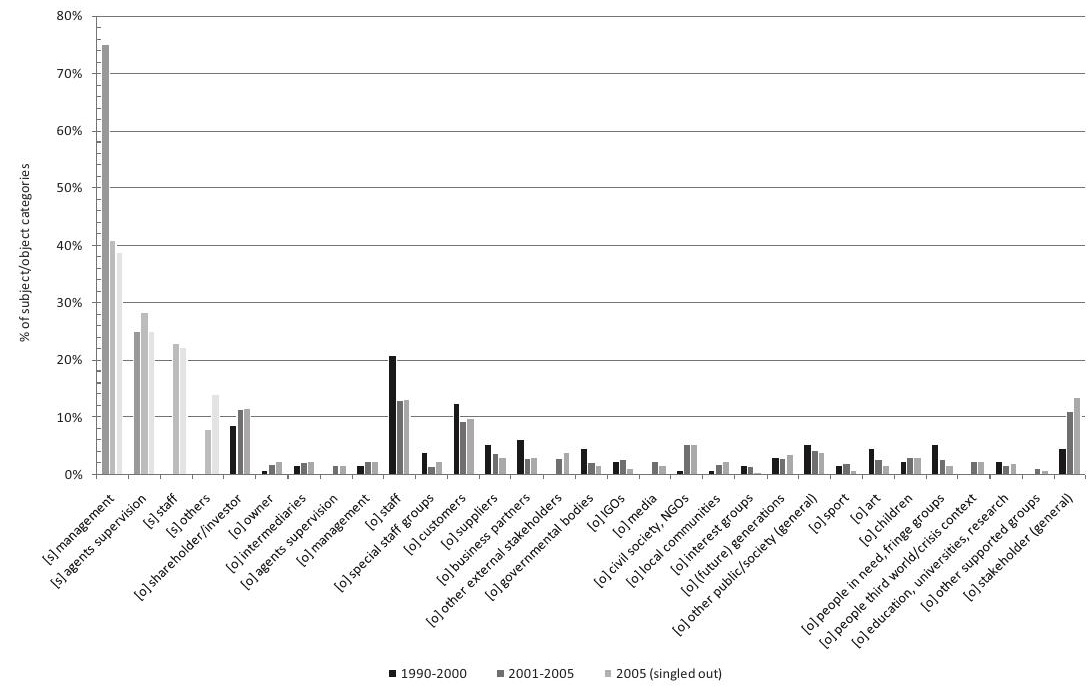

Figure 18: Relative importance of actor categories over time

The overall trend here is clear: On the subject side, a shift from management toward other subjects of responsibility (i.e., especially the supervisory boards and employees other than management) becomes visible. On the object side, the classic stakeholder groups (e.g., staff, customers, suppliers, business partners) - but also governmental bodies and some target groups of sponsoring and donating activities - lose relevance, while civil society, NGOs, and other external stakeholders, media, and the generalized stakeholder clearly gain in significance. Again, one observes a much more prominent positioning of actor categories involved in financial accountability issues on the CSR agenda, both on subject and object side. The effects indicated in the last year (singled out) appear to be rather minor and seem to merely confirm an overall increasing extent of reporting on CSR issues and thus an increased mentioning of various affected actor categories.

In sum, the results for the contemporary CSR discourse in Austria seem to effectively mirror many of the principles of good corporate governance - maybe even more than they bear a resemblance to the indigenous idea of socioeconomic responsibility for society in general (but also for disadvantaged groups in society) that was a characteristic feature of the implicit notion of CSR in continental Europe for decades (see chapter on empirical context for more). Therefore, this might also indicate that the trend is not so much toward implicit $\operatorname{CSR}^{182}$ becoming

182 I am well aware of a central limitation of my methodological approach with regard to implicit understandings of CSR. These are, by definition, scarcely reported in corporate 
explicit, but rather toward a considerable shift in the understanding of social responsibility of corporations that goes hand in hand with a greater recognition of accountability issues. The latter shows a strong focus on the relationship between management and actors on the financial markets and is backed and institutionalized by specific codes of corporate governance and related soft law or legal regulation.

\subsubsection{Sub-discourses and actor categories: A first correspondence analysis}

I will now further extend my analysis in order to explore whether specific categories of actors are addressed by specific conceptual sub-discourses. This will also begin to roughly shape the empirical sub-discourses. I have chosen a methodical approach and tool that enables me to derive the underlying and structuring principles of meaning from my data: (multiple) correspondence analysis. The graphical representation of a first correspondence analysis plots two categorical variables issue markers and actors - in a two-dimensional space. The key analytical objective of Figure 19 is to identify more profound and more general principles that account for the arrangement of categories within such a "topographic map" (Meyer \& Höllerer, 2010) and help to understand how meaning is structured (Mohr, 1998).

The correspondence map in Figure 19 accounts for $86.4 \%$ of total inertia. The first and most important dimension (the x-axis) is highly explanatory and accounts for $58.5 \%$ of inertia, while the second dimension (the y-axis) adds another $27.9 \%{ }^{183}$ For the overall model - and not surprisingly -, issue markers contribute greatly to the explanation of variance in dimensions; for actors, the picture is more mixed. With regard to the overall quality of the model, almost all categories are clearly determined by the two dimensions (exceptions include suppliers and the others category for subjects of CSR).

I wish to point out that a merely visual assessment of the correspondence map might lead to false conclusions, as the categories contribute to the dimensions in different ways and are themselves explained to a varying degree by these axes.

communication - which makes CSR difficult to measure in terms of verbal commitment prior to it becoming explicit.

183 Joint correspondence analysis attempts to remedy inflation of the total inertia by the block diagonal submatrices of the Burt matrix (for an example, see the remarks on the mca command in StataCorp LP, 2007a) and requires, as an iterative method, advance specification of the number of dimensions. In general, correspondence analysis is designed to provide a lowdimensional representation of data. In order to graphically portray the correspondence table, I must restrict my calculation to two dimensions, which often cannot account for $100.0 \%$ of inertia. With regard to a threshold value, there is no general rule; the literature indicates a rough heuristic rule of $80.0 \%$ to $90.0 \%$ of explained inertia (e.g., Greenacre \& Blasius, 2006; StataCorp LP, 2007a) or argues for a "scree test" (Cattell, 1966; the "scree" identifies the number of dimensions at the point where the singular values flatten out; see StataCorp LP, 2007 a, among others). In my case, both criteria support the approach and results. 
Hence, to achieve a proper understanding and labeling of axes, one also must thoroughly analyze the statistical output provided by the respective statistics software. The same applies, then, to a detailed interpretation of the individual categories (label points). For the reader's convenience, the graph - plotted using STATA 10 - is further refined in order to indicate the label points that are most expressive of the topographic map (i.e., those categories that determine the poles of the dimensions and thus span the space in which all categories are plotted): The font size of the labels represents the degree of contribution to dimension. However, note that categories occasionally do not contribute to dimensions but are nonetheless well determined, by one or both axes; for this reason, they are also an important element of the graph (see chapter on methodology for all details concerning interpretation). 


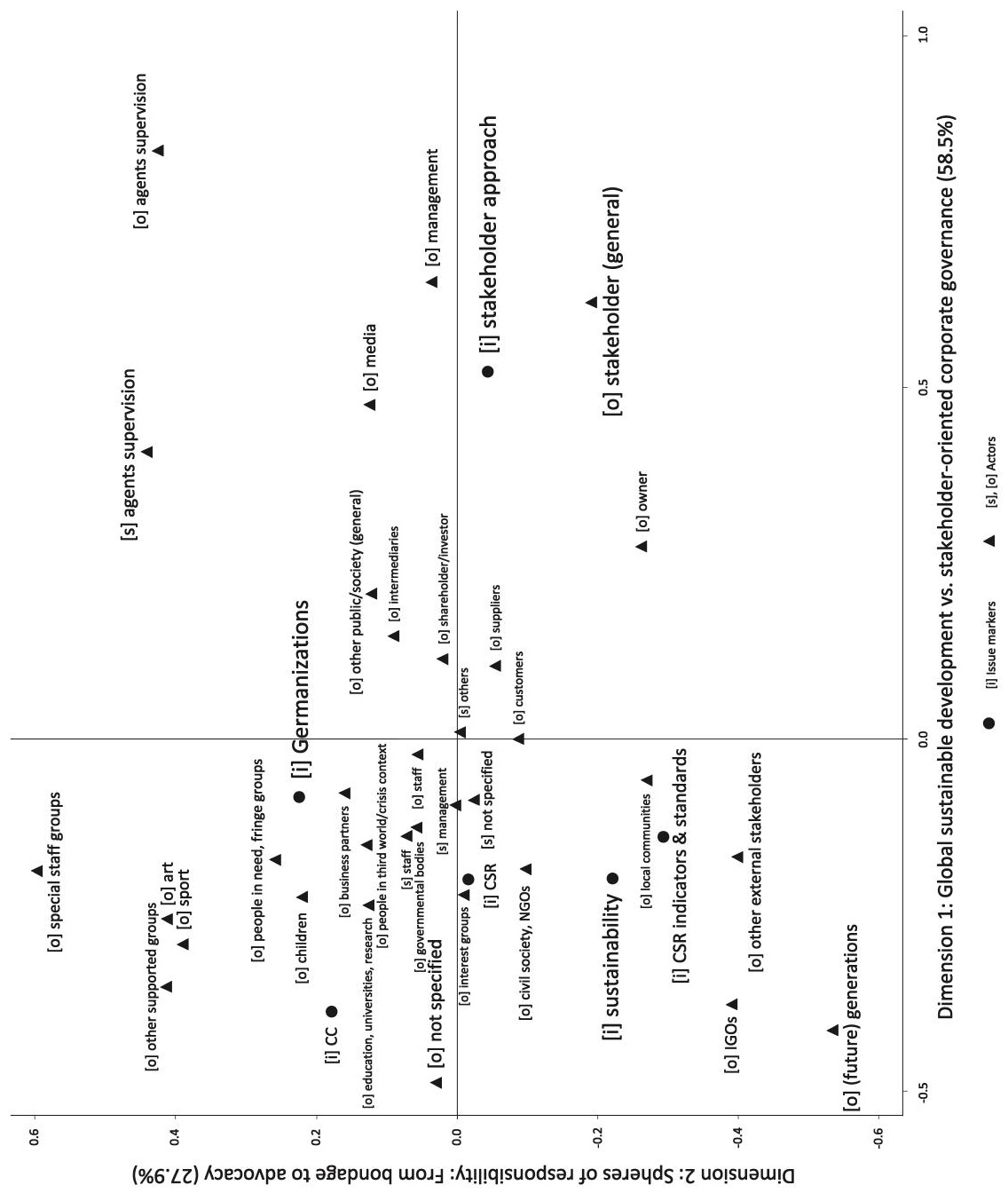

Figure 19: Correspondence map: Issue markers and actors 


\subsubsection{Sustainability versus stakeholder-oriented corporate governance}

The guiding question for this correspondence analysis centers on the actor categories involved in the overall CSR discourse: For the given conceptual sub-discourses, who is responsible for and accountable to whom? As I will describe in greater detail below, a first and central meaning-generating principle that shapes the association between the variables in the correspondence map is the organizational objective of sustainable development. Here, a more global focus on society and planet earth is opposed to a focus on the individual organization (i.e., corporate sustainability); the latter is linked to both a stakeholder orientation as well as to distinct rules of (good) corporate governance.

To the left of Figure 19, a first pole states that the corporations - mainly in form of a not specified subject category (i.e., using the organization's name or the anonymous "we") or in form of the entire staff (the management is mentioned only to a lesser degree) - are responsible in general (note the outstanding role of the not specified objects of CSR). In addition, various beneficiaries and supported groups, (future) generations, IGOs, governmental bodies, interest groups, and civil society, NGOs appear as relevant objects here. The main mobilizing conceptual sub-discourses are sustainability and - to a limited extent - the Anglo-American labels. However, all these stress the more global elements of CSR (see chapter on CSR for more).

To the right, the second pole of the dimension clearly alludes to the role of agents supervision that ensure that the corporations fulfill their responsibility (and, in particular, accountability) toward all relevant organizational and societal actors involved in issues of corporate governance. This especially holds true for the generalized stakeholder, as well as for shareholder/investor, owner, and intermediaries on the financial markets. Moreover, corporate executive and advisory boards (management and agents supervision) are also named as important object categories. Eventually, the media and the more general public - both crucial instances of organizational legitimacy - are prominently addressed. The extremely dominant conceptual subdiscourse here is the stakeholder approach. In sum, and interestingly, the two poles of this dimension are both concerned with issues of either global or local sustainability.

\subsubsection{Spheres of responsibility: From bondage to advocacy}

While the first dimension casts the opposition of divergent issues concerning sustainable development within the overall CSR discourse, the second, vertical dimension addresses the question of how corporations theorize themselves as accountable to categories of actors, and the degree to which one can witness advocacy for other societal groups in light of the notion of social responsibility. The correspondence map reveals a juxtaposition of divergent degrees of commitment: While at the bottom (and around the $\mathrm{x}$-axis) corporations are bound by 
regulation and economic pressure to take into consideration the interests of various stakeholders, at the top, actor categories are addressed more through voluntary actions (e.g., corporate giving and philanthropy at the top left, and goodwill and transparency issues at the top right). Obviously, this also gives - as an underlying rationale - some indication of who is attributed power. ${ }^{184}$

Such an interpretation is very much in line with a model that distinguishes between several spheres of responsibility (Hiß, 2006; see chapter on CSR): At the bottom, and more assigned to a minimum sphere of responsibility (i.e., required by market mechanisms and legal requirements) are future generations (see, for instance, limited resources and intergenerational contract), other external stakeholders (e.g., experts and consultants; see expert knowledge and expert power), IGOs (global issues, trends, and pressures), local communities (e.g., special legal protection of neighbors, also in environmental issues), as well as owners (as opposed to sharebolder/investor, this term is commonly referred to in order to address blockholders or owner families). The main mobilizing conceptual sub-discourses are sustainability and CSR indicators \& standards. Customers and - due to the vagueness of the label the generalized stakeholder from below the x-axis, as well as staff and business partners from above the x-axis, belong more to an intermediate sphere of responsibility (i.e., voluntary CSR activity within the value creation chain).

At the top, the graph plots actor categories that are part of an extended sphere of responsibility (voluntary CSR activity outside the value creation chain). From a societal aspect (top left), such framing goes hand in hand with advocacy for special stakeholders, societal actors, and beneficiaries (among them special staff groups, sport, art, children, people in need, fringe groups); from an organizational aspect (top right), this is more of a statement on increased transparency (i.e., advocacy from the side of agents supervision as subjects that safeguard that the individual corporations develop as sound, transparent organizations). The foremost group of issue markers used here is, for both, Germanizations.

\subsubsection{Some implications}

In sum, Figure 19 not only reveals a triangle constellation within the overall CSR discourse that juxtaposes the stakeholder approach, sustainability, and Germanizations, but also shows that the Anglo-American labels of CSR and CC are of rather minor importance in the discourse in Austria. Obviously, the latter do not constitute the appropriate means to address the broad array of categories of actors involved in CSR issues that indeed goes beyond the traditional range of stakeholders. Corporations seem to ascribe the established German terminology the highest potential to

184 Note that the classic/primary stakeholders are referred to throughout most CSR statements; therefore, these actor categories are not significant within the correspondence analysis and cluster more or less around the origin. 
succeed in this task. I also note that the stakebolder approach remains rather vague in specifying categories of actors in the context of CSR issues, whereas the Germanizations category explicitly specifies a broad range of stakeholders and beneficiaries; moreover, only a few actor categories are primarily linked to sustainability.

At a more abstract level, one notices that all conceptual CSR sub-discourses despite having different foci as to whether a minimum or rather extended sphere of responsibility is the main concern - seem to be united in their disagreement with the stakeholder approach (they are all positioned to the left of the graph). This is a very interesting phenomenon that is not to be expected from the conceptual discussion of CSR (see chapter on CSR). As I will show on the following pages, the stakeholder approach is, empirically, closely related to (i.e., used by corporations to allude to) more economic and shareholder-driven interests.

\subsection{What are we/ they talking about? Thematic embeddings of CSR}

Management concepts - and CSR in particular - are especially characterized by the social relations between the focal organization, members of the organization, and actors from the organization's environment. However, each and every attempt at reconstructing meaning must take equally into consideration the themes and topics that are linked to such organizational practice. The thematic embeddings of CSR issue markers serve as important tentative framing cues for CSR.

\subsubsection{Topics linked to CSR}

While a first approach to tackle the broader thematic embeddings has been the analysis of placement of CSR in annual report sections (Figure 10), the recording of the specific topics addressed in the immediate context of CSR issue markers provides a much more fine-grained picture. Figure 20 introduces the categories of topics that typically embed CSR issue markers (see chapter on methodology for details on clustering and development of categories). 


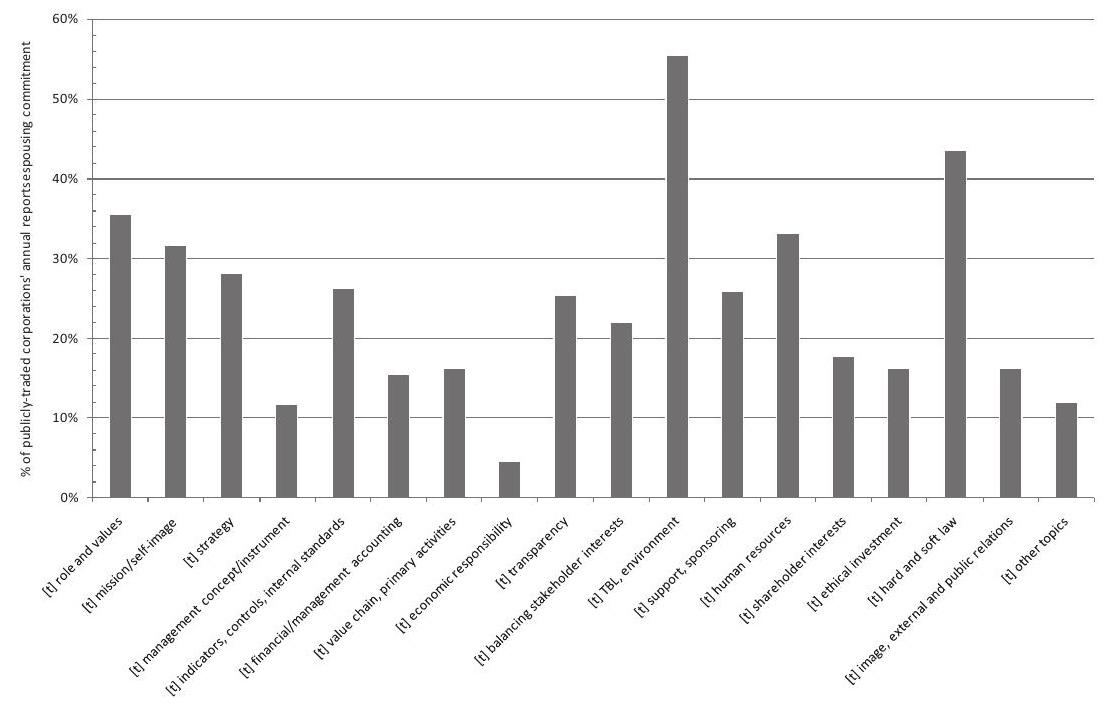

Figure 20: Thematic embeddings of CSR issue markers

Not surprisingly, sustainability issues that link with the triple bottom line and with environmental concerns (TBL, environment) are among the most invoked topics when corporations indicate commitment to CSR. Also, hard and soft law as well as transparency, both related to issues of good corporate governance, score high. The same applies to role and values of the corporation (i.e., the role and positioning of corporations within society) and mission/self-image (i.e., organizational identity); this corresponds well with the findings for annual report sections. Human resources and strategy are also very prominent here, despite their lack of importance for the alignment with report sections. Finally, support, sponsoring, the balancing of divergent stakeholders' interests (balancing stakeholder interests), as well as indicators, controls, internal standards are further and central topics within the CSR discourse. Other thematic embeddings of CSR issue markers (such as a primarily economic responsibility, management concept/instrument, financial/management accounting, value chain, primary activities, ethical investment, shareholder interests, and image, external and public relations) play a less significant role. Having in mind the classic pyramid of corporate control (and controlling instruments) that is organized by the degree of concretization - i.e., characterized by a broad basis of highly specified (operative) instruments and a rather narrow top of more abstract (strategic) organizational objectives - CSR is to be positioned more on the upper end. Most of the thematic embeddings to which CSR is linked remain too vague to qualify for the purpose of corporate control, whereas only a few topics actually touch upon or suggest specific tools. 


\subsubsection{Thematic embeddings and the stabilization of discourse over time}

It is also interesting to investigate how the specific topics in which CSR is embedded develop over time. As a general trend, one observes an increase in virtually all thematic embeddings except economic responsibility (see Figure 21), and also in the number of topics linked to CSR within an individual annual report. What is most clearly discernible is how a range of topics concerning the corporations' relations to shareholders gains in significance: shareholder interests, transparency, hard and soft law all these are corporate governance issues -, or etbical investment. Strategic issues (mission/self-image, strategy, and image, external and public relations) and indicators, controls, internal standards, among others, are also on the rise. Role and values as well as support, sponsoring, by contrast, see relatively modest increases.

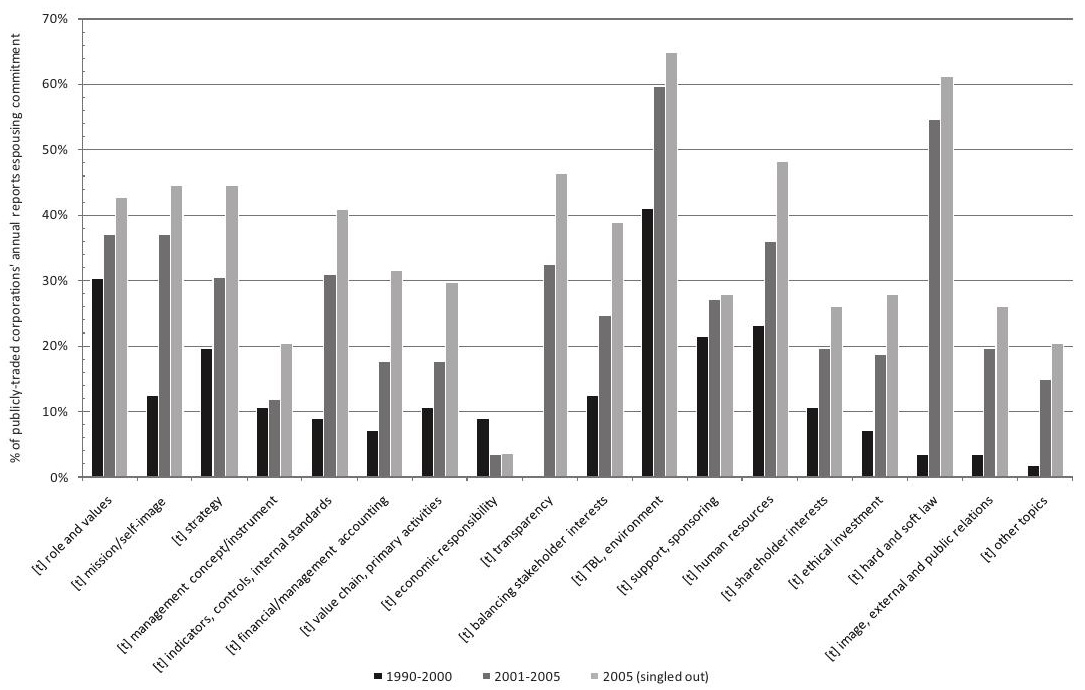

Figure 21: Thematic embeddings of CSR issue markers over time

With almost all thematic embeddings more on the rise in the 2000s than in the 1990s - due to a higher extent of reporting on CSR, among other things -, the relative importance of individual topics naturally moves to the center of attention. I thus consider an alternative take on my data in order to provide another perspective of how the discourse is shaped in terms of topics. Figure 22 illustrates the trend which might be also interpreted as a differentiation of the discourse: While some thematic embeddings (e.g., buman resources, support and sponsoring, role and values) are visible throughout almost the entire observation period, others are clearly on 
the rise (e.g., hard and soft law, transparency, indicators, controls, internal standards, sharebolder interests, and image, external and public relations) or even decline (i.e., lose relative importance) (e.g., economic responsibility) over time.

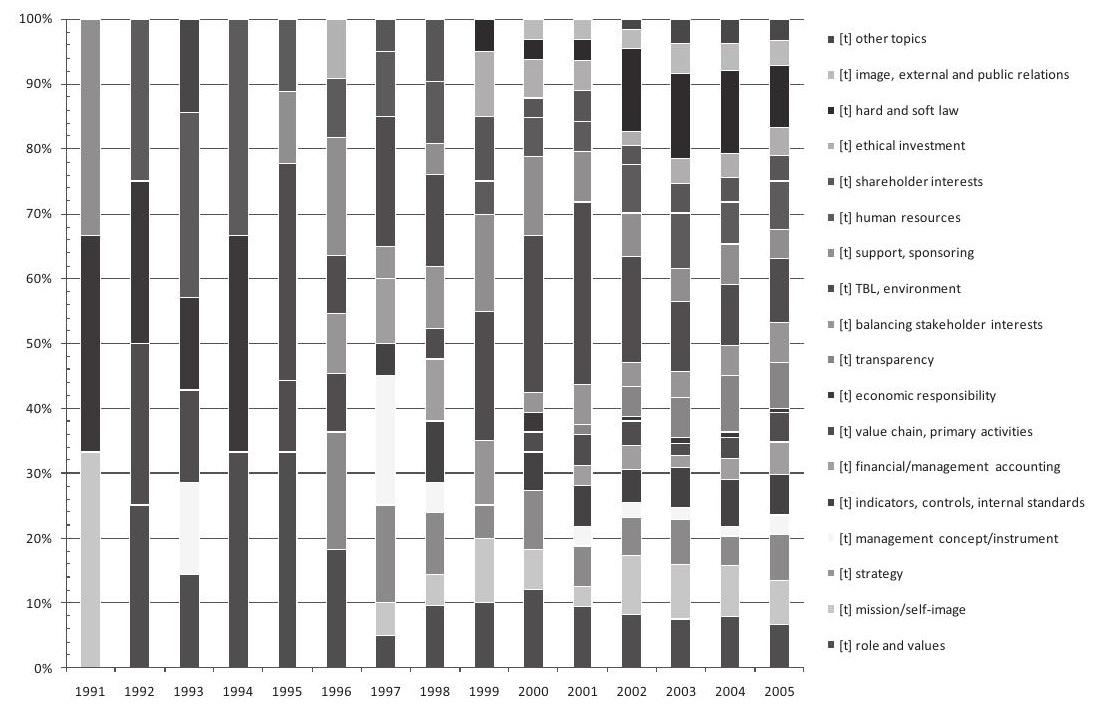

Figure 22: Stabilization of thematic embeddings over time

Until 2000, one observes a great deal of dynamic and variation within the topics embedding CSR issue markers - and thus, as one might conclude, also within the overall framing of the issue. Some thematic embeddings emerge, others vanish, and the proportions between the divergent topics prove to be rather unstable. Building on insights of this study, these early years are characterized by "pioneers" advocating explicit CSR as a corporate practice. ${ }^{185}$ They aim at initial rationalization and theorization, as well as at translation of the issue into the specific local context. Therefore, the 1990s might also be understood as the period in which corporations are in search for meaning - or even as a struggle over the practice's actual meaning in the Austrian context (i.e., sense-making and/or sense-giving).

At the beginning of my observation period (i.e., in the years when explicit CSR surfaces in the Austrian corporate world), buman resources, role and values, and economic responsibility are the dominant themes in those cases in which corporations refer to CSR. While the first two continue to be relevant, the latter is superseded by a focus on sustainability (TBL, environment) and the need to balance divergent interests

185 That is, the early adopters or "institutional entrepreneurs". 
(balancing stakeholder interests) in the mid-1990s. Corporate governance topics and issues of management control join the scene later in the 1990s.

However, starting around 1999/2000, and especially during the last four years of my observation period (2002-2005), the data indicate a stabilization and differentiation of the CSR discourse: In Figure 22, one clearly recognizes greater diversity of thematic embeddings, as well as more even and stable proportions as central characteristics. This trend goes hand in hand with the remarkable stabilization in terms of issue markers used (see also remarks on Figure 13 above) and can also be reported for other variables. ${ }^{186}$ Thus, in sum, my findings here corroborate those from above, with corporate malfeasance around the turn of the millennium being a decisive moment for the subsequent and unparalleled career of CSR. Moreover, they also point at an increasing institutionalization of explicit CSR as an organizational practice (see the stages of institutionalization and their comparative dimensions in the model presented by Tolbert \& Zucker, 1996, that predicts, among other things, a moderate/low variance in implementation for the semi-/fullinstitutionalization stage; see also Table 2).

\subsubsection{Sub-discourses and thematic embeddings: A second correspondence analysis}

The bedrock question of this section points in the direction of the framing of CSR. ${ }^{187}$ In order to further explore profound principles and the structuring dimensions of meaning, I will carry out a second correspondence analysis that will comprise the variables issue markers and thematic embeddings. Bringing together conceptual sub-discourses and topics in which CSR statements are embedded, Figure 23 sheds another spotlight on the configuration of the empirical CSR discourse. As highlighted above, thematic embeddings also fulfill a crucial role as tentative cues for the framing of CSR: It will be interesting to see which thematic embeddings - in interaction with specific conceptual sub-discourses - "organize" the discourse.

The correspondence map in Figure 23 accounts for $92.3 \%$ of total inertia. The first and most important dimension (the x-axis) is highly explanatory and accounts for $61.7 \%$ of inertia, while the second dimension (the y-axis) adds another $30.6 \%$. For the overall model, both variables - issue markers and thematic embeddings contribute greatly to the explanation of variance in dimensions. With regard to the overall quality of the model, almost all categories are well determined by the two dimensions (the only exception, to some extent, is value chain, primary activities).

186 A similar picture of increasing stabilization emerges when investigating the anchoring in annual report sections or the reference to categories of stakeholders over time: The last four years of the observation period are surprisingly stable and show almost even proportions.

187 Ultimately, explanation and justification of this practice are important parts of the discursive activity around the issue of CSR (at least from the side of its advocates). 


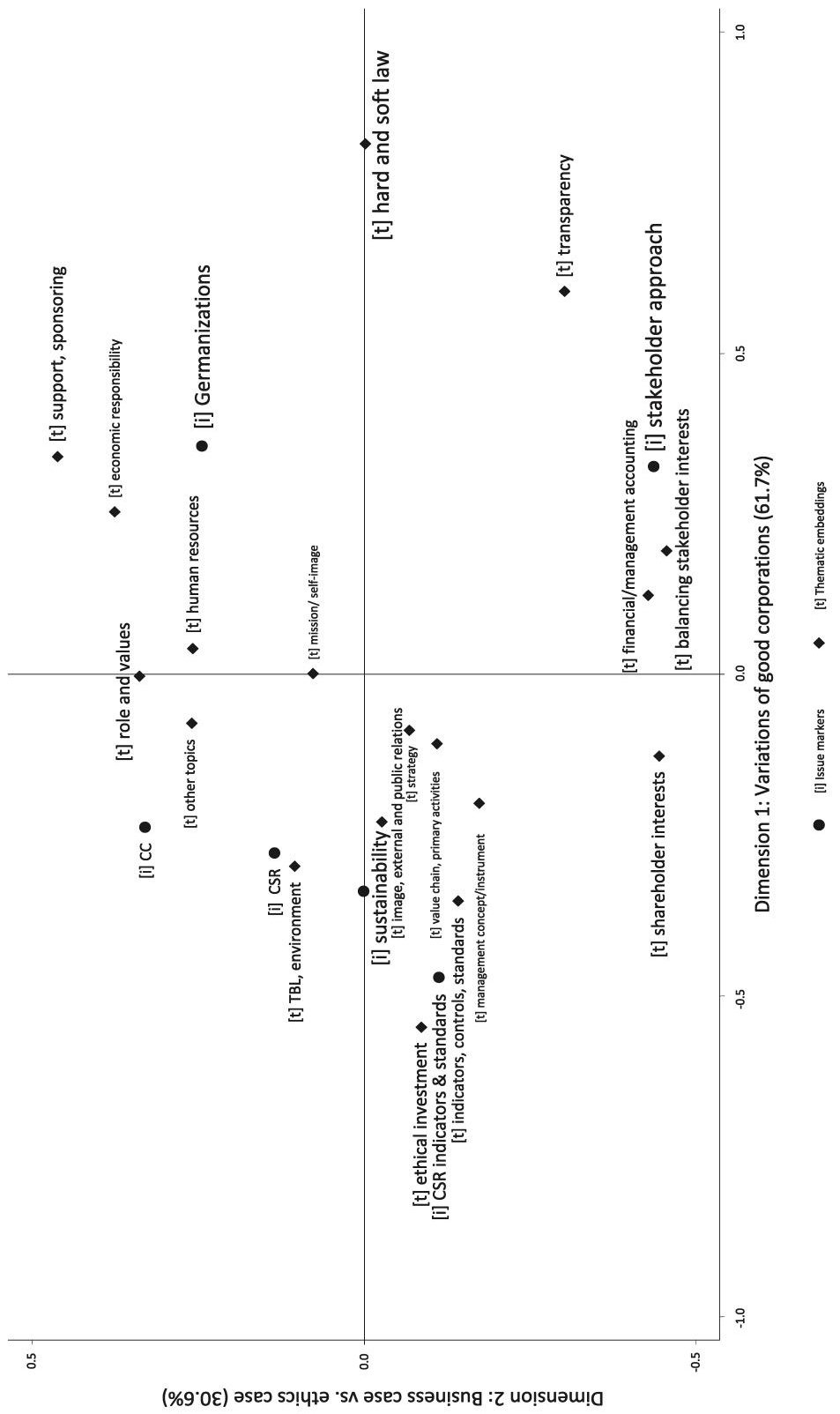

Figure 23: Correspondence map: Issue markers and thematic embeddings

Markus A. Höllerer - 978-3-653-01464-8

Downloaded from PubFactory at 01/11/2019 11:31:02AM

via free access 


\subsubsection{Variations of good corporations}

The central meaning-generating principle of Figure 23 expounds on divergent ways of depicting an organization as a socially responsible corporation toward divergent audiences (i.e., on variations of good corporations).

On the left, the main objective seems to attract ethical investors by portraying the corporation as a sound and sustainable investment. Consequently, ethical investment and the triple bottom line approach toward reporting (TBL, environment as a special focus) are crucial. CSR is also perceived as a management concept to enhance image, external and public relations by means of reference to an array of indicators, controls, standards. Not surprisingly, sustainability and CSR indicators \& standards are the most dominant conceptual sub-discourses (complemented - to some extent - by CSR).

On the right, good corporations are depicted as those that are in line with more general norms of corporate governance and control. Especially compliance with standards and codes of (good) corporate governance - therefore the extraordinarily strong focus on hard and soft law, as well as on transparency, is a central characteristic. To a lesser degree, support, sponsoring contributes to this pole of the horizontal dimension. At first sight, this topic does not seem to be related to the issue of corporate governance. However, the underlying message becomes more evident when taking into consideration the argument of CSR as essentially voluntary action (see chapter on CSR): Corporations voluntarily support other societal actors and live up to their social responsibility as business organizations embedded in society so there is no need for stronger rules or legal regulation. ${ }^{188}$ Germanizations and the stakeholder approach are the most influential conceptual sub-discourses here.

\subsubsection{Business case versus ethics case}

The second dimension of Figure 23 - although harder to interpret - also offers intriguing insights. It differentiates between two main normative ways to argue for CSR: The business case argument versus the framing as ethics (or moral) case.

At the bottom, thematic categories depict CSR as an entrepreneurial imperative in order to protect the financial and economic interests of the corporation and its shareholders (shareholder interests, financial/ management accounting). In modern economies and business systems, CSR is considered to offer appropriate instruments and tools to navigate the corporation through troubled waters: Transparency and especially the reflection of divergent stakeholder interests and claims (balancing stakebolder interests) contribute - as organizational objectives - to such a framing that, at its core, addresses the long-term well-being of corporations. The foremost im-

188 While categories to the left of the horizontal axis address financial market constituents more, the right hand side could be interpreted as being directed toward regulators - with the implicit aim of keeping them at bay. 
portant conceptual sub-discourse and issue marker for arguing a business case for CSR is the stakeholder approach.

At the top, one can identify the strong, normative reasoning of the ethics case. Addressing the corporations' role within society as well as corporations' commitment to certain values (role and values), CSR is clearly depicted as a moral obligation. However, supporting underprivileged societal groups and beneficiaries also corresponds to an elitist view on corporations: CSR is thus not so much based on what Gioia (1999) criticized as a naïve egalitarian or democratic illusion of multiple stakeholders having an equal say, nor on mere altruism. Rather, it is derived from the notion that the economic and managerial elite is partly responsible for, and in charge of, the socioeconomic architecture of the nation and the well-being of society at large (see chapter on empirical context for more). Support, sponsoring is, alongside role and values, the central topic of such a framing. The traditional supervision of staff is also included (buman resources issues), as is - albeit to a lesser extent a creed toward CSR via mission/self-image of corporations. Interestingly, one also finds an emphasis of social responsibility as a primarily economic responsibility. ${ }^{189}$ The most important conceptual sub-discourse is Germanizations, complemented although to a very limited extent - by CC.

\subsubsection{Some implications}

In sum, Figure 23 corroborates the juxtaposition of the conceptual sub-discourses of Germanizations and sustainability, as well as of stakeholder approach and sustainability (see also Figure 19). The correspondence analysis also introduces a disassociation of Germanizations and stakeholder approach in the second dimension. ${ }^{190}$ Again, the Anglo-American labels of CSR and CC are of rather minor importance for structuring the empirical CSR discourse.

Thematic embeddings turn out to be less ambiguous than actor categories; they determine distinct ways of how to present business organizations as good corporations, and of how to argue for - and, at a general level, frame - CSR. The corre-

189 Economic responsibility as a specific part of the ethics case does not necessarily contradict the juxtaposition of the business and ethics case, but opens yet another line of argument. While the business case suggests that CSR is good for the economic well-being of the corporation, the causality here is argued the other way round: Only an economically healthy corporation can live up to its social responsibility as an employer, source of profit, innovator, and economic driving force for society (see also the discussion in line with Friedman's phrase - borrowed from Sloan - of "the business of business is business"). It is, thus, the social responsibility and moral obligation to be successful in business conduct. Moreover, the slack resource argument is present here: Only financially strong corporations can afford to substantially support societal groups in need.

190 Overall, the angle between the two label points in the correspondence map is roughly $90^{\circ}-$ meaning that these categories are independent within the model presented here. 
spondence map at hand is stunning insofar as almost no categories cluster around the origin (i.e., are shared by all CSR sub-discourses to a similar degree). Furthermore, the core structuring principles that will persist in a final - multiple - correspondence analysis are already clearly recognizable. ${ }^{191}$

\subsection{Variation and patterns within discourse: Translation into Austrian?}

In a last step, I will integrate the three variables - issue markers, actors, and thematic embeddings - into one analysis. ${ }^{192} \mathrm{By}$ arranging all categories within a single correspondence map, this procedure provides for a fine-grained analysis and an integrated view of CSR. In particular, I aim to reveal general patterns within the empirical CSR discourse from the perspective of the Austrian corporate world.

\subsubsection{The comprehensive model: A third correspondence analysis}

The correspondence map in Figure 24 accounts for $77.4 \%$ of total inertia. The first and most important dimension (the x-axis) is sufficiently explanatory and accounts for $49.5 \%$ of inertia; the second dimension (the y-axis) adds another $27.8 \%$. For the overall model, issue markers again contribute greatly to the explanation of variance in dimensions; thematic embeddings are relevant in a variety of categories, while actors are of relatively minor importance. With regard to the overall quality of the model, most categories are determined to a reasonable degree by the two dimensions; however, there is also a range of categories that merits less analytic focus (many of these more or less cluster around the origin and are depicted in smaller font size for this reason and due to their limited contribution in explaining variance in dimensions).

Admittedly, the correspondence map in Figure 24 presents itself as rather complex at first sight. However, it confirms the insights discussed above: The configuration of the graph changes slightly but - in principle - corroborates central findings of Figure 19 and Figure 23.

191 In this context, also note the corridor that splits the correspondence map - and thus the empirical CSR discourse - from bottom left to top right (see below for more details).

192 The use of three variables radically increases the number of observations: While

Figure 19 and Figure 23 are based on co-occurrences of issue markers and either actors or thematic embeddings within identified text fragments of an annual report (however, aggregated at the level of the annual report; please see chapter on methodology for details), Figure 24 must take into consideration all possible combinations of categories of these three variables (resulting in $\mathrm{N}=12,999$ compared to $\mathrm{N}=2,626$ and 2,145, respectively). 


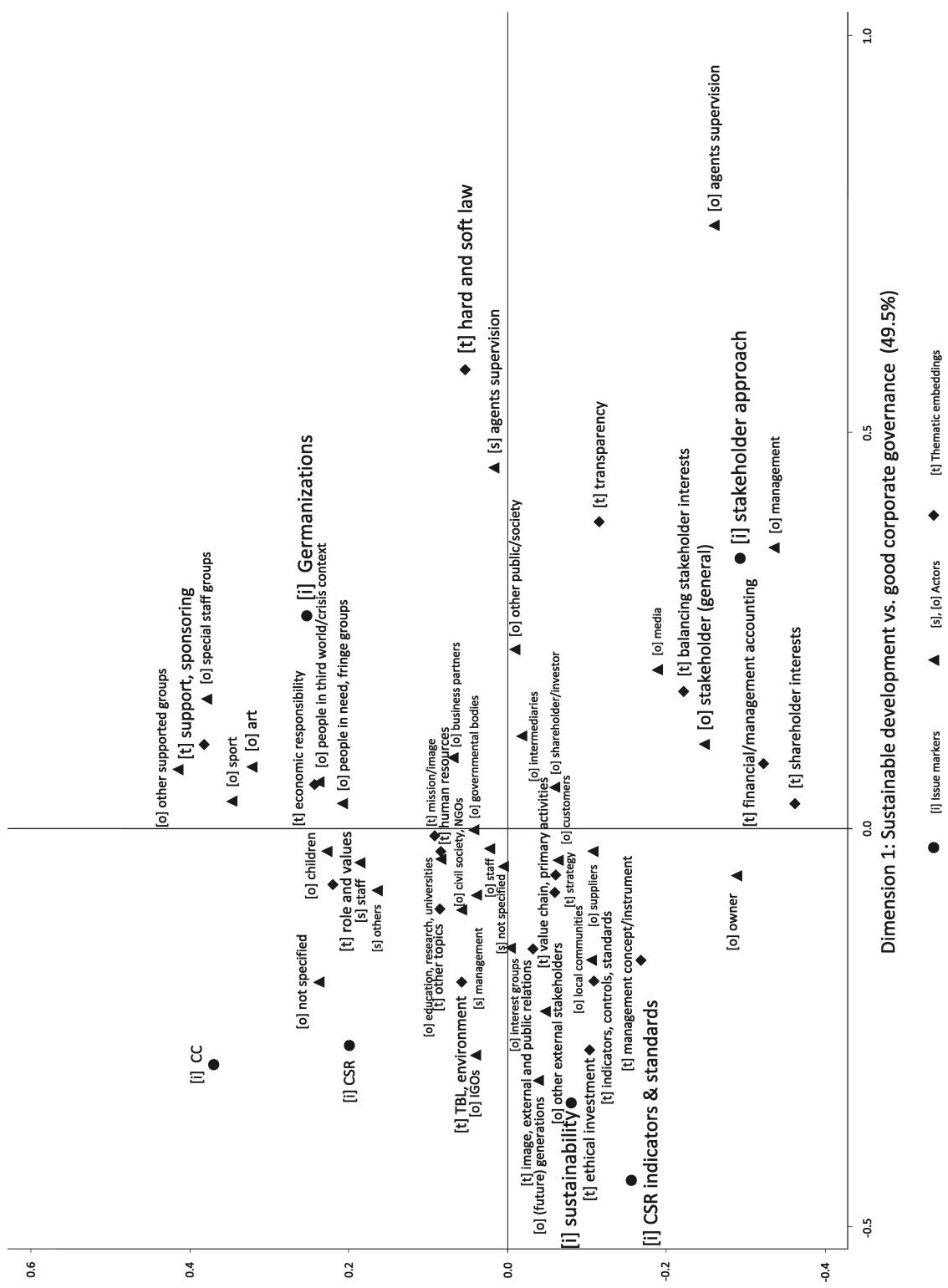

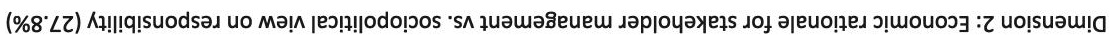

Figure 24: Correspondence map: Issue markers, actors, and thematic embeddings

Markus A. Höllerer - 978-3-653-01464-8

Downloaded from PubFactory at 01/11/2019 11:31:02AM 


\subsubsection{Sustainable development versus good corporate governance}

The structuring principles throughout the three correspondence analyses roughly resemble each other. Thus, the central meaning-generating principle of the horizontal axis already seems familiar to some extent: a differentiation between sustainable development and corporate governance issues.

To the left, a first pole is characterized by triple bottom line reporting and environmental concerns (TBL, environment) as well as aspiring to be perceived (image, external and public relations) as an etbical investment by the capital market; referring to indicators, controls, standards qualifies as a sustainable business organization and as a sound investment. CSR is also framed as a management concept/instrument with management - although not very well associated with this dimension - as the main subject. Furthermore, responsibility for (future) generations, attitudes and policy initiatives of IGOs, and positions of other external stakeholders (experts and consultants, among others) are incorporated. To some extent, this is also true for local communities, interest groups, and civil society, NGOs. The main conceptual sub-discourses and groups of issue markers here are sustainability, CSR indicators \& standards, but also - albeit to a much lesser extent - the label CSR. Interestingly, most actor categories that - as the objects of corporations' endeavors in explicit CSR - cluster around the sustainable development pole can be broadly subsumed under civil society actors that are not the ultimate recipients of CSR activities, but are themselves to be characterized as agentic actors (Meyer \& Jepperson, 2000); they are assumed to act on behalf of other members of society.

On the right, I identify a range of actors and topics that make sense under the auspices of the good corporate governance debate. The compliance to rules and standards of good corporate governance (hard and soft law) as well as a reasonable level of transparency make corporations eligible as responsible societal actors in the eyes of the general public (other public/society) and - to some extent - the media. The supervisory board (agents supervision) plays a crucial role both as a subject of responsibility and as an object of accountability (see below for more); management is another important object category. The two correspondence analyses above have already outlined that the stakeholder approach is the main vehicle for such a framing of CSR as good corporate governance. Interestingly, Figure 24 informs us that the category Germanizations is also of crucial importance in determining this pole of the horizontal dimension - and, as I will elaborate in more detail below, somehow bridges the cluster of good corporate governance and a more sociopolitical point of view on responsibility.

\subsubsection{Economic rationale versus sociopolitical view}

The second, vertical dimension also resembles insights from above: A primarily economic rationale for stakeholder management is contrasted with a much broader 
and sociopolitically inspired - perhaps even elitist - perspective on social responsibility.

Below the $\mathrm{x}$-axis, shareholder interests, the need to balance divergent stakeholder interests, the issue of financial/management accounting, and CSR as a management concept/instrument dominate. The business case argument for CSR implies an economic rationale in defining objects of CSR (the generalized stakebolder, management, as well as owner and shareholder/investor are especially relevant for the area at the bottom of the pole). The main purpose of CSR is to ensure the long-term survival of the corporation: Not surprisingly, the stakeholder approach serves as the main issue marker for this understanding of CSR.

At the top, however, the ethics case results in a much broader definition of stakeholders and places emphasis on those that are not included in the classic definition of corporate stakeholders (e.g., in strategy literature). Such a sociopolitical view on responsibility corresponds quite well with the indigenous, continental European understanding - and especially with the traditional perspective within the Austrian corporatist system of governance. Thus, a range of beneficiaries are relevant above the $\mathrm{x}$-axis: art, people in need, fringe groups, sport, children, and people in third world/crisis context, but also special staff groups. Moreover, the thematic embeddings of support, sponsoring, roles and values, as well as mission/self-image dominate. Interestingly, references are also made to staff as a subject of responsibility. The message here seems clear: CSR is not solely the responsibility of the corporation or of executive management; instead, it can only be achieved by the efforts of every individual employee (see also Figure 19). Finally, the arrangement of beneficiaries also makes evident the dominant function of Germanizations in addressing specific objects of corporate responsibility. ${ }^{193}$

\subsubsection{Some implications}

With all the associations and disassociations outlined above, one eventually recognizes at least three distinct clusters ${ }^{194}$ that are arranged in form of a triangle in Figure 24: A more global sustainable development cluster featuring - among others - the labels and categories of sustainability and CSR indicators \& standards, etbical investment, and TBL, environment (and also partly CSR); a cluster of corporate philanthropy including the main categories of Germanizations, support and sponsoring, role and values, and - to a limited extent - the Anglo-American labels of CSR and CC; and finally a cluster centering around the need to balance stakeholder interests and

193 Note that the object category not specified (i.e., statements on CSR that do not refer to any object category) is plotted much closer to the Anglo-American labels of CSR and CC that are also - although to a limited degree - associated with the vertical dimension.

194 One might argue, with good reason, that especially the second and third clusters could be broken down further. 
issues of good corporate governance, featuring, among others, the categories of stakeholder approach, hard and soft law, transparency, stakeholder (general), shareholder interests, financial/management accounting, and agents supervision. Interestingly, while the borderline between the first two clusters is rather blurred, they are clearly separated from the last one: Note the blank corridor that splits Figure 24 from bottom left to top right.

Also, it is apparent that CSR is a multifaceted concept: On the one hand, to be responsible has a very strong normative connotation, elaborating on how corporations - and also gradually the individual members of the corporation - should act, whom they must consider in corporate decision making, and for whom they are generally responsible as privileged members of society. On the other hand, being responsible also entails being accountable for one's behavior, actions, decisions, and policies. Such accountability exists, in particular, toward shareholders and investors, toward all members of the focal organization, and toward society at large that grants the license to operate. For both dimensions, decision makers at all levels are responsible for an optimal use of resources (i.e., for an appropriate relationship with employees, customers, suppliers, and other business partners), in addition to the well-being of the organization's members. In all cases, one witnesses agentic actors at work (Meyer \& Jepperson, 2000).

An exciting observation is that the second dimension of Figure 24 indeed quite well disentangles responsibility and accountability. While more or less all actor categories and thematic embeddings below the $\mathrm{x}$-axis allude to corporations' obligation "to give an account for something", the categories above the x-axis are closely linked to "being responsible for someone". In this way, the underlying meaning mapped by the dimension becomes even more apparent when taking into consideration the power relations between corporations and actor categories: Stakeholders with power and voice, and those without, are plotted separately (for a classification, see also Mitchell et al., 1997). While the framings at the bottom clearly favor dominant and definitive stakeholders embedded in core management topics, I find a framing at the top that is mainly concerned with the role and values of corporations within society. In terms of actor categories, I observe, in the latter case, a broad range of groups that all share a common feature: They are beneficiaries or recipients of corporate giving and philanthropy and have no voice unless management or other more powerful groups choose to attend to their claims or needs.

\subsubsection{Discussion of core findings}

\subsubsection{Structuring principles of the CSR discourse in Austria}

This chapter has shed light on the CSR discourse at two different angles. First, a network of conceptual sub-discourses (Figure 14), among others, illustrated the 
more quantitative dimension: frequencies and connectivity. Naturally, the more prominent sub-discourses are, the higher the chances are that they occur (i.e., are referred to) side by side within an annual report (e.g., sustainability and Germanizations). While this essentially informed us about more standard pillars of discourse and the "power balance" between categories, it did not reveal too much of the underlying - structuring and differentiating - principles/dimensions of meaning (i.e., those that lead to opposition or complementarity of categories). The same holds true for the second network graph as well as for the various descriptive charts that illustrate the distribution of categories of actors and thematic embeddings - regardless of the crucial insights these results have to offer. Nonetheless, it is important to note that only firm insights into the standard pillars enable a correct interpretation and relation of distinctions within the discourse.

Second, and as a remedy to above, (multiple) correspondence analysis accentuated associations and disassociations of categories within the empirical discourse on CSR. Interpreting the vectors from various label points to origin reveals, for instance - and at a general level -, juxtapositions of the conceptual sub-discourses of Germanizations and sustainability, or of stakeholder approach and CSR. An investigation of the various categories that are highly expressive of the structuring dimensions of discourse (from all three variables: issue markers, actors, and thematic embeddings) leads to peculiarities and distinctions becoming visible. Label points and categories that are equally important and common for divergent sub-discourses merit less analytic focus and explanatory value. In order to grasp and understand the CSR discourse adequately, I argue for an integration of these two perspectives.

Empirically, I demonstrated that the overall discourse on CSR in Austria primarily addresses the classic range of contractual stakeholders - shareholders and investors, employees, customers, and suppliers - and only secondarily encompasses a comprehensive responsibility at a societal level. This especially holds true for the empirical sub-discourse revolving around a stakeholder approach for CSR. More novel stakeholder groups are civil society representatives such as NGOs and local communities, but also IGOs; the latter organizations play a much greater role in issues of sustainable development. Actor categories theorized "to be in need of support", such as specific groups among staff (e.g., handicapped, trainees, women), people in third world countries or in crisis situations, children, or the more traditional recipients of corporate sponsorship and philanthropy (e.g., arts and sports) are primarily addressed by using Germanizations. Finally, I identified yet another distinct set of actors that is almost exclusively involved in corporate governance issues. In sum, I showed that the actor categories addressed by the individual empirical clusters significantly differ. In this respect, the results of this study could be applied fruitfully to further research in the domain of CSR concerned with detailed business-society relations.

Similar and surprisingly stable structuring principles - as well as spatial patterns - evolved throughout all correspondence maps, with thematic embeddings playing 
a very central role. Evidence from the analyses above suggests that partly overlapping, nonetheless distinct clusters (or empirical sub-discourses) exist within the overall CSR discourse: (a) More global sustainable development, including environmental issues; (b) corporate philanthropy as advocacy for and support of societal actors without voice in corporate decision making (which is also a connecting line between the Anglo-American version of CSR and the traditional, implicit understanding in the Austrian corporate world, also including corporate values and the role of business within society); and (c) the need to balance powerful stakeholder interests - something that goes hand in hand with issues of good corporate governance and transparency. The last cluster might, in a sense, also point at the increasing consolidation of two highly influential, yet - at a normative level - contradictory global management concepts that entered the Austrian arena during the last fifteen years: CSR and shareholder value (see also Meyer \& Höllerer, 2009).

In general, what I observed by focusing on the different labels employed, actor categories referred to, and thematic embeddings in which they are placed, is that contemporary CSR in Austria is by no means a monolithic discourse. It presents itself rather as a collage that combines, integrates, and further develops ideas with different legacies: One finds environmental concerns centering around sustainability issues that have been on the agenda of the corporate world since the ecomovement of the 1980s, a stakeholder tradition (as contrasted with a mere shareholder orientation) that has been emblematic for continental European governance structures ever since, and finally, the more indigenous understanding of a sociopolitical responsibility of economic elites that exceeds and moves beyond adhering to the claims of central stakeholder.

A look at the dynamics over time underscores this interpretation: In the early years (before the English labels of CSR and CC emerge), I find a significant negative correlation between sustainability, stakeholder approach, and Germanizations. When they appeared in the Austrian corporate world around 2000, these AngloAmerican concepts - and especially their integration into Germanizations - represent a discursive "umbrella term" (Matten \& Moon, 2008: 405). Their success can partly be ascribed to bringing together ${ }^{195}$ otherwise disparate constructs that are - despite having different foci as to whether responsibility or accountability issues are the main concern - united in their opposition to a system of governance that primarily accepts accountability toward the shareholders and/or investors. It comes as no surprise that two rather novel managerial ideas - the Anglo-American version of CSR, and the (CSR-related) notion of good corporate governance - began to resonate in the Austrian context exactly at a time when various corporate scandals

195 See also the remarks on frame alignment within social movement literature (Snow et al., 1986; Snow \& Benford, 1988, among others): Such bridging significantly increases the potential for resonance among target audiences and thus also enhances the number of actors at risk of adopting this communicative/discursive practice. 
drew attention to the darker sides of another popular management concept of North American provenance that essentially challenged the core idea of continental European business systems: shareholder value (see Meyer \& Höllerer, 2010 for details).

\subsubsection{Accountability: Adding a political dimension}

Another core insight of this chapter - particularly evident for Germanizations - is that the original notion of social responsibility of business organizations in Austria has been conceptualizing objects of responsibility as rather passive societal actors that are dependent on corporate decision makers (i.e., on a powerful corporate and managerial elite). What one observes is that, over time, topics emphasizing accountability rather than responsibility are clearly on the rise (for instance, hard and soft law, transparency, indicators, controls, internal standards, and some strategic issues). These enrich the traditional conceptualization and increasingly assign power to categories of actors relevant in the context of CSR. As outlined above, especially Figure 24 informs us - for the overall discourse - on the distinction of responsibility and accountability, as well as on power relations between the corporation and actor categories: Accountability is the assumption and acknowledgment of responsibility for the corporations' behavior, actions, decisions, and policies - including the obligation to report and explain, as well as to be liable for resulting consequences. In this way, the notion of accountability is clearly an extension of the previous understanding of responsibility that only obliged corporate decision makers to act in the interest of core stakeholders (see, for instance, the remarks on the wording of the Austrian Stock Corporations Act).

Above all, it also adds an essentially political dimension to the issue of CSR. Accountability must be characterized - perhaps even more than responsibility - as ambiguous, elusive, or murky: a multifaceted and "chameleon" concept (Sinclair, 1995), evaluative rather than analytical (Bovens, 2007), an empty signifier that needs to be filled with meaning in the historical-cultural context in which it is enacted. Accountability thus depends on "a shared set of expectations and a common currency of justification" about conduct and performance that is agreed upon within a social framework (Day \& Klein, 1987: 5). As Scott and Lyman (1970: 107) point out,

"[...] [t] he ability of an account to re-establish sociation is at the outset dependent on its comprehensibility and acceptance by others. To the extent that everyone in the audience to whom an account is given shares a common universe of discourse and a common basis of beliefs, an account is likely to be routinely acceptable."

In modern societies, global processes of rationalization have changed prevailing systems and forms of accountability and given priority to the naturalizing power of 
numbers, figures, and indicators - the "calculative priority" (Hopwood, 1990: 395). While financial accounting systems constituted the main focus of research in the past, more recently - not least triggered by corporate scandals and financial crises an increasing awareness that financial accountability is only part of a broader framework of societal accountability is taking hold (see Roberts \& Scapens, 1985; Munro \& Mouritsen, 1996, among others). Building on notions of responsiveness and integrity, accountability of corporations is understood as part of a comprehensive responsibility at a societal level - with explicit CSR policies spreading on a global scale being emblematic for this transformation and integration of accountability and responsibility. The definition of what these concepts mean provides the socially agreed construction of the role of corporations in society, as well as the evaluation of their conduct and performance. Thus, both are essentially contested and contestable concepts; how they are filled and given significance is a political process. ${ }^{196}$

Accountability establishes culturally charged social categorizations of themes, actors, and social relationships, not only between organizations and society, but - at a more concrete level - between different subject and object categories that are "arranged" in a social field and "warranted" voice (Potter \& Wetherell, 1987) to varying degrees (Phillips \& Hardy, 1997; Caruana \& Crane, 2008). For the corporate world, this makes visible distinct actors and manifests their divergent claims toward a corporation, thereby also negotiating power relations and struggling over a hierarchical order of claimants. In this sense, Giddens (1986) points out that - by reproducing the social stocks of knowledge - accountability is located at the intersection of signification, domination, and legitimation. Naming and treating go hand in hand; categories of actors and types of practices mutually constitute each other (Berger \& Luckmann, 1967). Thus, it is precisely the discursive construction of social categories that constructs accountability and responsibility as a social practice.

\subsection{Summary}

The fundamentally contested and socially constructed nature of CSR is one of the concept's most notable features. Therefore, the second part of this study - characterized by an integration of qualitative and quantitative methods in data generation and analysis - is essentially built on the notions of micro-level categorization, sense-giving and rationalization, and repercussion (i.e., theorization across various

196 In this sense, Scott and Lyman (1970: 94, 97) refer to accounts - quoting Wittgenstein - as "move[s] in a social game" and as "face games". Moreover, accountability in particular always entails intersubjectivity (Schweiker, 1993; Shearer, 2002) and a certain social relation between actors: "To talk about accountability is to define who can call for an account, and who owes a duty of explanation" (Day \& Klein, 1987: 5). 
levels). A detailed examination of culturally informed categories of actors involved in CSR (subject and object categories alike) and of thematic embeddings has been the analytical backbone of this chapter.

At the beginning, however, I first explored how the CSR discourse is empirically structured as a bundle of nuanced conceptual sub-discourses. Under a common umbrella term, the CSR discourse among Austrian publicly-traded corporations has been dominated by the German equivalents and predecessors of the Anglo-American version/concept of CSR, by issues of sustainability, and by a stakeholder orientation that is typical for the continental European system of governance.

Building on these initial insights, I closely investigated - in a second and third step - the web of relevant actor categories in the context of CSR, as well as the specific thematic embeddings of CSR issue markers in corporations' annual reports. While actors as objects of CSR are, on the one hand, dominated by a classic set very much in line with a strategic stakeholder approach (i.e., shareholders, staff, customers, and other business partners), the complementing notion of more generalizable stakeholders, on the other hand, draws attention to a broad range of alternative societal actors (e.g., civil society, general public, various beneficiaries) that have become increasingly relevant. On the subject side, however, the commitment to CSR remains in most cases limited to a not further specified subject category (i.e., the corporation, or "we"). In terms of topics, sustainability issues that link with the triple bottom line and with environmental concerns are among the most prominent topics, alongside issues of good corporate governance, corporate values, self-image, and the role of business within society. Furthermore, HR and strategic issues, the balancing of divergent stakeholder interests, as well as the implementation of CSR indicators, controls, and standards are additional, important embeddings of CSR issue markers. Two (simple) correspondence analyses allowed an initial understanding of how the overall discourse is structured.

Finally, I employed the powerful tool of multiple correspondence analysis in order to identify central patterns and the structuring dimensions of meaning of the CSR discourse. Evidence from such analysis suggests that three distinct clusters (or empirical sub-discourses) exist: Global sustainable development, including environmental issues; corporate philanthropy; and the balancing of stakeholder interests, which is inevitably related to issues of good corporate governance. Another overall structuring principle of the CSR discourse in Austria is the distinction of responsibility and accountability (with the latter adding an essentially political dimension to CSR). This can be interpreted both in terms of a divergent level of power assigned to actor categories, as well as in light of classic ethical theories (i.e., ethics of duties or virtue ethics versus utilitarian ethics linked to a business case perspective on CSR).

With regard to dynamics over time - and across all findings -, the mid-1990s can be understood as a period in which corporations were struggling with the 
practice's meaning in the Austrian context. However, especially during the last four years of my observation period (2002-2005), the data indicated a stabilization and differentiation of the discourse; this can also be interpreted as an increasing institutionalization of the concept (and discursive practice) of CSR. 
"As a field of inquiry, corporate social responsibility [...] is still in an embryonic stage."

Andrew Crane, Abagail McWilliams, Dirk Matten, Jeremy Moon, \& Donald Siegel (2008a: 568)

\section{Conclusion: Contributions, limitations, and outlook}

\subsection{Synopsis}

The study at hand - fueled by the rich theoretical perspective of organizational institutionalism - has been interested in, and concerned with, the dissemination and theorization of explicit CSR in a continental European context. More precisely, it has focused on Austrian corporations and their efforts to gain and manage their legitimacy by employing this comprehensive and dynamic management concept. I gathered empirical data on all Austrian publicly-traded corporations between 1990 and 2005, collecting information from corporations' annual reports and various other sources. Conceptually, my research has been built on the fundamental understanding that mobilization of legitimacy is primarily a discursive process. I therefore analyzed corporations' efforts to become identified with ideas and symbols that are thought to be in line with wider societal expectations and cultural context. Processes of institutionalization - and thus theorization and diffusion are central inasmuch as CSR has been promoted, across various cultural fields, as a global solution for a specific set of social/organizational problems; it represents one of the most prominent and opalescent examples of worldwide diffusion of management ideas in recent times. Empirically, the main concern of my project has been to explore the dissemination of CSR and to reconstruct the meaning of this very notion at field level. Moreover, it was a central objective to identify and understand the structuring dimensions/principles that organize the discourse revolving around the issue of CSR.

The questions guiding my research - delineated in greater depth in the introductory chapter - were dealt with in several steps. After expounding, in some detail, the state of the field of scholarly research on CSR, and following the presentation of the conceptual cornerstones of organizational institutionalism (i.e., the primary theoretical approach used here), I outlined the methodology and empirical design of the study. A first analysis then explored the Austrian corporate world as its specific empirical setting: I described both the more general institutional framework in place, as well as activities and key actors in the Austrian CSR arena. Empirical results on social disclosure practices in Austrian publicly-traded corporations' annual reports brought this part of the study to a close.

Core findings were organized into two individual chapters, each addressing a specific set of questions. A first chapter discussed, on the one hand, results for the 
emergence, significance, and placement of CSR on the corporations' agenda. Analyzing the increasing relevance of CSR for Austrian business organizations especially after the turn of the millennium, I illustrated that CSR was either addressed in newly created sections of annual reports, integrated with issues of investor relations and corporate governance, or utilized for public relations and marketing purposes (or a combination thereof). On the other hand, this chapter elaborated on the specifics of dissemination of CSR, and on the characteristics of adopters (i.e., especially which corporations are "at risk" of indicating commitment). I tested a broad set of hypotheses comprising organizational, institutional, and more genre-specific variables in a number of binary logistic regression models. In general, I found large, young, and profitable corporations that employ capitalintense technologies and operate in high impact industries to be more inclined to espouse explicit commitment to CSR policies and activities. This very much corresponds with the suspicion that it is not the typical Austrian corporation that primarily endorsed explicit CSR policies and practices; for these organizations, "responsible business practices have been and continue to be implicitly part of their day-to-day business activities" (Matten \& Moon, 2008: 405). Therefore, in some respect, they are also a taken-for-granted feature of the institutional framework, but nothing to be addressed and promoted in corporate communication. I also referred to some evidence of an ongoing institutionalization of explicit CSR over time (most importantly, the co-occurrence of CSR with broader issues of corporate governance and control, the finding that early adopters of CSR differed from late adopters in terms of organizational characteristics, and the fact that field-level pressures gained significance over time).

A second chapter on findings went beyond the scope of existing work and the study of diffusion processes. With the fundamentally contested and socially constructed nature of CSR being one of the concept's most notable features, this part of the study essentially drew on the notions of micro-level categorization, sense-giving and rationalization, and repercussion in order to reconstruct the meaning of CSR in Austria. This also covered the ways in which corporations respond to pressures from their environment. Empirically I showed, among other things, that (a) the CSR discourse is structured as a bundle of nuanced conceptual sub-discourses; that (b) both a web of relevant actor categories and the thematic embeddings of issue markers serve as a basis for the theorization of CSR; and that (c) specific, structuring dimensions (or principles) of meaning organize the CSR discourse in Austria. Taken together, results from several correspondence analyses suggested three distinct clusters of discourse at empirical level: global sustainable development, corporate philanthropy, and the balancing of stakeholder interests (in issues of corporate governance and control). Another key feature of the empirical CSR discourse, adding an essentially political dimension, has been the distinction of responsibility and accountability. Finally, dynamics over time showed evidence of stabilization and differentiation of the discourse toward the end of my observation 
period, which can be interpreted as the increasing institutionalization of the concept (and discursive practice) of explicit CSR.

On the following pages, I will elaborate on various ways in which this project contributes to scholarly research. I will also briefly address some limitations, as well as point out implications and potential avenues for a future research agenda.

\subsection{Main contributions}

The work presented in this doctoral dissertation contributes and adds to existing literature at the empirical, conceptual, and methodical/methodological level. Moving beyond standard research, it is not so much focused on top-down theorization and dissemination of new organizational ideas and practices as it is on innovation from the periphery and the gradual modification of existing practices. Overall, this study tells the empirical story of how an implicit CSR orientation has become explicit over the years (see also Matten \& Moon, 2008). With an "invading" concept that challenges indigenous traditions being an important piece of the puzzle, it is reflected in the various research questions and analyses.

One of the unique characteristics of this study is that it grasps institutionalization "in the making" (see also Zilber, 2008) as well as its underlying processes of rationalization and theorization. It is in such a way that it exceeds the contributions common to most studies of diffusion in organizational institutionalism. My work especially highlights that CSR, like all modern management concepts - despite being extensively theorized and often promoted by globally active knowledge entrepreneurs -, needs to be aligned with more locally- and culturally-shaped opportunity structures; this implies that not just the actual practices, but also their theorizations must be adapted and translated. It is important to hold that the assignment of meaning points to the crucial importance of the actual adopters of new ideas and practices (i.e., in my case, the corporations), as they actively adopt, modify, and reject certain elements and features of the concept of CSR. The culturally informed - outcomes of such editing and translation processes, then, unfold at field level; this is also the domain in which one can access the structuring dimensions/principles of meaning.

\subsubsection{Contributions related to the empirical context and the phenomenon of CSR}

Although CSR has become a buzzword both in the academic arena as well as among practitioners, one still encounters a considerable lack of empirical research in this field (Crane et al., 2008a, 2008b). My work has investigated the phenomenon of (explicit) CSR - its emergence, career, and empirical meaning - in a non-standard national/cultural context (see also the call for scholarly work that highlights meaning and cultural embedding; for instance, Fiss \& Zajac, 2004, or the current 
special issues in the Academy of Management Journal and in Organization Science). As argued in greater detail in the chapter on empirical context, being an icon of corporatist and stakeholder governance in post-war Europe, Austria serves as an excellent complement to studies that focus more on Anglo-American contexts (and, in the field of CSR, on an Anglo-American reading of CSR). Moreover, this work represents - to my knowledge - one of the first large-scale, longitudinal studies on the dissemination and theorization/meaning of CSR; prior research has focused more on a limited evaluation of sustainability reporting (for Austria see, e.g., Denkstatt, 2004) or on an investigation of corporate managers' general attitude toward CSR (see, CSR Austria, 2003, among others).

With my research featuring various dimensions of theorization activities, I also presented novel insights into the assignment of meaning and the construction of CSR as a management concept. While it is often assumed that CSR mirrors a rather monolithic discourse, I showed that it is to be characterized - not only conceptually, but also empirically - as a rather fragmented one; individual sub-discourses are relevant to different degrees, shape the concept's divergent framings, and lead to distinct patterns within empirical discourse.

I also argue that it is an important contribution - in terms of CSR theory development - that this study has linked the academic debate and discursive practice in the corporate world (with its focus on reporting on CSR issues). The findings are qualified to inspire future work. For instance, while overall employees remain the most central reference group among societal actors, CSR has also proven to be closely related to issues of corporate governance and accountability toward capital market constituents (see hypothesis 14 and the various correspondence maps). Even though larger corporations (measured in terms of staff; see hypothesis 1) are significantly more "at risk" of adopting explicit CSR, employees are not the primary addressees of corporations' commitment to CSR (see also the interpretation of results for hypothesis 8). Rather, CSR seems to equally target the capital market, the general public, and regulators.

Finally, I contribute to the current debate on the global dissemination of managerial ideas and practices (i.e., it is also related to questions of, for instance, a convergence toward an Anglo-American model of governance) as well as to their modification in local contexts (i.e., global models diffusing worldwide by their refraction through local prisms). Thus, my research is also relevant for the scholarly debate beyond the boundaries of CSR research.

\subsubsection{Contributions at conceptual level}

Existing literature has so far focused more on "culturally legitimated theorists" (Strang \& Meyer, 1993: 494) or knowledge entrepreneurs (e.g., Abrahamson \& Fairchild, 1999) as the main promoters of innovative practices (for exceptions, see 
research on social movements within organizational fields, e.g., Rao, Morrill, \& Zald, 2000; Schneiberg, 2002; Schneiberg \& Soule, 2005; for an overview, see also Schneiberg \& Lounsbury, 2008). In addition to this traditional line of argument, I highlighted the active and creative role of actual adopters. ${ }^{197}$ By making sense of adopted or adoptable practices in interpretive struggles, adopters contribute significantly to the ongoing theorization of disseminating ideas and practices. ${ }^{198}$ Such bottom-up theorizing, however, is not necessarily an explicit endeavor, but is in fact included in routinely accomplished rationalization. Investigations of selfperception and self-presentation take corporations seriously (in their role) as key participants in the discourse on new corporate practices (and, in particular, in its reproduction); they shed light on how the "typified actors" - i.e., the actors that are expected to perform a script - engage with definitions of the "typified act" (Berger \& Luckmann, 1967). It is in this sense that my work exceeds classic models (e.g., Strang \& Meyer, 1993; Tolbert \& Zucker, 1996) and enhances the understanding of theorization as a more dynamic concept, spanning all levels of legitimating activities (see also Berger \& Luckmann, 1967) and throughout the entire life cycle of an idea or practice.

Moreover, while literature on translation covers the overall modification of practices when being adopted in an institutional context other than that of their origin, it does not sufficiently explore the dynamics and micro-processes of theorization as well as implications these have on the social construction of institutions (Zilber, 2008). Several scholars have noted that there is still a lack of understanding of the "enactment of beliefs over time" (Porac, Ventresca, \& Mishina, 2001: 595) and called for "in-vivo studies of meanings" focusing on the "ongoing and unfolding processes of institutionalization" (Zilber, 2008: 164). The study at hand provides an analysis of a case in which an organizational practice of foreign origin links with locally available meanings, integrating and transforming deeply rooted indigenous traditions - yet without any tendency of eradicating them. Especially with these indigenous practices being tacitly accepted - i.e., they have not been referred to explicitly by corporations but are now surfacing within the emerging discourse -, particular sub-discourses are assumed to play an important role during adoption and translation of a new management concept; they connect new and old practices as well as establish lines of shared understanding.

197 Powerful adopters champion their own adaptation and theorization of a concept/practice thus considerably shaping its theorization at field level as other societal actors imitate, and knowledge entrepreneurs pick up, at least core elements of successful practices/theorizations. Literature in the field of innovation research also points at the crucial role of adopters in the development of innovative practices (von Hippel, 1995, among others).

198 With regard to social agency, my research thus differs from existing literature in its focus not only on organizations as agents but also on their active role in socially constructing categories of other societal entities and themes involved. Here, the critical role of vocabulary and rhetorical strategies becomes evident once more. 
In sum, and with regard to locus of theorization, I thus argued that bottom-up theorization is relevant and far from being trivial, and pointed out the mutual relationship of macro- and micro-processes of theorization: I suggested paying closer attention to the repercussions between the various levels at which theorizations take place. It is important to hold that mainstream institutional research has so far mainly conceptualized theorization as part of a linear process in which theorization is followed by translation/enactment: While theorization takes place at a more global field level prior to diffusion with the purpose of abstraction and the outcome of legitimacy, ideas are then, during diffusion, applied to and enacted in local contexts. Here, I have argued that such a picture might be too simplistic: Theorization is a constant activity - even for fully institutionalized practices; it is embedded in a complex process with micro-level sense-giving, rationalization, and bottom-up theorizing playing a crucial role in essentially shaping the more general, higher-level theorization of a practice.

At conceptual level, this study has addressed institutions and institutional practices as primarily social/cultural constructions. Recently, several scholars have criticized that - although culture and meaning have been essential pillars in institutional thinking - only a few studies actually empirically address these issues. Categorization and typification are central to all knowledge (Schütz, 1974); classification into social categories lies at the heart of all institutions (Berger \& Luckmann, 1967; Meyer, 2008). For example Meyer, Boli, and Thomas (1994: 18; see also Meyer \& Jepperson, 2000) point to this close - indeed, tautological - relationship between social categorization of actors and patterns of action:

"Both social actors and patterns of action they engage in are institutionally anchored. The particular types of actors perceived by self and others and the specific forms their activity takes reflect the institutionalized rules of great generality and scope. It is in this sense that social reality including both social units and socially patterned action - is 'socially constructed' [...]. Institutionalized rules, located in the legal, social scientific, customary, linguistic, epistemological, and other 'cultural' foundations of society, render the relation between actor and action more socially tautological than causal. Actors enact as much as they act: What they do is inherent in the social definition of the actor itself. Consequently, rules constituting actors legitimate types of action, and legitimated action constitutes and shapes the social actors."

I have argued that such typification of actors and action - which is crucial for the theorization and, subsequently, institutionalization of management concepts - does not only include distinct types of actors that are, as subjects, performing a certain patterned activity, but also categorizes the very objects of these actions, as well as their thematic embeddings (and framings). Thereby, the essential relations between categories are also defined, with some of the business-society relations included in the theorization of CSR being more symmetrical while others are more asymmetrical. Hence, social categorization includes the definition of rights and obligations and assigns (power) positions to different categories of actors in a cultural field (see 
also Bachrach \& Baratz, 1962; Roberts \& Scapens, 1985). In a similar vein, CSR must be understood as a relational concept: Relationships of accountability entail rights and legitimate claims on the part of the recipient, while in relationships of responsibility the power asymmetry is much more visible. This study has revealed and empirically highlighted such a divide by plotting powerful constituents and the need to balance these stakeholders' claims on the one hand, and a variety of supported or sponsored groups that obviously do not have a voice in corporate decision making on the other (see especially Figure 24).

\subsubsection{Contributions at methodological level}

Another contribution is located more at the intersection of the conceptual and methodological levels. Despite language and symbolism having always played a central role in organizational institutionalism (Meyer, 2008), this very field of research only recently witnessed a distinct turn back toward culture and meaning, with current research re-focalizing on the crucial role of communication, language, and discourse (for an overview, see Grant, Hardy, Oswick, \& Putnam, 2004, among others). Over the past few years, the surge in the interest in how institutions work through the interpretive experience of actors, and how these are constructed, sustained, and altered in contested political struggles, has drawn more and more scholars to investigate the role of meanings, interpretive schemata, and discourse in processes of institutionalization and deinstitutionalization (see also Meyer \& Höllerer, 2010). This interest in interpretive processes, however, is neither new nor exogenous. Rather, as several scholars have pointed out (e.g., Tolbert, 1985; Tolbert \& Zucker, 1996; Barley \& Tolbert, 1997; Greenwood et al., 2002; Meyer, 2006, 2008; Zilber, 2008), reconstructing meaning and examining its dynamics is a return to the phenomenological origins of organizational institutionalism. Nonetheless it is still true, as Phillips, Lawrence, and Hardy (2004: 635) emphasize, that the mainstream of empirical research has to date been more concerned with organizational practices than with the discursive practices that constitute them although the latter are of crucial importance to better understand how institutions are produced and maintained: "As a result, institutional research has tended to focus on the effects rather than the process of institutionalization, which largely remains a 'black box'." Institutions, however, are social constructions constituted through discourse - "structured collections of texts that exist in a particular field and that produce the social categories and norms that shape the understandings and behaviors of actors" (Phillips et al., 2004: 638; see also Keller, 2005). The production of texts is viewed as crucial to any institutional action (Zilber, 2008). As Phillips and Malhotra (2008: 715; see also Nigam \& Ocasio, 2010) ${ }^{199}$ stress, the

199 Nigam and Ocasio (2010: 826, with reference to Ocasio \& Joseph, 2005; Zilber, 2006, among others) point out that all institutional logics are "embodied in vocabularies and com- 
"[...] process through which institutions come into being is empirically accessible. Researchers can follow the production of texts looking for the appearance of key concepts and understandings and can therefore trace the production of institutions as well as the processes through which institutions change [...]. The focus on the appearance of influential texts and the meanings that these texts create as they accrete over time provides a clear empirical approach to the processes of social construction that underlie institutional dynamics."

My research has taken the discursive practices of theorization and institutionalization seriously, as a phenomenon, as well as in empirically accessing these practices. While such a research design is able to produce important results and insights and thus contributes to existing knowledge, it also entails some limitations (see below).

One of the objectives of my doctoral dissertation was to be innovative on the methodological level. Here, the combined application of qualitative and quantitative methods in both data collection and analysis seems noteworthy; this also follows a long-standing call in organizational institutionalism (Lawrence \& Suddaby, 2006, among others). In a similar vein, several scholars urged researchers to examine meaning more rigorously and, in particular, to measure meaning structures thoroughly (Mohr, 1998; Scott, 2008, among others). In order to explore the characteristics and structuring dimensions/principles of the CSR discourse in Austria, I integrated - alongside descriptive methods and visualizations - regression analysis, network analysis, and (multiple) correspondence analysis in a single study. While regression models, however, are standard methods in organization and management studies, and network analysis is increasingly applied in related research, the potential of correspondence analysis has to date scarcely been exploited at all. Thus, the empirical application of this innovative approach constitutes a main contribution of my work at methodical/methodological level.

Lastly, I employed a comprehensive, rich, and unique set of time-series crosssectional data. These empirical data cover the entirety of organizations within one field over a considerable period of time. I used the full population of annual reports of Austrian publicly-traded corporations between 1990 and 2005 (i.e., time-authentic material), complemented by various other sources, in order to generate my variables.

\subsection{Some limitations}

As in any study, my project has its limitations and provides opportunities for future research. I will, in the following, highlight some central limitations, as well as point out possible remedies.

munication $[\ldots]$. Both the prevalence of specific words, phrases, or signs and their use to denote specific meanings can serve as indicators of societal and field-level institutional logics". 


\subsubsection{Reflections on methodology: Sampling, genre specifics, and empirical setting}

Structure and "topography" (Meyer \& Höllerer, 2010) of the CSR discourse are not directly accessible but through the manifestations of the issue, especially in various genres of communication (Luckmann, 2006). A more general remark is concerned with the fact that implicit, taken-for-granted understandings are, however, not explicitly referred to in genres of communication - which makes CSR difficult to measure prior to it becoming explicit, rationalized, and equipped with distinct labels. ${ }^{200}$ It is thus not easy to empirically address the complex interplay of implicit and explicit CSR (see also Matten \& Moon, 2008).

The selection of empirical material is never conclusive and remains a crucial decision within the empirical research program and design. Thus, sampling decisions in the social sciences necessarily imply potential limitations. The project at hand has focused on the genre of annual reports and the perspective of actual adopters of CSR (i.e., on one of the most central actors in the issue field). However, other perspectives (such as those of addressees, beneficiaries, interest groups, NGOs, regulators, and the media) are included only indirectly (i.e., only in the event that they impact on corporations' way of thinking about CSR). In this sense, when interpreting results, one must be aware of the fact that these might represent only part of the full story.

It is important to note that CSR is also relevant - and perhaps in a different way - for privately-held corporations and business organizations other than publicly-traded. ${ }^{201}$ One might therefore argue for a stratified random sampling strategy in order to avoid and/or remedy a potential (financial market) bias. ${ }^{202}$ This, however, requires precise data on the contribution of subsets; moreover, it implies abandoning the advantages of a full count (see above). The observation period, although carefully chosen, must also be taken into consideration: I especially expect the global financial crisis around 2008 to impact findings for the most recent years, and to create a new set of dynamics (which is, by the way, very much in line with my argument of an ongoing process of theorization and renegotiation of meaning).

Limitations also arise due to genre specifics. Annual reports, like every genre of

200 Note that deeply ingrained institutions considerably shape reality, but are nonetheless "background programs". According to Berger and Kellner (1984: 138; translation by the author; see also Meyer \& Höllerer, 2009), "every instance of conscious attention to an institutionalized practice is the dawn of its deinstitutionalization".

201 However, the publication of annual reports (beyond annual accounts and other mandatory information filed in the Austrian Commercial Register) is not required for non-listed firms in Austria. Only some privately-held corporations publish these documents on a voluntary basis; even when they are published, it is usually hard to trace copies back into the 1990s.

202 Note that I empirically showed, on the one hand, that CSR is relevant for publicly-traded corporations (see also Miller \& Guthrie, 2007); on the other, CSR is - overall - not explicitly driven by expectations of capital markets (see regression models) like other management concepts (for the example of shareholder value, see Meyer \& Höllerer, 2009). 
communication, have their own characteristics and genre rules. One solution would be to draw on several communicative/discursive genres simultaneously (e.g., media, websites, or internal protocols) or include other forms of data generation (e.g., interviews). For the genre used here, it is important to state that the actual processes of creation and production of these documents have not been covered in my research (with the exception of controlling for the involvement of public relations agencies).

Finally, I argued that the concept/discourse analyzed is embedded in, and shaped by, the wider cultural and social field - and that understanding this cultural context is essential. In this respect, the example of Austria may help to extract some of the taken-for-granted assumptions of research primarily conducted in and on Anglo-American contexts (Meyer \& Höllerer, 2009). This, however, also poses a potential limitation to my results, and might raise questions about the potential for extrapolation: As Dobbin (1994) and Djelic (1998) have impressively demonstrated, the most powerful institutional characteristics can only be revealed in comparative analyses (see also Zald \& Lounsbury, 2010).

\subsubsection{Actual practice versus discursive action}

Another more general concern and critique might arise from the fact that I did not measure "actual" practice, but rather discursive action. ${ }^{203}$ Practice, understood in a narrow sense, has been covered only if it makes its way into communication and discourse; questions of, for instance, decoupling cannot be answered on this basis. In this way, one might argue that annual reports are problematic insofar as they (only) mirror social structures of expectations if these are perceived as such by corporations; with this in mind, however, my findings depict the relevant structures of expectations from the perspective of business organizations. A study that aims at addressing actual practices would be a completely different story in need of a different methodological and empirical design. While interviews, for example, could be equally criticized for "just" covering talk rather than action (plus implying the risk of ex-post rationalizations and subsumption of originally non-related action under the CSR agenda), the method of observation, or, for instance, examining the cash flows to beneficiaries could yield interesting insights. However, actions are hardly accessible in retrospect unless data already exists in sufficient quality.

203 Annual reports are instruments of self-presentation, and research drawing on them has been criticized for treating the proclamation of commitment as a discrete phenomenon, neglecting to examine variation, extent, and actual implementation. 


\subsubsection{Further integration of results}

I wish to address outright another important limitation with regard to methodology - which, at the same time, is also a major strength of this research: the integration of structure-testing and structure-generating methods. The overall plot of this study was chosen because it makes sense to first explore who is participating in the discourse on CSR, while, in a second step, addressing how this discourse is structured. As Meyer (2006: 729) notes, it is necessary to first fully understand (verstehen) the specific characteristics of a phenomenon at issue before being able to explain (erklären) it in greater detail. I argued that the structure-generating approach of correspondence analysis is a novel and powerful method for tracking complex relationships between categorical variables - one that could inspire other researchers to continue along this line (see also Meyer \& Höllerer, 2010). The philosophy behind correspondence analysis is, similar to a grounded theory approach, that the conceptual model must follow data. It has therefore been used to explore the structuring dimensions of data without imposing a pre-defined set of propositions. However, the findings can and should be used for explanatory multivariate techniques (and/or profound case study research). For instance, it would be tempting to develop and formulate, based on the findings of my study, a number of propositions and integrate these in a structure-testing research design (for instance, testing the individual clusters evolving in Figure 24 against a set of hypotheses and independent/control variables in binary, ordinal, or categorical regression models). However, the endeavor of running a set of refined regression models anew ${ }^{204}$ exceeds the confines of a doctoral dissertation, but could well be the subject of future research.

Correspondence analyses as presented in this study draw a rather static picture of the discourse that helps us to understand how the general system of meaning is structured. A more dynamic picture is somewhat tricky to create, as the methodology and method of correspondence analysis implies that the central dimensions develop out of data (i.e., the dimensions might be defined differently for each yearly dataset, which would on the one hand make a direct comparative interpretation rather difficult; on the other, this would enable alternative insights). However, adding the timeline to the static model (which slightly compromises model quality and is therefore not presented in the findings) indicates a rather low degree of influence of the individual years in defining the underlying meaning structures. Future research might use a comparative setup that presents and compares selected "snapshots" of the discourse (for instance, contrasting the years of 2001, 2005, and 2009).

204 This could also imply alternative statistical techniques (e.g., multinomial or ordinal regression models) employing the findings of this study in the form of new dependent variables on a restricted data sample. 
Furthermore, the categories used for multiple correspondence models could be further clustered and collapsed in follow-up research in order to reduce complexity and enhance the (statistical) quality of the models (this holds especially true for the labels of CSR and CC, for instance, or for some of the actor categories like beneficiaries or more standard groups of stakeholders). Naturally, there is a substantial trade-off between reducing complexity and presenting detailed information: It is, for example, indeed an interesting result that CSR and CC are used synonymously and positioned in a similar way with regard to actors, thematic embeddings, and other issue markers, or that standard stakeholders do not considerably influence the field-level configuration (i.e., the correspondence maps). However, it has been an explicit objective of my work to show these distinct differences and similarities in greater depth.

\subsection{Terra incognita: Signposts and outlook}

The previous chapters presented selected empirical findings for the research questions that have initiated and motivated this study; in this chapter, I summarized the main contributions. However, and as always, alternative avenues of tackling these questions and/or of presenting results do exist; I addressed some of these concerns as limitations of my research design. In a final step, I will point out several areas that I regard as potentially fruitful for follow-up research based on my project. While it was not possible to accommodate them within the confines of this doctoral dissertation, I am convinced that these ideas, directions, and signposts are suitable to continue and advance research in the spirit of this study. For some of these ideas, I have already commenced projects with various collaborators in order to gather additional or new data; others are building more on the extensive dataset available.

\subsubsection{Stand-alone annual CSR reports: A novel sub-genre of annual reports}

The study at hand has drawn on annual reports - required by law from publiclytraded corporations in Austria - as a formal outlet for publishing information (see chapter on methodology for more). While corporations' websites have become another important but more informal genre for organizational self-presentation (perhaps the most important one in recent times; see also Oberg, Schöllhorn, \& Woywode, 2009; Wruk, Scheiber, Oberg, \& Woywode, 2010, among others), (financial) annual reports have been increasingly complemented by stand-alone annual CSR or sustainability reports.

This new and interesting sub-genre only recently emerged in continental Europe: While not in existence among publicly-traded corporations before 2001, it appeared on the Austrian stage between 2001 and 2005 to varying degrees (2.8\% of 
corporations included in my sample also issued a stand-alone annual CSR or sustainability report in 2001; 2002: 5.9\%; 2003: 6.5\%; 2004: 8.3\%; 2005: 4.9\%). The documents address - usually in addition to specific passages in financial annual reports - issues related to CSR or (ecological) sustainability ${ }^{205}$ and essentially target the same diffuse audience (see Denkstatt, 2004). The trend for issuing stand-alone annual CSR reports is, however, not conclusive: While the recent past has seen a stronger reintegration of social and environmental disclosure into annual financial reports for some corporations, others obviously prefer to keep these two genres completely separate (e.g., assign different locations on their websites for download options of the electronic versions), and again others publish stand-alone documents but jointly design and distribute them. ${ }^{206}$

While financial annual reports have been a more or less standard genre for quantitative and qualitative research on organizations during the last few decades (for an overview see, Stanton \& Stanton, 2002, among others), stand-alone annual CSR reports have not yet received much scholarly attention. Even if sometimes condemned as glossy brochures, marketing instruments, or rhetoric and decoupled statements (see also Höllerer, Jancsary, Meyer, \& Vettori, 2010), such discursive material nonetheless essentially reproduces discourse and contains important references to institutions and the construction of meaning of CSR (both at cognitive and actual behavior/practice level). Thus, it is also suitable for manifold research purposes. Furthermore, it is assumed that this sub-genre might be analyzed - especially in a comparative research design - in order to understand institutionalization processes across divergent communicative genres.

\subsubsection{Visual elements: The visual construction of meaning}

With language playing a pivotal role, the study of meaning is mostly tied to the study of verbal communication and discourse (see also Jancsary, Höllerer, Vettori, \& Meyer, 2010). However, when analyzing meaning structures in aesthetically appealing documents like the genre of annual reports, a gut feeling tells the researcher that he or she might be missing out on something: the meaning incorporated in pictures, images, and other visual material employed in such documents.

Language is, as Meyer (2008: 529, with reference to Berger \& Luckmann, 1967) notes, "the most important sign system and 'reservoir' of typifications and institutional knowledge, although, by no means, the only one". Other complex systems of

205 In contrast to the Anglo-American tradition of HSE reports, CSR or sustainability reports in Austria usually build more on former environmental reports, although the latter were usually not issued on an annual basis (see also Denkstatt, 2004).

206 For instance, when asking for a hard copy of the financial annual report, both the financial and CSR report come attached to each other - sometimes even tied together by a ribbon that symbolically alludes to their liaison. 
symbolic signs equally store and transport sedimented social knowledge - with visual material playing a crucial and essential role. Also, during the past few decades, the use of visual media in everyday life has dramatically increased (Mitchell, 1994; Kress \& van Leeuwen, 1996; Mitchell, 2008). Nonetheless, the constructive power and constitutive role of the visual have been neglected in most empirical research that analyzes field-level discourse (admittedly, also in the study at hand). While the role and significance of imagery in meaning construction is widely acknowledged in other disciplines, especially in sociology (for an overview, see Bohnsack, 2008) and marketing (for an overview, see Schroeder, 2008), visual research in organization and management theory can be considered to still be in a state of "infancy" (Davison \& Warren, 2009: 852): Even when analyzing genres in which pictorial elements are central, their role in meaning assignment is - at field level - rather neglected (Boczkowski \& Orlikowski, 2004). As we show in related research (e.g., Höllerer et al., 2010; Jancsary et al., 2010), the relevance of visual elements goes far beyond a purely aesthetic moment. In annual reports, for instance, they serve "the rhetorical purpose of arguing the truth claims of those reports and the social constructs they represent" (Graves, Flesher, \& Jordan, 1996: 83). Hence, visual material is not trivial or a simple add-on. It plays a crucial role in transporting messages (Kress \& van Leeuwen, 1996) by stimulating the readers' sense-making and sense-giving capacity, especially in case of still rather ill-defined concepts like CSR. Figure 25 shows, as an example, the cover pages of 15 randomly selected stand-alone CSR reports of Austrian publicly-traded corporations (retrieved from corporations' websites).

Our research on the "visual (re-)construction of meaning" of CSR (e.g., Höllerer et al., 2010; Jancsary et al., 2010) thus aims at addressing an important gap within scholarly work. In short, we suggest an innovative approach to the study of visual media in organizational research, primarily building on accomplishments of organizational institutionalism and social movement research. ${ }^{207} \mathrm{~A}$ novel methodology, combining elements of both qualitative and quantitative research traditions, enables the grasping of visual elements at field level and provides insights into meaning construction (yet without compromising methodical rigor during analysis, coding, and interpretation).

Future work might also be interested in combining both the realms of verbal and visual discourse to explore an even richer source of data. Kress and van Leeuwen (1996: 17; for an overview, see also Royce \& Bowcher, 2007), for example, retain that "language and visual communication both realize the same more fundamental and far-reaching systems of meaning that constitute our cultures, but $[\ldots]$ each does so by means of its own specific forms, and independently".

207 We argue that institutional change and processes of interpretation and framing, as well as of translation, institutionalization, and theorization are not only reflected in practices and verbal text but also in pictures, images, design, and other artifacts (for details see, e.g., Höllerer et al., 2010; Jancsary et al., 2010). 

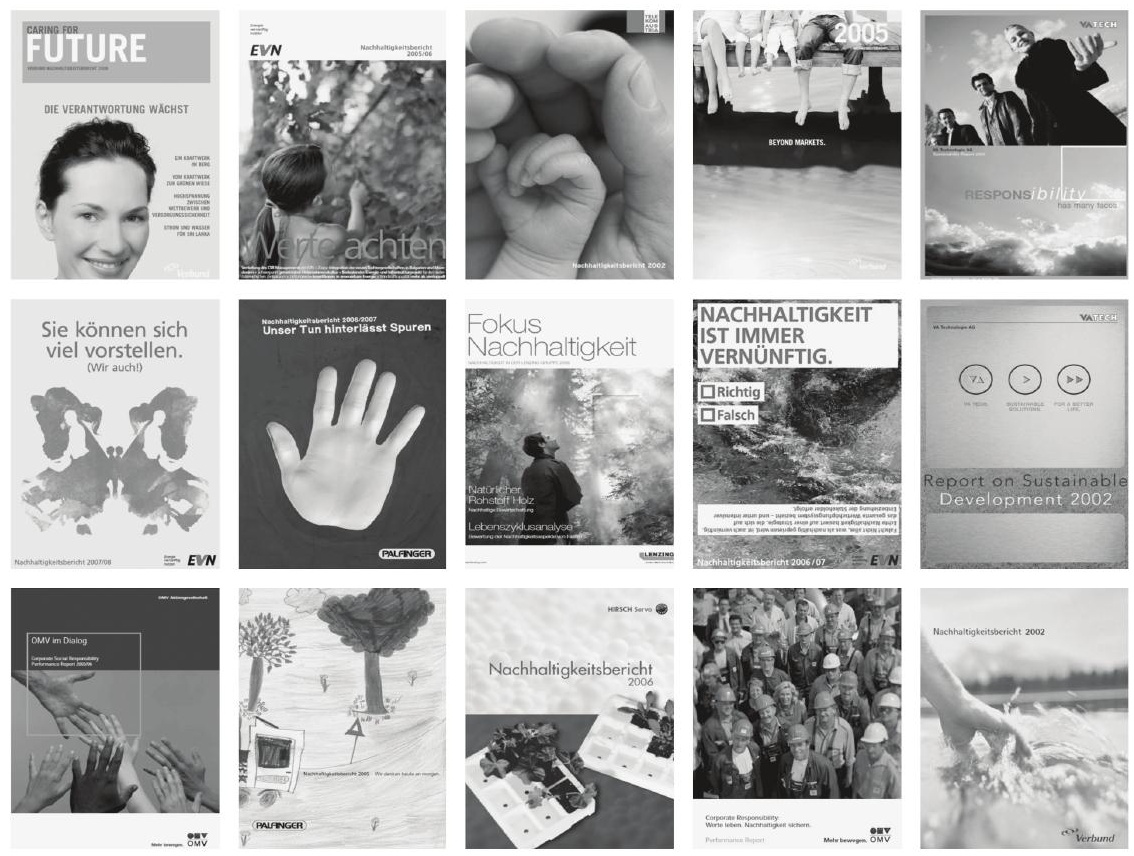

Figure 25: Cover pages of selected stand-alone annual CSR reports

\subsubsection{Interrelated bundles: V alue management versus values management}

The study at hand has demonstrated that the debate on contested issues - especially if the rationalization/theorization of such issues diffuses across divergent cultural fields and boundaries - is in itself not a monolithic discourse, but rather consists of various more or less intertwined sub-discourses. However, the question arises as to what extent such dissemination and theorization is also influenced by the simultaneous dissemination and theorization of other related issues (specifically, ideas and practices).

As Meyer and Höllerer (2009) note, interdependencies between various concepts as well as related field-level mechanisms (e.g., the ongoing dynamics of multiple translations) have so far been neglected in organization and management studies. In several working papers (e.g., Höllerer \& Meyer, 2007; Meyer \& Höllerer, 2009) we explored some of these effects by addressing a specific bundle of management concepts that is intertwined at the normative or programmatic level insofar as its theorizations point in opposing directions: shareholder value, CSR, 
and corporate governance. In this sense, Figure 26 extends the network of Figure 14 by replicating the (adapted) coding procedure for several pre-defined shareholder value sub-discourses (for the discourse on shareholder value in Austria, see Meyer, 2004; Meyer \& Höllerer, 2010).

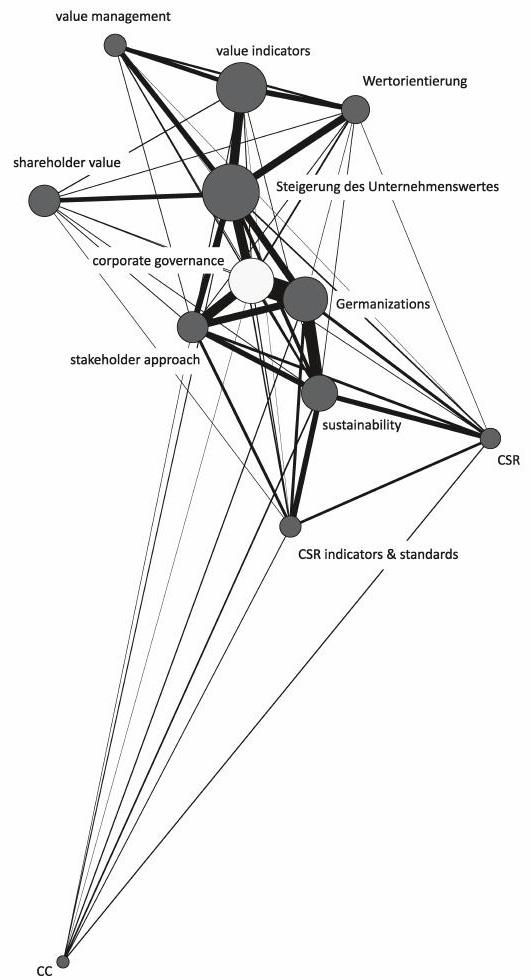

Figure 26: Network of conceptual sub-discourses of several management concepts

The study at hand has (for instance, in the regression models and in Figure 14) already shown the relevance of corporate governance for the dissemination of CSR. Figure 26 then demonstrates, very much in line with Meyer and Höllerer (2009), how corporate governance actually serves as a discursive "linking pin" (Drori, 2006) between the notions of shareholder value and CSR, appeasing apparent lines of conflict. In their study on contesting logics, Meyer and Höllerer (2009) find instead of ongoing competition and combat - that an increasing number of corporations tend to be susceptible to these two concepts at the same time. We show that critical events and the negative tenor of media discourse do not dampen shareholder value commitment but induce corporations to additionally endorse 
CSR: These two management concepts, contradicting at normative level, actually seem to come as one "discursive package", with the concept of corporate governance creating opportunities to bridge the divergent underlying institutional logics (for details, see Meyer \& Höllerer, 2009).

Future research might carry forward these insights. It will be highly interesting to go beyond the level of adoption/non-adoption in the context of bundles of management concepts and to take into account the various relations at the level of sub-discourses. Although it implies a considerable additional coding effort, a comparative analysis of actors, thematic embeddings, anchorage etc. (i.e., the variables I used in the previous chapters) within such a bundle might be a worthwhile endeavor.

\subsubsection{Meaning construction at micro level: Close-ups}

Finally, many of the questions raised when discussing the findings of my study - or while sketching a future research agenda - will only fully unfold in a purely qualitative, in-depth research design that targets the micro level and "backstage" processes of meaning construction.

Several avenues and/or trajectories might be worth considering: One of the many directions could be (a) to zoom in on an individual corporation and collect additional data surrounding this specific case (i.e., to address and contextualize meaning assignment at organizational level; such case study research might include rationalization at the level of individual decision makers); also (b) a close-up on processes of "translating CSR into Austrian" might be an absorbing endeavor that could embrace various critical events, core actors, and activities within the Austrian arena over time in more detail; the shift from implicit to explicit might be explored in greater depth, probably in a more comparative research design and by tapping new data sources; finally, one could (c) further investigate meaning structures and relations within the discourse in greater detail (e.g., in the form of a dense description of empirical sub-discourses - using selected material from the texts - in order to gain an in-depth understanding of the inherent logics, structures, meanings, and interpretive schemata; or, for actor categories, including more information on the wider context in which object categories are referred to, as well as on the very character and modus operandi of subject-object relations, i.e., the types of action that link subject and object categories).

\subsection{Concluding remarks}

CSR has developed to become a global trend in corporate governance since the turn of the millennium. However, for corporations that have shifted toward explicitly addressing this issue, the notion of a social responsibility of business has 
turned out to be an elusive concept that needs to be specified and lent meaning within particular cultural settings. This contingent specification entails questions such as who is responsible for and accountable toward whom, and in what kind of thematic context. My overall aim in this study was to explore characteristics of adopters and mechanisms that lead to the adoption of CSR, as well as to unravel the cultural categories of actors and topics invoked during the translation and bottom-up theorization of CSR. During the observation period of my study, Austria as well as continental Europe in general have experienced the "deconstruction" of institutionalized solidarity (i.e., of implicit CSR) and the "construction" of a new and explicit CSR infrastructure (Hiss, 2009). The notion of CSR has been transformed from a taken-for-granted, traditional understanding into an explicit, rationalized management concept. While old-style CSR was characterized by "doing good to do good", the new mantra has turned out to be "doing good to do well" (Vogel, 2005). In this respect, my work complements current research on CSR and empirically reaffirms the conceptual framework of Matten and Moon (2008) by showing how cultural resonance influences the rise of explicit CSR.

The global victory march of Anglo-American-style CSR has definitely not come to a halt at Austria's door. After a worldwide series of corporate malfeasance and scandals that in turn made evident the limitations of the local institutional framework in the face of a globalized economy, and also due to the diminishing public endorsement of a "pure" shareholder orientation (i.e., the concept's antagonist at the normative level, see Meyer \& Höllerer, 2009, 2010), my study empirically illustrated how the traditional understanding of responsible business practices was superseded by explicit corporate CSR policies. In this way, my work also emphasized the role of critical events in such transformation processes: Corporate scandals and increasing pressure on business organizations contributed to the explication of the formerly quiescent CSR (albeit with a potential change in meaning). This, however, is much in line with prior findings from research on organizational impression management (e.g., Elsbach \& Sutton, 1992; Elsbach et al., 1998): Accounts grounded in widely accepted and taken-for-granted beliefs are particularly effective in times of contestation when legitimacy is fundamentally challenged. Alongside new issues of corporate governance and sustainability, some of the virtues of "good old Austrian entrepreneurship" - with its more elitist and paternalistic features - were invoked and have been experiencing their revival flagged as "new" CSR.

Although actors in the arena increasingly made use of the Anglo-American labels, I have not to date found the emergence of a homogeneous concept, but rather observed a fragmented debate and discourse among corporations on how to make sense of the idea of responsibility of business. Austrian corporations currently address a broad range of rather divergent "problems" by using the concept and terminology of CSR: As societal expectations and "threats" are diffuse, responses from the corporate world seem to be as well. 


\section{References}

Abbott, Walter F. \& R. Joseph Monsen (1979): On the measurement of corporate social responsibility: Self-reported disclosures as a method of measuring corporate social involvement. In: Academy of Management Journal 22/3, 501-515.

Abrahamson, Eric (1991): Managerial fads and fashions: The diffusion and rejection of innovations. In: Academy of Management Review 16/3, 586-612.

Abrahamson, Eric (1996): Management fashion. In: Academy of Management Review 21/1, 254-285.

Abrahamson, Eric \& Gregory Fairchild (1999): Management fashion: Lifecycles, triggers, and collective learning processes. In: Administrative Science Quarterly 44/4, 708-740.

Abrahamson, Eric \& Lori Rosenkopf (1993): Institutional and competitive bandwagons: Using mathematical modeling as a tool to explore innovation diffusion. In: Academy of Management Review 18/3, 487-517.

Abu-Baker, Nafez \& Kamal Naser (2000): Empirical evidence on corporate social disclosure (CSD) practices in Jordan. In: International Journal of Commerce \& Management 10/3, 18-34.

Ackerman, Robert (1973): How companies respond to social demands. In: Harvard Business Review $51 / 4,88-89$.

Ackerman, Robert \& Raymond A. Bauer (1976): Corporate social responsiveness: Modern dilemma. Cambridge: Harvard University Press.

Aerts, Walter \& Denis Cormier (2009): Media legitimacy and corporate environmental communication. In: Accounting, Organizations and Society 34/1, 1-27.

AFRAC Austrian Financial Reporting and Auditing Committee (2006): Stellungnabme "Lagebericht-

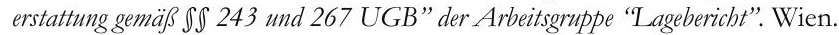

AFRAC Austrian Financial Reporting and Auditing Committee (2009): Stellungnahme "Lageberichterstattung gemäß IS 243, 243 a und 267 UGB" der Arbeitsgruppe "Lagebericht". Wien.

Aguilera, Ruth V. \& Alvaro Cuervo-Cazurra (2004): Codes of good governance worldwide: What is the trigger? In: Organization Studies 25/3, 415-443.

Aguilera, Ruth V. \& Gregory Jackson (2003): The cross-national diversity of corporate governance: Dimensions and determinants. In: Academy of Management Review 28/3, 447-465.

Aguilera, Ruth V., Deborah E. Rupp, Cynthia A. Williams, \& Jyoti Ganapathi (2007): Putting the $\mathrm{S}$ back in corporate social responsibility: A multilevel theory of social change in organizations. In: Academy of Management Review 32/3, 836-863.

Albinger, Heather Schmidt \& Sarah J. Freeman (2000): Corporate social performance and attractiveness as an employer to different job seeking populations. In: Journal of Business Ethics 28/3, 243-253.

Alford, Robert R. \& Roger Friedland (1985): Powers of theory: Capitalism, the state, and democracy. Cambridge: Cambridge University Press.

Amis, John, Trevor Slack, \& C. R. Hinings (2004): The pace, sequence, and linearity of radical change. In: Academy of Management Journal 47/1, 15-39.

Anderson, John C. \& Alan W. Frankle (1980): Voluntary social reporting: An iso-beta portfolio analysis. In: Accounting Review 55/3, 467-479.

Anheier, Helmut K., Jürgen Gerhards, \& Frank P. Romo (1995): Forms of capital and social structure in cultural fields: Examining Bourdieu's social topography. In: American Journal of Sociology 100/4, 859-903. 
Ansari, Shahzad M., Peer C. Fiss, \& Edward J. Zajac (2010): Made to fit: How practices vary as the diffuse. In: Academy of Management Review 35/1, 67-92.

Aoki, Masahiko (2004): Comparative institutional analysis of corporate governance. In: Anna Grandori (ed.): Corporate governance and firm organization: Microfoundations and structural forms. Oxford: Oxford University Press, 31-45.

Aras, Güler \& David Growther (ed.) (2010): A handbook of corporate governance and social responsibility. Farnham: Gower Publishing.

Atkinson, Lisa \& Joseph Galaskiewicz (1988): Stock ownership and company contributions to charity. In: Administrative Science Quarterly 33/1, 82-100.

Audi, Robert (2010): The place of ethical theory in business ethics. In: George G. Brenkert \& Tom L. Beauchamp (ed.): The Oxford handbook of business ethics. Oxford: Oxford University Press, 46-69.

Aupperle, Kenneth E., Archie B. Carroll, \& John D. Hatfield (1985): An empirical examination of the relationship between corporate social responsibility and profitability. In: Academy of Management Journal 28/2, 446-463.

Austrian Federal Ministry for Agriculture, Forestry, Environment, and Water Management, (2010): http://www.bmlfuw.gv.at. Last accessed January 21, 2010.

Austrian Federal Ministry of Economy, Family, and Youth (2010): http://www.bmwfj.gv.at. Last accessed January 21, 2010.

Austrian Federal Ministry of Labor, Social Affairs, and Consumer Protection (2010): http://www.bmask.gv.at. Last accessed January 21, 2010.

Bachrach, Peter \& Morton S. Baratz (1962): Two Faces of Power. In: American Political Science Review 56/4, 947-952.

Backhaus, Klaus, Bernd Erichson, Wulff Plinke, \& Rolf Weiber (2000): Multivariate Analysemethoden: Eine Anwendungsorientierte Einführung. $9^{\text {th }}$ ed., Berlin: Springer.

Bansal, Pratima (2005): Evolving sustainability: A longitudinal study of corporate sustainable development. In: Strategic Management Journal 26/3, 197-218.

Bansal, Pratima \& Iain Clelland (2004): Talking trash: Legitimacy, impression management, and unsystematic risk in the context of the natural environment. In: Academy of Management Journal 47/1, 93-103.

Bansal, Pratima \& Kendall Roth (2000): Why companies go green: A model of ecological responsiveness. In: Academy of Management Journal 43/4, 717-736.

Barca, Fabrizio \& Marco Becht (ed.) (2002): The control of corporate Europe. Oxford: Oxford University Press.

Barley, Stephen R. \& Gideon Kunda (1992): Design and devotion: Surges of rational and normative ideologies of control in managerial discourse. In: Administrative Science Quarterly 37/3, 363-399.

Barley, Stephen R. \& Pamela S. Tolbert (1997): Institutionalization and structuration: Studying the links between action and institution. In: Organization Studies 18/1, 93-117.

Barney, Jay (1991): Firm resources and sustained competitive advantage. In: Journal of Management 17/1, 99-120.

Baron, David P. (2001): Private politics, corporate social responsibility, and integrated strategy. In: Journal of Economics \& Management Strategy 10/1, 7-45. 
Baron, James N., Frank R. Dobbin, \& P. Devereaux Jennings (1986): War and peace: The evolution of modern personnel administration in U.S. industry. In: American Journal of Sociology $92 / 2,350-383$.

Bartley, Tim (2004): The theorization and framing of new practices in organizational fields: Industry discourse about "voluntary" labor and environmental standards. Paper presented at the American Sociological Association Annual Meeting. San Francisco, August.

Basil, Debra Z. \& Jill Erlandson (2008): Corporate social responsibility website representations: A longitudinal study of internal and external self-presentations. In: Journal of Marketing Communications $14 / 2,125-137$.

Bassen, Alexander, Sarah Jastram, \& Katrin Meyer (2005): Corporate social responsibility: Eine Begriffserläuterung. In: Zeitschrift für Wirtschafts- und Unternebmensetbik 6/2, 231-236.

Basu, Kunal \& Guido Palazzo (2008): Corporate social responsibility: A process model of sensemaking. In: Academy of Management Review 33/1, 122-136.

Beaver, William (1999): Is the stakeholder model dead? In: Business Horizons March-April 1999, 812.

Beckert, Jens (1999): Agency, entrepreneurs, and institutional change: The role of strategic choice and institutionalized practices in organizations. In: Organization Studies 20/5, 777-799.

Beckert, Jens (2006): Sind Unternehmen sozial verantwortlich? Max-Planck-Institut für Gesellschaftsforschung Working Paper 06/4.

Benford, Robert D. \& David A. Snow (2000): Framing processes and social movements: An overview and assessment. In: Annual Review of Sociology 26/1, 611-639.

Beresford, Dennis R. (1973): Compilation of social measurement disclosures in Fortune 500 annual reports. Ernst and Ernst.

Beresford, Dennis R. (1974): How companies are reporting social performance. In: Management Accounting 56/2, 41-44.

Berger, Peter L. \& Hansfried Kellner (1984): Für eine neue Soziologie. Frankfurt am Main: Fischer Taschenbuch Verlag.

Berger, Peter L. \& Thomas Luckmann (1967): The social construction of reality: A treatise in the sociology of knowledge. New York: Anchor Books.

Berman, Shawn L., Andrew C. Wicks, Suresh Kotha, \& Thomas M. Jones (1999): Does stakeholder orientation matter? The relationship between stakeholder management models and firm financial performance. In: Academy of Management Journal 42/5, 488-506.

Bhattacharya, C. B. \& Sankar Sen (2003): Consumer-company identification: A framework for understanding consumers' relationships with companies. In: Journal of Marketing 67/2, 76-88.

Bhattacharya, C. B. \& Sankar Sen (2004): Doing better at doing good: When, why, and how consumers respond to corporate social initiatives. In: California Management Review 47/1, 9-24.

Bhattacharya, C. B., Sankar Sen, \& Daniel Korschun (2008): Using corporate social responsibility to win the war for talent. In: MIT Sloan Management Review 49/2, 37-44.

Birch, David (2001): Corporate citizenship: Rethinking business beyond corporate social responsibility. In: Jörg Andriof \& Malcolm McIntosh (ed.): Perspectives on corporate citizenship. Sheffield: Greenleaf, 53-65.

Boczkowski, Pablo J. \& Wanda J. Orlikowski (2004): Organizational discourse and new media: A practice perspective. In: David Grant, Cynthia Hardy, Cliff Oswick, \& Linda Putnam (ed.): The SAGE handbook of organizational discourse. London: Sage Publications, 359-377. 
Bohnsack, Ralf (2008): The interpretation of pictures and the documentary method. In: Forum Qualitative Sozialforschung / Forum: Qualitative Social Research 9/3.

Boström, Magnus \& Christina Garsten (2008): Organizing for accountability. In: Magnus Boström \& Christina Garsten (ed.): Organizing transnational accountability. Cheltenham: Edward Elgar, 1-26.

Bovens, Mark (2007): Analysing and assessing accountability: A conceptual framework. In: European Law Journal 13/4, 447-468.

Bowen, Howard R. (1953): Social responsibilities of the businessman. New York: Harper \& Row.

Bowen, Shannon A. \& Robert L. Heath (2005): Issues management, systems, and rhetoric: Exploring the distinction between ethical and legal guidelines at Enron. In: Journal of Public Affairs 5/2, 84-98.

Bowie, Norman (1999): Business etbics: A Kantian perspective. Malden: Blackwell.

Bowie, Norman E. \& Thomas W. Dunfee (2002): Confronting morality in markets. In: Journal of Business Ethics 38/4, 381-393.

Bowman, Edward H. \& Mason Haire (1975): A strategic posture toward corporate social responsibility. In: California Management Review 18/2, 49-58.

Bowman, Edward H. \& Mason Haire (1976): Social impact disclosure and corporate annual reports. In: Accounting, Organizations and Society 1/1, 11-21.

Brammer, Stephen J. \& Stephen Pavelin (2006): Corporate reputation and social performance: The importance of fit. In: Journal of Management Studies 43/3, 435-455.

Brammer, Stephen \& Stephen Pavelin (2004): Voluntary social disclosures by large UK companies. In: Business Ethics: A European Review 13/2-3, 86-99.

Branco, Manuel \& Lúcia Rodrigues (2006): Corporate social responsibility and resource-based perspectives. In: Journal of Business Ethics 69/2, 111-132.

Branco, Manuel \& Lúcia Rodrigues (2008): Factors influencing social responsibility disclosure by Portuguese companies. In: Journal of Business Ethics 83/4, 685-701.

Breiger, Ronald L. (2000): A tool kit for practice theory. In: Poetics 27/2-3, 91-115.

Brenkert, George G. \& Tom L. Beauchamp (ed.) (2010): The Oxford handbook of business ethics. Oxford: Oxford University Press.

Brint, Steven \& Jerome Karabel (1991): Institutional origins and transformations: The case of American community colleges. In: Walter W. Powell \& Paul J. DiMaggio (ed.): The new institutionalism in organizational analysis. Chicago: The University of Chicago Press, 337-360.

Brown, Noel \& Craig Deegan (1998): The public disclosure of environmental performance information: A dual test of media agenda setting theory and legitimacy theory. In: Accounting \& Business Research 29/1, 21-41.

Brown, Tom J. \& Peter A. Dacin (1997): The company and the product: Corporate associations and consumer product responses. In: Journal of Marketing 61/1, 68-84.

Bruch, Heike \& Frank Walter (2005): The keys to rethinking corporate philanthropy. In: MIT Sloan Management Review 47/1, 49-55.

Brunsson, Nils (1989): The organization of hypocrisy: Talk, decisions and actions in organizations. Chichester: John Wiley.

Brunsson, Nils \& Bengt Jacobsson (ed.) (2002): A world of standards. Oxford: Oxford University Press. 
Buchholtz, Ann K., Jill A. Brown, \& Kareem M. Shabana (2008): Corporate governance and corporate social responsibility. In: Andrew Crane, Abagail McWilliams, Dirk Matten, Jeremy Moon, \& Donald S. Siegel (ed.): The Oxford handbook of corporate social responsibility. New York: Oxford University Press, 327-345.

Burns, Lawton R. \& Douglas R. Wholey (1993): Adoption and abandonment of matrix management programs: Effects of organizational characteristics and interorganizational networks. In: Academy of Management Journal 36/1, 106-138.

Campbell, John L. (2004): Institutional change and globalization. Princeton: Princeton University Press.

Campbell, John L. (2006): Institutional analysis and the paradox of corporate social responsibility. In: American Behavioral Scientist 49/7, 925-938.

Campbell, John L. (2007): Why would corporations behave in socially responsible ways? An institutional theory of corporate social responsibility. In: Academy of Management Review 32/3, 946-967.

Capriotti, Paul \& Angeles Moreno (2007): Corporate citizenship and public relations: The importance and interactivity of social responsibility issues on corporate websites. In: Public Relations Review 33/1, 84-91.

Carrington, Peter J., John Scott, \& Stanley Wasserman (ed.) (2005): Models and methods in social network analysis. Cambridge: Cambridge University Press.

Carroll, Archie B. (1979): A three dimensional conceptual model of corporate performance. In: Academy of Management Review 4/4, 497-505.

Carroll, Archie B. (1991): The pyramid of corporate social responsibility: Toward the moral management of organizational stakeholders. In: Business Horizons July-August 1991, 39-48.

Carroll, Archie B. (1998): The four faces of corporate citizenship. In: Business and Society Review 100/101, 1-7.

Carroll, Archie B. (1999): Corporate social responsibility: Evolution of a definitional construct. In: Business \& Society 38/3, 268-295.

Carroll, Archie B. (2004): Managing ethically with global stakeholders: A present and future challenge. In: Academy of Management Executive 18/2, 114-120.

Carroll, Archie B. (2008): A history of corporate social responsibility. In: Andrew Crane, Abagail McWilliams, Dirk Matten, Jeremy Moon, \& Donald S. Siegel (ed.): The Oxford handbook of corporate social responsibility. New York: Oxford University Press, 19-46.

Carroll, Archie B. \& Kareem M. Shabana (2010): The business case for corporate social responsibility: A review of concepts, research, and practice. In: International Journal of Management Reviews 12/1, 85-105.

Caruana, Robert \& Andrew Crane (2008): Constructing consumer responsibility: Exploring the role of corporate communications. In: Organization Studies 29/12, 1495-1519.

Cashore, Benjamin (2002): Legitimacy and the privatization of environmental governance: How non-state market-driven (NSMD) governance systems gain rule-making authority. In: Governance: An International Journal of Policy and Administration 15/4, 503-529.

Cattell, Raymond B. (1966): The scree test for the number of factors. In: Multivariate Behavioral Research 1/2, 245-276.

CED Committee for Economic Development (1971): Social responsibilities of business corporations. New York: CED.

Chase, W. Howard (1984): Issue management: Origins of the future. Stamfort: Issue Action Publications. 
Cheney, George \& Lars Thøger Christensen (2001): Organizational identity: Linkages between internal and external organizational communication. In: Frederic M. Jablin \& Linda L. Putnam (ed.): The new handbook of organizational communication. Thousand Oaks: Sage Publications, 231-269.

Chih, Hsiang-Lin, Hsiang-Hsuan Chih, \& Tzu-Yin Chen (2010): On the determinants of corporate social responsibility: International evidence on the financial industry. In: Journal of Business Ethics 93/1, 115-135.

Clarkson, Max B.E. (1995): A stakeholder framework for analysing and evaluating corporate social performance. In: Academy of Management Review 20/1, 92-117.

Clausen, Sten-Erik (1998): Applied correspondence analysis: An introduction. Thousand Oaks: Sage Publications.

Clemens, Elisabeth S. (1997): The people's lobby: Organizational innovation and the rise of interest group politics in the United States, 1890-1925. Chicago: University of Chicago Press.

Clemens, Elisabeth S. \& James M. Cook (1999): Politics and institutionalism: Explaining durability and change. In: Annual Review of Sociology 25/1, 441-466.

Cochran, Philip L. \& Robert A. Wood (1984): Corporate social responsibility and financial performance. In: Academy of Management Journal 27/1, 42-56.

Coffee, John C. (2001): The rise of dispersed ownership: The roles of law and the state in the separation of ownership and control. In: Yale Law Journal 111/1, 1-82.

Cormier, Denis \& Michel Magnan (2003): Environmental reporting management: A continental European perspective. In: Journal of Accounting \& Public Policy 22/1, 43-62.

Cormier, Denis, Michel Magnan, \& Barbara van Velthoven (2005): Environmental disclosure quality in large German companies: Economic incentives, public pressures or institutional conditions? In: European Accounting Review 14/1, 3-39.

Cowen, Scott S., Linda B. Ferreri, \& Lee D. Parker (1987): The impact of corporate characteristics on social responsibility disclosure: A typology and frequency-based analysis. In: Accounting, Organizations and Society 12/2, 111-122.

Crane, Andrew (2001): Unpacking the ethical product. In: Journal of Business Ethics 30/4, 361-373.

Crane, Andrew \& Dirk Matten (2004): Business ethics: A European perspective. New York: Oxford University Press.

Crane, Andrew \& Dirk Matten (2010): Business ethics: Managing corporate citizenship and sustainability in the age of globalization. $3^{\text {rd }}$ ed., New York: Oxford University Press.

Crane, Andrew, Abagail McWilliams, Dirk Matten, Jeremy Moon, \& Donald Siegel (2008a): Conclusion. In: Andrew Crane, Abagail McWilliams, Dirk Matten, Jeremy Moon, \& Donald S. Siegel (ed.): The Oxford handbook of corporate social responsibility. New York: Oxford University Press, 568-575.

Crane, Andrew, Abagail McWilliams, Dirk Matten, Jeremy Moon, \& Donald Siegel (2008b): Introduction. In: Andrew Crane, Abagail McWilliams, Dirk Matten, Jeremy Moon, \& Donald S. Siegel (ed.): The Oxford handbook of corporate social responsibility. New York: Oxford University Press, 3-15.

Crane, Andrew, Abagail McWilliams, Dirk Matten, Jeremy Moon, \& Donald S. Siegel (ed.) (2008c): The Oxford handbook of corporate social responsibility. New York: Oxford University Press.

Creed, W. E. Douglas, Maureen A. Scully, \& John R. Austin (2002): Clothes make the person? The tailoring of legitimating accounts and the social construction of identity. In: Organization Science 13/5, 475-496. 
Crook, Clive (2005): The good company. In: The Economist, January 20, 1-3.

CSR Austria (2003): Die gesellschaftliche Verantwortung österreichischer Unternehmen. Wien.

Czarniawska, Barbara \& Bernward Joerges (1996): Travel of ideas. In: Barbara Czarniawska \& Guje Sevón (ed.): Translating organizational change. Berlin et al.: de Gruyter, 13-48.

Czarniawska, Barbara \& Guje Sevón (ed.) (1996): Translating organizational change. Berlin: de Gruyter.

Czarniawska, Barbara \& Guje Sevón (ed.) (2005): Global ideas: How ideas, objects and practices travel in the global economy. Malmö: Liber and Copenhagen Business School Press.

Dacin, M. Tina, Marc J. Ventresca, \& Brent D. Beal (1999): The embededdness of organizations: Dialogue \& directions. In: Journal of Management 25/3, 317-356.

Davis, Gerald F. (2005): New directions in corporate governance. In: Annual Review of Sociology 31, 143-162.

Davis, Gerald F. \& Henrich R. Greve (1997): Corporate elite networks and governance changes in the 1980s. In: American Journal of Sociology 103/1, 1-37.

Davis, Gerald F. \& Tracy A. Thompson (1994): A social movement perspective on corporate control. In: Administrative Science Quarterly 39/1, 141-173.

Davis, Keith (1973): The case for and against business assumption of social responsibilities. In: Academy of Management Journal 16/2, 312-322.

Davison, Jane \& Samantha Warren (2009): Imag[in]ing accounting and accountability. In: Accounting, Auditing \& Accountability Journal 22/6, 845-857.

Dawkins, Cedric \& Faith Wambura Ngunjiri (2008): Corporate social responsibility reporting in South Africa. In: Journal of Business Communication 45/3, 286-307.

Day, Patricia \& Rudolf Klein (1987): Accountabilities: Five public services. London: Tavistock.

de Bakker, Frank G. A., Claes Ohlsson, Frank den Hond, Stefan Tengblad, \& Marie-France B. Turcotte (2007): Tracing the evolution of corporate discourse on corporate social responsibility: A longitudinal, lexicological study. In: Frank den Hond, Frank G. A. de Bakker, \& Peter Neergard (ed.): Managing corporate social responsibility in action: Talking, doing and measuring. Aldershot: Ashgate, 53-73.

de Nooy, Wouter (2003): Fields and networks: Correspondence analysis and social network analysis in the framework of field theory. In: Poetics 31/5-6, 305-327.

de Nooy, Wouter, Andrej Mrvar, \& Vladimir Batagelj (2005): Exploratory Social Network Analysis with Pajek. Cambridge: Cambridge University Press.

Deephouse, David L. (1996): Does isomorphism legitimate? In: Academy of Management Journal 39/4, 1024-1039.

Deephouse, David L. (2000): Media reputation as a strategic resource: An integration of mass communication and resource-based theories. In: Journal of Management 26/6, 1091-1112.

Deephouse, David L. \& Suzanne M. Carter (2005): An examination of differences between organizational legitimacy and organizational reputation. In: Journal of Management Studies 42/2, 329-360.

Deephouse, David L. \& Mark Suchman (2008): Legitimacy in organizational institutionalism. In: Royston Greenwood, Christine Oliver, Kerstin Sahlin, \& Roy Suddaby (ed.): The SAGE bandbook of organizational institutionalism. Los Angeles: Sage Publications, 49-77. 
den Hond, Frank, Frank G. A. de Bakker, \& Peter Neergaard (2007a): Introduction to managing corporate social responsibility in action: Talking, doing and measuring. In: Frank den Hond, Frank G. A. de Bakker, \& Peter Neergaard (ed.): Managing corporate social responsibility in action. Talking, doing and measuring. Aldershot: Ashgate, 1-12.

den Hond, Frank, Frank G.A de Bakker, \& Peter Neergard (ed.) (2007b): Managing corporate social responsibility in action: Talking, doing, measuring. Aldershot: Ashgate.

Denkstatt (2004): Österreichische Nachbaltigkeitsberichterstattung im internationalen Vergleich. Wien.

DiMaggio, Paul J. (1986): Structural analysis of organizational field: A blockmodel approach. In: Research in Organizational Behavior 8, 335-370.

DiMaggio, Paul J. (1988): Interest and agency in institutional theory. In: Lynne G. Zucker (ed.): Institutional patterns and organizations: Culture and environment. Cambridge: Ballinger, 3-21.

DiMaggio, Paul J. \& Walter W. Powell (1983): The iron cage revisited: Institutional isomorphism and collective rationality in organizational fields. In: American Sociological Review 48/2, 147-160.

Djelic, Marie-Laure (1998): Exporting the American model: The postwar transformation of European business. Oxford: Oxford University Press.

Djelic, Marie-Laure \& Sigrid Quack (ed.) (2003): Globalization and institutions: Redefining the rules of the economic game. Cheltenham: Elgar.

Djelic, Marie-Laure \& Kerstin Sahlin-Andersson (ed.) (2006): Transnational governance: Institutional dynamics of regulation. Cambridge: Cambridge University Press.

Dobbin, Frank (1994): Forging industrial policy: The United States, Britain, and France in the railway age. Cambridge: Cambridge University Press.

Dobbin, Frank \& John R. Sutton (1998): The strength of a weak state: The rights revolution and the rise of human resources management divisions. In: American Journal of Sociology 104/2, 441-476.

Dobbin, Frank \& Dirk Zorn (2005): Corporate malfeasance and the myth of shareholder value. In: Political Power and Social Theory 17, 179-198.

Doh, Jonathan P. \& Terrence R. Guay (2006): Corporate social responsibility, public policy, and NGO activism in Europe and the United States: An institutional-stakeholder perspective. In: Journal of Management Studies 43/1, 47-73.

Domini, Amy (2001): Socially responsible investing: Making a difference and making money. Chicago: Dearborn Trade.

Domini, Amy L. \& Peter D. Kinder (1986): Ethical investing. Reading: Addison Wesley.

Donaldson, Thomas (2008): The transatlantic paradox: How outdated concepts confuse the American/European debate about corporate governance. In: Andrew Crane, Abagail McWilliams, Dirk Matten, Jeremy Moon, \& Donald S. Siegel (ed.): The Oxford handbook of corporate social responsibility. New York: Oxford University Press, 543-551.

Donaldson, Thomas \& Lee E. Preston (1995): The stakeholder theory of the corporation: Concepts, evidence and implications. In: Academy of Management Review 20/1, 65-91.

Donati, Paolo R. (1992): Political discourse analysis. In: Mario Diani \& Ron Eyerman (ed.): Studying collective action. London: Sage Publications, 136-167.

Drori, Gili S. (2006): Governed by governance: The institutionalization of governance as a prism for organizational change. In: Gili S. Drori, John W. Meyer, \& Hokyu Hwang (ed.): Globalization and organization: World society and organizational change. Oxford: Oxford University Press, 91-118. 
Drucker, Peter F. (2007): The practice of management. Oxford: Butterworth-Heinemann.

Drumwright, Minette E. (1996): Company advertising with a social dimension: The role of noneconomic criteria. In: Journal of Marketing 60/4, 71-87.

du Plessis, Jean Jacques, James McConvill, \& Mirko Bagaric (2005): Principles of contemporary corporate governance. Cambridge: Cambridge University Press.

Du, Shuili, C. B. Bhattacharya, \& Sankar Sen (2010): Maximizing business returns to corporate social responsibility (CSR): The role of CSR communication. In: International Journal of Management Reviews 12/1, 8-19.

Dunfee, Thomas W. (2008): Stakeholder theory: Managing corporate social responsibilty in a multiple actor context. In: Andrew Crane, Abagail McWilliams, Dirk Matten, Jeremy Moon, \& Donald S. Siegel (ed.): The Oxford handbook of corporate social responsibility. New York: Oxford University Press, 346-362.

Edelman, Lauren B., Christopher Uggen, \& Howard S. Erlanger (1999): The endogeneity of legal regulation: Grievance procedures as rational myth. In: American Journal of Sociology 105/2, 406454.

Elkington, John (1999): Cannibals with forks: The triple bottom line of 21st century business. Oxford: Capstone.

Elsbach, Kimberly D. (1994): Managing organizational legitimacy in the California cattle industry: The construction and effectiveness of verbal accounts. In: Administrative Science Quarterly 39/1, 57-88.

Elsbach, Kimberly D. \& Robert I. Sutton (1992): Acquiring organizational legitimacy through illegitimate actions: A marriage of institutional and impression management theories. In: Academy of Management Journal 35/4, 699-738.

Elsbach, Kimberly D., Robert I. Sutton, \& Kristine E. Principe (1998): Averting expected challenges through anticipatory impression management: A study of hospital billing. In: Organization Science 9/1, 68-86.

Epstein, Marc J. \& Martin Freedman (1994): Social disclosure and the individual investor. In: Accounting, Auditing \& Accountability Journal 7/4, 94-109.

European Central Bank (2002): Report on financial structures. Frankfurt am Main.

European Commission (2001): Promoting a European framework for corporate social responsibility. Green Paper. Luxembourg: Office for official publications of the European Communities.

European Management Forum (1973): Davos Manifesto. Davos.

Evan, William M. \& R. Edward Freeman (1988): A stakeholder theory of the modern corporation: Kantian capitalism. In: Tom L. Beauchamp \& Norman Bowie (ed.): Ethical theory and business. Englewood Cliffs: Prentice Hall, 75-84.

Fiesner, James (ed.) (2000): Metaethics, normative ethics, and applied ethics: Historical and contemporary readings. Belmont: Wadsworth.

Fiss, Peer C. (2008): Institutions and corporate governance. In: Royston Greenwood, Christine Oliver, Kerstin Sahlin, \& Roy Suddaby (ed.): The SAGE handbook of organizational institutionalism. Los Angeles: Sage Publications, 389-410.

Fiss, Peer C. \& Edward J. Zajac (2004): The diffusion of ideas over contested terrain: The (non)adoption of a shareholder value orientation among German firms. In: Administrative Science Quarterly 49/4, 501-534.

Fiss, Peer C. \& Edward J. Zajac (2006): The symbolic management of strategic change: Sensegiving via framing and decoupling. In: Academy of Management Journal 49/6, 1173-1193. 
Flick, Uwe, Ernst von Kardoff, \& Ines Steinke (ed.) (2004): A companion to qualitative research. London: Sage Publications.

Fligstein, Neil (1991): The structural transformation of American industry: An institutional account of the causes of diversification in the largest firms, 1919-1979. In: Walter W. Powell \& Paul J. DiMaggio (ed.): The new institutionalism in organisational analysis. Chicago: University of Chicago Press, 311-336.

Fligstein, Neil (2005): The end of (shareholder value) ideology? In: Political Power and Social Theory $17,223-228$.

Fligstein, Neil (1990): The transformation of corporate control. Cambridge: Harvard University Press.

Fombrun, Charles \& Mark Shanley (1990): What's in a name? Reputation building and corporate strategy. In: Academy of Management Journal 33/2, 233-258.

Frederick, William C. (2008): Corporate social responsibility: Deep roots, flourishing growth, promising future. In: Andrew Crane, Abagail McWilliams, Dirk Matten, Jeremy Moon, \& Donald S. Siegel (ed.): The Oxford handbook of corporate social responsibility. New York: Oxford University Press, 522-531.

Freeman, Bennett (2006): Substance sells: Aligning corporate reputation and corporate responsibility. In: Public Relations Quarterly 51/1, 12-19.

Freeman, R. Edward (1984): Strategic management: A stakeholder approach. Boston: Pitman.

Freeman, R. Edward (1994): The politics of stakeholder theory. In: Business Etbics Quarterly 4/4, 409-422.

Freeman, R. Edward, Jeffrey S. Harrison, Andrew C. Wicks, Bidhan Parmar, \& Simone de Colle (2010): Stakeholder theory: The state of the art. Cambridge: Cambridge University Press.

Friedland, Roger (2009): Institution, practice, and ontology: Toward a religious sociology. In Renate E. Meyer, Kerstin Sahlin, Marc J. Ventresca, \& Peter Walgenbach (ed.): Institutions and ideology. Research in the Sociology of Organizations 27, 45-84.

Friedland, Roger \& Robert R. Alford (1991): Bringing society back in: Symbols, practices, and institutional contradictions. In: Walter W. Powell \& Paul J. DiMaggio (ed.): The new institutionalism in organizational analysis. Chicago: The University of Chicago Press, 232-263.

Friedman, Milton (1962): Capitalism and freedom. Chicago: University of Chicago Press.

Friedman, Milton (1970): The social responsibility of business is to increase its profits. In: The New York Times Magazine, September 13, 32-33, 122-126.

Früh, Werner (2004): Inhaltsanalyse: Theorie und Praxis. $5^{\text {th }}$ ed., Konstanz: UVK.

Fukukawa, Kyoto \& Jeremy Moon (2004): A Japanese model of corporate social responsibility? In: Journal of Corporate Citizenship 16/1, 45-59.

Furrer, Oliver, Howard Thomas, \& Anna Goussevskaia (2008): The structure and evolution of the strategic management field: A content analysis of 26 years of strategic management research. In: International Journal of Management Reviews 10/1, 1-23.

Gamson, William A. (1992): Talking politics. Cambridge: Cambridge University Press.

Garriga, Elisabet \& Domènec Melé (2004): Corporate social responsibility: Mapping the territory. In: Journal of Business Ethics 53/1, 51-71.

Giddens, Anthony (1979): Central problems in social theory: Action, structure and contradiction in social analysis. London: Macmillan.

Giddens, Anthony (1986): The constitution of society: Outline of the theory of structuration. Cambridge: Polity Press. 
Ginzel, Linda E., Roderick M. Kramer, \& Robert I. Sutton (1992): Organizational impression management as a reciprocal influence process: The neglected role of the organizational audience. In: Research in Organizational Behavior 15, 227-266.

Gioia, Dennis A. (1999): Practicability, paradigms, and problems in stakeholder theorizing. In: Academy of Management Review 24/2, 228-232.

Godfrey, Paul C. (2005): The relationship between corporate philanthropy and shareholder wealth: A risk management perspective. In: Academy of Management Review 30/4, 777-798.

Godfrey, Paul C., Craig B. Merrill, \& Jared M. Hansen (2009): The relationship between corporate social responsibility and shareholder value: An empirical test of the risk management hypothesis. In: Strategic Management Journal 30/4, 425-445.

Gondo, Maria \& John Amis (2007): Realizing radical change: The process of theorization. Paper presented at the Cornell-McGill Conference on Institutions and Entrepreneurship. Ithaca, July 22-24.

Gourevitch, Peter A. \& James Shinn (2007): Political power and corporate control: The new global politics of corporate governance. Princeton: Princeton University Press.

Granovetter, Mark (1978): Threshold models of collective behavior. In: American Journal of Sociology 83/6, 1420-1443.

Granovetter, Mark (1985): Economic action and social structure: The problem of embeddedness. In: American Journal of Sociology 91/3, 481-510.

Grant, David, Cynthia Hardy, Cliff Oswick, \& Linda Putnam (ed.) (2004): The SAGE bandbook of organizational discourse. London: Sage Publications.

Graves, O. Finley, Dale L. Flesher, \& Robert E. Jordan (1996): Pictures and the bottom line: The television epistemology of U.S. annual reports. In: Accounting, Organizations and Society 21/1, 57-88.

Gray, Rob (2001): Thirty years of social accounting, reporting and auditing: What (if anything) have we learnt? In: Business Ethics: A European Review 10/1, 9-15.

Green, Sandy Edward (2004): A rhetorical theory of diffusion. In: Academy of Management Review 29/4, 653-669.

Greenacre, Michael (2007): Correspondence analysis in practice. $2^{\text {nd }}$ ed., Boca Raton: Chapman \& Hall/CRC.

Greenacre, Michael \& Jörg Blasius (ed.) (1994): Correspondence analysis in the social sciences: Recent developments and applications. London: Academic Press.

Greenacre, Michael \& Jörg Blasius (ed.) (2006): Multiple correspondence analysis and related methods. Boca Raton: Chapman \& Hall/CRC.

Greenacre, Michael J. (1984): Theory and applications of correspondence analysis. $2^{\text {nd }}$ ed., New York: Academic Press.

Greenacre, Michael J. (1991): Interpreting multiple correspondence analysis. In: Applied Stochastic Models and Data Analysis 7/1, 195-210.

Greenwood, Royston \& C. R. Hinings (1993): Understanding strategic change: The contribution of archetypes. In: Academy of Management Journal 36/5, 1052-1081.

Greenwood, Royston \& C. R. Hinings (1996): Understanding radical organizational change: Bringing together the old and the new institutionalism. In: Academy of Management Review 21/4, 1022-1054. 
Greenwood, Royston \& C. R. (Bob) Hinings (2006): Radical organizational change. In: Stewart R. Clegg, Cynthia Hardy, Thomas B. Lawrence, \& Walter R. Nord (ed.): The SAGE Handbook of organization studies. London: Sage Publications, 814-842.

Greenwood, Royston, Christine Oliver, Kerstin Sahlin, \& Roy Suddaby (ed.) (2008): The SAGE bandbook of organizational institutionalism. Los Angeles: Sage Publications.

Greenwood, Royston, Roy Suddaby, \& C. Robert Hinings (2002): Theorizing change: The role of professional associations in the transformation of institutionalized fields. In: Academy of Management Journal 45/1, 58-80.

Gugler, Klaus, Susanne Kalss, Alex Stomper, \& Josef Zechner (2002): The separation of ownership and control in Austria. In: Fabrizio Barca \& Marco Becht (ed.): The control of corporate Europe. Oxford: Oxford University Press.

Guler, Isin, Mauro F. Guillén, \& John Muir Macpherson (2002): Global competition, institutions, and the diffusion of organizational practices: The international spread of ISO 9000 quality certificates. In: Administrative Science Quarterly 47/2, 207-232.

Guthrie, Doug \& Rodolphe Durand (2008): Social issues in the study of management. In: European Management Review 5/3, 137-149.

Habisch, André, Jan Jonker, Martina Wegner, \& René Schmidpeter (ed.) (2005): Corporate social responsibility across Europe. Berlin: Springer.

Habisch, André, Hans-Peter Meister, \& René Schmidpeter (ed.) (2001): Corporate citizenship as investing in social capital. Berlin: Logos.

Hall, Peter A. \& David Soskice (ed.) (2001): Varieties of capitalism. The institutional foundations of comparative advantage. Oxford: Oxford University Press.

Harcourt, Bernard E. (2002): Measured interpretation: Introducing the method of correspondence analysis to legal studies. In: University of Illinois Law Review, 979-1017.

Hardy, Cynthia \& Steve Maguire (2008): Institutional entrepreneurship. In: Royston Greenwood, Christine Oliver, Kerstin Sahlin, \& Roy Suddaby (ed.): The SAGE handbook of organizational institutionalism. Los Angeles: Sage Publications, 198-217.

Hart, Stuart L. (1995): A natural-resource-based view of the firm. In: Academy of Management Review 20/4, 986-1014.

Hasse, Raimund \& Georg Krücken (2005): Der Stellenwert von Organisationen in Theorien der Weltgesellschaft: Eine kritische Weiterentwicklung systemtheoretischer und neoinstitutionalistischer Forschungsperspektiven. In: Zeitschrift für Soziologie (Sonderheft Weltgesellschaft), 186204.

Haunschild, Pamela R. \& Anne S. Miner (1997): Modes of interorganizational imitation: The effects of outcome salience and uncertainty. In: Administrative Science Quarterly 42/3, 472-500.

Haveman, Heather A. (1993): Follow the leader: Mimetic isomorphism and entry into new markets. In: Administrative Science Quarterly 38/4, 593-627.

Haveman, Heather A. \& Hayagreeva Rao (1997): Structuring a theory of moral sentiments: Institutional and organizational coevolution in the early thrift industry. In: American Journal of Sociology 102/6, 1606-1651.

Haveman, Heather A. \& Hayagreeva Rao (2006): Hybrid forms and the evolution of thrifts. In: American Behavioral Scientist 49/7, 974-986.

Hay, Robert \& Ed Gray (1974): Social responsibilities of business managers. In: Academy of Management Journal 17/1, 135-143.

Heath, Robert L. (1997): Strategic issues management: Organizations and public policy challenges. Thousand Oaks: Sage Publications. 
Henderson, David (2001): Misguided virtue: False notions of corporate social responsibility. London: The Institute of Economic Affairs.

Hirsch, Paul M. (1986): From ambushes to golden parachutes: Corporate takeovers as an instance of cultural framing and institutional integration. In: American Journal of Sociology 91/4, 800-837.

Hirsch, Paul M. \& Michael Lounsbury (1997): Ending the family quarrel: Toward a reconciliation of "old" and "new" institutionalisms. In: American Behavioral Scientist 40/4, 406-418.

Hiß, Stefanie (2006): Warum übernehmen Unternehmen gesellschaftliche Verantwortung? Ein soziologischer Erklärungsversuch. Frankfurt am Main: Campus.

Hiss, Stefanie (2009): From implicit to explicit corporate social responsibility: Institutional change as a fight for myths. In: Business Ethics Quarterly 19/3, 433-451.

Hoffman, Andrew J. (1999): Institutional evolution and change: Environmentalism and the U.S. chemical industry. In: Academy of Management Journal 42/4, 351-371.

Hoffman, Andrew J. (2001): From heresy to dogma: An institutional history of corporate environmentalism. Stanford: Stanford Business Books.

Höllerer, Markus A., Dennis Jancsary, Renate E. Meyer, \& Oliver Vettori (2010): Ways of seeing: The visual (re-)construction of corporate social responsibility. Working Paper, Institute for Public Management, WU Vienna University of Economics and Business.

Höllerer, Markus A. \& Renate E. Meyer (2007): Value management versus values management: Contrasting views - or just two sides of the same coin? Shareholder value and corporate (social) responsibility in reporting activities of Austrian publicly listed corporations. Paper presented at the 23rd EGOS Colloquium. Vienna, July 5-7.

Hollingsworth, J. Rogers \& Robert Boyer (ed.) (1997): Contemporary capitalism: The embeddedness of institutions. Cambridge: Cambridge University Press.

Holzer, Boris (2008): From accounts to accountability: Corporate self-presentation in response to public criticism. In: Magnus Boström \& Christina Garsten (ed.): Organižng transnational accountability. Cheltenham: Edward Elgar, 80-97.

Hopt, Klaus J., Hideki Kanda, Mark Roe, Eddy Wymeersch, \& Stefan Prigge (ed.) (1998): Comparative corporate governance: The state of the art and emerging research. Oxford: Oxford University Press.

Hopwood, Anthony (1990): Accounting and the domain of the public: Some observations on current developments. In: James Guthrie, Lee Parker, \& David Shand (ed.): The Public sector: Contemporary readings in accounting and auditing. Sydney: Harcourt Brace Jovanovich, 392-407.

Hopwood, Anthony G. (1996): Introduction. In: Accounting, Organizations and Society 21/1, 55-56.

Hsung, Ray-May \& Ronald L. Breiger (2009): Position generators, affiliations, and the institutional logics of social capital: A study of Taiwan firms and individuals. In: Ray-May Hsung, Nan Lin, \& Ronald L. Breiger (ed.): Contexts of social capital: Social networks in markets, communities, and families. New York: Routlegde, 3-27.

Husted, Bryan W. \& José de Jesus Salazar (2006): Taking Friedman seriously: Maximizing profits and social performance. In: Journal of Management Studies 43/1, 75-91.

Idowu, Samuel O. \& Brian A. Towler (2004): A comparative study of the contents of corporate social responsibility reports of UK companies. In: Management of Environmental Quality 15/4, 420-437.

Ingram, Robert W. (1978): An investigation of the information content of (certain) social responsibility disclosures. In: Journal of Accounting Research 16/2, 270-285.

Inman, J. Jeffrey, Venkatesh Shankar, \& Rosellina Ferraro (2004): The roles of channel-category associations and geodemographics in channel patronage. In: Journal of Marketing 68/1, 51-71. 
Institut für Ökologische Wirtschaftsforschung (2008): Leitlinie zu wesentlichen nichtfinanziellen Leistungsindikatoren, insbesondere zu Umwelt- und ArbeitnehmerInnenbelangen, im Lagebericht. Wien.

Jackson, Gregory \& Androniki Apostolakou (2010): Corporate social responsibility in Western Europe: An institutional mirror or substitute? In: Journal of Business Ethics 94/3, 371-394.

Jancsary, Dennis, Markus A. Höllerer, Oliver Vettori, \& Renate E. Meyer (2010): Framing images: Visually embodied meaning and its reconstruction on the field level. Working Paper, Institute for Public Management, WU Vienna University of Economics and Business.

Janis, Irving L. \& Raymond Fadner (1965): The coefficient of imbalance. In: Harold D. Lasswell, Nathan Leites, \& associates (ed.): Language of politics: Studies in quantitative semantics. Cambridge: MIT Press, 153-169.

Jennings, P. Devereaux \& Paul A. Zandbergen (1995): Ecologically sustainable organizations: An institutional approach. In: Academy of Management Review 20/4, 1015-1052.

Jensen, Michael C. (2001): Value maximization, stakeholder theory, and the corporate objective function. In: Journal of Applied Corporate Finance 14/3, 8-21.

Jensen, Michael C. \& William H. Meckling (1976): Theory of the firm: Managerial behaviour, agency cost and ownership structure. In: Journal of Financial Economics 3/4, 305-360.

Jones, Kevin \& Jennifer L. Bartlett (2009): The strategic value of corporate social responsibility: A relationship management framework for public relations practice. In: PRism 6/1, 1-16.

Jones, Thomas M. (1995): Instrumental stakeholder theory: A synthesis of ethics and economics. In: Academy of Management Review 20/2, 404-437.

Joyner, Brenda E. \& Dinah Payne (2002): Evolution and implementation: A study of values, business ethics and corporate social responsibility. In: Journal of Business Ethics 41/4, 297-311.

Kagan, Shelly (1998): Normative ethics. Boulder: Westview Press.

Kalss, Susanne, Christina Burger, \& Georg Eckert (2003): Die Entwicklung des österreichischen Aktienrechts: Geschichte und Materialien. Wien: Linde.

Kang, David L. \& Aage B. Sørensen (1999): Ownership organization and firm performance. In: Annual Review of Sociology 25/1, 121-144.

Kaplan, Sarah (2008): Framing contests: Strategy making under uncertainty. In: Organization Science 19/5, 729-752.

Karnøe, Peter (1997): Only in social action. In: American Behavioral Scientist 40, 419-430.

Keller, Reiner (2005): Wissensoziologische Diskursanalyse: Grundlegung eines Forschungsprogramms. Wiesbaden: VS Verlag für Sozialwissenschaften.

Keller, Reiner, Andreas Hirseland, Werner Schneider, \& Willy Viehöver (ed.) (2005): Die diskursive Konstruktion von Wirklichkeit: Zum Verbältnis von Wissenssoziologie und Diskursforschung. Konstanz: UVK.

Kelly, Erin \& Frank Dobbin (1998): How affirmative action became diversity management. In: The American Behavioral Scientist 41/7, 960-984.

Kennedy, Mark Thomas \& Peer Christian Fiss (2009): Institutionalization, framing, and diffusion: The logic of TQM adoption and implementation decisions among U.S. hospitals. In: Academy of Management Journal 52/5, 897-918.

Kieser, Alfred (1996): Moden \& Mythen des Organisierens. In: Die Betriebswirtschaft 56/1, 21-39.

Kieser, Alfred (1997): Rhetoric and myth in management fashion. In: Organization 4/1, 49-74.

Kinder, Peter D., Stephen D. Lydenberg, \& Amy L. Domini (1993): Investing for good: Making money while being socially responsible. New York: Harper Business. 
King, Andrew A. \& Michael J. Lenox (2000): Industry self-regulation without sanctions: The chemical industry's responsible care program. In: Academy of Management Journal 43/4, 698716.

King, Brayden (2008): A social movement perspective of stakeholder collective action and influence. In: Business \& Society 47/1, 21-49.

Knoblauch, Hubert \& Thomas Luckmann (2004): Genre analysis. In: Uwe Flick, Ernst von Kardoff, \& Ines Steinke (ed.): A companion to qualitative research. London: Sage Publications, 303307.

Kok, Peter, Ton van der Wiele, Richard McKenna, \& Alan Brown (2001): A corporate social responsibility audit within a quality management framework. In: Journal of Business Ethics 31/4, 285-297.

Kondra, Alex Z. \& C. R. Hinings (1998): Organizational diversity and change in institutional theory. In: Organization Studies 19/5, 743-767.

Köppl, Peter \& Martin Neureiter (ed.) (2004): Corporate Social Responsibility: Leitlinien und Konzepte im Management der gesellschaftlichen Verantwortung von Unternehmen. Wien: Linde.

Koslowski, Peter (2000): The limits of shareholder value. In: Journal of Business Ethics 27/1-2, 137 148.

Kotler, Philip \& Nancy Lee (2005): Corporate social responsibility: Doing the most good for your company and your cause. Hoboken: John Wiley \& Sons.

KPMG International (2008): KPMG international survey of corporate responsibility reporting 2008.

Kraatz, Matthew S. (1998): Learning by association? Interorganizational networks and adaption to environmental change. In: Academy of Management Journal 41/6, 621-643.

Kraatz, Matthew S. \& James H. Moore (2002): Executive migration and institutional change. In: Academy of Management Journal 45/1, 120-143.

Kress, Gunther \& Theo van Leeuwen (1996): Reading images: The grammar of visual design. London: Routledge.

Krippendorf, Klaus (2004): Content analysis: An introduction to its methodolgy. $2^{\text {nd }}$ ed., Thousand Oaks: Sage Publications.

Kurtz, Lloyd (2008): Socially responsible investment and shareholder activism. In: Andrew Crane, Abagail McWilliams, Dirk Matten, Jeremy Moon, \& Donald S. Siegel (ed.): The Oxford handbook of corporate social responsibility. New York: Oxford University Press, 249-280.

Kurucz, Elizabeth C., Barry A. Colbert, \& David Wheeler (2008): The business case for corporate social responsibility. In: Andrew Crane, Abagail McWilliams, Dirk Matten, Jeremy Moon, \& Donald S. Siegel (ed.): The Oxford handbook of corporate social responsibility. New York: Oxford University Press, 83-112.

Kutner, Michael H., Chris J. Nachtsheim, \& John Neter (2004): Applied linear regression models. $4^{\text {th }}$ ed., New York: McGraw-Hill.

La Porta, Rafael, Florencio Lopez-de-Silanes, Andrei Shleifer, \& Robert W. Vishny (1998): Law and finance. In: Journal of Political Economy 106/6, 1113-1155.

Lamertz, Kai \& Joel A. C. Baum (1998): The legitimacy of organizational downsizing in Canada: An analysis of explanatory media accounts. In: Canadian Journal of Administrative Sciences 15/1, 93-107.

Lane, Melissa (2010): Moral Case. In: Wayme Visser, Dirk Matten, Manfred Pohl, \& Nick Tolhurst (ed.): The $A-Z$ of corporate social responsibility. Chichester: John Wiley \& Sons, 281-288. 
Latour, Bruno (1986): The powers of association. In: John Law (ed.): Power, action and belief: A new sociology of knowledge? London: Routledge \& Kegan Paul, 264-280.

Lauf, Edmund (2001): .96 nach Holsti: Zur Reliabilität von Inhaltsanalysen und deren Darstellung in kommunikationswissenschaftlichen Fachzeitschriften. In: Publiristik 46/1, 57-68.

Lawrence, Thomas B. \& Roy Suddaby (2006): Institutions and institutional work. In: Stewart R. Clegg, Cynthia Hardy, Thomas B. Lawrence, \& Walter R. Nord (ed.): The SAGE Handbook of organization studies. London: Sage Publications, 215-254.

Le Roux, Brigitte \& Henry Rouanet (2004): Geometric data analysis: From correspondence analysis to structured data analysis. Dordrecht: Kluwer.

Le Roux, Brigitte \& Henry Rouanet (2010): Multiple correspondence analysis. Thousand Oaks: Sage Publications.

Lee, Min-Dong Paul (2008): A review of the theories of corporate social responsibility: Its evolutionary path and the road ahead. In: International Journal of Management Reviews 10/1, 53-73.

Lehmbruch, Gerhard \& Phillipe C. Schmitter (ed.) (1982): Patterns of corporatist policy-making. Beverly Hills: Sage Publications.

Leitl, Christoph (2004): Gesellschaftliche Verantwortung von Unternehmen: Eine Selbstverständlichkeit nachhaltigen Unternehmertums. In: Wirtschaftspolitische Blätter 51/3, 313-317.

Lepsius, M. Rainer (1997): Institutionalisierung und Deinstitutionalisierung von Rationalitätskriterien. In: Gerhard Göhler (ed.): Institutionenwandel. Opladen: Westdeutscher Verlag, 57-69.

Levitt, Theodore (1958): The dangers of social responsibility. In: Harvard Business Review September/October, 41-50.

Lockett, Andy, Jeremy Moon, \& Wayne Visser (2006): Corporate social responsibility in management research: Focus, nature, salience and sources of influence. In: Journal of Management Studies 43/1, 115-136.

Löfstedt, Ragnar E. \& David Vogel (2001): The changing character of regulation: A comparison of Europe and the United States. In: Risk Analysis: An International Journal 21/3, 399-416.

Long, J. Scott \& Jeremy Freese (2006): Regression models for categorical dependent variables using Stata. College Station: Stata Press.

Lounsbury, Michael (1997): Exploring the institutional tool kit: The rise of recycling in the U.S. solid waste field. In: American Behavioral Scientist 40/4, 465-477.

Lounsbury, Michael (2001): Institutional sources of practice variation: Staffing college and university recycling programs. In: Administrative Science Quarterly 46/1, 29-56.

Lounsbury, Michael (2002): Institutional transformation and status mobility: The professionalization of the field of finance. In: Academy of Management Journal 45/1, 255-266.

Lounsbury, Michael (2007): A tale of two cities: Competing logics and practice variation in the professionalizing of mutual funds. In: Academy of Management Journal 50/2, 289-307.

Lounsbury, Michael (2008): Institutional rationality and practice variation: New directions in the institutional analysis of practice. In: Accounting, Organizations and Society 33/4-5, 349-361.

Lounsbury, Michael \& Mary Ann Glynn (2001): Cultural entrepreneurship: Stories, legitimacy, and the acquisition of resources. In: Strategic Management Journal 22/6-7, 545-564.

Lounsbury, Michael, Marc Ventresca, \& Paul M. Hirsch (2003): Social movements, field frames and industry emergence: A cultural-political perspective on US recycling. In: Socio-Economic Review 1/1, 71-104. 
Luckmann, Thomas (2002): Wissen und Gesellschaft. Ausgewählte Aufsätze 1981-2002. Konstanz: UVK.

Luckmann, Thomas (2006): Die kommunikative Konstruktion der Wirklichkeit. In: Dirk Tänzler, Hubert Knoblauch, \& Hans-Georg Soeffner (ed.): Neue Perspektiven der Wissenssoziologie. Konstanz: UVK, 15-26.

Lueger, Manfred (2001): Auf den Spuren der sozialen Welt: Methodologie und Organisierung interpretativer Sozialforschung. Frankfurt am Main: Peter Lang Verlag.

Mackenzie, Craig \& Alan Lewis (1999): Morals and markets: The case of ethical investing. In: Business Ethics Quarterly 9/3, 439-452.

Mackey, Alison, Tyson B. Mackey, \& Jay B. Barney (2007): Corporate social responsibility and firm performance: Investor preferences and corporate strategies. In: Academy of Management Review 32/3, 817-835.

Maguire, Steve, Cynthia Hardy, \& Thomas B. Lawrence (2004): Institutional entrepreneurship in emerging fields: HIV/AIDS treatment advocacy in Canada. In: Academy of Management Journal 47/5, 657-679.

Maignan, Isabelle \& David A. Ralston (2002): Corporate social responsibility in Europe and the U.S.: Insights from businesses' self-presentations. In: Journal of International Business Studies 33/3, 497-514.

Mäntysaar, Petri (2005): Comparative corporate governance: Shareholders as a rule-maker. Berlin: Springer.

March, James C. \& Johan P. Olsen (1989): Rediscovering institutions: The organizational basis of politics. New York: Free Press.

Margolis, Joshua D. \& James P. Walsh (2001): People and profits? The search for a link between a company's social and financial performance. Mahwah: Erlbaum.

Margolis, Joshua D. \& James P. Walsh (2003): Misery loves companies: Rethinking social initiatives by business. In: Administrative Science Quarterly 48/2, 268-305.

Mark-Ungericht, Bernhard \& Richard Weiskopf (2007): Filling the empty shell: The public debate on CSR in Austria as a paradigmatic example of political discourse. In: Journal of Business Ethics 70/3, 285-297.

Marquis, Christopher, Mary Ann Glynn, \& Gerald F. Davis (2007): Community isomorphism and corporate social action. In: Academy of Management Review 32/3, 925-945.

Marquis, Christopher \& Michael Lounsbury (2007): Vive la résistance: Competing logics and the consolidation of U.S. community banking. In: Academy of Management Journal 50/4, 799-820.

Marrewijk, Marcel van \& Marco Werre (2003): Multiple levels of corporate sustainability. In: Journal of Business Ethics 44/2\&3, 107-119.

Matten, Dirk \& Andrew Crane (2005): Corporate citizenship: Toward an extended theoretical conceptualization. In: Academy of Management Review 30/1, 166-179.

Matten, Dirk, Andrew Crane, \& Wendy Chapple (2003): Behind the mask: Revealing the true face of corporate citizenship. In: Journal of Business Ethics 45/1-2, 109-120.

Matten, Dirk \& Jeremy Moon (2008): "Implicit" and "explicit" CSR: A conceptual framework for a comparative understanding of corporate social responsibility. In: Academy of Management Review 33/2, 404-424.

Maurer, Cara C., Pratima Bansal, \& Mary M. Crossan (2010): Creating economic value through social values: Introducing a culturally informed resource-based view. In: Organization Science (forthcoming). 
McAdam, Doug, John D. McCarthy, \& Mayer N. Zald (ed.) (1996): Comparative perspectives on social movements: Political opportunities, mobilizing structures, and cultural framings. New York: Cambridge University Press.

McCombs, Maxwell E. \& Donald L. Shaw (1972): The agenda-setting function of mass media. In: Public Opinion Quarterly 36/2, 176-187.

McGuire, Jean B., Alison Sundgren, \& Thomas Schneeweis (1988): Corporate social responsibility and firm financial performance. In: Academy of Management Journal 31/4, 854-872.

McMurtrie, Tony (2005): Factors influencing the publication of social performance information: An Australian case study. In: Corporate Social Responsibility \& Environmental Management 12/3, 129-142.

McWilliams, Abagail \& Donald Siegel (2001): Corporate social responsibility: A theory of the firm perspective. In: Academy of Management Review 26/1, 117-127.

McWilliams, Abagail, Donald S. Siegel, \& Patrick M. Wright (2006a): Corporate social responsibility: International perspectives. In: Journal of Business Strategies 23/1, 1-12.

McWilliams, Abagail, Donald S. Siegel, \& Patrick M. Wright (2006b): Corporate social responsibility: Strategic implications. In: Journal of Management Studies 43/1, 1-18.

Melé, Domènec (2008): Corporate social responsibility theories. In: Andrew Crane, Abagail McWilliams, Dirk Matten, Jeremy Moon, \& Donald S. Siegel (ed.): The Oxford handbook of corporate social responsibility. New York: Oxford University Press, 47-82.

Meyer, John (2002): Globalization and the expansion and standardization of management. In: Kerstin Sahlin-Andersson \& Lars Engwall (ed.): The expansion of management knowledge. Carriers, flows, and sources. Stanford: Stanford Business Books, 33-44.

Meyer, John W., John Boli, \& George M. Thomas (1994): Ontology and rationalization in the Western cultural account. In: W. Richard Scott \& John W. Meyer (ed.): Institutional environments and organizations: Structural complexity and individualism. Thousand Oaks: Sage Publications, 9-27.

Meyer, John W. \& Ronald L. Jepperson (2000): The "actors" of modern society: The cultural construction of social agency. In: Sociological Theory 18/1, 100-120.

Meyer, John W. \& Brian Rowan (1977): Institutionalized organizations: Formal structure as myth and ceremony. In: American Journal of Sociology 83/2, 340-363.

Meyer, Renate E. (2004): Globale Managementkonzepte und lokaler Kontext. Organisationale Wertorientierung im österreichischen öffentlichen Diskurs. Wien: WUV.

Meyer, Renate E. (2006): Visiting relatives: Current developments in the new sociology of knowledge. In: Organization 13/5, 725-738.

Meyer, Renate E. (2008): New sociology of knowledge: Historical legacy and contributions to current debates in institutional research. In: Royston Greenwood, Christine Oliver, Kerstin Sahlin, \& Roy Suddaby (ed.): The SAGE handbook of organizational institutionalism. Los Angeles: Sage Publications, 519-538.

Meyer, Renate E. \& Gerhard Hammerschmid (2006a): Changing institutional logics and executive identities. In: American Behavioral Scientist 49/7, 1000-1014.

Meyer, Renate E. \& Gerhard Hammerschmid (2006b): Public management reform: An identity project. In: Public Policy and Administration 21/1, 99-115.

Meyer, Renate E. \& Markus A. Höllerer (2009): Peaceful coexistence, temporary truce, or combat of contesting institutional logics? Shareholder value and corporate social responsibility in Austrian corporations. Working paper, Institute for Public Management, WU Vienna University of Economics and Business. 
Meyer, Renate E. \& Markus A. Höllerer (2010): Meaning structures in a contested issue field: A topographic map of shareholder value in Austria. In: Academy of Management Journal, 53/6, 1241-62.

Meznar, Martin B. \& Douglas Nigh (1995): Buffer or bridge? Environmental and organizational determinants of public affairs activities in American firms. In: Academy of Management Journal 38/4, 975-996.

Milgrom, Paul \& John Roberts (1992): Economics, organization, and management. Englewood Cliffs: Prentice Hall.

Miller, Justin I. \& Doug Guthrie (2007): Corporate social responsibility: Institutional response to labor, legal and shareholder environments. In: Academy of Management Proceedings, 1-5.

Mitchell, Ronald K., Bradley R. Agle, \& Donna J. Wood (1997): Toward a theory of stakeholder identification and salience: Defining the principle of who and what really counts. In: Academy of Management Review 22/4, 853-886.

Mitchell, William J. Thomas (1994): Picture theory: Essays on verbal and visual representation. Chicago: The University of Chicago Press.

Mitchell, William J. Thomas (2008): Bildtheorie. Frankfurt: Suhrkamp.

Mohr, John W. (1998): Measuring meaning structures. In: Annual Review of Sociology 24/1, 345-370.

Mohr, John W. \& Harrison C. White (2008): How to model an institution. In: Theory and Society $37 / 5,485-512$.

Molina, Oscar \& Martin Rhodes (2002): Corporatism: The past, present, and future of a concept. In: Annual Review of Political Science 5, 305-331.

Moon, Jeremy, Andrew Crane, \& Dirk Matten (2005): Can corporations be citizens? Corporate citizenship as a metaphor for business participation in society. In: Business Ethics Quarterly 15/3, 429-453.

Moon, Jeremy \& David Vogel (2008): Corporate social responsibility, government, and civil society. In: Andrew Crane, Abagail McWilliams, Dirk Matten, Jeremy Moon, \& Donald S. Siegel (ed.): The Oxford handbook of corporate social responsibility. New York: Oxford University Press, 303-323.

Mörth, Ulrika (ed.) (2004): Soft law in governance and regulation: An interdisciplinary analysis. Cheltenham: Elgar.

Munro, Rolland \& Jan Mouritsen (ed.) (1996): Accountability: Power, ethos and the technologies of managing. London: Thomson International Business Press.

Navarro, Peter (1988): Why do corporations give to charity? In: Journal of Business 61/1, 65-93.

NeSoVe (2010): http://www.nesove.at. Last accessed January 20, 2010.

Nigam, Amil \& William Ocasio (2010): Event attention, environmental sensemaking, and change in institutional logics: An inductive analysis of the effects of public attention to Clinton's health care reform initiative. In: Organization Science 21/4, 823-841.

Oakes, Leslie S., Barbara Townley, \& David J. Cooper (1998): Business planning as pedagogy: Language and control in a changing institutional field. In: Administrative Science Quarterly 43/2, 257-292.

Oberg, Achim, Tino Schöllhorn, \& Michael Woywode (2009): Isomorphism in organizational self-representation in the world wide web? Institutionalization processes regarding internet presentations of organizations. In: Academy of Management Best Paper Proceedings 2009.

Ocasio, William \& John Joseph (2005): Cultural adaptation and institutional change: The evolution of vocabularies of corporate governance, 1972-2003. In: Poetics 33/3-4, 163-178. 
OECD (2001): Corporate social responsibility: Partners for progress. Paris: OECD Publications.

OECD (2004): OECD principles of corporate governance. Paris: OECD Publications.

Okoye, Adaeze (2009): Theorising corporate social responsibility as an essentially contested concept: Is a definition necessary? In: Journal of Business Ethics 89/4, 613-627.

Oliver, Christine (1991): Strategic responses to institutional processes. In: Academy of Management Review 16/1, 145-179.

Orlitzky, Marc (2008): Corporate social performance and financial performance: A research synthesis. In: Andrew Crane, Abagail McWilliams, Dirk Matten, Jeremy Moon, \& Donald S. Siegel (ed.): The Oxford handbook of corporate social responsibility. New York: Oxford University Press, 113-134.

Orlitzky, Marc, Frank L. Schmidt, \& Sara L. Rynes (2003): Corporate social and financial performance: A meta-analysis. In: Organization Studies 24/3, 403-441.

Österreichischer Arbeitskreis für Corporate Governance (2002): Österreichischer Corporate Governance Kodex. Wien.

Österreichisches Institut für nachhaltige Entwicklung (2003): Guidelines: Reporting about sustainability: 7 steps to a successful sustainability report. Wien.

Owen-Smith, Jason, Massimo Riccaboni, Fabio Pammolli, \& Walter W. Powell (2002): A comparison of U.S. and European university-industry relations in the life sciences. In: Management Science 48/1, 24-43.

Owen, David L. \& Brendan O'Dwyer (2008): Corporate social responsibility: The reporting and assurance dimension. In: Andrew Crane, Abagail McWilliams, Dirk Matten, Jeremy Moon, \& Donald S. Siegel (ed.): The Oxford handbook of corporate social responsibility. New York: Oxford University Press, 384-409.

Owen, Geoffrey (2001): Shareholder value and corporate social responsibility. In: David Henderson: Misguided virtue: False notions of corporate social responsibility. London, The Institute of Economic Affairs, 8-13.

Palazzo, Guido (2004): The politicization of the corporation: Towards a thicker concept of organisational legitimacy. Paper presented at the $20^{\text {th }}$ EGOS Colloquium. Ljubljana, July 1-3.

Palazzo, Guido \& Andreas Georg Scherer (2006): Corporate legitimacy as deliberation: A communicative framework. In: Journal of Business Ethics 66/1, 71-88.

Palmer, Donald A., P. Devereaux Jennings, \& Xueguang Zhou (1993): Late adoption of the multidivisional form by large U.S. corporations: Institutional, political, and economic accounts. In: Administrative Science Quarterly 38/1, 100-131.

Paul, Karen (2008): Corporate sustainability, citizenship and social responsibility reporting. In: Journal of Corporate Citizenship 32/1, 63-78.

Pelinka, Anton (1998): Austria: Out of the shadow of the past. Boulder: Westview Press.

Penz, Elfriede \& Barbara Stöttinger (2008): Original brands and counterfeit brands - do they have anything in common? In: Journal of Consumer Behavior 7/1, 146-163.

Pfeffer, Jeffrey \& Gerald R. Salancik (1978): The external control of organizations: A resource dependence perspective. New York: Harper \& Row.

Phillips, Nelson \& Cynthia Hardy (1997): Managing multiple identities: Discourse, legitimacy and resources in the UK refugee system. In: Organization 4/2, 159-185.

Phillips, Nelson, Thomas B. Lawrence, \& Cynthia Hardy (2000): Inter-organizational collaboration and the dynamics of institutional fields. In: Journal of Management Studies 37/1, 23-43. 
Phillips, Nelson, Thomas B. Lawrence, \& Cynthia Hardy (2004): Discourse and institutions. In: Academy of Management Review 29/4, 635-652.

Phillips, Nelson \& Namrata Malhotra (2008): Taking social construction seriously: Extending the discursive approach in institutional theory. In: Royston Greenwood, Christine Oliver, Kerstin Sahlin, \& Roy Suddaby (ed.): The SAGE bandbook of organizational institutionalism. Los Angeles: Sage Publications, 702-720.

Phillips, Robert, R. Edward Freeman, \& Andrew Wicks (2003): What stakeholder theory is not. In: Business Ethics Quarterly 13/4, 479-502.

Pieper, Annemarie (2000): Einführung in die Ethik. $4^{\text {th }}$ ed., Tübingen: Francke.

Pivato, Sergio, Nicola Misani, \& Antonio Tencati (2008): The impact of corporate social responsibility on consumer trust: The case of organic food. In: Business Ethics: A European Review 17/1, 3-12.

Pollock, Timothy G. \& Violina P. Rindova (2003): Media legitimation effects in the market for initial public offerings. In: Academy of Management Journal 46/5, 631-642.

Porac, Joseph F., Marc J. Ventresca, \& Yuri Mishina (2001): Interorganizational cognition and interpretation. In: Joel A. C. Baum (ed.): The Blackwell companion to organization. Oxford: Blackwell, 579-598

Porter, Michael E. \& Mark R. Kramer (2002): The competitive advantage of corporate philanthropy. In: Harvard Business Review 80/12, 56-69.

Porter, Michael E. \& Mark R. Kramer (2006): Strategy \& society: The link between competitive advantage and corporate social responsibility. In: Harvard Business Review 84/12, 78-92.

Post, James E. \& Sandra A. Waddock (1995): Strategic philanthropy and partnerships for economic progress. In: Richard F. America (ed.): Philanthropy and economic development. Westport: Greenwood Press, 65-84.

Potter, Jonathan \& Margaret Wetherell (1987): Discourse and social psychology: Beyond attitudes and behavior. London: Sage Publications.

Powell, Walter W. (1988): Institutional effects on organizational structure and performance. In: Lynne G. Zucker (ed.): Institutional patterns and organizations: Culture and environment. Cambridge: Ballinger Publishing, 115-136.

Powell, Walter W. (1991): Expanding the scope of institutional analysis. In: Walter W. Powell \& Paul J. DiMaggio (ed.): The new institutionalism in organizational analysis. Chicago: The University of Chicago Press, 183-203.

Prahalad, C. K. (2004): The fortune at the bottom of the pyramid: eradicating poverty thorugh profits. Upper Saddle River: Wharton School Publishing.

Prahalad, C. K. \& Allen Hammond (2002): Serving the world's poor, profitably. In: Harvard Business Review 80/9, 48-57.

Preston, Alistair M., Christopher Wright, \& Joni J. Young (1996): Imag[in]ing annual reports. In: Accounting, Organizations and Society 21/1, 113-137.

Preston, Lee E. \& James E. Post (1981): Private management and public policy. In: California Management Review 23/3, 56-62.

PricewaterhouseCoopers (2003): $6^{\text {th }}$ annual global CEO survey. Leadership, responsibility, and growth in uncertain times.

PricewaterhouseCoopers (2010): $13^{\text {th }}$ annual global CEO survey. Setting a smarter course for growth. 
Rao, Hayagreeva, Henrich R. Greve, \& Gerald F. Davis (2001): Fool's gold: Social proof in the initiation and abandonment of coverage by Wall Street analysts. In: Administrative Science Quarterly 46/3, 502-526.

Rao, Hayagreeva, Philippe Monin, \& Rodolphe Durand (2003): Institutional change in Toque Ville: Nouvelle cuisine as an identity movement in French gastronomy. In: American Journal of Sociology 108/4, 795-843.

Rao, Hayagreeva, Calvin Morrill, \& Mayer N. Zald (2000): Power plays: How social movements and collective action create new organizational forms. In: Research in Organizational Behavior 22, 237-282.

Rao, Hayagreeva \& Kumar Sivakumar (1999): Institutional sources of boundary-spanning structures: The establishment of investor relations departments in the Fortune 500 industrials. In: Organization Science 10/1, 27-42.

Rawls, John (1971): A theory of justice. Cambridge: The Belknap Press of Harvard University Press.

Reay, Trish \& C. R. Hinings (2005): The recomposition of an organizational field: Health care in Alberta. In: Organization Studies 26/3, 351-384.

Reay, Trish \& C. R. Hinings (2009): Managing the rivalry of competing institutional logics. In: Organization Studies 30/6, 629-652.

respACT (2010): http://www.respact.at. Last accessed January 19, 2010.

Richardson, Alan J. \& Michael Welker (2001): Social disclosure, financial disclosure and the cost of equity capital. In: Accounting, Organizations and Society 26/7-8, 597-616.

Riegler, Josef (ed.) (1990): Antworten für die Zukunft: Ökosoziale Marktwirtschaft [Politische Akademie der Österreichischen Volkspartei]. Wien: Verlag für Geschichte und Politik.

Riordan, Christine M., Robert D. Gatewood, \& Jodi Barnes Bill (1997): Corporate image: Employee reactions and implications for managing corporate social performance. In: Journal of Business Ethics 16/4, 401-412.

Roberts, John \& Robert Scapens (1985): Accounting systems and systems of accountability: Understanding accounting practices in their organisational contexts. In: Accounting, Organizations and Society 10/4, 443-456.

Rogers, Everett M. (1995): Diffusion of innovations. New York: Free Press.

Royce, Terry D. \& Wendy L. Bowcher (ed.) (2007): New directions in the analysis of multimodal discourse. Mahwah: Lawrence Erlbaum.

Rucht, Dieter (1994): Öffentlichkeit als Mobilisierungsfaktor für soziale Bewegungen. In: Friedhelm Neidhardt (ed.): Öffentlichkeit, öffentliche Meinung, soziale Bewegungen. Kölner Zeitschrift für Soziologie und Sozialpsychologie. Sonderheft 34. Opladen: Westdeutscher Verlag, 337-358.

Russo, Michael V. \& Paul A. Fouts (1997): A resource-based perspective on corporate environmental performance and profitability. In: Academy of Management Journal 40/3, 534-559.

Ruwet, Coline \& Kristina Tamm Hallström (2007): How are the contents of multi-stakeholder standards shaped? The danger of using stakeholder categories as analytical tools - the case of the ISO 26000 standard on social responsibility. Paper presented at the $23^{\text {rd }}$ EGOS Colloquium. Vienna, July 5-7.

Sacconi, Lorenzo (2004): Corporate social responsibility (CSR) as a model of "extended" corporate governance: An explanation based on the economic theories of social contract, reputation and reciprocal conformism. In: LIUC Papers n. 142, Serie Etica, Diritto ed Economica $10,1-49$.

Sahlin-Andersson, Kerstin (1996): Imitating by editing success: The construction of organizational fields. In: Barbara Czarniawska \& Guje Sevón (ed.): Translating organizational change. Berlin: de Gruyter, 69-92. 
Sahlin-Andersson, Kerstin (2006): Corporate social responsibility: A trend and a movement, but of what and for what? In: Corporate Governance 6/5, 595-608.

Sahlin-Andersson, Kerstin \& Lars Engwall (2002a): Carriers, flows, and sources of management knowledge. In: Kerstin Sahlin-Andersson \& Lars Engwall (ed.): The expansion of management knowledge: Carriers, flows, and sources. Stanford: Stanford Business Books, 3-32.

Sahlin-Andersson, Kerstin \& Lars Engwall (ed.) (2002b): The expansion of management knowledge: Carriers, flows, and sources. Stanford: Stanford Business Books.

Sahlin, Kerstin \& Linda Wedlin (2008): Circulating ideas: Imitation, translation and editing. In: Royston Greenwood, Christine Oliver, Kerstin Sahlin, \& Roy Suddaby (ed.): The SAGE bandbook of organizational institutionalism. Los Angeles: Sage Publications, 218-242.

Salazar, José \& Bryan W. Husted (2008): Principals and agents: Further thoughts on the Friedmanite critique of corporate social responsibility. In: Andrew Crane, Abagail McWilliams, Dirk Matten, Jeremy Moon, \& Donald S. Siegel (ed.): The Oxford handbook of corporate social responsibility. New York: Oxford University Press, 137-155.

Salzmann, Oliver, Aileen Ionescu-Somers, \& Ulrich Steger (2005): The business case for corporate sustainability: Literature review and research options. In: European Management Journal 23/1, 27-36.

Sanders, W. Gerard \& Anja Tuschke (2007): The adoption of institutionally contested organizational practices: The emergence of stock option pay in Germany. In: Academy of Management Journal 50/1, 33-56.

Scherer, Andreas Georg \& Guido Palazzo (2007): Toward a political conception of corporate responsibility: Business and society seen from a Habermasian perspective. In: Academy of Management Review 32/4, 1096-1120.

Schmitter, Philippe C. \& Gerhard Lehmbruch (ed.) (1979): Trends toward corporatist intermediation. London: Sage Publications.

Schneiberg, Marc (2002): Organizational heterogeneity and the production of new forms: Politics, social movements and mutual companies in American fire insurance, 1900-1930. In: Michael Lounsbury \& Marc J. Ventresca (ed.): Social structure and organizations revisited. Oxford: JAI Press, 39-89.

Schneiberg, Marc (2007): What's on the path? Path dependence, organizational diversity and the problem of institutional change in the US economy, 1900-1950. In: Socio-Economic Review 5/1, 47-80.

Schneiberg, Marc \& Elisabeth S. Clemens (2006): The typical tools for the job: Research strategies in institutional analysis. In: Sociological Theory 24/3, 195-227.

Schneiberg, Marc \& Michael Lounsbury (2008): Social movements and institutional analysis. In: Royston Greenwood, Christine Oliver, Kerstin Sahlin, \& Roy Suddaby (ed.): The SAGE bandbook of organizational institutionalism. Los Angeles: Sage Publications, 650-672.

Schneiberg, Marc \& Sarah A. Soule (2005): Institutionalization as a contested, multilevel process: The case of rate regulation in American fire insurance. In: Gerald F. Davis, Doug McAdam, W. Richard Scott, \& Mayer N. Zald (ed.): Social movements and organization theory. Cambridge: Cambridge University Press, 122-160.

Schneper, William D. \& Mauro F. Guillén (2004): Stakeholder rights and corporate governance: A cross-national study of hostile takeovers. In: Administrative Science Quarterly 49/2, 263-295.

Schütz, Alfred (1974): Der sinnhafte Aufbau der sozialen Welt. Frankfurt am Main: Suhrkamp.

Schutz, Alfred \& Thomas Luckmann (1973): The structures of the life-world. London: Heineman. 
Schwartz, Mark S. \& Archie B. Carroll (2003): Corporate social responsibility: A three-domain approach. In: Business Ethics Quarterly 13/4, 503-530.

Schweiker, William (1993): Accounting for ourselves: Accounting practices and the discourse of ethics. In: Accounting, Organizations and Society 18/2-3, 231-252.

Scott, John (2000): Social network analysis: $A$ handbook. $2^{\text {nd }}$ ed., London: Sage Publications.

Scott, Marvin B. \& Stanford M. Lyman (1968): Accounts. In: American Sociological Review 33/1, 4662.

Scott, Marvin B. \& Stanford M. Lyman (1970): Accounts, deviance, and social order. In: Jack D. Douglas (ed.): Deviance \& respectability: The social construction of moral meanings. New York: Basic Books, 89-119.

Scott, W. Richard (1994): Conceptualizing organizational fields. Linking organizations and societal systems. In: Hans Ulrich Derlien, Uta Gerhardt, \& Fritz W. Scharpf (ed.): Systemrationalität und Partialinteresse: Festschrift für Renate Maynt\%: Baden-Baden: Nomos Verlag, 203-222.

Scott, W. Richard (1995): Institutions and organizations. Thousand Oaks: Sage Publications.

Scott, W. Richard (2001): Institutions and organizations. $2^{\text {nd }}$ ed., Thousand Oaks: Sage Publications.

Scott, W. Richard (2008): Institutions and organizations: Ideas and interests. $3^{\text {rd }}$ ed., Thousand Oaks: Sage Publications.

Scott, W. Richard, Martin Ruef, Peter J. Mendel, \& Carol A. Caronna (2000): Institutional change and healthcare organizations: From professional dominance to managed care. Chicago: University of Chicago Press.

Selznick, Philip (1957): Leadership in administration: A sociological interpretation. New York: Harper \& Row.

Sethi, S. Prakash (1975): Dimensions of corporate social performance: An analytical framework. In: California Management Review 17/3, 58-64.

Sethi, S. Prakash (1979): A conceptual framework for environmental analysis of social issues and evaluation of business response patterns. In: Academy of Management Review 4/1, 63-74.

Shearer, Teri (2002): Ethics and accountability: From the for-itself to the for-the-other. In: Accounting, Organizations and Society 27/6, 541-573.

Shrivastava, Paul (1995): The role of corporations in achieving ecological sustainability. In: Academy of Management Review 20/4, 936-960.

Sinclair, Amanda (1995): The chameleon of accountability: Forms and discourses. In: Accounting, Organizations and Society 20/2-3, 219-237.

Smith, Jeffrey D. (ed.) (2009): Normative theory and business ethics. Lanham: Rowman \& Littlefield.

Smith, N. Craig (1990): Morality and the market: Consumer pressures for corporate accountability. London: Routledge.

Smith, N. Craig (2008): Consumers as drivers of corporate social responsibility. In: Andrew Crane, Abagail McWilliams, Dirk Matten, Jeremy Moon, \& Donald S. Siegel (ed.): The Oxford handbook of corporate social responsibility. New York: Oxford University Press, 281-302.

Smith, Timothy (2005): Institutional and social investors find common ground. In: Journal of Investing 14/3, 57-65.

Snow, David A. \& Robert D. Benford (1988): Ideology, frame resonance, and participant mobilization. In: Bert Klandermans, Hanspeter Kriesi, \& Sidney Tarrow (ed.): From structure to action: Comparing social movement research across cultures. Greenwich: JAI Press, 197-217. 
Snow, David A. \& Robert D. Benford (1999): Alternative types of cross-national diffusion in the social movement arena. In: Donatella della Porta, Hanspeter Kriesi, \& Dieter Rucht (ed.): Social movements in a globalizing world. Basingstoke: Macmillan, 23-39.

Snow, David A., E. Burke Rochford, Steven K. Worden, \& Robert D. Benford (1986): Frame alignment processes, micromobilization, and movement participation. In: American Sociological Review 51/4, 464-481.

Solomon, Robert C. (1993): Ethics and excellence: Cooperation and integrity in business. Oxford: Oxford University Press.

Sozialwort (2010): http:/ /www.sozialwort.at. Last accessed January 20, 2010.

Spector, Malcolm \& John I. Kitsuse (1977): Constructing social problems. Menlo Park: Cummings.

Stanton, Patricia \& John Stanton (2002): Corporate annual reports: Research perspectives used. In: Accounting, Auditing \& Accountability Journal 15/4, 478-500.

StataCorp LP (2007a): STATA base reference manual. Release 10. College Station: Stata Press.

StataCorp LP (2007b): STATA multivariate statistics reference manual. Release 10. College Station: Stata Press.

Statistik Austria (2001): Leistungs- und Strukturerbebung: Sonderauswertung nach der Kammersystematik im Auftrag der Wirtschaftskammer Österreich. Wien.

Steinmann, Horst (1973): Zur Lehre von der „Gesellschaftlichen Verantwortung der Unternehmensführung“ - zugleich eine Kritik des Davoser Manifests. In: Wirtschaftswissenschaftliches Studium 10, 467-473.

Story, Dawn \& Trevor J. Price (2006): Corporate social responsibility and risk management? In: Journal of Corporate Citizenship 22/1, 39-51.

Strandgaard Pedersen, Jesper \& Frank Dobbin (2006): In search of identity and legitimation: Bridging organizational culture and neoinstitutionalim. In: American Behavioral Scientist 49/8, 897-907.

Strang, David \& Michael W. Macy (2001): In search of excellence: Fads, success stories, and adaptive emulation. In: American Journal of Sociology 107/1, 147-182.

Strang, David \& John W. Meyer (1993): Institutional conditions for diffusion. In: Theory and Society 22/4, 487-511.

Strang, David \& Sarah A. Soule (1998): Diffusion in organizations and social movements: From hybrid corn to poison pills. In: Annual Review of Sociology 24/1, 265-290.

Stratling, Rebecca (2007): The legitimacy of corporate social responsibility. In: Corporate Ownership \& Control 4/4, 65-73.

Streeck, Wolfgang \& Kathleen Thelen (2005): Beyond continuity: Institutional change in advanced political economies. Oxford: Oxford University Press.

Strigl, Alfred (2005): Concerted actions towards sustainable development. In: André Habisch, Jan Jonker, Martina Wegner, \& René Schmidpeter (ed.): Corporate social responsibility across Europe. Berlin: Springer, 125-140.

Suchman, Mark C. (1995): Managing legitimacy: Strategic and institutional approaches. In: Academy of Management Review 20/3, 571-610.

Suddaby, Roy \& Royston Greenwood (2005): Rhetorical strategies of legitimacy. In: Administrative Science Quarterly 50/1, 35-67.

Swanson, Diane L. (1995): Addressing a theoretical problem by reorienting the corporate social performance model. In: Academy of Management Review 20/1, 43-64. 
Swanson, Diane L. (1999): Toward an integrative theory of business and society: A research strategy for corporate social performance. In: Academy of Management Review 24/3, 506-521.

Swedberg, Richard (2006): The toolkit of economic sociology. In: Donald Wittman \& Barry Weingast (ed.): The handbook of political economy. New York: Oxford University Press, 937-950.

Tarrow, Sidney (1998): Power in movement: Social movements and contentious politics. ${ }^{2 n d}$ ed., Cambridge: Cambridge University Press.

Tempel, Anne \& Peter Walgenbach (2007): Global standardization of organizational forms and management practices? What new institutionalism and the business-systems approach can learn from each other. In: Journal of Management Studies 44/1, 1-24.

Tengblad, Stefan \& Claes Ohlsson (2010): The framing of corporate social responsibility and the globalization of national business systems: A longitudinal case study. In: Journal of Business Ethics 93/4, 653-669.

Thompson, Lindsay J. (2008): Gender equity and corporate social responsibility in a post-feminist era. In: Business Ethics: A European Review 17/1, 87-106.

Thompson, Paul \& Zarina Zakaria (2004): Corporate social responsibility reporting in Malaysia. In: Journal of Corporate Citizenship 13/1, 125-136.

Thornton, Patricia H. \& William Ocasio (1999): Institutional logics and the historical contingency of power in organizations: Executive succession in the higher education publishing industry, 1958-1990. In: American Journal of Sociology 105/3, 801-844.

Thornton, Patricia H. \& William Ocasio (2008): Institutional logics. In: Royston Greenwood, Christine Oliver, Kerstin Sahlin, \& Roy Suddaby (ed.): The SAGE handbook of organizational institutionalism. Los Angeles: Sage Publications, 517-536.

Tolbert, Pamela S. (1985): Institutional environments and resource dependence: Sources of administrative structure in institutions of higher education. In: Administrative Science Quarterly 30/1, 1-13.

Tolbert, Pamela S. \& Lynne G. Zucker (1983): Institutional sources of change in the formal structure of organizations: The diffusion of civil service reform, 1880-1935. In: Administrative Science Quarterly 28/1, 22-39.

Tolbert, Pamela S. \& Lynne G. Zucker (1996): The institutionalization of institutional theory. In: Stewart R. Clegg, Cynthia Hardy, \& Walter R. Nord (ed.): Handbook of organizational studies. London: Sage Publications, 175-190.

Townley, Barbara (2002): The role of competing rationalities in institutional change. In: Academy of Management Journal 45/1, 163-179.

Traxler, Franz (1998): Austria - Still the country of corporatism. In: Anthony Ferner \& Richard Hyman (ed.): Changing industrial relations in Europe. Oxford: Blackwell, 239-261.

Trotman, Ken T. \& Graham W. Bradley (1981): Associations between social responsibility disclosure and characteristica of companies. In: Accounting, Organizations and Society 6/4, 355362.

Tsang, Eric W. K. (1998): A longitudinal study of corporate social reporting in Singapore: The case of banking, food and beverages and hotel industries. In: Accounting, Auditing \& Accountability Journal 11/5, 624-641.

Tucker, Kerry, Glen M. Broom, \& Clarke L. Caywood (1993): Managing issues acts as bridge to strategic planning. In: Public Relations Journal 49/11, 38-40.

Tully, Stephen (ed.) (2005): International documents on corporate responsibility. Cheltenham: Edward Elgar Publishing. 
Turban, Daniel B. \& Daniel W. Greening (1997): Corporate social performance and organizational attractiveness to prospective employees. In: Academy of Management Journal 40/3, 658672.

Udayasankar, Krishna (2008): Corporate social responsibility and firm size. In: Journal of Business Ethics 83/2, 167-175.

Ulrich, Hans (1980): Management-Philosophie in einer sich wandelnden Gesellschaft. In: Dietger Hahn (ed.): Führungsprobleme industrieller Unternehmungen: Festschrift für Friedrich Thomée zum 60. Geburtstag. Berlin: de Gruyter, 3-18.

Ulrich, Peter (1986): Transformation der ökonomischen Vernunft: Fortschrittsperspektiven der modernen Industriegesellschaft. Bern: Haupt.

Ulrich, Peter \& Edgar Fluri (1975): Management. Bern: Haupt.

Useem, Michael (1993): Executive defense: Shareholder power and corporate reorganization. Cambridge: Harvard University Press.

Useem, Michael (1996): Investor capitalism: How money managers are changing the face of corporate America. New York: Basic Books.

Valor, Carmen (2005): Corporate social responsibility and corporate citizenship: Towards corporate accountability. In: Business and Society Review 110/2, 191-212.

van Dijk, Teun A. (1980): Macrostructures: An interdisciplinary study of global structures in discourse, interaction, and cognition. Hillsdale: Erlbaum.

van Dijk, Teun A. (1985): Structures of news in the press. In: Teun A. van Dijk (ed.): Discourse and communication: New approaches to the analysis of mass media disocurse and communication. Berlin: de Gruyter, 69-93.

van Dijk, Teun A. (1988): News as discourse. Hillsdale: Erlbaum.

van Dijk, Teun A. \& Walter Kintsch (1983): Strategies of discourse comprehension. New York: Academic Press.

Varadarajan, P. Rajan \& Anil Menon (1988): Cause-related marketing: A coalignment of marketing strategy and corporate philanthropy. In: Journal of Marketing 52/3, 58-74.

Ventresca, Marc J. \& John W. Mohr (2002): Archival research methods in organization analysis. In: Joel A. C. Baum (ed.): The Blackwell companion to organizations. Oxford: Blackwell, 805-828.

Villiers, Charlotte L. (2006): Corporate reporting and company law. Cambridge: Cambridge University Press.

Vogel, David (2005): The market for virtue: The potential and limits of corporate social responsibility. Washington: Brookings Institution Press.

von Hippel, Eric (1995): The sources of innovation. Oxford: Oxford University Press.

Votaw, Dow (1973): Genius becomes rare. In: Dow Votaw \& S. Prakash Sethi (ed.): The corporate dilemma: Traditional values versus contemporary problems. Englewood Cliffs: Prentice Hall, 11-45.

Vuontisjärvi, Taru (2006): Corporate social reporting in the European context and human resource disclosures: An analysis of Finnish companies. In: Journal of Business Ethics 69/4, 331-354.

Vyakarnam, Shailendra (1992): Social responsibility: What leading companies do. In: Long Range Planning 25/5, 59-67.

Waddock, Sandra (2000): The multiple bottom lines of corporate citizenship: Social investing, reputation, and responsibility audits. In: Business and Society Review 105/3, 323-345.

Waddock, Sandra (2001): Corporate citizenship enacted as operating practice. In: International Journal of V alue-Based Management 14/3, 237-246. 
Waddock, Sandra A. \& Samuel B. Graves (1997): The corporate social performance - financial performance link. In: Strategic Management Journal 18/4, 303-319.

Walgenbach, Peter (2002): Neoinstitutionalistische Organisationstheorie: State of the Art und Entwicklungslinien. In: Georg Schreyögg \& Peter Conrad (ed.): Theorien des Managements. Wiesbaden: Gabler Verlag, 155-202.

Walgenbach, Peter \& Renate E. Meyer (2008): Neoinstitutionalistische Organisationstheorie. Stuttgart: Kohlhammer.

Wartick, Steven L. (1992): The relationship between intense media exposure and change in corporate reputation. In: Business \& Society 31/1, 33-49.

Wartick, Steven L. \& Philip L. Cochran (1985): The evolution of the corporate social performance model. In: Academy of Management Review 10/4, 758-769.

Wasserman, Stanley \& Katherine Faust (1994): Social network analysis: Methods and application. Cambridge: Cambridge University Press.

Watson, Tony J. (1995): Rhetoric, discourse and argument in organizational sense making: A reflexive tale. In: Organization Studies 16/5, 805-821.

Weaver, Gary R., Linda Klebe Trevino, \& Philip L. Cochran (1999): Integrated and decoupled corporate social performance: Management commitments, external pressures, and corporate ethics practices. In: Academy of Management Journal 42/5, 539-552.

Weber, Klaus (2005): A toolkit for analyzing corporate cultural toolkits. In: Poetics 33/3-4, $227-$ 252.

Weller, Susan C. \& Antone Kimball Romney (1990): Metric scaling: Correspondence analysis. Newbury Park: Sage Publications.

Wernerfelt, Birger (1984): A resource-based view of the firm. In: Strategic Management Journal 5/2, 171-180.

Werther, William B. \& David Chandler (2006): Strategic corporate social responsibility: Stakeholders in a global environment. Thousand Oaks, CA: Sage Publications.

Werther, William B. \& David Chandler (2011): Strategic corporate social responsibility: Stakeholders in a global environment. $2^{\text {nd }}$ ed., Thousand Oaks: Sage Publications.

Westphal, James D., Ranjay Gulati, \& Stephen M. Shortell (1997): Customization or conformity? An institutional and network perspective on the content and consequences of TQM adoption. In: Administrative Science Quarterly 42/2, 366-394.

Wheeler, David, Barry Colbert, \& R. Edward Freeman (2003): Focusing on value: Reconciling corporate social responsibility, sustainability and a stakeholder approach in a network world. In: Journal of General Management 28/3, 1-28.

Wheeler, David, Kevin McKague, Jane Thomson, Rachel Davies, Jacqueline Medalye, \& Marina Prada (2005): Creating sustainable local enterprise networks. In: MIT Sloan Management Review 47/1, 33-40.

Whitley, Richard (1992): The social construction of organizations and markets: The comparative analysis of business recipes. In: Michael Reed \& Michael Hughes (ed.): Rethinking organizations: New directions in organization theory and analysis. London: Sage Publications, 120-143.

Whitley, Richard (1999): Divergent capitalisms: The social structuring and change of business systems. Oxford: Oxford University Press.

Whitley, Richard \& Peer Hull Kristensen (ed.) (1996): The changing European firm: Limits to convergence. London: Routledge. 
Wicks, Andrew C., Shawn L. Berman, \& Thomas M. Jones (1999): The structure of optimal trust: Moral and strategic implications. In: Academy of Management Review 24/1, 99-116.

Wilson, Mel (2003): Corporate sustainability: What is it and where does it come from? In: Ivey Management Journal March/April 2003, 1-5.

Windsor, Duane (2001): Corporate citizenship: Evolution and interpretation. In: Jörg Andriof \& Malcolm McIntosh (ed.): Perspectives on corporate citizenship. Sheffield: Greenleaf, 39-52.

Windsor, Duane (2006): Corporate social responsibility: Three key approaches. In: Journal of Management Studies 43/1, 93-114.

Wood, Donna J. (1991): Corporate social performance revisited. In: Academy of Management Review 16/4, 691-718.

Wood, Donna J. \& Raymond E. Jones (1995): Stakeholder mismatching: A theoretical problem in empirical research on corporate social performance. In: International Journal of Organizational Analysis 3/3, 229-267.

Wood, Donna J. \& Jeanne M. Logsdon (2001): Theorising business citizenship. In: Jörg Andriof \& Malcolm McIntosh (ed.): Perspectives on corporate citizenship. Sheffield: Greenleaf, 83-103.

Wooten, Melissa \& Andrew J. Hoffman (2008): Organizational fields: Past, present and future. In: Royston Greenwood, Christine Oliver, Kerstin Sahlin, \& Roy Suddaby (ed.): The SAGE bandbook of organizational institutionalism. Los Angeles: Sage Publications, 130-147.

World Business Council for Sustainable Development (2000): Corporate social responsibility: Making good business sense.

World Commission on Environment and Development (1987): Our common future ("Brundtland Report”). Oxford: Oxford University Press.

Wruk, Dominika, Florian Scheiber, Achim Oberg, \& Michael Woywode (2010): Diversity of management labels on organizational websites: A reflection of multiple expectations? Paper presented at the $26^{\text {rd }}$ EGOS Colloquium. Lisbon, July 5-7.

Zadek, Simon (2000): Doing good and doing well: Making the business case for corporate citizenship. New York: The Conference Board.

Zald, Mayer N. \& Michael Lounsbury (2010): The wizards of Oz: Towards an institutional approach to elites, expertise and command post. In: Organization Studies 31/7, 963-996.

Zenisek, Thomas J. (1979): Corporate social responsibility: A conceptualization based on organizational literature. In: Academy of Management Review 4/3, 359-368.

Zilber, Tammar B. (2006): The work of the symbolic in institutional processes: Translations of rational myths in Israeli high tech. In: Academy of Management Journal 49/2, 281-303.

Zilber, Tammar B. (2007): Stories and the discursive dynamics of institutional entrepreneurship: The case of Israeli high-tech after the bubble. In: Organization Studies 28/7, 1035-1054.

Zilber, Tammar B. (2008): The work of meanings in institutional processes and thinking. In: Royston Greenwood, Christine Oliver, Kerstin Sahlin, \& Roy Suddaby (ed.): The SAGE bandbook of organizational institutionalism. Los Angeles, CA: Sage Publications, 151-169.

Zorn, Dirk M. (2004): Here a chief, there a chief: The rise of the CFO in the American firm. In: American Sociological Review 69/3, 345-364.

Zucker, Lynne G. (1977): The role of institutionalization in cultural persistence. In: American Sociological Review 42/5, 726-743.

Zucker, Lynne G. (1991): The role of institutionalization in cultural persistence. In: Walter W. Powell \& Paul J. DiMaggio (ed.): The new institutionalism in organizational analysis. Chicago: The University of Chicago Press, 83-107. 


\title{
Forschungsergebnisse der Wirtschaftsuniversität Wien
}

\author{
Herausgeber: Wirtschaftsuniversität Wien - \\ vertreten durch a.o. Univ. Prof. Dr. Barbara Sporn \\ INFORMATION UND KONTAKT: \\ WU (Wirtschaftsuniversität Wien) \\ Department of Finance, Accounting and Statistics \\ Institute for Finance, Banking and Insurance \\ Heiligenstädter Straße 46-48, 1190 Wien \\ Tel.: 0043-1-313 36/4556 \\ Fax: 0043-1-313 36/904556 \\ valentine.wendling@wu.ac.at \\ www.wu.ac.at/finance
}

Band 1 Stefan Felder: Frequenzallokation in der Telekommunikation. Ökonomische Analyse der Vergabe von Frequenzen unter besonderer Berücksichtigung der UMTS-Auktionen. 2004.

Band 2 Thomas Haller: Marketing im liberalisierten Strommarkt. Kommunikation und Produktplanung im Privatkundenmarkt. 2005.

Band 3 Alexander Stremitzer: Agency Theory: Methodology, Analysis. A Structured Approach to Writing Contracts. 2005.

Band 4 Günther Sedlacek: Analyse der Studiendauer und des Studienabbruch-Risikos. Unter Verwendung der statistischen Methoden der Ereignisanalyse. 2004.

Band 5 Monika Knassmüller: Unternehmensleitbilder im Vergleich. Sinn- und Bedeutungsrahmen deutschsprachiger Unternehmensleitbilder - Versuch einer empirischen (Re-)Konstruktion. 2005.

Band 6 Matthias Fink: Erfolgsfaktor Selbstverpflichtung bei vertrauensbasierten Kooperationen. Mit einem empirischen Befund. 2005.

Band 7 Michael Gerhard Kraft: Ökonomie zwischen Wissenschaft und Ethik. Eine dogmenhistorische Untersuchung von Léon M.E. Walras bis Milton Friedman. 2005.

Band 8 Ingrid Zechmeister: Mental Health Care Financing in the Process of Change. Challenges and Approaches for Austria. 2005.

Band 9 Sarah Meisenberger: Strukturierte Organisationen und Wissen. 2005.

Band 10 Anne-Katrin Neyer: Multinational teams in the European Commission and the European Parliament. 2005.

Band 11 Birgit Trukeschitz: Im Dienst Sozialer Dienste. Ökonomische Analyse der Beschäftigung in sozialen Dienstleistungseinrichtungen des Nonprofit Sektors. 2006

Band 12 Marcus Kölling: Interkulturelles Wissensmanagement. Deutschland Ost und West. 2006.

Band 13 Ulrich Berger: The Economics of Two-way Interconnection. 2006.

Band 14 Susanne Guth: Interoperability of DRM Systems. Exchanging and Processing XML-based Rights Expressions. 2006.

Band 15 Bernhard Klement: Ökonomische Kriterien und Anreizmechanismen für eine effiziente Förderung von industrieller Forschung und Innovation. Mit einer empirischen Quantifizierung der Hebeleffekte von F\&E-Förderinstrumenten in Österreich. 2006. 
Band 16 Markus Imgrund: Wege aus der Insolvenz. Eine Analyse der Fortführung und Sanierung insolventer Klein- und Mittelbetriebe unter besonderer Berücksichtigung des Konfigurationsansatzes. 2007.

Band 17 Nicolas Knotzer: Product Recommendations in E-Commerce Retailing Applications. 2008.

Band 18 Astrid Dickinger: Perceived Quality of Mobile Services. A Segment-Specific Analysis. 2007.

Band 19 Nadine Wiedermann-Ondrej: Hybride Finanzierungsinstrumente in der nationalen und internationalen Besteuerung der USA. 2008.

Band 20 Helmut Sorger: Entscheidungsorientiertes Risikomanagement in der Industrieunternehmung. 2008.

Band 21 Martin Rietsch: Messung und Analyse des ökonomischen Wechselkursrisikos aus Unternehmenssicht: Ein stochastischer Simulationsansatz. 2008.

Band 22 Hans Christian Mantler: Makroökonomische Effizienz des Finanzsektors. Herleitung eines theoretischen Modells und Schätzung der Wachstumsimplikationen für die Marktwirtschaften und Transformationsökonomien Europas. 2008.

Band 23 Youri Tacoun: La théorie de la valeur de Christian von Ehrenfels. 2008.

Band 24 Monika Koller: Longitudinale Betrachtung der Kognitiven Dissonanz. Eine Tagebuchstudie zur Reiseentscheidung. 2008.

Band 25 Marcus Scheiblecker: The Austrian Business Cycle in the European Context. 2008.

Band 26 Aida Numic: Multinational Teams in European and American Companies. 2008.

Band 27 Ulrike Bauernfeind: User Satisfaction with Personalised Internet Applications. 2008.

Band 28 Reinhold Schodl: Systematische Analyse und Bewertung komplexer Supply Chain Prozesse bei dynamischer Festlegung des Auftragsentkopplungspunkts. 2008.

Band 29 Bianca Gusenbauer: Öffentlich-private Finanzierung von Infrastruktur in Entwicklungsländern und deren Beitrag zur Armutsreduktion. Fallstudien in Vietnam und auf den Philippinen. 2009.

Band 30 Elisabeth Salomon: Hybrides Management in sino-österreichischen Joint Ventures in China aus österreichischer Perspektive. 2009.

Band 31 Katharina Mader: Gender Budgeting: Ein emanzipatorisches, finanzpolitisches und demokratiepolitisches Instrument. 2009.

Band 32 Michael Weber: Die Generierung von Empfehlungen für zwischenbetriebliche Transaktionen als gesamtwirtschaftliche Infrastrukturleistung. 2010.

Band 33 Lisa Gimpl-Heersink: Joint Pricing and Inventory Control under Reference Price Effects. 2009.

Band 34 Erscheint nicht.

Band 35 Dagmar Kiefer: Multicultural Work in Five United Nations Organisations. An Austrian Perspective. 2009.

Band 36 Gottfried Gruber: Multichannel Management. A Normative Model Towards Optimality. 2009.

Band 37 Rainer Quante: Management of Stochastic Demand in Make-to-Stock Manufacturing. 2009.

Band 38 Franz F. Eiffe: Auf den Spuren von Amartya Sen. Zur theoriegeschichtlichen Genese des Capability-Ansatzes und seinem Beitrag zur Armutsanalyse in der EU. 2010. 
Band 39 Astrid Haider: Die Lohnhöhe und Lohnstreuung im Nonprofit-Sektor. Eine quantitative Analyse anhand österreichischer Arbeitnehmer-Arbeitgeber-Daten. 2010.

Band 40 Maureen Lenhart: Pflegekräftemigration nach Österreich. Eine empirische Analyse. 2010.

Band 41 Oliver Schwank: Linkages in South African Economic Development. Industrialisation without Diversification? 2010.

Band 42 Judith Kast-Aigner: A Corpus-Based Analysis of the Terminology of the European Union's Development Cooperation Policy, with the African, Caribbean and Pacific Group of States. 2010.

Band 43 Emel Arikan: Single Period Inventory Control and Pricing. An Empirical and Analytical Study of a Generalized Model. 2011.

Band 44 Gerhard Wohlgenannt: Learning Ontology Relations by Combining Corpus-Based Techniques and Reasoning on Data from Semantic Web Sources. 2011.

Band 45 Thomas Peschta: Der Einfluss von Kundenzufriedenheit auf die Kundenloyalität und die Wirkung der Wettbewerbsintensität am Beispiel der Gemeinschaftsverpflegungsgastronomie. 2011.

Band 46 Friederike Hehle: Die Anwendung des Convenience-Konzepts auf den Betriebstyp Vending. 2011

Band 47 Thomas Herzog: Strategisches Management von Koopetition. Eine empirisch begründete Theorie im industriellen Kontext der zivilen Luftfahrt. 2011.

Band 48 Christian Weismayer: Statische und longitudinale Zufriedenheitsmessung. 2011.

Band 49 Johannes Fichtinger: The Single-Period Inventory Model with Spectral Risk Measures. 2011.

Band 50 Isabella R. Hatak: Kompetenz, Vertrauen und Kooperation. Eine experimentelle Studie. 2011.

Band 51 Birgit Gusenbauer: Der Beitrag der Prospect Theory zur Beschreibung und Erklärung von Servicequalitätsurteilen und Kundenzufriedenheit im Kontext von Versicherungsentscheidungen. 2012.

Band 52 Markus A. Höllerer: Between Creed, Rhetoric Façade, and Disregard. Dissemination and Theorization of Corporate Social Responsibility in Austria. 2012.

www.peterlang.de 